PNL-10358

UC-602

\title{
Field Investigation Source Area ST58 \\ Old Quartermaster Service Station, Eielson Air Force Base, Alaska
}

T. L. Liikala

J. C. Evans

January 1995

Prepared for

Eielson Air Force Base

Fairbanks, Alaska

under Contract DE-AC06-76RLO 1830

Pacific Northwest Laboratory

Richland, Washington 99352

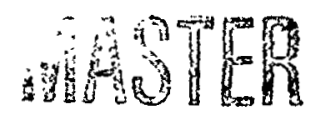




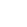




\section{DISCLAIMER}

This report was prepared as an account of work sponsored by an agency of the United States Government. Neither the United States Government nor any agency thereof, nor any of their employees, make any warranty, express or implied, or assumes any legal liability or responsibility for the accuracy, completeness, or usefulness of any information, apparatus, product, or process disclosed, or represents that its use would not infringe privately owned rights. Reference herein to any specific commercial product, process, or service by trade name, trademark, manufacturer, or otherwise does not necessarily constitute or imply its endorsement, recommendation, or favoring by the United States Government or any agency thereof. The views and opinions of authors expressed herein do not necessarily state or reflect those of the United States Government or any agency thereof. 


\section{DISCLAIMER}

\section{Portions of this document may be illegible in electronic image products. Images are produced from the best available original document.}




\section{Summary}

Source area ST58 is the site of the old Quartermaster service station at Eielson Air Force Base, Alaska. The source area is one of several Source Evaluation Report sites being investigated by Pacific Northwest Laboratory for the U.S. Air Force as candidates for no further remedial action, interim removal action, or a remedial investigation/feasibility study under a Federal Facilities Agreement.

The purpose of this work was to characterize source area ST58 and excavate the most contaminated soils for use in composting treatability studies. A field investigation was conducted to determine the nature and extent of soil contamination. The field investigation entailed a records search; grid node location, surface geophysical, and soil gas surveys; and test pit soil sampling. Soil excavation followed based on the results of the field investigation. The site was backfilled with clean soil.

Results from this work indicate close spatial correlation between screening instruments, used during the field investigation and soil excavation, and laboratory analyses. Gasoline was identified as the main subsurface contaminant based on the soil gas surveys and test pit soil sampling. A center of contamination was located near the northcentral portion of the source area, and a center was located in the northwestern corner. The contamination typically occurred near or below a former soil horizon probably as a result of surface spills and leaks from discontinuities and/or breaks in the underground piping. Piping locations were delineated during the surface geophysical surveys and corresponded very well to unscaled drawings of the site. The high subsurface concentrations of gasoline detected in the northwestern corner of the source area probably reflect ground-water contamination and/or possibly floating product.

Approximately $700 \mathrm{yd}^{3}$ of soil were removed during excavation of the northcentral portion of source area ST58. Of those, approximately $600 \mathrm{yd}^{3}$ of soil were contaminated and transported to the soil composting demonstration site. Ground water was evident in the excavation and probably became contaminated through dissolution of the gasoline.

A significant amount of contaminated soil remains at the site. The clean backfill soil probably will become contaminated over time. A remedial investigation/feasibility study will likely be required for the source area. 



\section{Acknowledgments}

The authors would like to thank several Pacific Northwest Laboratory staff members who contributed their time and effort to this project. Special thanks go to Don Glover for his organization, preparation, and dedication. Thanks to Chuck Veverka and Ned Clayton for their field work. Thanks also to Khris Olsen for coordinating laboratory analyses, John Fruchter for technical peer review, and Kristin Manke and Denice Carrothers for editorial review. 


\section{Contents}

Summary $\ldots \ldots \ldots \ldots \ldots \ldots \ldots \ldots \ldots \ldots \ldots \ldots \ldots \ldots \ldots \ldots \ldots$ iii

Acknowledgments $\ldots \ldots \ldots \ldots \ldots \ldots \ldots \ldots \ldots \ldots \ldots \ldots \ldots \ldots \ldots$

Acronyms $\ldots \ldots \ldots \ldots \ldots \ldots \ldots \ldots \ldots \ldots \ldots \ldots \ldots \ldots \ldots \ldots \ldots \ldots$

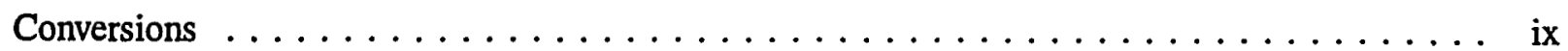

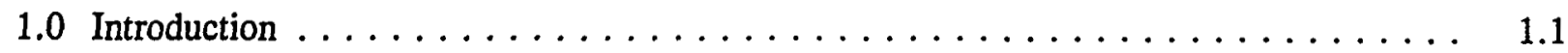

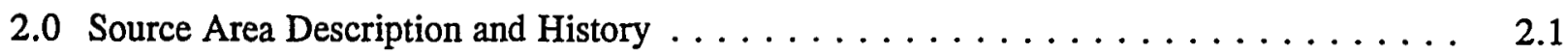

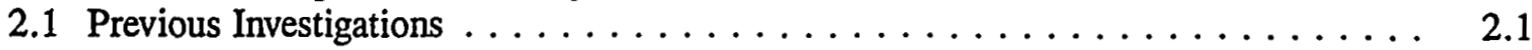

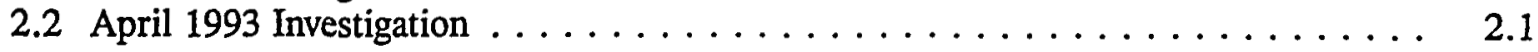

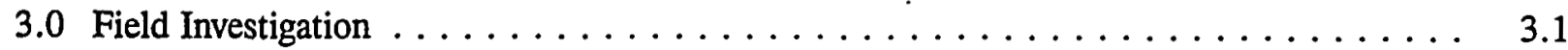

3.1 Records Search . . . . . . . . . . . . . . . . . . . . 3.1

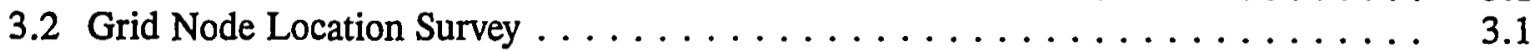

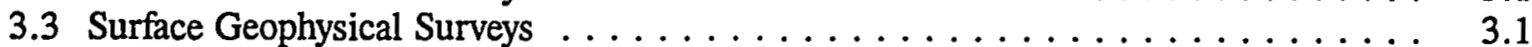

3.3.1 Electromagnetic Induction Survey $\ldots \ldots \ldots \ldots \ldots \ldots \ldots \ldots \ldots . \ldots \ldots$

3.3.2 Radiodetection Unit Survey $\ldots \ldots \ldots \ldots \ldots \ldots \ldots \ldots \ldots \ldots \ldots$

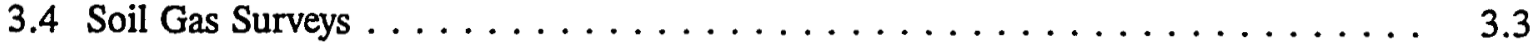

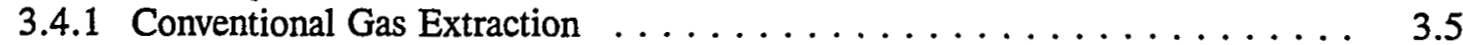

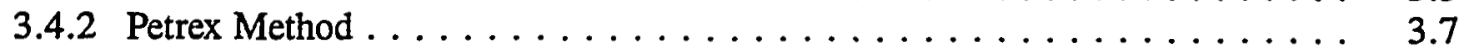

3.4.3 Survey Comparison and Conclusions $\ldots \ldots \ldots \ldots \ldots \ldots \ldots \ldots \ldots .12$

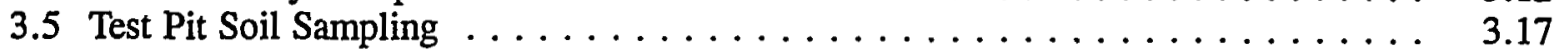

4.0 Soil Excavation and Backfilling $\ldots \ldots \ldots \ldots \ldots \ldots \ldots \ldots \ldots \ldots \ldots \ldots$

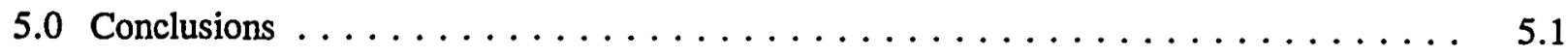

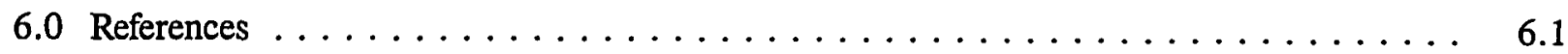

Appendix A - Source Area Characterization Plan $\ldots \ldots \ldots \ldots \ldots \ldots \ldots \ldots$

Appendix B - Letter from A. E. Schumacher to D. W. Glover, Dated January 6, 1993, Subject History of Old Quartermaster Service Station $\ldots \ldots \ldots \ldots$. . . . .

Appendix C - April 1993 Analytical Results . . . . . . . . . . . . . . C.1

Appendix D - Base Civil Engineering Work Clearance Request . . . . . . . . . D.1

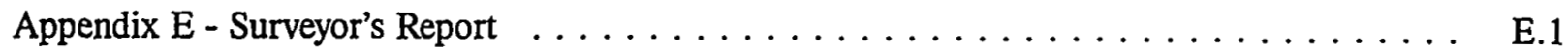

Appendix F - Surface Geophysical Surveys Report . . . . . . . . . . . . . F.1

Appendix G - Petrex Method Report . . . . . . . . . . . . . . . . . 


\section{Figures}

1.1 Generalized Location Map of Source Area ST58 $\ldots \ldots \ldots \ldots \ldots \ldots \ldots \ldots \ldots$

2.1 Source Area ST58 Map Showing Well Locations and Benzene Concentrations . . . . . 2.2

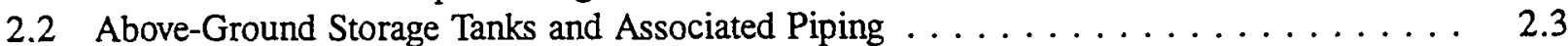

2.3 Benzene Concentrations in Ground Water, April $1993 \ldots \ldots \ldots \ldots \ldots \ldots$

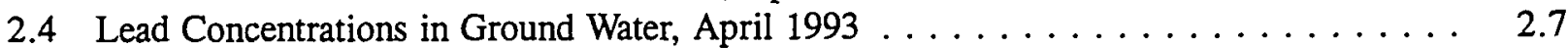

3.1 Field Investigation Grid and Surface Geophysical Surveys $\ldots \ldots \ldots \ldots \ldots \ldots$

3.2 Electromagnetic Induction Survey Results $\ldots \ldots \ldots \ldots \ldots \ldots \ldots \ldots \ldots \ldots$

3.3 Conventional Gas Extraction Probe Locations . . . . . . . . . . . . . . . 3.6

3.4 Total Hydrocarbon Concentrations in Soil Gas from Field PID Readings . . . . . . . . . 3.9

3.5 Benzene Concentrations in Soil Gas from Gas Chromatography Analysis . . . . . . . . . 3.10

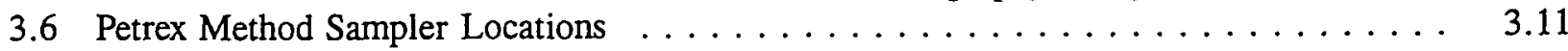

3.7 Petrex Method Results for Benzene, Toluene, Ethylbenzene, and Xylene in Soil Gas . . . 3.15

3.8 Petrex Method Results for Cycloalkanes and Alkenes in Soil Gas . . . . . . . . . . . . . . . . . . . . . . . . . . .

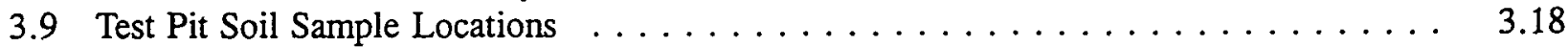

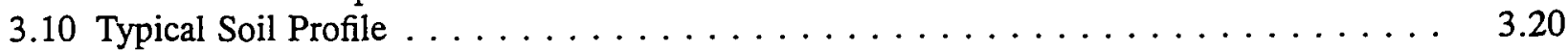

3.11 Benzene Concentrations in Soil, 4 to $5.5 \mathrm{ft}$ bls $\ldots \ldots \ldots \ldots \ldots \ldots \ldots \ldots \ldots \ldots$

3.12 Benzene Concentrations in Soil, 9 to $10 \mathrm{ft}$ bls $\ldots \ldots \ldots \ldots \ldots \ldots \ldots \ldots . .24$

3.13 Total Petroleum Hydrocarbons - Gasoline Concentrations in Soil, 4 to $5.5 \mathrm{ft}$ bls . . . . 3.25

4.1 Flagged Soil Excavation Area $\ldots \ldots \ldots \ldots \ldots \ldots \ldots \ldots \ldots \ldots \ldots$

4.2 Soil Excavation Area and Underground Piping $\ldots \ldots \ldots \ldots \ldots \ldots \ldots \ldots$

\section{Tables}

1.1 Division of Work Between Pacific Northwest Laboratory; EA Engineering, Science,

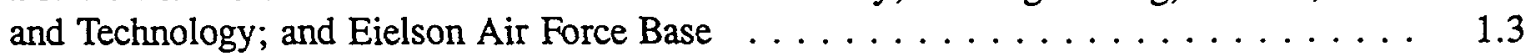

2.1 Summary of Analytical Results from April $1993 \ldots \ldots \ldots \ldots \ldots \ldots \ldots \ldots$

3.1 Conventional Gas Extraction Results $\ldots \ldots \ldots \ldots \ldots \ldots \ldots \ldots \ldots \ldots$

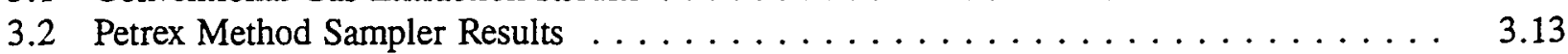

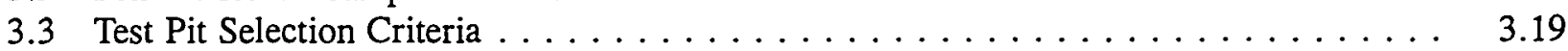

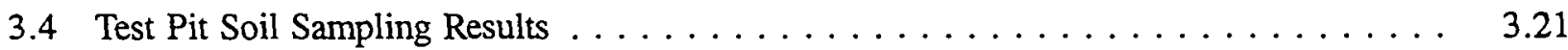

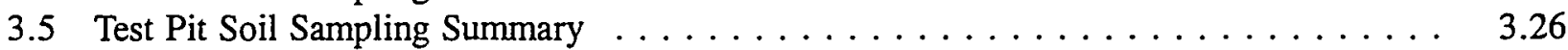

4.1 Soil Excavation Results $\ldots \ldots \ldots \ldots \ldots \ldots \ldots \ldots \ldots$ 


\section{Acronyms}

$\begin{array}{ll}\text { AFB } & \text { Air Force Base } \\ \text { AST } & \text { above-ground storage tank } \\ \text { bls } & \text { below land surface } \\ \text { BTEX } & \text { benzene, toluene, ethylbenzene, and xylene } \\ \text { EA } & \text { EA Engineering, Science, and Technology } \\ \text { ECD } & \text { electron capture detector } \\ \text { EMI } & \text { electromagnetic induction } \\ \text { EPA } & \text { U.S. Environmental Protection Agency } \\ \text { HP } & \text { Hewlett-Packard } \\ \text { MCL } & \text { maximum contaminant level } \\ \text { MOGAS } & \text { motor gasoline } \\ \text { NERI } & \text { Northeast Research Institute, Inc. } \\ \text { PCE } & \text { perchloroethylene } \\ \text { PID } & \text { photoionization detector } \\ \text { PNL } & \text { Pacific Northwest Laboratory } \\ \text { SER } & \text { Source Evaluation Report } \\ \text { TCE } & \text { trichloroethylene } \\ \text { TPH-D } & \text { total petroleum hydrocarbons - diesel } \\ \text { TPH-G } & \text { total petroleum hydrocarbons - gasoline } \\ \text { VOC } & \text { volatile organic compound }\end{array}$

\section{Conversions}

\begin{tabular}{|c|c|c|}
\hline To Convert From & To & Multiply By \\
\hline inch & centimeter & 2.540 \\
\hline foot & meter & 3.048 E-01 \\
\hline acre & kilometer $^{2}$ & $4.048 \mathrm{E}-03$ \\
\hline feet $^{3}$ per minute & centimeter ${ }^{3}$ per second & 472 \\
\hline $\operatorname{yard}^{3}$ & meter $^{3}$ & 7.645 E-01 \\
\hline gallon & liter & 3.785 \\
\hline pounds per inch ${ }^{2}$ & kilograms per centimeter ${ }^{2}$ & 7.031 E-02 \\
\hline
\end{tabular}




\subsection{Introduction}

The U.S. Air Force is conducting an environmental restoration program at Eielson Air Force Base (AFB), near Fairbanks, Alaska, in accordance with the Federal Facility Agreement (EPA et al. 1990) between the U.S. Environmental Protection Agency (EPA), the Alaska Department of Environmental Conservation, and the U.S. Air Force. As part of this program, Pacific Northwest Laboratory $(\mathrm{PNL})^{(a)}$ is investigating several Source Evaluation Report (SER) sites as candidates for no further remedial action, interim removal action, or a remedial investigation/feasibility study. The SER sites comprise approximately half of the 64 source areas on the base.

The purpose of this work was to characterize SER source area ST58, the old Quartermaster service station (Figure 1.1), and excavate the contaminated soils for use in composting treatability studies. A field investigation was required to determine the nature and extent of soil contamination. Excavation of those soils with the highest contamination and backfilling of the excavation followed. The objectives were to

- determine the contaminant types, concentrations, and distributions in the soil resulting from source area ST58

- excavate approximately $500 \mathrm{yd}^{3}$ of the most contaminated soil and transport it to the soil composting demonstration site for remediation of hydrocarbon contamination

- backfill the excavation with clean soil.

The work at source area ST58 was subdivided into 10 tasks as follows:

1. determine the nature and location of any underground piping, leaks, and/or spills through a records search

2. survey grid nodes for surface geophysical and soil gas surveys

3. further identify the location of the underground piping using surface geophysical surveys

4. further estimate the contaminant types, concentrations, and distributions using soil gas surveys

5. confirm the contaminant types, concentrations, and distributions through test pit soil sampling and analysis

6. excavate approximately $500 \mathrm{yd}^{3}$ of the most contaminated soil and transport it to the soil composting demonstration site

(a) PNL is a multiprogram national laboratory operated for the U.S. Department of Energy by Battelle Memorial Institute under Contract DE-AC06-76RLO 1830. 


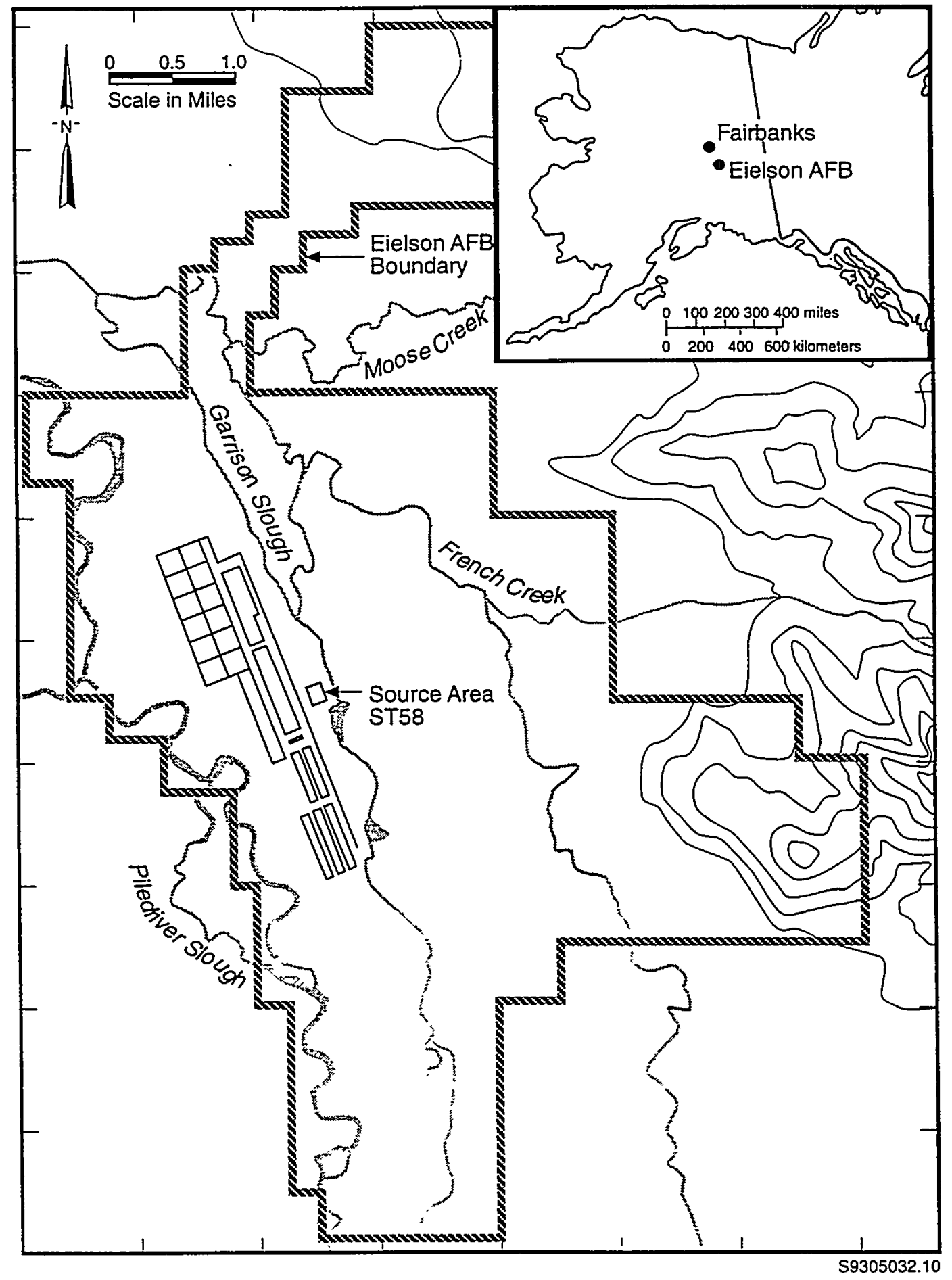

Figure 1.1. Generalized Location Map of Source Area ST58 
7. remove and dispose of any residual product from the underground piping

8. remove and dispose of the underground piping from the excavation

9. remove and dispose of any free product

10. backfill the excavation with clean soil.

PNL; EA Engineering, Science, and Technology (EA); and Eielson AFB performed the work as shown in Table 1.1 in May and June 1993. Appendix A contains the complete source area characterization plan.

This report is organized as follows. Chapter 2.0 contains a source area description and history. Chapter 3.0 presents the field investigation methodologies and results. Soil excavation and backfilling are described in Chapter 4.0. Conclusions from this work are given in Chapter 5.0. References cited in the text are listed in Chapter 6.0. Appendix A contains the complete source area characterization plan. Appendix B provides historical information on the old Quartermaster service station. Analytical results from April 1993 are given in Appendix C. The base civil engineering work clearance request is shown in Appendix D. The surveyor's report is included as Appendix E. Appendix F contains the surface geophysical surveys report, and Appendix G contains the Petrex method report.

Table 1.1. Division of Work Between Pacific Northwest Laboratory; EA Engineering, Science, and Technology; and Eielson Air Force Base

\begin{tabular}{|c|c|}
\hline Company & Task \\
\hline \multirow{7}{*}{$\begin{array}{l}\text { Pacific Northwest } \\
\text { Laboratory }\end{array}$} & Perform Records Search \\
\hline & Grid, Perform, and Interpret Surface Geophysical Surveys \\
\hline & Grid, Perform, and Interpret Soil Gas Surveys \\
\hline & Perform Test Pit Soil Sampling \\
\hline & Recommend Soil Excavation Area \\
\hline & Perform Laboratory Analyses ${ }^{(a)}$ \\
\hline & Complete and Submit Technical Report \\
\hline \multirow{2}{*}{$\begin{array}{c}\text { EA Engineering, } \\
\text { Science, and } \\
\text { Technology }\end{array}$} & Operate Backhoe and Dump Truck for Soil Excavation \\
\hline & $\begin{array}{l}\text { Perform Residual Product, Underground Piping, and Free Product Removal } \\
\text { and Disposal }\end{array}$ \\
\hline \multirow{3}{*}{$\begin{array}{l}\text { Eielson } \\
\text { Air Force Base }\end{array}$} & Obtain Base Civil Engineering Work Clearance Request \\
\hline & Operate Backhoe for Test Pit Soil Sampling \\
\hline & Perform Site Backfilling \\
\hline
\end{tabular}




\subsection{Source Area Description and History}

Source area ST58 is the site of the old Quartermaster service station. It is located on the northwest corner at the intersection of Division Street and Wabash Avenue (Figure 2.1). The service station covered approximately 1 acre (135 by $300 \mathrm{ft}$ ). The site is currently a flat, grassy field.

The service station was operated from 1970 to 1988 by Eielson AFB. It serviced vehicles for AFB personnel and their dependents until 1975 and, thereafter, AFB vehicles only. The station utilized four 25,000-gal above-ground storage tanks (ASTs) (Figure 2.2), containing motor gasoline (MOGAS) and diesel. Both leaded and unleaded MOGAS were used. Blueprints show two fuel supply lines from bulk storage to the ASTs. The blueprints also show an isopropyl alcohol AST; AFB personnel indicate only MOGAS was stored in this tank (Appendix B). Two barrels of motor oil were stored at the service station for customer use.

The ASTs and above-ground piping were removed in August 1988; the underground piping was left in place. Reportedly, the site was covered with approximately 3 to $4 \mathrm{ft}$ of fill after the ASTs and above-ground piping were removed.

\subsection{Previous Investigations}

No known spills have occurred at source area ST58. One of the fuel supply lines for the service station was suspected of leaking at the intersection of Industrial Drive and Division Street, east of the source area (Appendix B). Geotechnical investigations conducted in October and November 1991 (Shannon and Wilson, Inc. 1991) and January and February 1992 (Shannon and Wilson, Inc. 1992) indicated benzene contamination in ground water immediately downgradient of source area ST58 (Figure 2.1). Ground-water flow is generally to the north and northwest beneath the source area and across the developed portion of the base. Benzene concentrations above the maximum contaminant level (MCL) of 5 micrograms per liter $(\mu \mathrm{g} / \mathrm{L})$ ranged from 5.4 to $145 \mu \mathrm{g} / \mathrm{L}$. The MCL was exceeded in four wells, 58MW03, 58MW04, 58MW05, and 58MW08. Benzene concentrations in the remaining wells were below detection. Low levels of toluene in well 58MW06; ethylbenzene in wells 58MW04, 58MW05, and 58MW08; and xylenes in well 58MW08 were detected. Detectable levels of total dissolved solids, sulfate, and trace levels of chromium and mercury were found in selected samples. Analytical results for other organic and inorganic constituents were below detection. No chemical analyses were performed on the soils.

\subsection{April 1993 Investigation}

Ground-water samples were collected from wells 58MW01 through 58MW12 in April 1993 by PNL. These samples were collected to confirm previous results and guide the planned field investigation at source area ST58. The samples were analyzed for volatile organic compounds (VOCs), total petroleum hydrocarbons-gasoline (TPH-G), total petroleum hydrocarbons-diesel (TPH-D), and lead by DataChem Laboratories, using EPA methods 8240, 8015-M, and 7421, respectively (EPA 1986). 


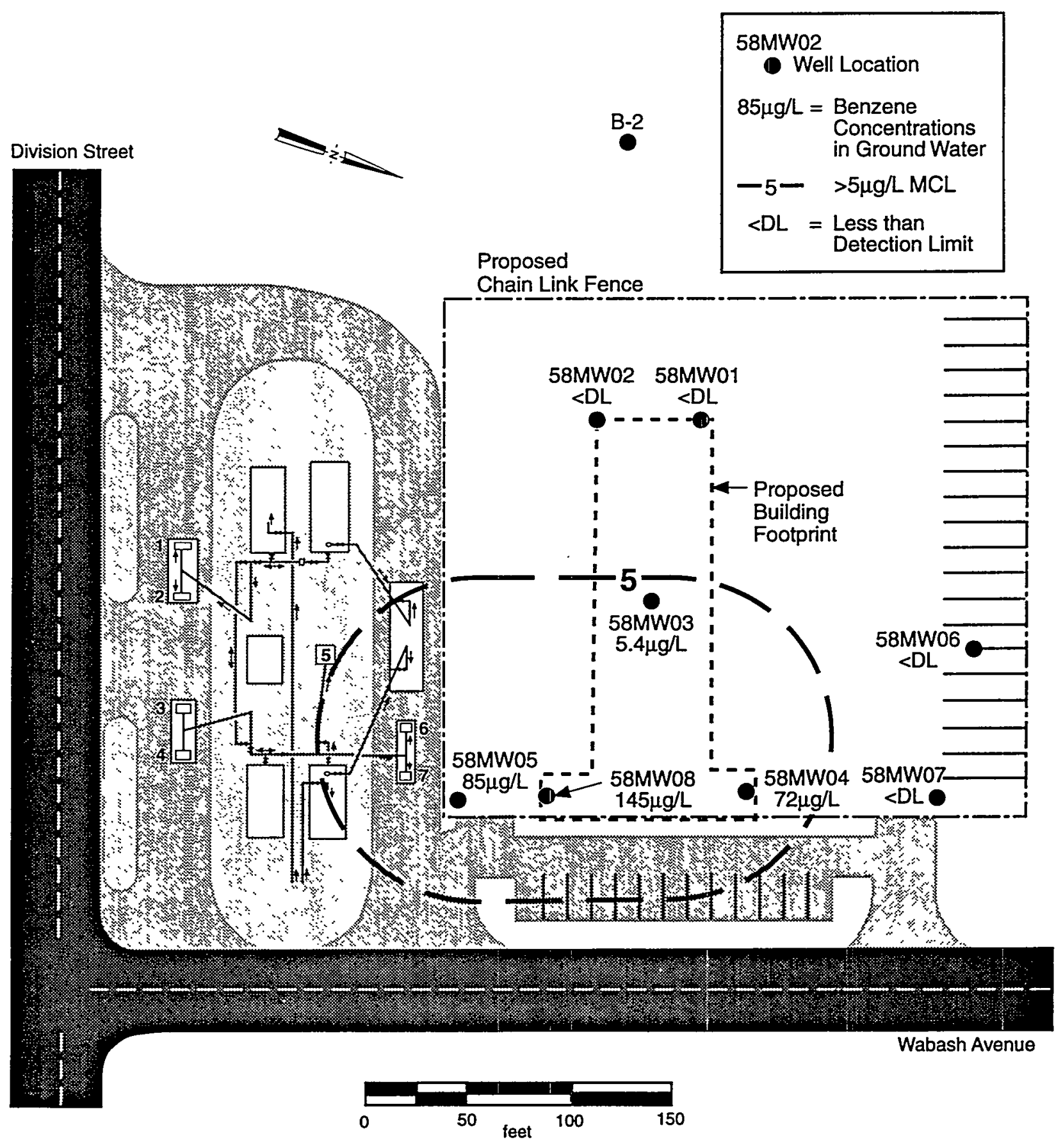

$\$ 9406010.2$

Figure 2.1. Source Area ST58 Map Showing Well Locations and Benzene Concentrations 


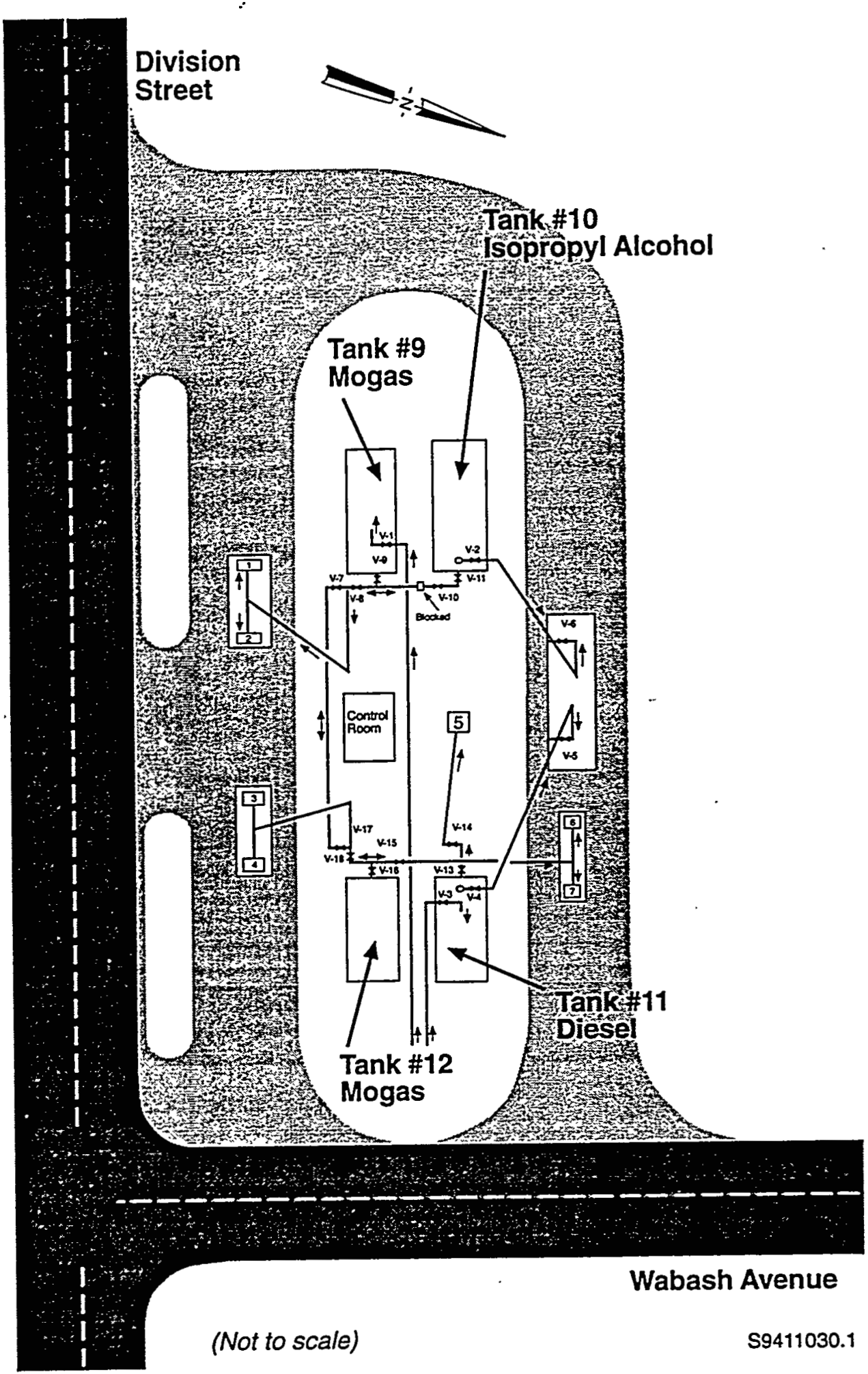

Figure 2.2. Above-Ground Storage Tanks and Associated Piping (Adapted from unscaled blueprints) 
Results of the April 1993 sampling effort confirmed benzene contamination in the ground water above the MCL at several locations (Figure 2.3 and Table 2.1). The April 1993 concentrations were comparable (within one order of magnitude) to previous results, ranging from $24 \mu \mathrm{g} / \mathrm{L}$ in well $58 \mathrm{MW} 09$ to $450 \mu \mathrm{g} / \mathrm{L}$ in well $58 \mathrm{MW} 10$. Well $58 \mathrm{MW03}$ had $3.7 \mu \mathrm{g} / \mathrm{L}$ and the remaining wells were below detection. Toluene and total xylenes were detected significantly below MCLs in wells 58MW09 and 58MW10. Total xylenes were also noted in well 58MW08. No ethylbenzene analyses were performed. Interface probe measurements indicated a sheen of product in well 58MW09. Benzene is likely related to subsurface gasoline contamination; gasoline contains approximately 2 to 8 percent benzene by weight. Benzene at and downgradient from the source area with little or no toluene, ethylbenzene, and xylene is indicative of the higher mobility of benzene in ground water and suggests the contamination occurred relatively recently.

TPH-G was detected in well 58MW09 at 260 milligrams per liter (mg/L) (Table 2.1). All other samples were below the $2 \mathrm{mg} / \mathrm{L}$ detection limit. TPH-D was detected in 9 of the 12 wells, ranging in concentrations from 0.1 to $99 \mathrm{mg} / \mathrm{L}$. The highest concentration was detected in well 58MW09, which is located near the former diesel AST. Samples from wells 58MW02, 58MW03, and 58MW06 were below detection.

Lead was found above the EPA suggested cleanup level of $15 \mu \mathrm{g} / \mathrm{L}$ in all of the source area ST58 wells (Figure 2.4 and Table 2.1). Concentrations ranged from 35 to $180 \mu \mathrm{g} / \mathrm{L}$, with the highest contamination in well 58MW12. No lead samples were collected in previous investigations for comparison. The complete April 1993 data set for source area ST58 is contained in Appendix C.

Of note, dewatering was performed approximately $300 \mathrm{ft}$ downgradient of source area ST58 in May 1993 (before the field investigation commenced) during construction of an Alaska Air National Guard building. This pumping may have induced a temporary hydraulic gradient, resulting in groundwater contamination migrating further downgradient. In addition, the water was discharged to a bermed area south of the building and to the open field east of Wabash Avenue. Wells 58MW06 and 58MW07 were apparently removed or destroyed as construction progressed in May and June 1993. Well 58MW04 was evidently run over by heavy equipment; the polyvinyl chloride casing stickup was damaged but has been repaired by AFB and PNL personnel. 


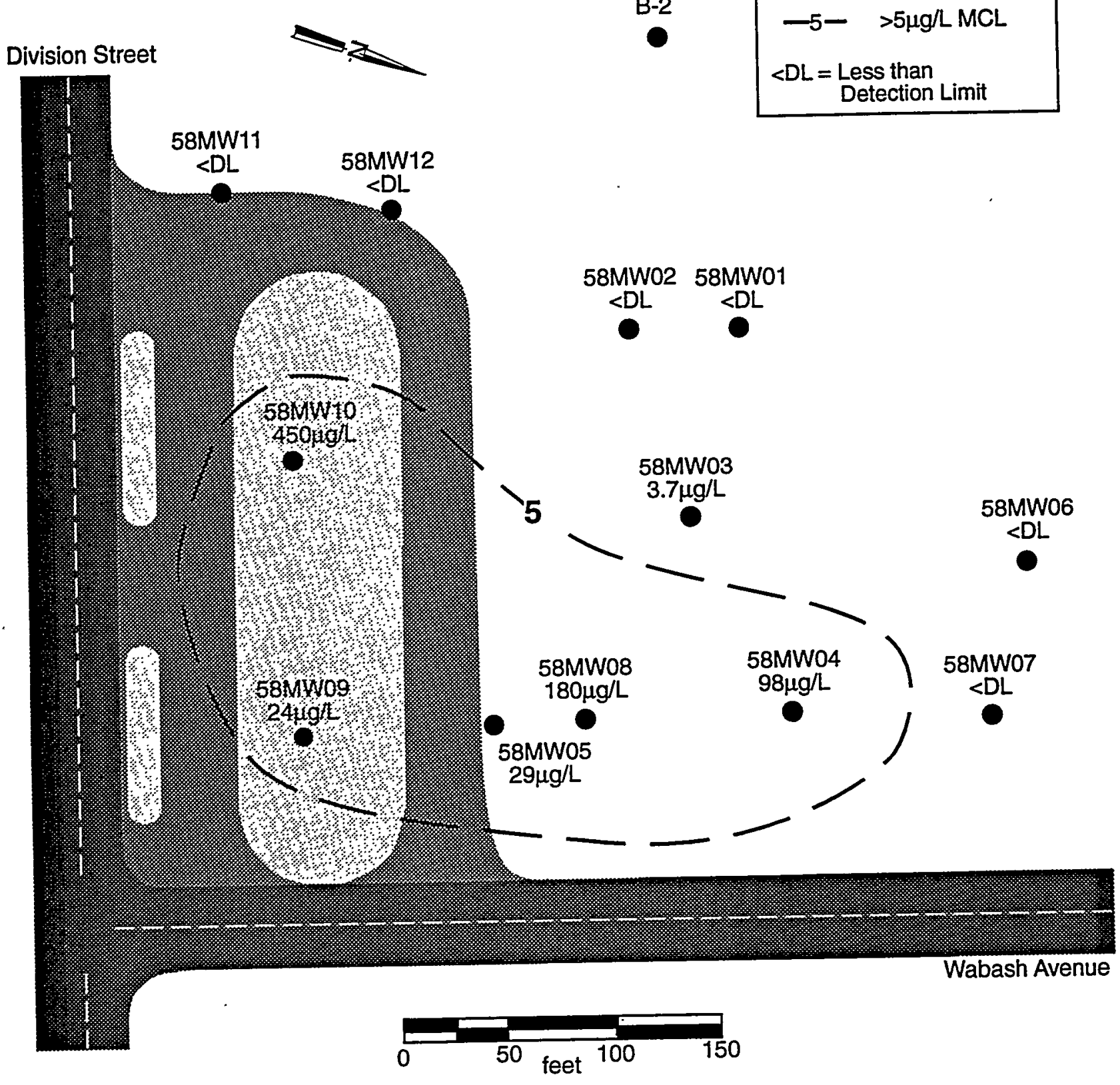

$\$ 9406010.3$

Figure 2.3. Benzene Concentrations in Ground Water, April 1993 
Table 2.1. Summary of Analytical Results from April 1993

\begin{tabular}{|c|c|c|c|c|c|c|}
\hline $\begin{array}{c}\text { Well } \\
\text { Number }\end{array}$ & $\begin{array}{c}\text { Benzene } \\
\text { (ug/L) }\end{array}$ & $\begin{array}{c}\text { Toluene } \\
\text { (ug/L) }\end{array}$ & $\begin{array}{c}\text { Total Xylenes } \\
\text { (ug/L) }\end{array}$ & $\begin{array}{l}\mathrm{TPH}-\mathrm{G} \\
(\mathrm{mg} / \mathrm{L})\end{array}$ & $\begin{array}{l}\text { TPH-D } \\
(\mathrm{mg} / \mathrm{L})\end{array}$ & $\begin{array}{l}\text { Lead } \\
\text { (ug/L) }\end{array}$ \\
\hline $58 \mathrm{MWOI}$ & $5.0 \mathrm{U}$ & $5.0 \mathrm{U}$ & $5 \mathrm{U}$ & $2 \mathrm{U}$ & 0.2 & 35.0 \\
\hline $58 \mathrm{MW02}$ & $5.0 \mathrm{U}$ & $5.0 \mathrm{U}$ & $5 \mathrm{U}$ & $2 \mathrm{U}$ & $0.1 \mathrm{U}$ & 39.0 \\
\hline $58 \mathrm{MW} 03$ & 3.7 & $5.0 \mathrm{U}$ & $5 \mathrm{U}$ & $2 \mathrm{U}$ & $0.1 \mathrm{U}$ & 41.0 \\
\hline 58MW04 & 98.0 & $5.0 \mathrm{U}$ & $5 \mathrm{U}$ & $2 \mathrm{U}$ & 0.3 & 63.0 \\
\hline 58MW05 & 29.0 & $5.0 \mathrm{U}$ & $5 \mathrm{U}$ & $2 \mathrm{U}$ & 0.1 & 40.0 \\
\hline 58MW06 & $5.0 \mathrm{U}$ & $5.0 \mathrm{U}$ & $5 \mathrm{U}$ & $2 \mathrm{U}$ & $0.1 \mathrm{U}$ & 44.0 \\
\hline 58MW07 & $5.0 \mathrm{U}$ & $5.0 \mathrm{U}$ & $5 \mathrm{U}$ & $2 \mathrm{U}$ & 0.1 & 110.0 \\
\hline 58MW08 & 180.0 & $5.0 \mathrm{U}$ & 29 & $2 \mathrm{U}$ & 0.7 & 51.0 \\
\hline 58MW09 & 24.0 & 2.8 & 45 & 260 & 99.0 & 130.0 \\
\hline $58 \mathrm{MW} 10$ & $450.0 \mathrm{~B}$ & 140.0 & 830 & $2 \mathrm{U}$ & 7.0 & 89.0 \\
\hline $58 \mathrm{MW} 11$ & $5.0 \mathrm{U}$ & $5.0 \mathrm{U}$ & $5 \mathrm{U}$ & $2 \mathrm{U}$ & 0.1 & 170.0 \\
\hline $58 \mathrm{MW} 12$ & $5.0 \mathrm{U}$ & $5.0 \mathrm{U}$ & $5 \mathrm{U}$ & $2 \mathrm{U}$ & 0.3 & 180.0 \\
\hline 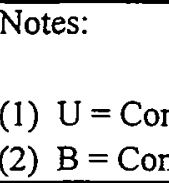 & $\begin{array}{l}\text { nt was ane } \\
\text { nt was als }\end{array}$ & $\begin{array}{l}\text { ed for but } \\
\text { tected in th }\end{array}$ & $\begin{array}{l}\text { detected. } \\
\text { associated blank. }\end{array}$ & & & \\
\hline
\end{tabular}




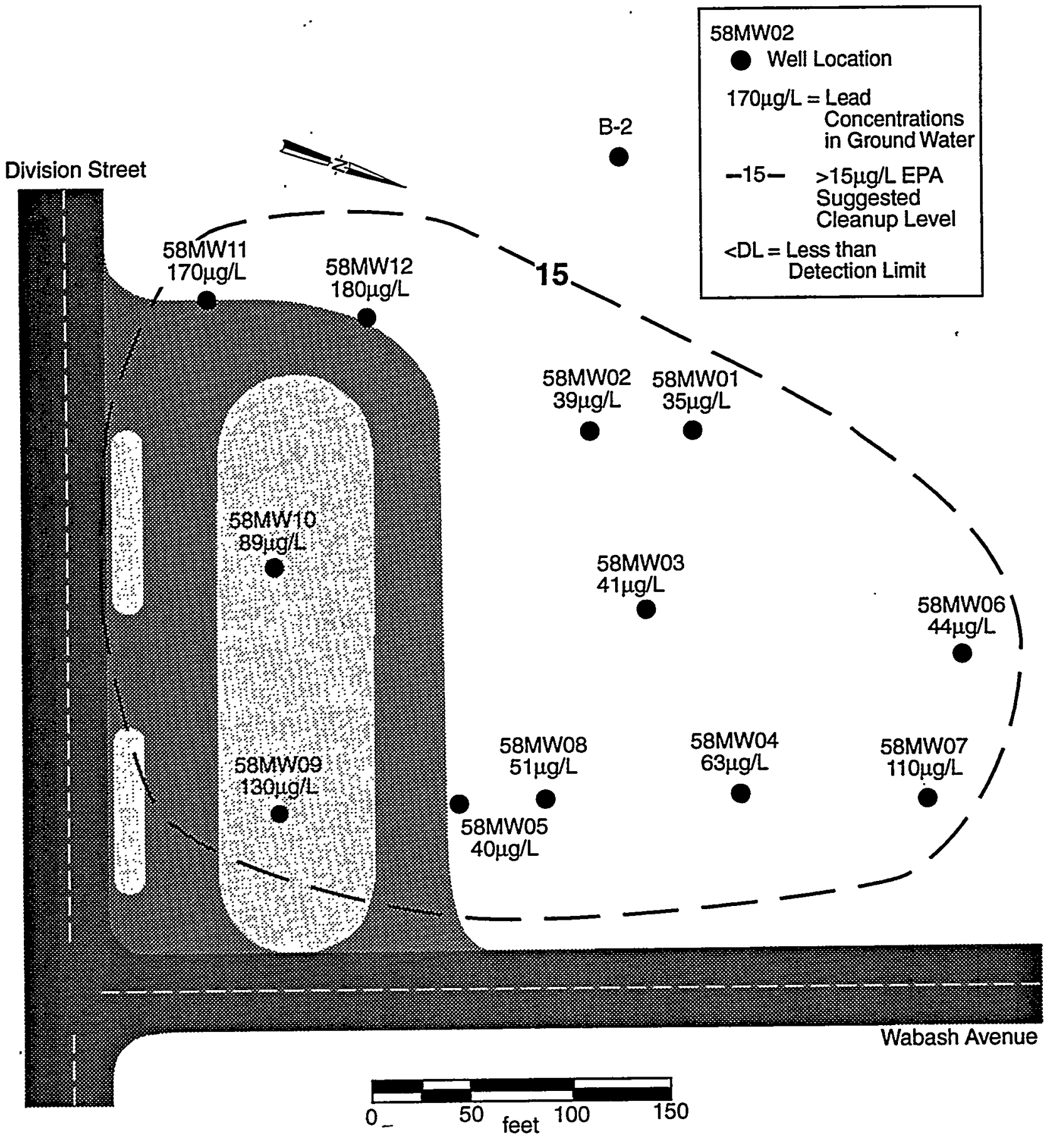

$\$ 9406010.4$

Figure 2.4. Lead Concentrations in Ground Water, April 1993 


\subsection{Field Investigation}

The field investigation at source area ST58 consisted of a records search; grid node location, surface geophysical, and soil gas surveys; and test pit soil sampling. Access around utilities and/or other restrictions for the intrusive work was coordinated with Eielson AFB using a Base Civil Engineering Work Clearance Request (Appendix D). The work clearance request was completed by AFB personnel and posted in the field. A discussion of the methodology and the results for each of the field investigation activities follows.

\subsection{Records Search}

A search was conducted to locate service station as-built drawings, maintenance records, observations during AST removal, and/or closure files for source area ST58. However, the only records found were unscaled blueprints of the ASTs and associated piping and a mid-1980s aerial photograph. Limited historical information was gained through personnel interviews.

\subsection{Grid Node Location Survey}

No records were available to help identify the location of the AST piping, leaks, and/or spills; therefore, a rectangular grid, encompassing the entire source area, was used throughout the field investigation. A 150 - by $300-\mathrm{ft}$ grid, with 25 -ft nodes, was set up using a transit and steel tape, with the 150 -ft axis parallel to Wabash Avenue (Figure 3.1). The nodes were marked with green flags and labeled 1 through 13 along the 300-ft axis and A through $\mathrm{G}$ along the 150-ft axis for ease of identification. Node $1 \mathrm{~A}$ was located $20 \mathrm{ft}$ from both Division Street and Wabash Avenue. The nodes were surveyed to the Eielson AFB coordinate system (U.S. Army Corps of Engineers brass cap control monuments) for horizontal and vertical control by Kalen and Associates, Inc. (Fairbanks, Alaska). Horizontal coordinates were taken to the nearest $0.02 \mathrm{ft}$ and elevations to the nearest $0.1 \mathrm{ft}$. Land surface elevations range from approximately 538 to $542 \mathrm{ft}$ above mean sea level. Appendix E contains the complete surveyor's report.

\subsection{Surface Geophysical Surveys}

Electromagnetic induction (EMI) and radiodetection unit surveys were performed in conjunction with the unscaled blueprints to help identify the location of the AST piping. These surveys are useful in locating buried objects.

\subsubsection{Electromagnetic Induction Survey}

The EMI survey was performed using a Geonics, Ltd. EM-31 instrument. This instrument measures ground conductivity noninvasively by inducing eddy currents in the subsurface. A secondary 


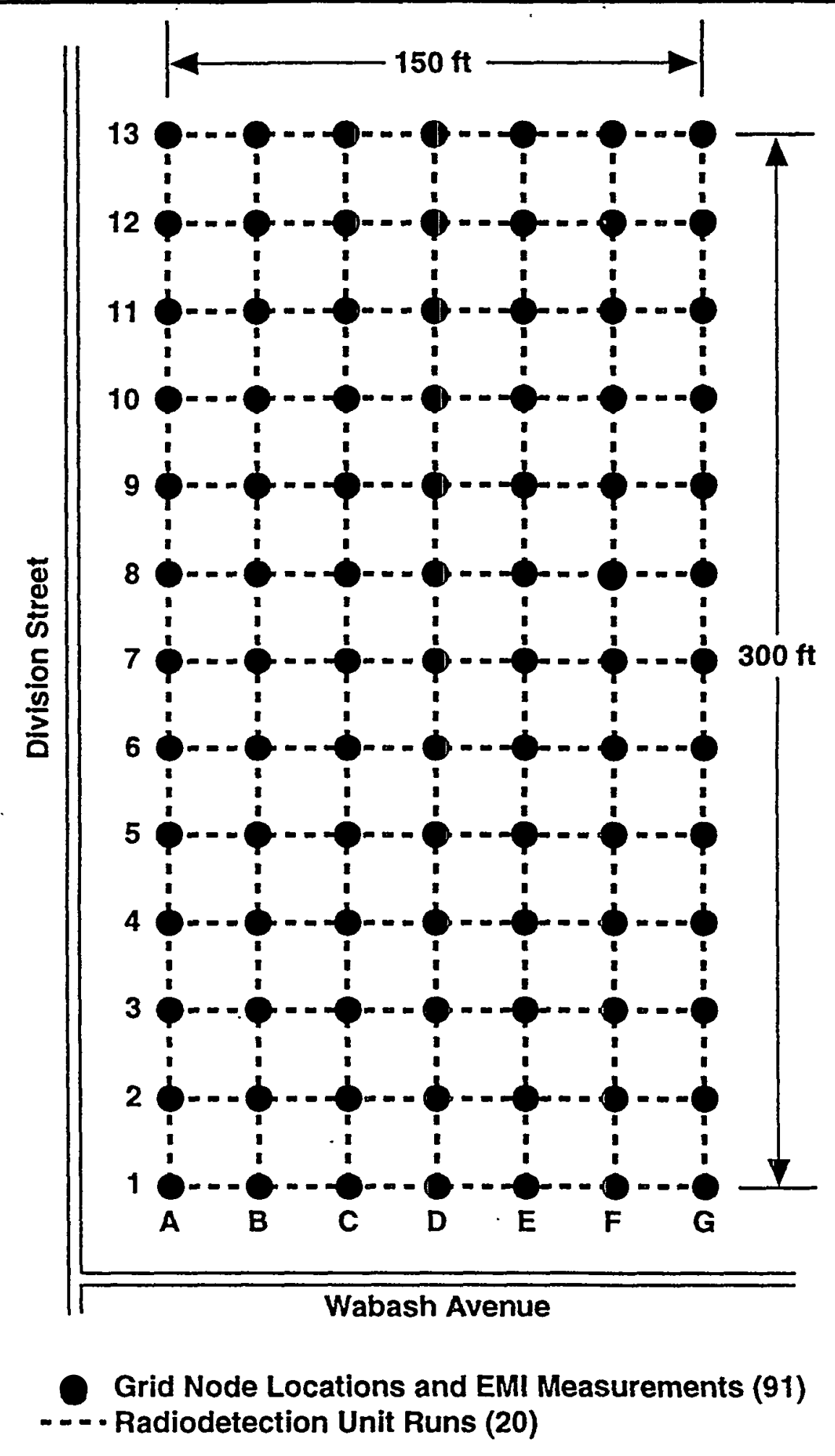

$\mathbf{5 9 3 0 5 0 3 2 . 1 2 \mathrm { ab }}$

Figure 3.1. Field Investigation Grid and Surface Geophysical Surveys 
magnetic field is generated by the subsurface eddy currents and is measured as output voltage by the EM-31. The output voltage is linearly related to the terrain conductivity. When the tool is passed over a buried metallic object, such as a pipe which acts as an electrical conductor, a deflection will occur. Once the deflection occurs, the location and the strike of the buried object can be accurately determined.

Initially, measurements were taken at each grid node (Figure 3.1) with the EM-31 facing parallel to Wabash Avenue. General regions where anomalous readings occurred were mapped for further investigation. Follow-up measurements were taken at these nodes with the EM-31 facing parallel to Division Street to help clarify the orientation of the buried metallic objects. Several additional measurements were taken between nodes to improve data resolution. The location and the strike of possible AST pipe lengths were traced, marked with pink flags, and mapped as shown in Figure 3.2. This map was used as a guide during the test pit soil sampling and soil excavation.

Results of the EMI survey corresponded very well to the AST piping indicated on the unscaled drawings (Figure 2.2) and radiodetection unit survey. Signatures interpreted as AST piping near nodes $7 \mathrm{~B}, 7 \mathrm{D}$ to $6 \mathrm{E}$, and $6 \mathrm{E}$ to $5 \mathrm{D}$ were confirmed as test pit soil sampling and soil excavation progressed. Survey results further indicated a significant amount of other buried metallic debris. Railroad rails, culvert pipe, cables, and rebar were also found during sampling and excavation.

\subsubsection{Radiodetection Unit Survey}

The radiodetection unit survey was performed by AFB personnel using an RD400 Buried Pipe and Cable Locator. A radio transmitter is attached to an above-ground section of pipe, whose subsurface location is being targeted. The pipe acts as an antenna, transmitting the radio signal. A hand-held receiver measures the intensity of the radio signal using an audible tone and analog meter. Maximum tone and readings occur directly over the pipe.

The transmitter was attached to an above-ground water valve on the inlet pipe across Wabash Avenue east of source area ST58. Responses were measured along the dashed lines between grid nodes (Figure 3.1) for a total of 20 runs. Points of maximum tone and signal strength were marked with pink flags.

The radiodetection unit was able to delineate the two main feeder pipes entering source area ST58 (Figure 2.2), but the signal was undetectable near nodes 4C and 4D. In general, the radio signal was attenuated and became difficult to detect with increased distance and branching from the transmitter. Discontinuities and/or breaks in the piping probably hindered transmission of the signal, making pipe detection impossible. The complete surface geophysical surveys report is in Appendix F.

\subsection{Soil Gas Surveys}

Soil gas surveys were employed to determine the contaminant types, concentrations, and distributions in the soil resulting from source area ST58. Two intrusive methods were used for comparison, conventional gas extraction, and the Petrex method. 


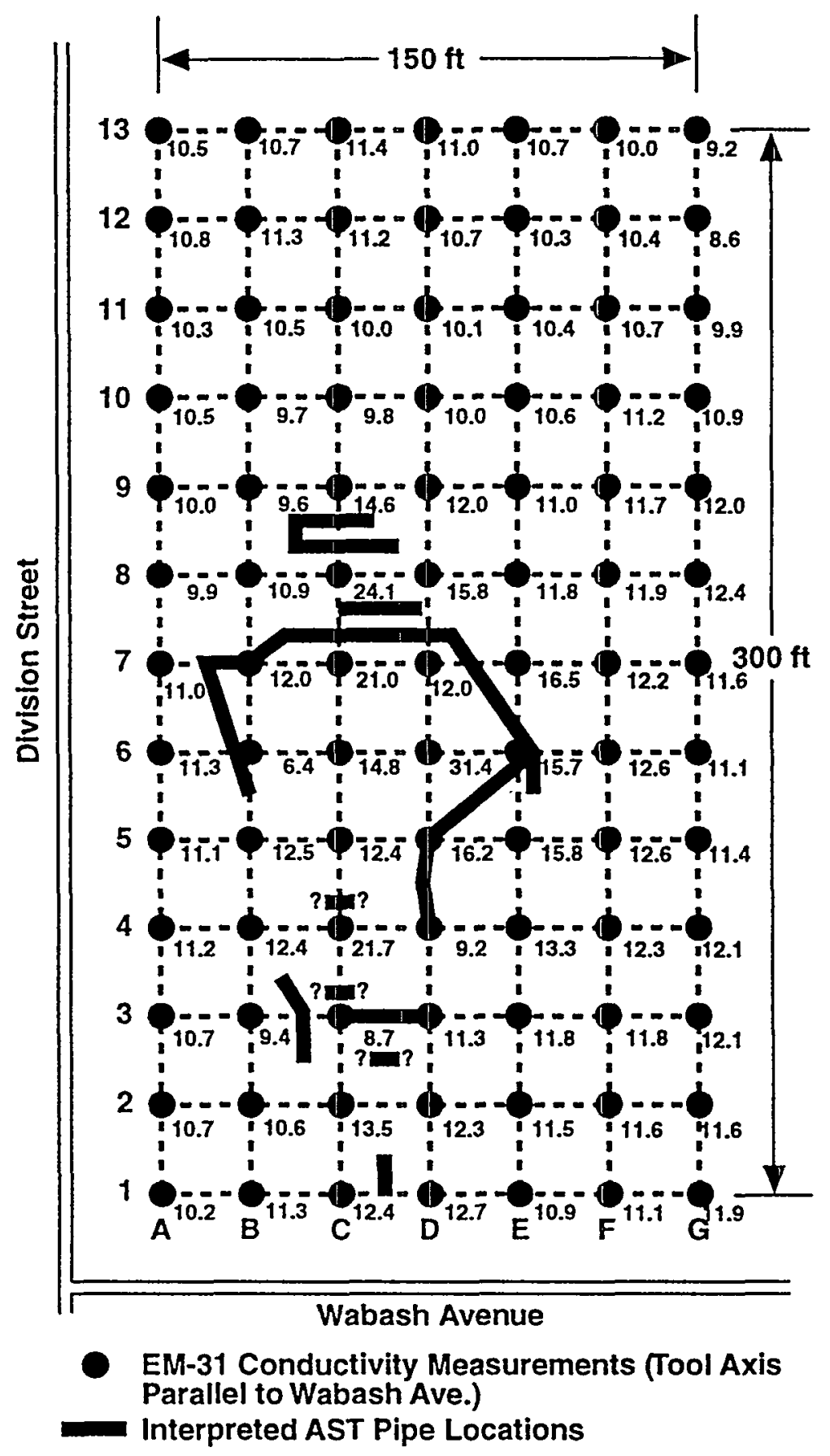

S9305032.12abc

Figure 3.2. Electromagnetic Induction Survey Results 


\subsubsection{Conventional Gas Extraction}

Conventional gas extraction is an active intrusive method where probes are inserted into the soil to a depth of approximately $4 \mathrm{ft}$. Gas samples are drawn through the probes and can be analyzed qualitatively using a monitoring instrument [e.g., photoionization detector (PID)] in the field and/or quantitatively by gas chromatography in the laboratory.

Conventional gas extraction probes were initially inserted on 50 -ft centers, beginning at node $1 \mathrm{~A}$ (Figure 3.3).. Additional probes were placed at selected 25-ft centers in areas of interest identified after the initial measurements were evaluated. A total of 45 probes were installed (58SG01 through 58SG45).

The sample probes consisted of 0.75 -in.-diameter stainless steel well points connected to 6 -ft lengths of 0.25 -in.-diameter polyethylene tubing. Before insertion, pilot holes were driven into the ground to a depth of approximately $3.5 \mathrm{ft}$ on the west side of each grid node, using a 1-in.-diameter sharpened solid steel rod. The rod was driven with a pneumatic post driver, operated at 90 pounds per square inch (psi). A trailer-mounted, 100 cubic feet per minute (cfm) air compressor was used to supply air. The rod was withdrawn with a modified lever-operated construction jack. A sample probe was driven back into the same hole using a 1-in.-diameter, thick-walled steel tube. The steel drive tube was tapered at the bottom to mate with the well point. The top of the tube was slotted to provide an exit for the internally routed polyethylene tubing. A 2-in.-diameter, threaded top piece, constructed of hardened steel, was used to mate the tube to the pneumatic post driver during insertion. Sample probes were driven to a depth of approximately $4 \mathrm{ft}$. Following removal of the drive tube, 20-40 mesh Colorado silica sand was poured into the hole to a depth of approximately $2 \mathrm{ft}$. The remainder of the hole was filled with granular bentonite, which was hydrated at the surface to complete the installation.

Each sample probe was allowed to equilibrate for at least $24 \mathrm{hr}$ before sample collection. Analytical samples were collected in 500-mL gas sampling bulbs connected directly to the polyethylene tubing for each probe. A PhotoVac Model HL200 MicroTip PID was used as a sampling pump to draw the sample through the bulb. The MicroTip pumped for $5 \mathrm{~min}$ at a rate of $750 \mathrm{~mL} / \mathrm{min}$, allowing sufficient time for the well point, the polyethylene tubing, and the sampling bulb to be fully purged and for the instrument readings to stabilize. At the end of the 5-min purge, the bulb was sealed and returned to the PNL field laboratory on base for immediate gas chromatography analysis. The MicroTip readings were recorded on prenumbered chain-of-custody sheets for laboratory reference.

The MicroTip was also used for initial evaluation of total hydrocarbon concentrations in the soil gas at the time of sampling. A 10.6-eV lamp was employed in the instrument, providing broad sensitivity to the expected contaminants at source area ST58. The MicroTip was calibrated daily with a known concentration of isobutylene in air. The MicroTip readings are reported in parts per million by volume (PPMv) based on the isobutylene response factor.

Gas chromatography analysis was performed using a Hewlett-Packard ${ }^{\circledast}$ (HP) 5880 gas chromatograph equipped with a Tekmar LSC-3 purge and trap sample introduction system. Gas samples were injected with a gas sampling syringe into the purge and trap system. Following desorption from

- Hewlett Packard is a registered trademark of Hewlett-Packard, Palo Alto, California. 


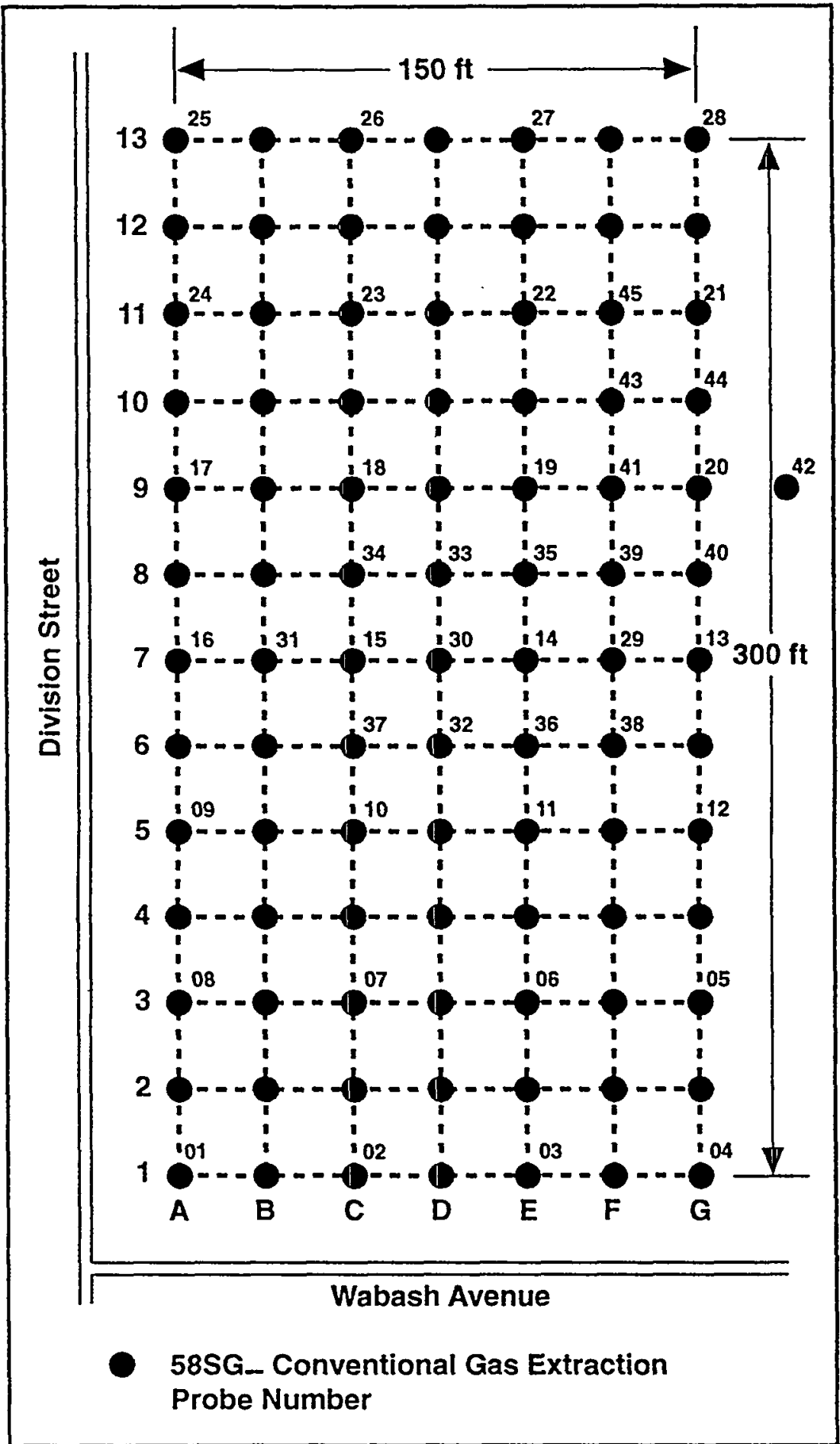

$\$ 9309058.3$

Figure 3.3. Conventional Gas Extraction Probe Locations 
the purge and trap system, the sample was transferred to an inlet splitter for separation on two gas chromatograph columns. One column was equipped with a PID $(10.2 \mathrm{eV})$ for quantification of benzene, toluene, ethylbenzene, and xylene (BTEX) and the other utilized an electron capture detector (ECD) with a nickel-63 source for measuring VOC concentrations. A pair of HP data terminals were used for instrument control and data reduction. Results were reported as micrograms per liter as received. Xylene was reported as the sum of the $\mathrm{m}-, \mathrm{p}-$, and $\mathrm{o}-\mathrm{xylene}$ isomers.

Conventional gas extraction results from the field PID readings and gas chromatography analyses for source area ST58 are shown in Table 3.1. Total hydrocarbon concentrations in soil gas from the field PID readings are plotted in Figure 3.4 with contours of 10, 100, and 1000 PPMv. Figure 3.5 shows benzene distribution in soil gas based on the gas chromatography analyses. Contours are plotted for 10,100 , and $1000 \mu \mathrm{g} / \mathrm{L}$. These plots emphasized the areas with the highest contamination and served as a basis for locating the test pits for soil sampling.

Figures 3.4 and 3.5 indicate close spatial correlation between field PID readings and gas chromatography analysis. Two locations containing high subsurface concentrations of gasoline were identified, centered near nodes $7 \mathrm{C}$ to $7 \mathrm{E}$ and $11 \mathrm{~F}$. Similar results were obtained from the toluene, ethylbenzene, and total xylenes analyses (Table 3.1). The high subsurface concentrations corresponded very well to the unscaled drawings showing the ASTs and associated piping (Figure 2.2), April 1993 benzene concentrations in ground water (Figure 2.3), and EMI signatures indicating AST piping locations (Figure 3.2).

In the soil gas samples collected at source area ST58, only the normal components of gasoline were detected. In particular, trichloroethylene (TCE) was not observed in spite of the very high sensitivity available with the ECD.

\subsubsection{Petrex Method}

The Petrex method, developed by Northeast Research Institute, Inc. (NERI), utilizes passive intrusive samplers. The samplers are installed to a depth of approximately $18 \mathrm{in}$. and integrate contaminant concentrations over time. Soil gas measurements were executed according to NERI's instructions. NERI supplied all samplers and performed analyses following completion of exposure.

Petrex method samplers were installed at every node within the field investigation grid (Figure 3.6). Duplicates were placed at approximately 5 percent of the nodes and three samplers were retained as blanks. In all, 100 samplers were used (58PX01 through 58PX100).

The samplers consisted of two collectors, each a ferromagnetic wire coated with an activated carbon adsorbent. The adsorbent collection wires were contained in screw-top glass culture tubes 6 in. in length and $1 \mathrm{in}$. in diameter. Before shipment, the wires were cleaned by heating to $358^{\circ} \mathrm{C}$ and packed under an inert atmosphere.

A tractor-mounted auger was used to drill ninety-one 4-in.-diameter holes to a depth of $18 \mathrm{in}$. on the east side of each grid node. Petrex samplers were placed in the holes by hand with the open ends of the tubes facing downward and pushed a short distance into the soil. A double plug of aluminum foil was placed at the top of each hole to minimize surface intrusion of contaminants. The samplers 
Table 3.1. Conventional Gas Extraction Results

\begin{tabular}{|c|c|c|c|c|c|c|}
\hline $\begin{array}{c}\text { Sample } \\
\text { Number }\end{array}$ & $\begin{array}{l}\text { Grid } \\
\text { Node }\end{array}$ & $\begin{array}{c}\text { PID } \\
\text { (PPMv) }\end{array}$ & $\begin{array}{l}\text { Benzene } \\
\text { (ug/L) }\end{array}$ & $\begin{array}{l}\text { Toluene } \\
\text { (ug/L) }\end{array}$ & $\begin{array}{c}\text { Ethylbenzene } \\
\text { (ug/L) }\end{array}$ & $\begin{array}{c}\text { Total Xylenes } \\
\text { (ug/L) }\end{array}$ \\
\hline 58SG01 & $1 \mathrm{~A}$ & 0 & \begin{tabular}{ll|} 
& $<0.4$
\end{tabular} & $<0.4$ & $<0.4$ & $<0.8$ \\
\hline $58 \mathrm{SG} 02$ & IC & 0 & $<0.4$ & $<0.4$ & $<0.4$ & $<0.8$ \\
\hline $58 \mathrm{SG} 03$ & $\mathrm{IE}$ & 0 & $<0.4$ & $<0.4$ & $<0.4$ & $<0.8$ \\
\hline $58 \mathrm{SG} 04$ & IG & 0 & $<0.4$ & $<0.4$ & $<0.4$ & $<0.8$ \\
\hline $58 \mathrm{SG} 05$ & $3 \mathrm{G}$ & 0 & $<0.4$ & $<0.4$ & $<0.4$ & $<0.8$ \\
\hline $58 \mathrm{SG} 06$ & $3 \mathrm{E}$ & 0 & $<0.4$ & $<0.4$ & $<0.4$ & $<0.8$ \\
\hline $58 \mathrm{SG} 07$ & $3 \mathrm{C}$ & 0 & $<0.4$ & $<0.4$ & $<0.4$ & $<0.8$ \\
\hline $5 \overline{58 G 08}$ & $3 \mathrm{~A}$ & 0 & $<0.4$ & $<0.4$ & $<0.4$ & $<0.8$ \\
\hline $58 \mathrm{SG} 09$ & $5 A$ & 0 & $<0.4$ & $<0.4$ & $<0.4$ & $<0.8$ \\
\hline $58 \mathrm{SGl0}$ & $5 \mathrm{C}$ & 0 & 0.06 & 0.83 & 0.37 & 3.90 \\
\hline 58SG11 & $5 \mathrm{E}$ & 0 & $<0.4$ & $<0.4$ & $<0.4$ & $<0.8$ \\
\hline $58 \mathrm{SGI2}$ & $5 \mathrm{G}$ & 0 & $<0.4$ & $<0.4$ & $<0.4$ & $<0.8$ \\
\hline $58 \mathrm{SGI3}$ & $7 \mathrm{G}$ & 0 & $<0.4$ & $<0.4$ & $<0.4$ & $<0.8$ \\
\hline 58SG14 & $7 \mathrm{E}$ & 680 & 5954 & 6794 & 317 & 2005 \\
\hline 58SG15 & $7 \mathrm{C}$ & 1050 & 97 & 46 & 19 & 388 \\
\hline 58 SG16 & $7 \mathrm{~A}$ & 0 & $<0.4$ & $<0.4$ & $<0.4$ & $<0.8$ \\
\hline 58 SG17 & $9 \mathrm{~A}$ & 0 & $<0.4$ & $<0.4$ & $<0.4$ & $<0.8$ \\
\hline $58 \mathrm{SG} 18$ & $9 \mathrm{C}$ & 0 & $<0.4$ & $<0.4$ & $<0.4$ & $<0.8$ \\
\hline 58SG19 & $9 \mathrm{E}$ & 0 & 0.70 & $<0.4$ & $<0.4$ & $<0.8$ \\
\hline $58 \mathrm{SG} 20$ & $9 \mathrm{G}$ & 420 & $<10$ & 4.3 & 24 & 15.6 \\
\hline $58 \mathrm{SG} 21$ & $11 \mathrm{G}$ & 0 & $<0.4$ & $<0.4$ & $<0.4$ & $<0.8$ \\
\hline $58 \mathrm{SG} 22$ & $11 E$ & 0 & $<0.4$ & $<0.4$ & $<0.4$ & $<0.8$ \\
\hline $58 \mathrm{SG} 23$ & $11 \mathrm{C}$ & 0 & $<0.4$ & $<0.4$ & $<0.4$ & $<0.8$ \\
\hline $58 \mathrm{SG} 24$ & $11 \mathrm{~A}$ & 0 & $<0.4$ & $<0.4$ & $<0.4$ & $<0.8$ \\
\hline $58 \mathrm{SG} 25$ & $13 \mathrm{~A}$ & 0 & $<0.4$ & $<0.4$ & $<0.4$ & $<0.8$ \\
\hline 58SG26 & $13 \mathrm{C}$ & 0 & $<0.4$ & $<0.4$ & $<0.4$ & $<0.8$ \\
\hline 58SG27 & $13 \mathrm{E}$ & 0 & $<0.4$ & $<0.4$ & $<0.4$ & $<0.8$ \\
\hline $58 \mathrm{SG} 28$ & $13 \mathrm{G}$ & 0 & $<0.4$ & $<0.4$ & $<0.4$ & $<0.8$ \\
\hline $58 \mathrm{SG} 29$ & $7 F$ & 0 & $<0.4$ & $<0.4$ & $<0.4$ & $<0.8$ \\
\hline $58 \mathrm{SG} 30$ & $7 \mathrm{D}$ & 2170 & 995 & 1326 & 29 & 1097 \\
\hline 58SG31 & $7 \mathrm{~B}$ & 0 & $<0.4$ & $<0.4$ & $<0.4$ & $<0.8$ \\
\hline $58 \mathrm{SG} 32$ & $6 \mathrm{D}$ & 35 & $<0.4$ & $<0.4$ & $<0.4$ & $<0.8$ \\
\hline $58 \mathrm{SG} 33$ & $8 \mathrm{D}$ & 22 & $<0.4$ & $<0.4$ & $<0.4$ & $<0.8$ \\
\hline $58 \mathrm{SG} 34$ & $8 \mathrm{C}$ & 2.5 & $<0.4$ & $<0.4$ & $<0.4$ & $<0.8$ \\
\hline $58 \mathrm{SG} 35$ & $8 \mathrm{E}$ & 1115 & 377 & 2433 & 116 & 1375 \\
\hline $58 \mathrm{SG} 36$ & $6 \mathrm{E}$ & 1335 & 479 & |4247 & 147 & 4199 \\
\hline 58 SG37 & $6 C$ & 1.4 & $<0.4$ & $<0.4$ & $<0.4$ & $<0.8$ \\
\hline $58 \mathrm{SG} 38$ & $6 \mathrm{~F}$ & 12 & \begin{tabular}{l|l}
0.69 \\
\end{tabular} & $<0.4$ & $<0.4$ & $<0.8$ \\
\hline $58 \mathrm{SG} 39$ & $8 \mathrm{~F}$ & 8 & $<0.4$ & $<0.4$ & $<0.4$ & $<0.8$ \\
\hline $58 \mathrm{SG} 40$ & $8 \mathrm{G}$ & 8 & $<0.4$ & $<0.4$ & $<0.4$ & $<0.8$ \\
\hline $58 \mathrm{SG} 41$ & $9 \mathrm{~F}$ & 125 & 65 & $<0.4$ & \begin{tabular}{|l|}
2.8 \\
\end{tabular} & 7.2 \\
\hline $58 \mathrm{SG} 42$ & $9 \mathrm{H}$ & 146 & $<0.4$ & 0.85 & 4.6 & 1.85 \\
\hline $58 \mathrm{SG} 43$ & $10 \mathrm{~F}$ & 70 & 40 & $<0.4$ & 1.7 & 19.50 \\
\hline $58 \mathrm{SG} 44$ & $10 \mathrm{G}$ & 45 & 2.4 & 0.69 & $<0.4$ & $<0.8$ \\
\hline 58SG45 & $11 \mathrm{~F}$ & 2090 & 30 & \begin{tabular}{l|}
5.2 \\
\end{tabular} & 21 & 1887 \\
\hline \multicolumn{7}{|l|}{ Note: } \\
\hline
\end{tabular}




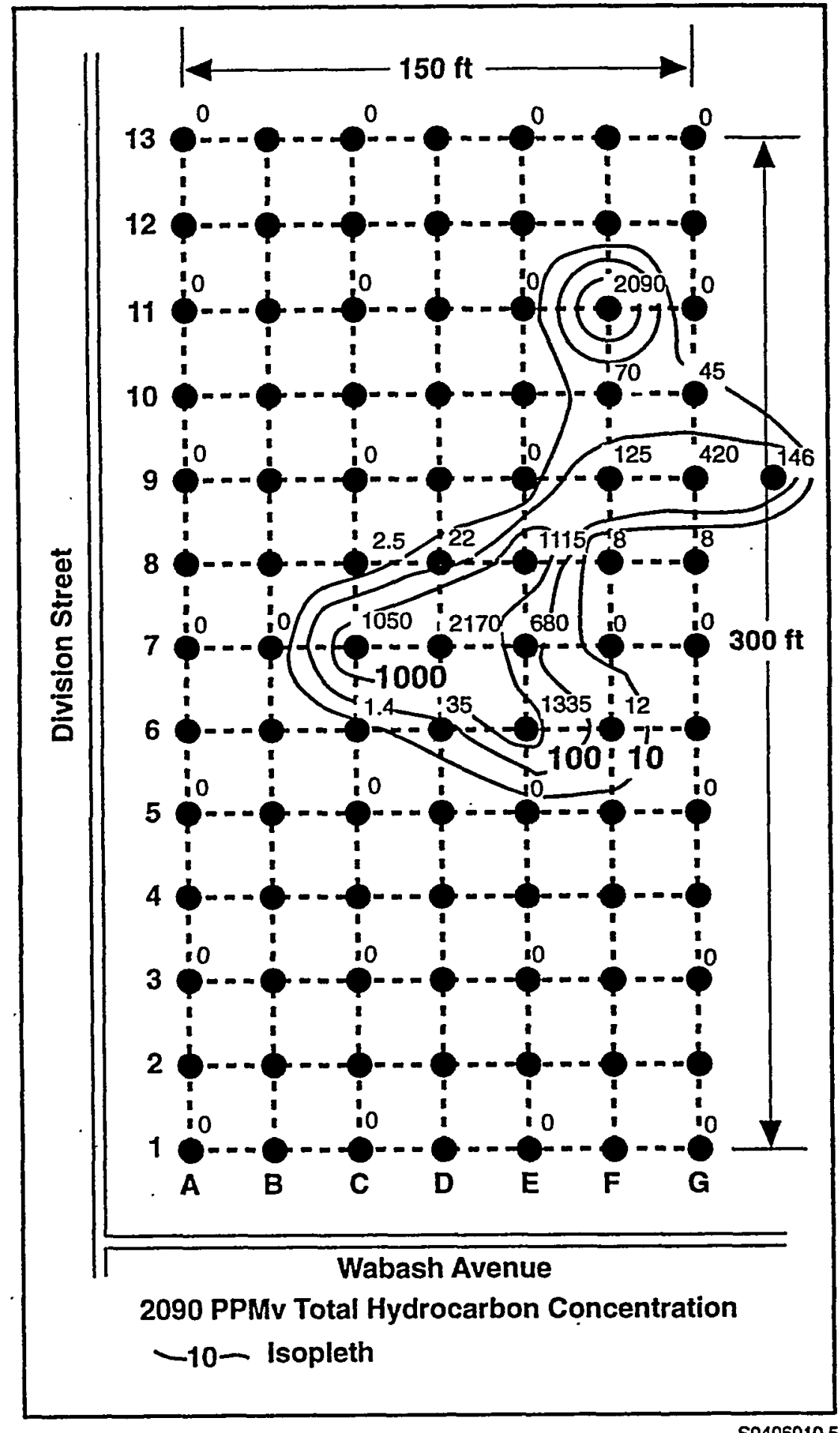

Figure 3.4. Total Hydrocarbon Concentrations in Soil Gas from Field PID Readings 


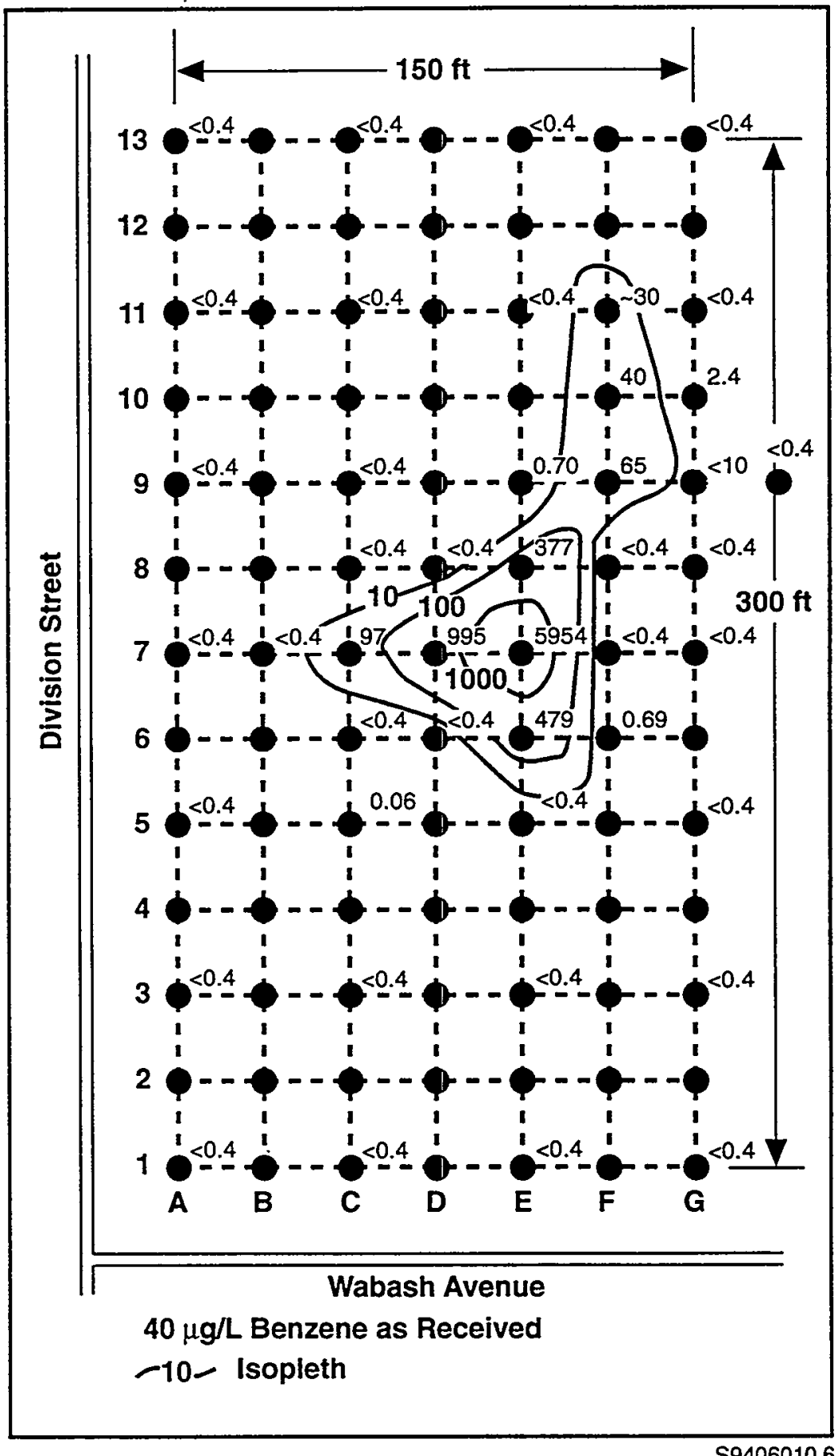

Figure 3.5. Benzene Concentrations in Soil Gas from Gas Chromatography Analysis 


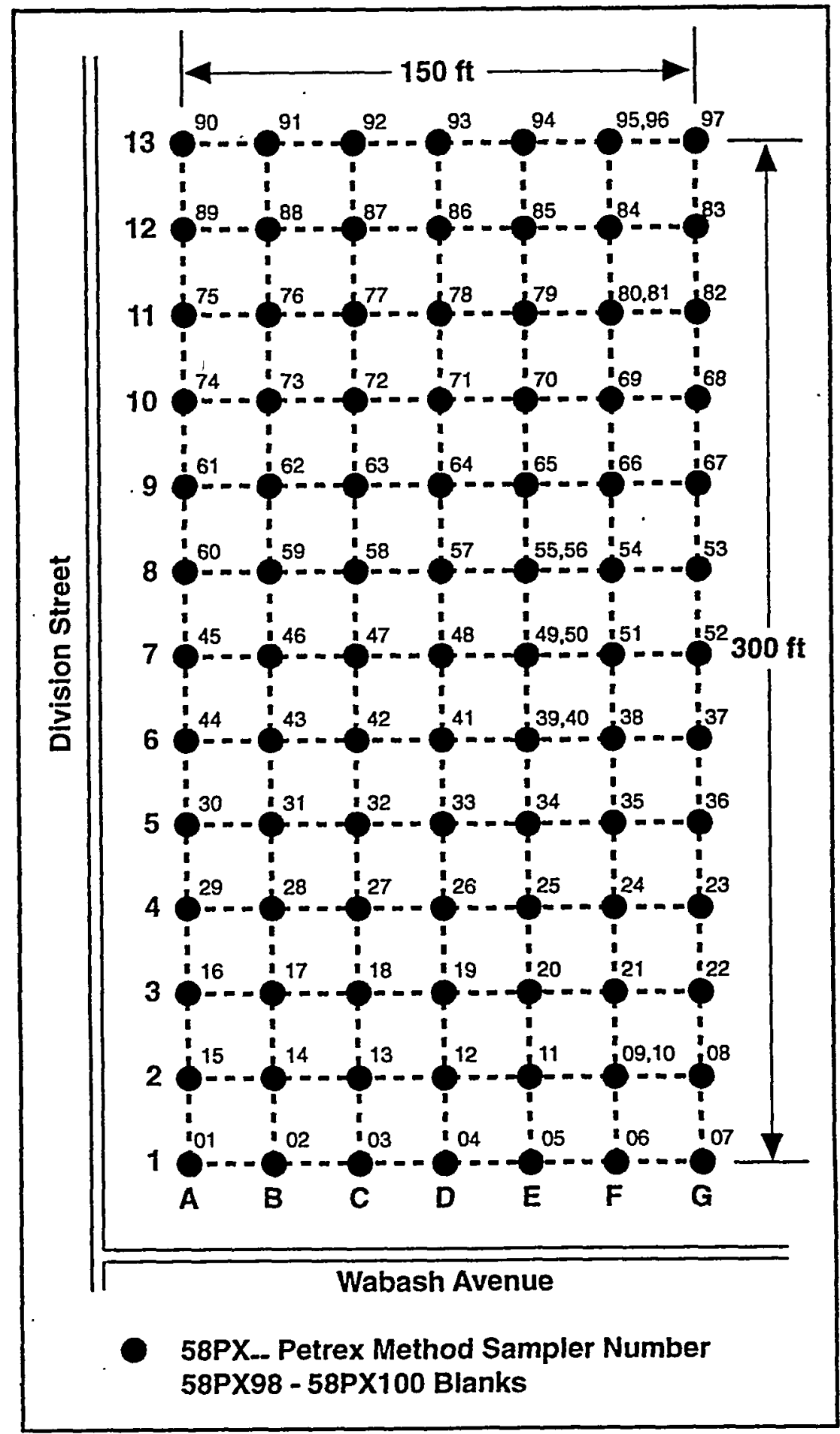

\$9309058.2

Figure 3.6. Petrex Method Sampler Locations 
were retrieved 5 days later, capped, and shipped to NERI for analysis by thermal desorption mass spectrometry. Selected samplers (eight total) were also analyzed by thermal desorption gas chromatography/mass spectrometry.

All samples were analyzed using an extranuclear quadruple mass spectrometer equipped with a Curie-point pyrolysis and thermal desorption inlet. Indicator peaks of subsurface contamination were reported based on the following mass spectral peak assignments: BTEX 78, 92, and 106; TCE 130; cycloalkanes and alkenes $84,98,112$, and 126 . Cycloalkanes are saturated hydrocarbon compounds found in petroleum. Alkenes are unsaturated hydrocarbon compounds found in petroleum. Results were reported on the basis of total ion counts summed for each of the mass peaks.

Soil gas survey results from the Petrex method are presented in Table 3.2. Results are shown for the mass peaks representative of BTEX and cycloalkanes and alkenes. Plots of the areal distribution of BTEX, and cycloalkanes and alkenes are shown in Figures 3.7 and 3.8, respectively. Contour lines are plotted for total ion counts of 300,000 and 3,000,000 per sample for BTEX and 30,000 and 300,000 for cycloalkanes and alkenes.

The Petrex method results were comparable to the conventional gas extraction results, with gasoline determined as the main subsurface contaminant. Contamination distributions for the two methods generally appear similar; however, the finer grid employed in the Petrex method survey produced better resolved contours. The two concentration centers near grid nodes $6 \mathrm{E}$ to $8 \mathrm{E}$ and $11 \mathrm{~F}$ are shown as separate sources on the Petrex method plots, whereas the distribution between centers is less distinct with the coarser grid used in the conventional gas extraction survey.

The thermal desorption gas chromatography/mass spectrometry results were consistent with the thermal desorption mass spectrometry results. NERI originally also reported the presence of TCE and perchloroethylene (PCE) at substantial levels near grid node 11F. However, the subsequent analysis by gas chromatography/mass spectrometry failed to reveal chlorinated compounds in those samples. The failure to detect chlorinated compounds in the samples from the conventional gas extraction survey as well suggests that the observations were spurious. Apparently, the observations were associated with a hydrocarbon interference at the TCE and PCE mass regions. Consequently, those species have been dropped from Table 3.2 with NERI's concurrence. Appendix G contains the complete NERI report entitled Final Report on the Findings of the Petrex Soil Gas Survey Performed at Eielson Air Force Base in Alaska.

\subsubsection{Survey Comparison and Conclusions}

Soil gas results from the conventional gas extraction and Petrex method surveys were comparable for source area ST58. Both surveys identified gasoline as the main subsurface contaminant. Contamination distributions generally appeared similar with the highest concentrations centered near grid nodes $7 \mathrm{E}$ and $11 \mathrm{~F}$. The finer grid employed in the Petrex method survey produced better contour resolution. Separate sources are shown on the Petrex method plots, whereas the distribution between centers is less distinct because of the coarser grid used in the conventional gas extraction survey. 


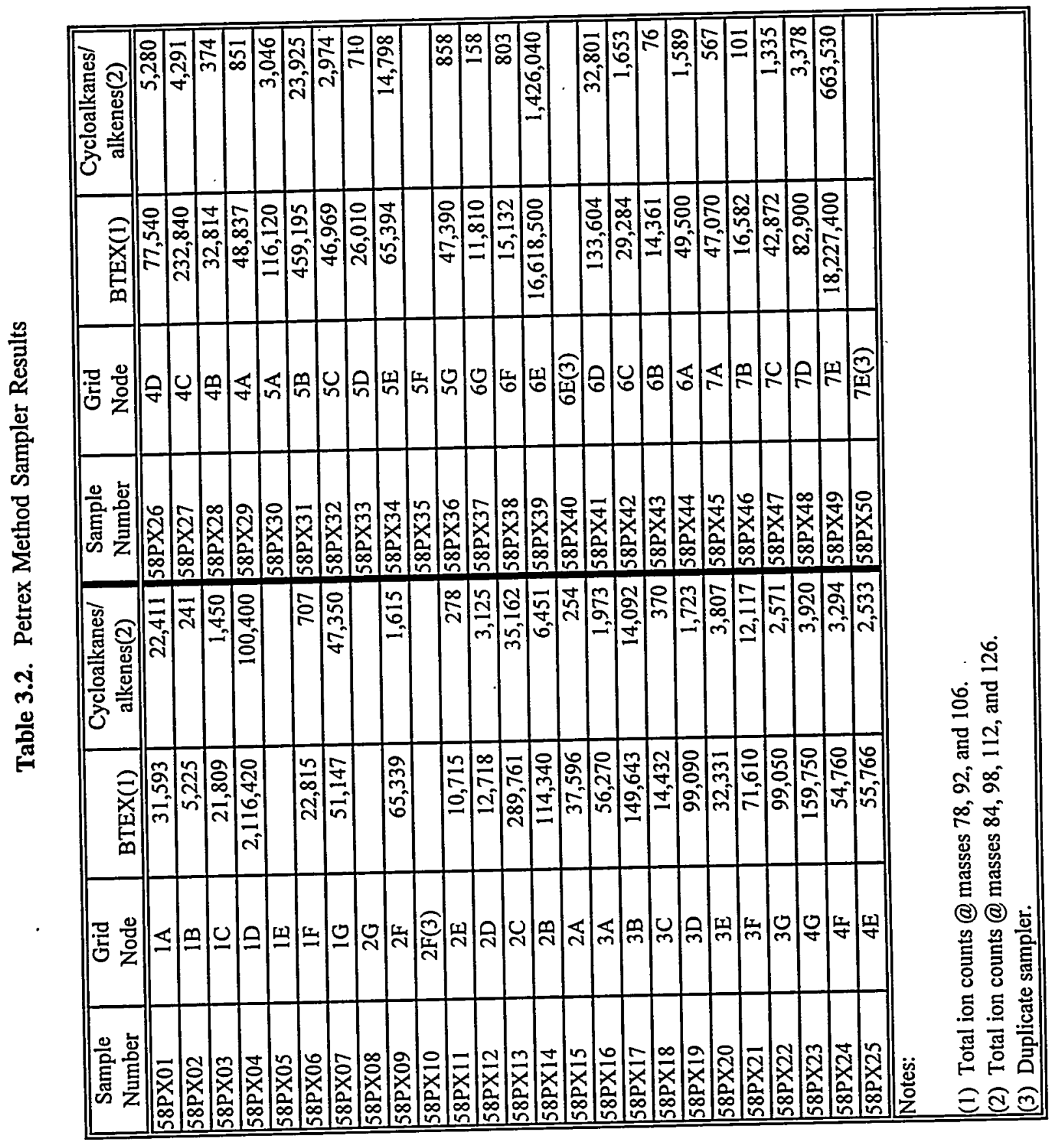




\begin{tabular}{|c|c|c|c|c|c|c|c|c|c|c|c|c|c|c|c|c|c|c|c|c|c|c|c|c|}
\hline 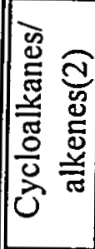 & $\mid \begin{array}{c}0 \\
\infty \\
\infty \\
-\end{array}$ & $\stackrel{9}{=}$ & $\mid$ & $\mid$ & $\left|\begin{array}{c}\frac{0}{2} \\
\frac{a}{a} \\
a\end{array}\right|$ & \begin{tabular}{l}
1 \\
\multirow{2}{n}{} \\
$\infty$ \\
$n$
\end{tabular} & 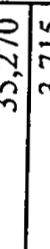 & $\begin{array}{l}n \\
n \\
n\end{array}$ & & 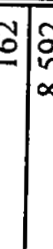 & 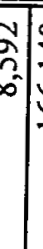 & $\begin{array}{l}8 \\
8 \\
8\end{array}$ & 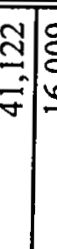 & $\begin{array}{l}|c| \\
0 \\
0\end{array}$ & $\begin{array}{l}0 \\
0 \\
0 \\
0\end{array}$ & 象 & 总 & $\mid$\begin{tabular}{l}
0 \\
\hdashline \\
$-i$
\end{tabular} & 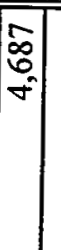 & $\begin{array}{l}\infty \\
2 \\
n \\
n\end{array}$ & & & & \\
\hline 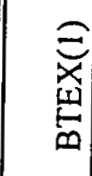 & 尔 & $\mid$\begin{tabular}{l}
\multirow{+}{\infty}{} \\
$\infty$ \\
2
\end{tabular} & $\mid \begin{array}{c}0 \\
0 \\
8 \\
q\end{array}$ & $\mid \begin{array}{l}8 \\
0 \\
2 \\
2 \\
-1\end{array}$ & $\begin{array}{l}8 \\
\vdots \\
-1 \\
a \\
\pm \\
\pm\end{array}$ & $\begin{array}{ll}8 \\
5 \\
5 \\
5 \\
5\end{array}$ & 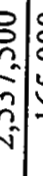 & & & & & & & 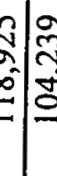 & $\sum_{\substack{n \\
\infty}}^{\infty}$ & 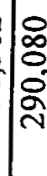 & 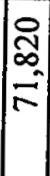 & $\left|\begin{array}{c}0 \\
0 \\
y \\
2\end{array}\right|$ & $\begin{array}{l}8 \\
\vdots \\
0 \\
0\end{array}$ & $\begin{array}{l}\text { S } \\
\infty \\
\text { J }\end{array}$ & & & & \\
\hline :군 & 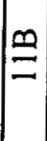 & $\stackrel{0}{=}$ & $\underline{\underline{ }}$ & $\underline{\Xi}$ & & & & v. & $\frac{1}{5}$ & & & & & & $\stackrel{m}{m}$ & U & $\underline{2}$ & $\stackrel{-10}{2}$ & & בิ & 窇 & 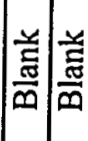 & & \\
\hline 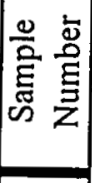 & $\begin{array}{l}0 \\
0 \\
x \\
\vdots \\
\infty \\
0 \\
0\end{array}$ & $\begin{array}{l}\Sigma \\
x \\
z \\
\infty \\
0 \\
n\end{array}$ & 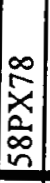 & $\mid \begin{array}{c}a \\
x \\
0 \\
\infty \\
\infty \\
\infty\end{array}$ & 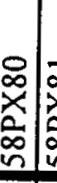 & & & & & 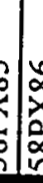 & & & 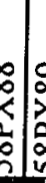 & 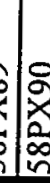 & & $\mid \begin{array}{l}2 \\
x \\
\infty \\
\infty \\
\infty \\
i\end{array}$ & $\mid \begin{array}{l}2 \\
2 \\
0 \\
\infty \\
0\end{array}$ & 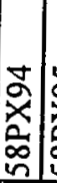 & & 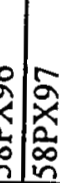 & $\left|\begin{array}{l}\infty \\
2 \\
x \\
\infty \\
\infty \\
1\end{array}\right|$ & 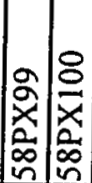 & ?. & \\
\hline 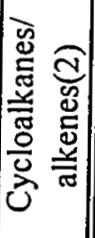 & $\left|\begin{array}{l}2 \\
2 \\
- \\
-\end{array}\right|$ & స్ & 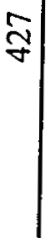 & 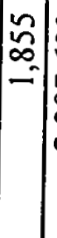 & $\begin{array}{c}8 \\
8 \\
0 \\
\infty \\
0 \\
0 \\
0 \\
0\end{array}$ & $\mid \begin{array}{l}8 \\
8 \\
0\end{array}$ & $=$ & & 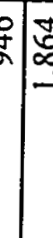 & $=$ & & 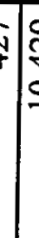 & 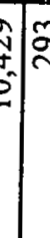 & $\frac{m}{n}$ & $\mid \begin{array}{l}2 \\
\infty \\
0 \\
0 \\
\tilde{N}\end{array}$ & $\begin{array}{l}m \\
\stackrel{m}{2} \\
\dot{\sim}\end{array}$ & 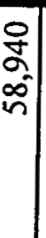 & ๙ุे & 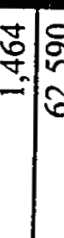 & $\hat{y}_{0}^{\infty}$ & 文 & 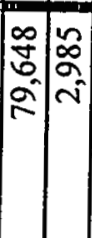 & & 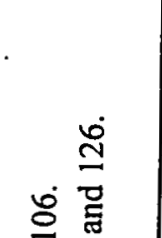 \\
\hline 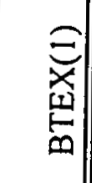 & $\frac{a}{5}$ & $\frac{N}{2}$ & $\begin{array}{l}\infty \\
\tilde{n} \\
\infty \\
\infty\end{array}$ & $\begin{array}{l}2 \\
8 \\
- \\
7\end{array}$ & 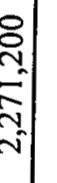 & m & $i_{0}^{\circ}$ & 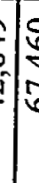 & 的 & $\mid \begin{array}{l}0 \\
0 \\
0 \\
0\end{array}$ & $\frac{\alpha}{2}$ & $=$ & 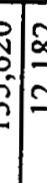 & $\begin{array}{l}0 \\
n \\
\text { r } \\
0\end{array}$ & 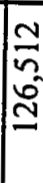 & $\begin{array}{l}\stackrel{\text { N}}{N} \\
\bar{N}\end{array}$ & $\begin{array}{l}8 \\
8 \\
0 \\
0 \\
0\end{array}$ & 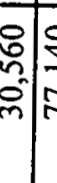 & 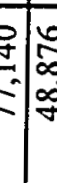 & $\frac{\sqrt{n}}{\sqrt[n]{2}}$ & 离 & 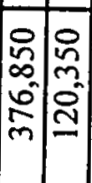 & & 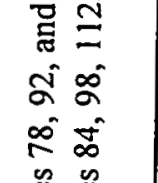 \\
\hline. & $\stackrel{4}{5}$ & 2 & ৩) & $\infty$ & $\infty$ & $\infty$ & $\mid c$ & 10 & $\mid \$$ & $\sigma$ & $1 \frac{10}{5}$ & d & ? & سूa & Ix & 'ू & 잉 & $\underline{\varrho}$ & 밀ㅇㅇㅇㅇ & 证 & 圆 & $\delta \leqq$ & & 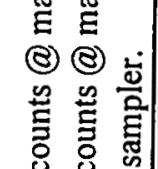 \\
\hline 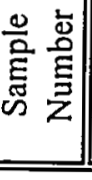 & $\begin{array}{l}\bar{n} \\
x \\
\vdots \\
\infty \\
n \\
\end{array}$ & & 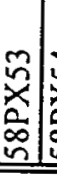 & 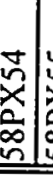 & 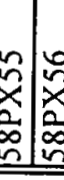 & & & & & & & & है & $\mid \begin{array}{l}n \\
x \\
\infty \\
\infty\end{array}$ & $\begin{array}{l}0 \\
0 \\
0 \\
0\end{array}$ & 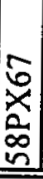 & $\begin{array}{l}\infty \\
0 \\
\dot{x} \\
0\end{array}$ & 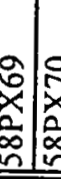 & 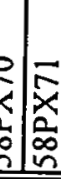 & 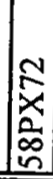 & $\begin{array}{l}m \\
x \\
\vdots \\
\infty \\
0 \\
0\end{array}$ & 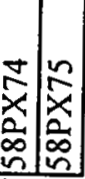 & d. & 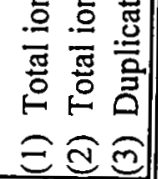 \\
\hline
\end{tabular}




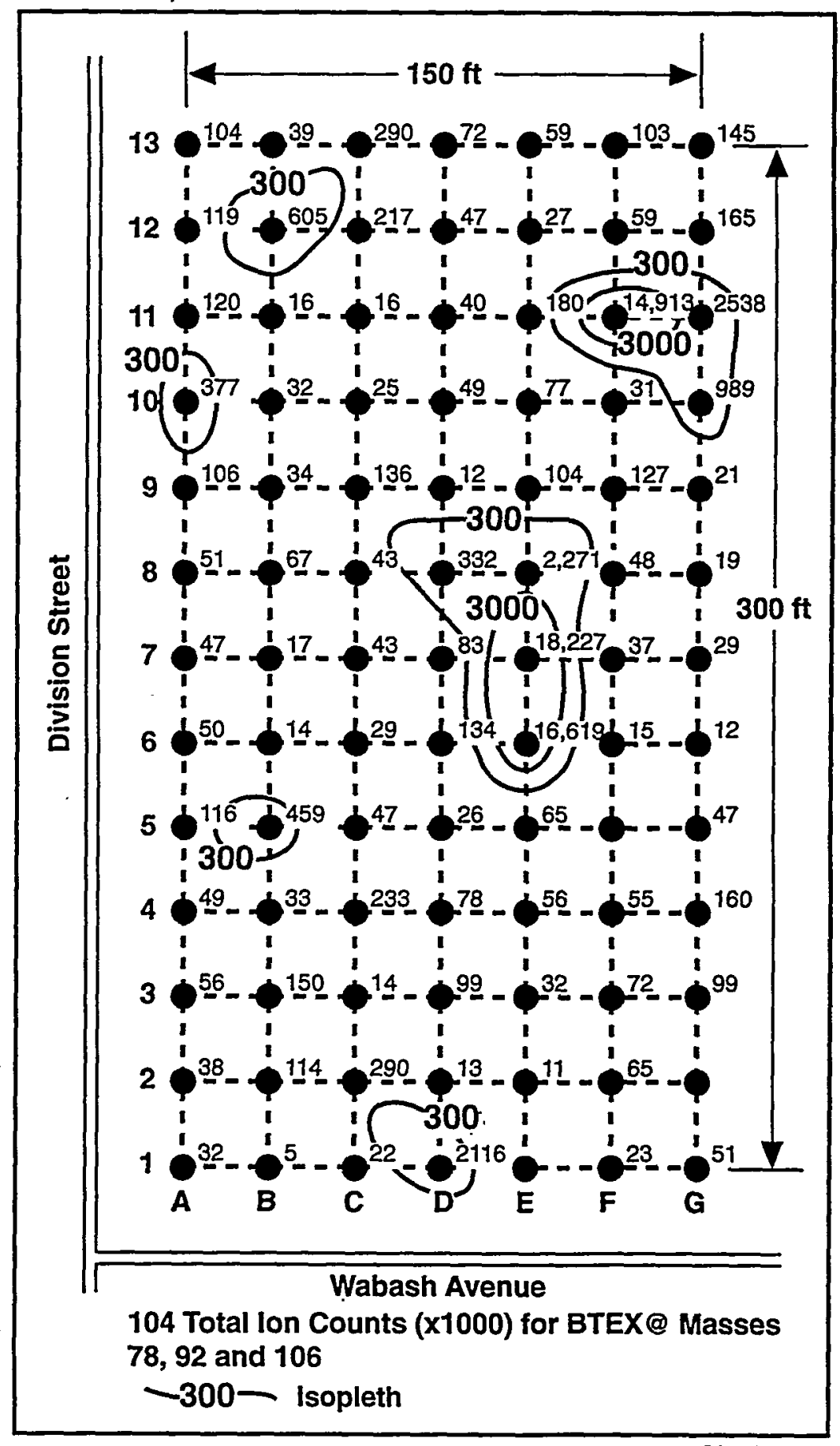

59403063.27

Figure 3.7. Petrex Method Results for Benzene, Toluene, Ethylbenzene, and Xylene in Soil Gas 


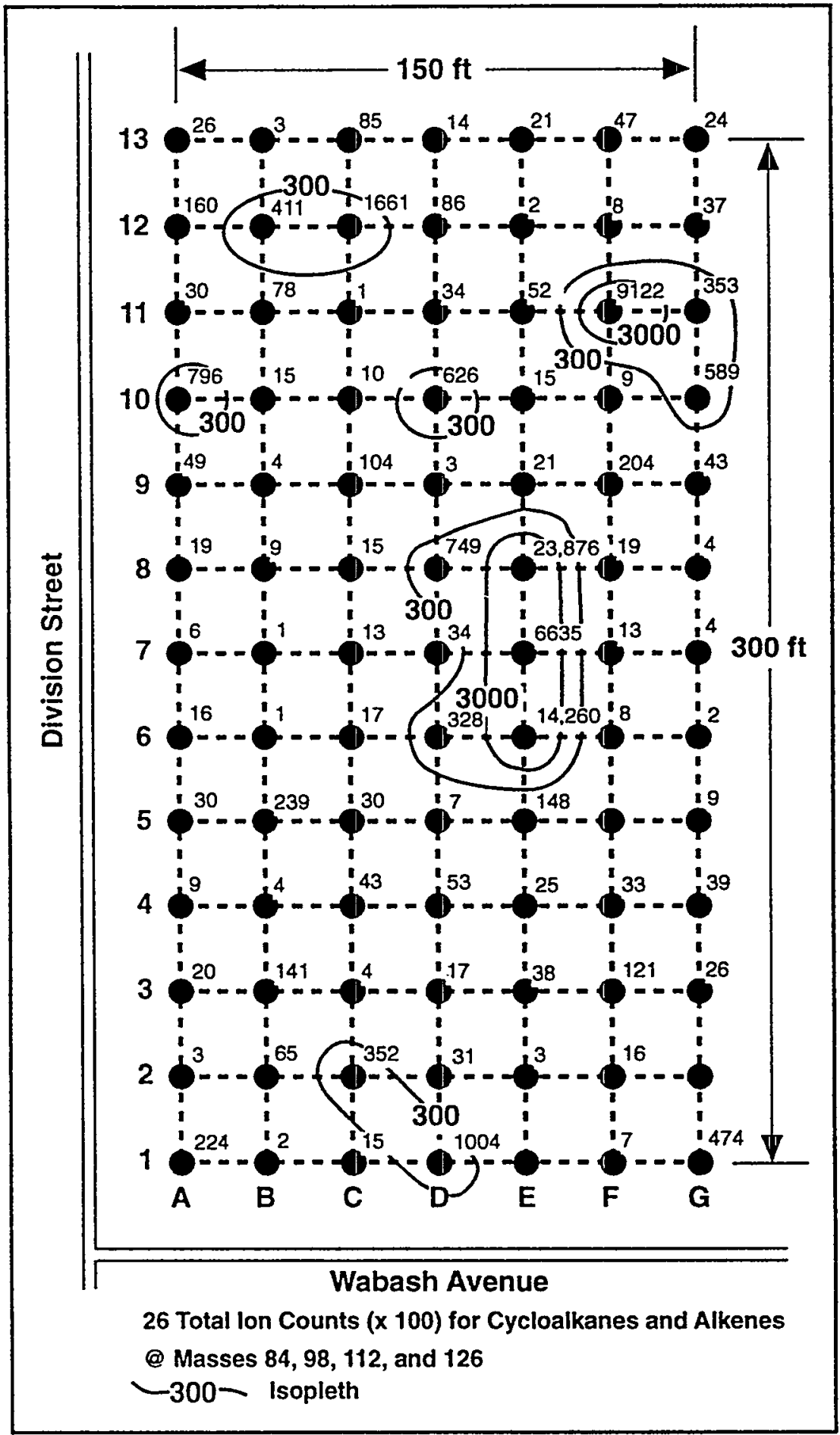

S9309058.18

Figure 3.8. Petrex Method Results for Cycloalkanes and Alkenes in Soil Gas 
The conventional gas extraction survey provided rapid results with the onsite laboratory but was labor intensive for probe insertion and sample analysis. Two operators were typically required to provide enough force for full penetration of the soils. The Petrex method survey proved to be less labor intensive but had a longer turnaround time for analytical results. Results took approximately 1 to 2 weeks longer to process but were still available before soil excavation. TCE and PCE were initially identified as contaminants by the Petrex method, though this is not surprising in view of the complexity of fuel mixtures. The use of gas chromatography and mass spectrometry by NERI was effective in resolving this problem and is a routine procedure for such cases.

Costs between the two methods were essentially equal. Major costs associated with conventional gas extraction were sample probes, mobilization and demobilization of field and laboratory personnel and equipment, and air compressor rental. Costs related to the Petrex method included samplers, auger rental, mobilization and demobilization of field personnel, and NERI analysis.

Overall, the two soil gas surveys were useful in producing high quality remote mapping of subsurface gasoline contamination. Conventional gas extraction provides a "snapshot" of the subsurface contamination whereas the Petrex method integrates contaminant concentrations over time, minimizing barometric effects. Both methods appear appropriate for other shallow applications in unconsolidated materials where contamination is known to exist.

\subsection{Test Pit Soil Sampling}

The contaminant types, concentrations, and distributions depicted at source area ST58 by the soil gas surveys were further evaluated through soil sampling and analysis. Soil samples were collected from 17 test pits (Figure 3.9) using a backhoe provided and operated by AFB personnel. Eight test pits (58TP01 through 58TP08) were selected based on the grid nodes with the highest contamination; five (58TP09 through 58TP13) were chosen from nodes with moderate contamination; and four (58TP14 through 58TP17) were peripheral to the areas of high and moderate contamination (Table 3.3). Three soil samples, A, B, and C, were collected from each test pit, approximately $0.5,4$ to 5.5 , and 9 to $10 \mathrm{ft}$ below land surface (bls), respectively. The samples were analyzed for VOCs, TPH-G, and TPH$\mathrm{D}$ on a rapid turnaround basis, and for lead on a normal turnaround basis. Head space analyses were performed in the field at each sample interval using the Microtip PID and mapped as sampling progressed. Excess soils were stockpiled adjacent to each test pit and placed back in the excavations after sampling.

Soils in the test pits were relatively similar across the site. Figure 3.10 shows the typical soil profile with approximate unit thicknesses from land surface to a depth of $10 \mathrm{ft}$. The site is covered with $1 \mathrm{ft}$ of topsoil. A lack of surface vegetation was observed at grid node 11F. Slightly moist, brown to gray, sandy gravels were noted between 1 and $3 \mathrm{ft}$ bls with brown, moist, gravelly sands from 3 to $5 \mathrm{ft}$ bls. A former soil horizon occurs at 5 to $6 \mathrm{ft}$ bls, confirming that the site was covered with approximately 3 to $4 \mathrm{ft}$ of fill. The former soil horizon contains organic matter, wood, and roots, 


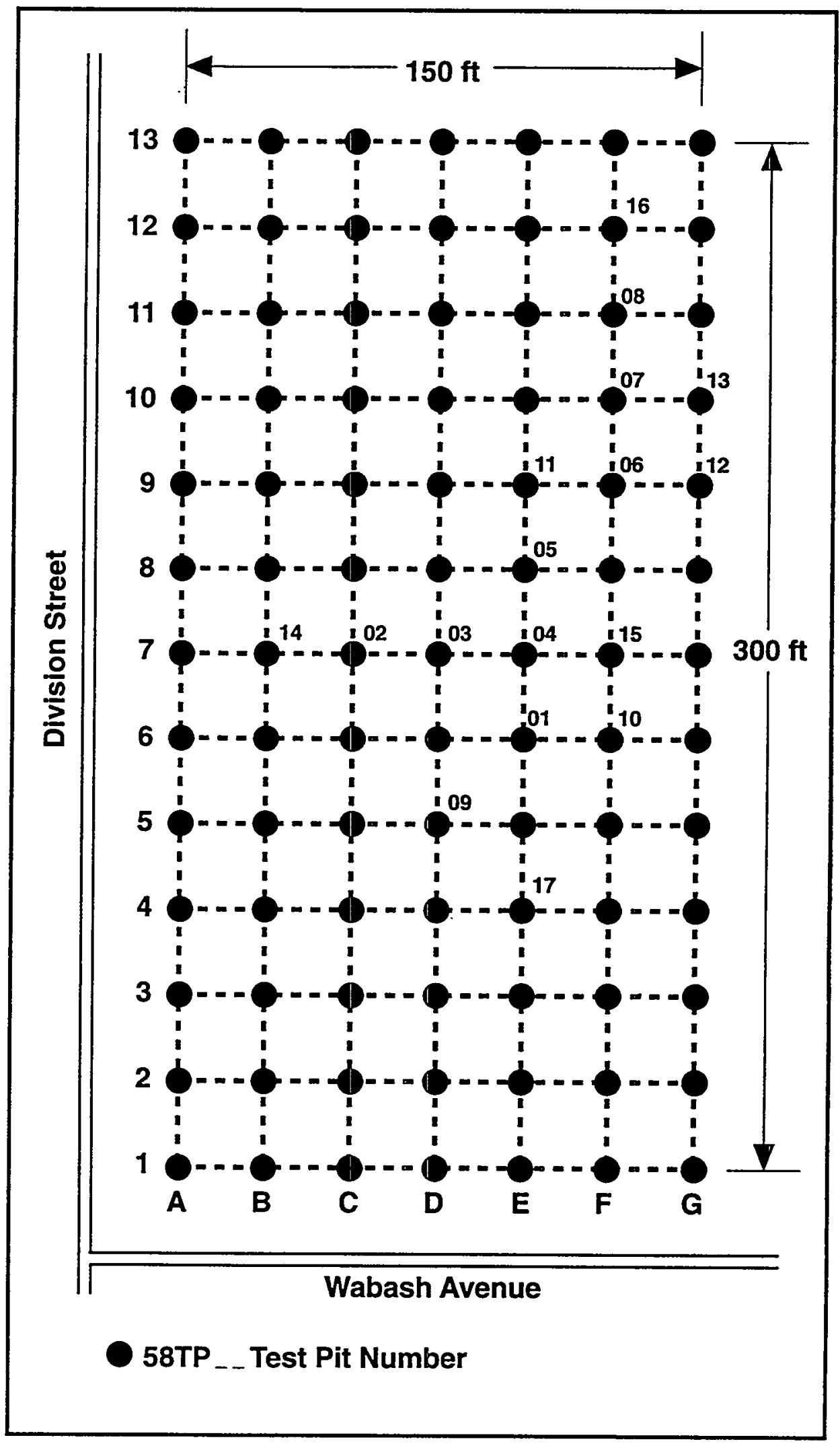

59309058.4

Figure 3.9. Test Pit Soil Sample Locations 
Table 3.3. Test Pit Selection Criteria

\begin{tabular}{|c|c|c|}
\hline $\begin{array}{l}\text { Sample } \\
\text { Number }\end{array}$ & $\begin{array}{l}\text { Grid } \\
\text { Node }\end{array}$ & $\begin{array}{c}\text { Selection } \\
\text { Criteria }\end{array}$ \\
\hline $58 \mathrm{TP01}$ & $6 \mathrm{E}$ & High Contamination \\
\hline $58 \mathrm{TP} 02$ & $7 \mathrm{C}$ & High Contamination \\
\hline 58TP03 & $7 \mathrm{D}$ & High Contamination \\
\hline $58 \mathrm{TP} 04$ & $7 \mathrm{E}$ & High Contamination \\
\hline 58TP05 & $8 \mathrm{E}$ & High Contamination \\
\hline 58TP06 & $9 \mathrm{~F}$ & High Contamination \\
\hline $58 \mathrm{TP07}$ & $10 \mathrm{~F}$ & High Contamination \\
\hline 58TP08 & $11 \mathrm{~F}$ & High Contamination \\
\hline 58TP09 & $5 \mathrm{D}$ & Moderate Contamination \\
\hline 58TP10 & $6 \mathrm{~F}$ & Moderate Contamination \\
\hline 58TP11 & $9 \mathrm{E}$ & Moderate Contamination \\
\hline 58TP12 & $9 \mathrm{G}$ & Moderate Contamination \\
\hline $58 \mathrm{TP} 13$ & $10 \mathrm{G}$ & Moderate Contamination \\
\hline 58TP14 & $7 \mathrm{~B}$ & Peripheral to High and/or Moderate Contamination \\
\hline $58 \mathrm{TP} 15$ & $7 \mathrm{~F}$ & Peripheral to High and/or Moderate Contamination \\
\hline 58TP16 & $12 \mathrm{~F}$ & Peripheral to High and/or Moderate Contamination \\
\hline 58TP17 & $4 \mathrm{E}$ & Peripheral to High and/or Moderate Contamination \\
\hline
\end{tabular}

and probably represents the land'surface during operation of the old Quartermaster service station. Underlying the former soil horizon is $2 \mathrm{ft}$ of orange to brown, clayey silt, mixed with gray sand, silt, and clay, which is underlain by $2 \mathrm{ft}$ of gravelly sand. A large amount of debris, including culvert pipes, cables, rebar, and steel pipes, were found during test pit excavation. Odors were noted in test pits 58TP04 (grid node 7E) and 58TP09 (grid node 5D). Purple- and yellow-stained soil, indicative of sand blasting and painting, was observed in test pit 58TP13 (grid node 10G). Ground water occurs at approximately $10 \mathrm{ft}$ bls.

Results from the head space and soil sample analyses at source Area ST58 are given in Table 3.4. Figures 3.11 and 3.12 show benzene concentrations for samples from the 4- to 5.5- and 9- to 10-ft depths. TPH-G distribution for the 4- to 5.5-ft interval is presented in Figure 3.13. Table 3.5 contains the concentration ranges and the grid nodes with the highest contamination.

The test pit soil sample results generally support the contaminant distributions interpreted from the soil gas surveys. Good spatial correlation was also achieved between the head space and soil sample analyses. Significant concentrations of BTEX and TPH-G were found in the soils, confirming gasoline as the main subsurface contaminant. The most contaminated soils were found in the northcentral part of the source area at the 4- to 5.5- and 9- to 10-ft sampling intervals. Typically, the contamination 


\section{Depth (ft bls)}

\section{Profile}

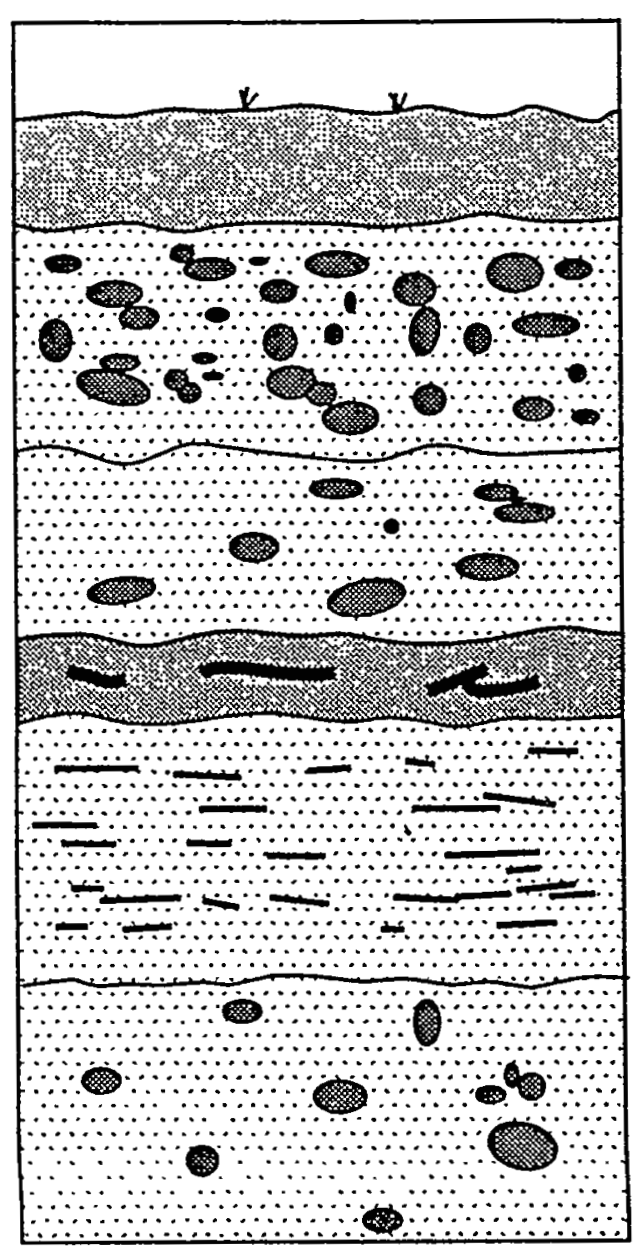

Description

\section{TS Topsoil}

SG Sandy Gravel, Brown to Gray, Slightly Moist

\section{GS Gravelly Sand, Brown Moist}

FSH Former Soil Horizon, Dark Brown Organic Matter, Roots, Wood

CS Clayey Silt, Orange, Brown, Mixed with Gray Sand, Silt, Clay

\section{GS Gravelly Sand, Brown, Moist}

Figure 3.10. Typical Soil Profile

$\$ 9406010.11$

occurred near or below the former soil horizon in the clayey silt and gravelly sand, suggesting surface spills contributed to the contamination present. Benzene concentrations ranged from $<10$ to $>90,137$ micrograms per kilogram $(\mu \mathrm{g} / \mathrm{kg})$ from 4 to $5.5 \mathrm{ft}$, with the highest concentrations in test pits $58 \mathrm{TP} 05$ (grid node 8E) and 58TP04 (grid node 7E). The highest benzene concentrations at the 9- to 10-ft interval were from samples in test pits 58TP03 and 58TP05 (grid nodes 7D and 8E, respectively). Concentrations in these test pits are significantly higher than the EPA suggested cleanup level of $500 \mu \mathrm{g} / \mathrm{kg}$. High concentrations of toluene, ethylbenzene, and total xylenes were also found in these test pits and test pit 58TP01 (grid node 6E) at both sampling depths. Significantly lower BTEX concentrations were found in the 0.5 -ft. samples. No chlorinated hydrocarbons were detected in any of the samples. 


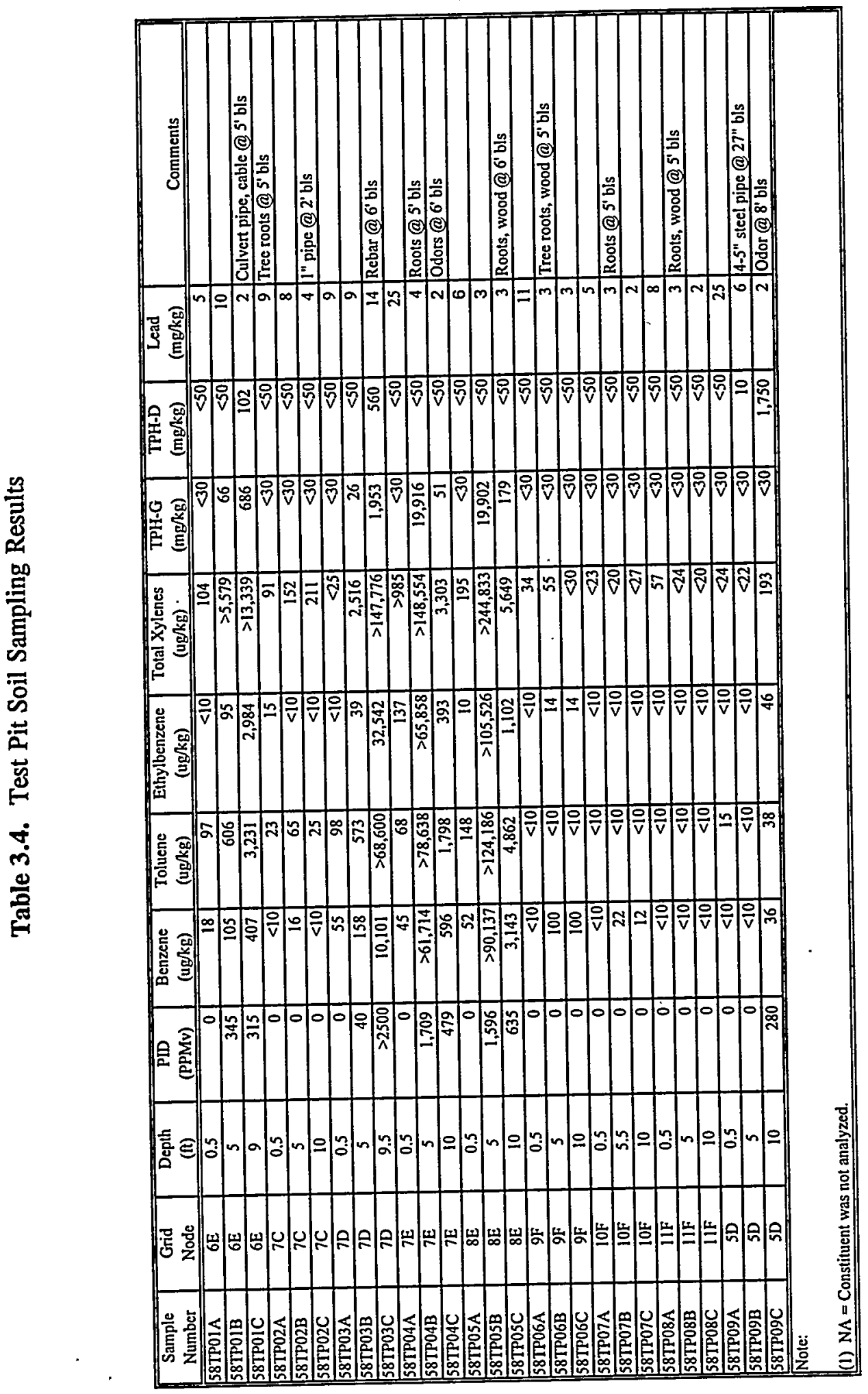




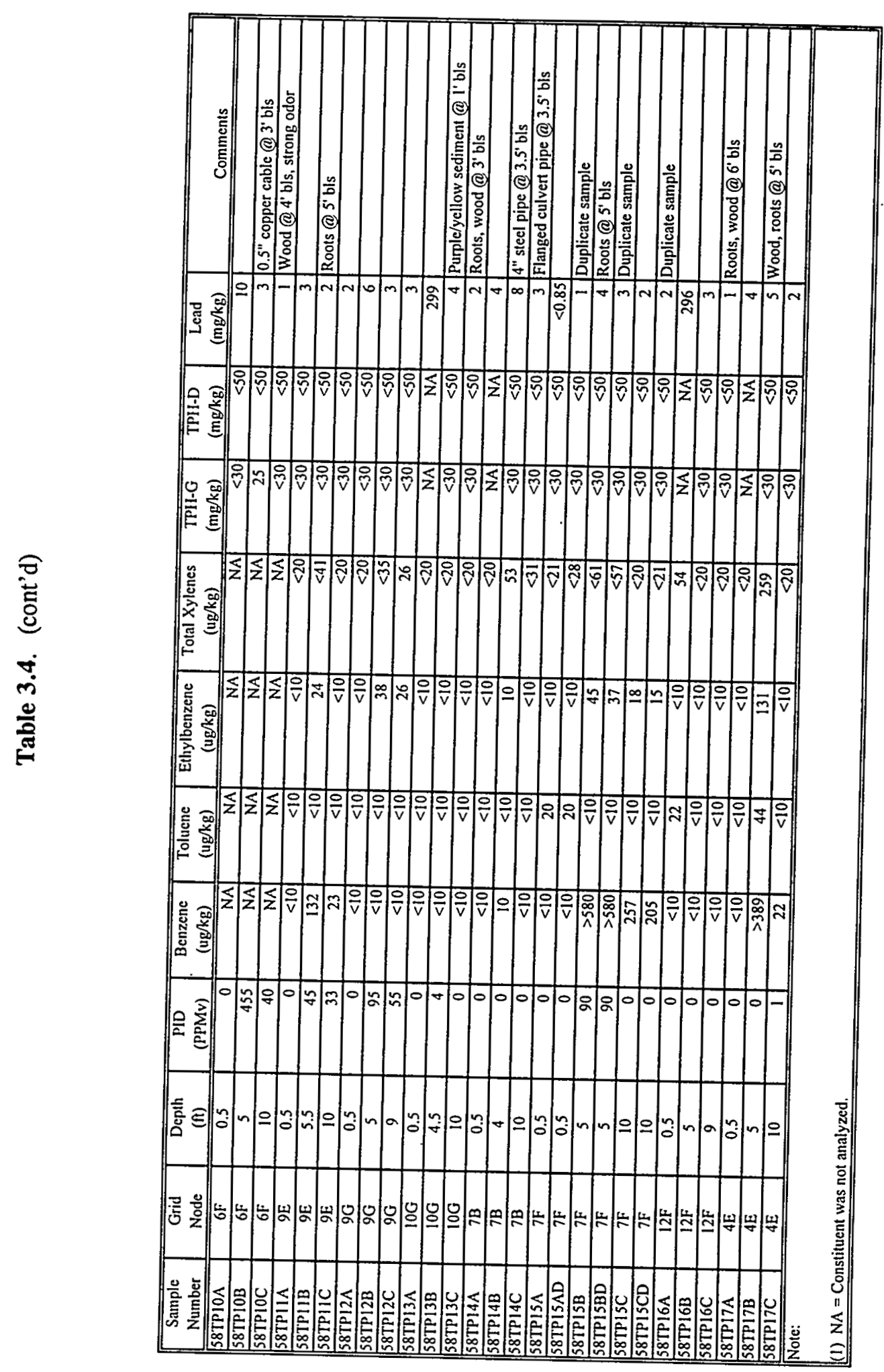




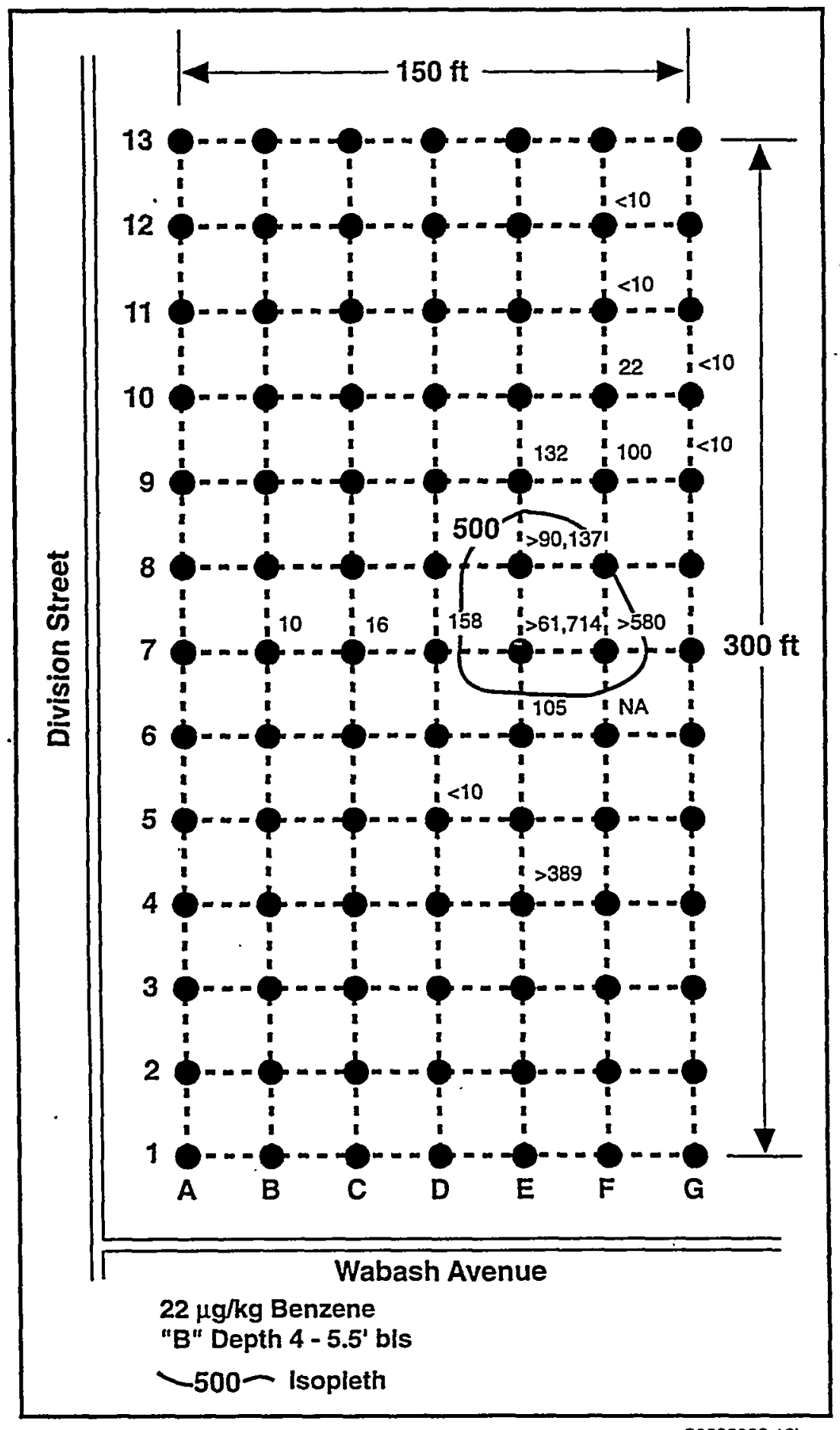

\$9305032.12bxyz

Figure 3.11. Benzene Concentrations in Soil, 4 to $5.5 \mathrm{ft}$ bls 


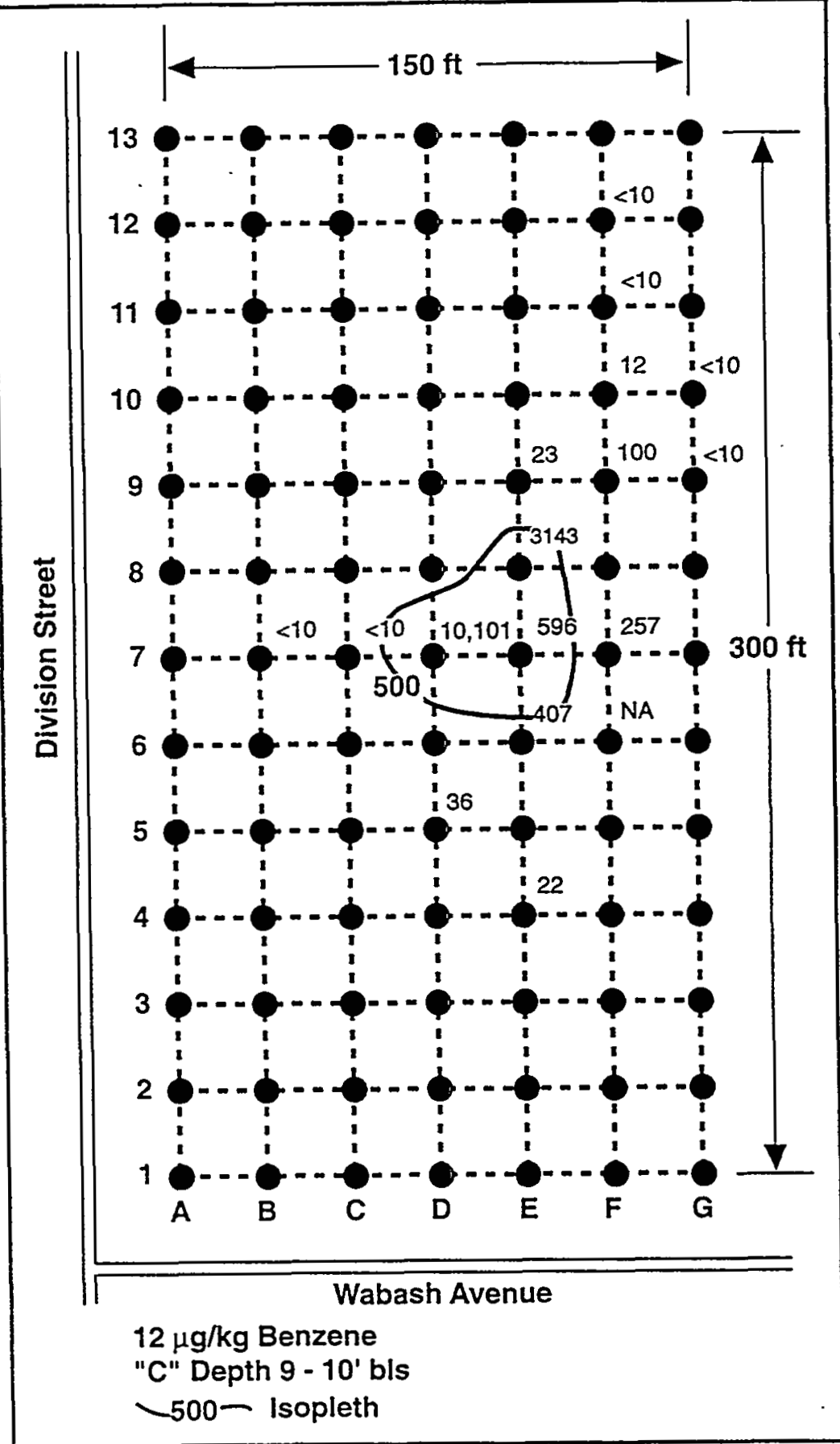

$59305032.12 a x y z$

Figure 3.12. Benzene Concentrations in Soil, 9 to $10 \mathrm{ft}$ bls 


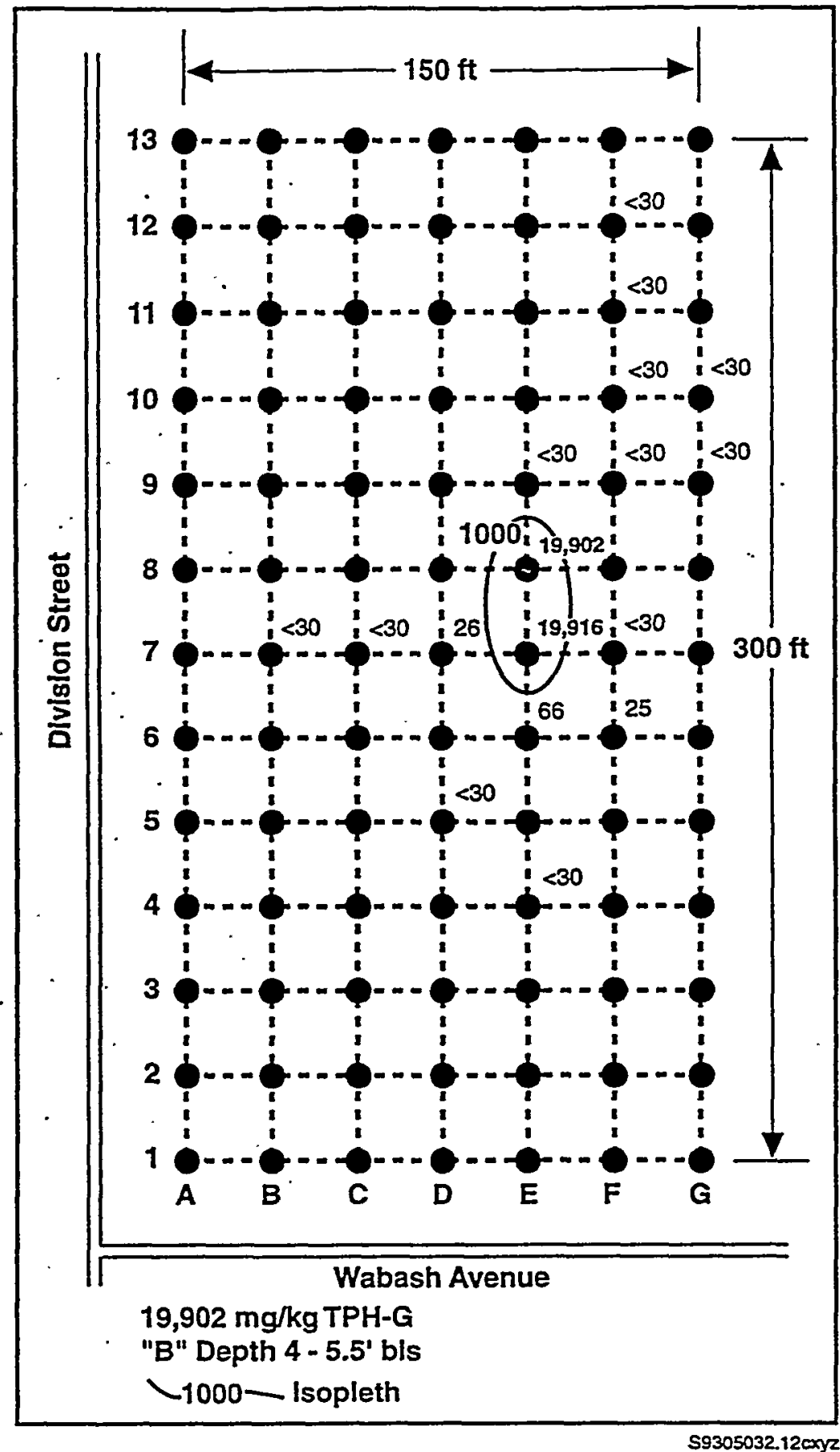

Figure 3.13. Total Petroleum Hydrocarbons - Gasoline Concentrations in Soil, 4 to $5.5 \mathrm{ft}$ bls 
Table 3.5. Test Pit Soil Sampling Summary

\begin{tabular}{|l|c|c|c|l||}
\hline \multicolumn{1}{|c|}{ Contaminant } & Depth & $\begin{array}{c}\text { Concentration } \\
\text { Range }\end{array}$ & Units & \multicolumn{1}{|c|}{$\begin{array}{c}\text { Highest } \\
\text { Grid Nodes }\end{array}$} \\
\hline PID & $\mathrm{A}$ & 0 & PPMv & NA \\
\hline PID & $\mathrm{B}$ & $0-1709$ & $\mathrm{PPMv}$ & $7 \mathrm{E}, 8 \mathrm{E}$ \\
\hline PID & $\mathrm{C}$ & $0->2500$ & $\mathrm{PPMv}$ & $7 \mathrm{D}$ \\
\hline Benzene & $\mathrm{A}$ & $<10-55$ & $\mathrm{ug} / \mathrm{kg}$ & $7 \mathrm{D}, 8 \mathrm{E}, 7 \mathrm{E}$ \\
\hline Benzene & $\mathrm{B}$ & $<10->90,137$ & $\mathrm{ug} / \mathrm{kg}$ & $8 \mathrm{E}, 7 \mathrm{E}$ \\
\hline Benzene & $\mathrm{C}$ & $<10-10,101$ & $\mathrm{ug} / \mathrm{kg}$ & $7 \mathrm{D}, 8 \mathrm{E}$ \\
\hline Toluene & $\mathrm{A}$ & $<10-148$ & $\mathrm{ug} / \mathrm{kg}$ & $8 \mathrm{E}, 7 \mathrm{D}, 6 \mathrm{E}$ \\
\hline Toluene & $\mathrm{B}$ & $<10->124,186$ & $\mathrm{ug} / \mathrm{kg}$ & $8 \mathrm{E}, 7 \mathrm{E}$ \\
\hline Toluene & $\mathrm{C}$ & $<10->68,600$ & $\mathrm{ug} / \mathrm{kg}$ & $7 \mathrm{D}, 8 \mathrm{E}, 6 \mathrm{E}, 7 \mathrm{E}$ \\
\hline Ethylbenzene & $\mathrm{A}$ & $<10-137$ & $\mathrm{ug} / \mathrm{kg}$ & $7 \mathrm{E}$ \\
\hline Ethylbenzene & $\mathrm{B}$ & $<10-105,526$ & $\mathrm{ug} / \mathrm{kg}$ & $8 \mathrm{E}, 7 \mathrm{E}$ \\
\hline Ethylbenzene & $\mathrm{C}$ & $<10-32,542$ & $\mathrm{ug} / \mathrm{kg}$ & $7 \mathrm{D}, 6 \mathrm{E}, 8 \mathrm{E}$ \\
\hline Total Xylenes & $\mathrm{A}$ & $<20->985$ & $\mathrm{ug} / \mathrm{kg}$ & $7 \mathrm{E}, 8 \mathrm{E}$ \\
\hline Total Xylenes & $\mathrm{B}$ & $<20->244,833$ & $\mathrm{ug} / \mathrm{kg}$ & $8 \mathrm{E}, 7 \mathrm{E}$ \\
\hline Total Xylenes & $\mathrm{C}$ & $<20->147,776$ & $\mathrm{ug} / \mathrm{kg}$ & $7 \mathrm{D}, 6 \mathrm{E}$ \\
\hline TPH-G & $\mathrm{A}$ & $<30$ & $\mathrm{mg} / \mathrm{kg}$ & $\mathrm{NA}$ \\
\hline TPH-G & $\mathrm{B}$ & $<30-19,916$ & $\mathrm{mg} / \mathrm{kg}$ & $7 \mathrm{E}, 8 \mathrm{E}$ \\
\hline TPH-G & $\mathrm{C}$ & $<30-1953$ & $\mathrm{mg} / \mathrm{kg}$ & $7 \mathrm{D}, 6 \mathrm{E}$ \\
\hline TPH-D & $\mathrm{A}$ & $<50$ & $\mathrm{mg} / \mathrm{kg}$ & $\mathrm{NA}$ \\
\hline TPH-D & $\mathrm{B}$ & $<50$ & $\mathrm{mg} / \mathrm{kg}$ & $\mathrm{NA}$ \\
\hline TPH-D & $\mathrm{C}$ & $<50-1750$ & $\mathrm{mg} / \mathrm{kg}$ & $5 \mathrm{D}, 7 \mathrm{D}$ \\
\hline Lead & $\mathrm{A}$ & $<0.85-299$ & $\mathrm{mg} / \mathrm{kg}$ & $10 \mathrm{G}, 12 \mathrm{~F}$ \\
\hline Lead & $\mathrm{B}$ & $2-10$ & $\mathrm{mg} / \mathrm{kg}$ & $\mathrm{NA}$ \\
\hline Lead & $\mathrm{C}$ & $1-14$ & $\mathrm{mg} / \mathrm{kg}$ & $\mathrm{NA}$ \\
\hline \hline Note: & & & & \\
(1) NA = Not applicable. & & & \\
\hline \hline & & & & \\
\hline
\end{tabular}

TPH-G concentrations for the 4- to 5.5-ft. samples were as much as 19,916 milligrams per kilogram $(\mathrm{mg} / \mathrm{kg}$ ) or approximately $2 \%$ by weight in test pits $58 \mathrm{TP} 04$ (grid node $7 \mathrm{E}$ ) and $58 \mathrm{TP} 05$ (grid node $8 \mathrm{E}$ ). The EPA suggested cleanup level for TPH-G in soil is $1000 \mathrm{mg} / \mathrm{kg}$. Concentrations were at or near the detection limit of $30 \mathrm{mg} / \mathrm{kg}$ at this depth in the remaining test pits. TPH-G concentrations ranged from $<30$ to $1953 \mathrm{mg} / \mathrm{kg}$ in the $9-$ to $10-\mathrm{ft}$ samples with the highest concentration in test pit $58 \mathrm{TPO} 3$ (grid node 7D). All of the 0.5 -ft sample were below detection.

Of note, BTEX and TPH-G concentrations were near or below the detection limits for all three sampling intervals in test pit 58TP08 (grid node $11 \mathrm{~F}$ ). The high subsurface concentrations of gasoline detected during the soil gas surveys probably reflect ground-water contamination and/or possibly floating product. 
TPH-D concentrations were below the $50 \mathrm{mg} / \mathrm{kg}$ detection limit in all test pits at both the 0.5 - and 4 to 5.5 -ft. sample intervals. All but three of the 9-to $10-\mathrm{ft}$ samples were below detection. Test pit 58TPO9 (grid node 5D), which is located near the former diesel AST, had the highest TPH-D concentration at $1750 \mathrm{mg} / \mathrm{kg}$. The suggested EPA cleanup level for TPH-D in soil is $200 \mathrm{mg} / \mathrm{kg}$.

Results from the lead analyses were significantly below the suggested EPA cleanup range of 500 to $1000 \mathrm{mg} / \mathrm{kg}$. The $0.5-\mathrm{ft}$ samples from test pits 58TP13 (grid node 10G) and 58TP16 (grid node 12F) contained the highest concentrations at 299 and $296 \mathrm{mg} / \mathrm{kg}$, respectively. This contamination is probably an artifact of the paint-stained soil noted earlier. The source of lead contamination in the ground water at source area ST58 cannot be determined from the available data. It may be the result of leaded gasoline having leaked from the underground piping. 


\subsection{Soil Excavation and Backfilling}

Soil excavation and backfilling at source area ST58 were performed by EA and AFB personnel under the guidance of PNL. Excavation was based on the results of the surface geophysical and soil gas surveys and test pit soil sampling. The objective was to excavate approximately $500 \mathrm{yd}^{3}$ of the most contaminated soil for use in composting treatability studies.

Concentration ranges and corresponding grid nodes with the highest contamination were summarized in Table 3.5. Grid nodes 7D, 7E, 8E, and $6 \mathrm{E}$ were clearly identified as "hot spots" of gasoline contamination based on the BTEX and TPH-G analyses. A 90 - by $40-\mathrm{ft}$ rectangular excavation area, centering on node $7 \mathrm{E}$, was marked with blue flags (Figure 4.1). The strategy was to remove the uppermost $3 \mathrm{ft}$ of overburden and excavate contaminated soils from approximately 3 to $8 \mathrm{ft}$ bls, below the former soil horizon.

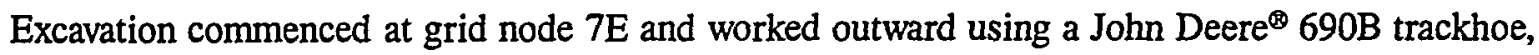
which provided greater maneuverability. Soils were segregated as clean (green), moderately contaminated (yellow), or highly contaminated (red) based on head space analyses with the MicroTip PID. Clean soils were designated by EA as $<70$ PPMv, moderately contaminated soils were 70 to 800 PPMv, and highly contaminated soils were $>800$ PPMv. The moderately and highly contaminated soils were transported to the soil composting demonstration site by three 10 -yd ${ }^{3}$ dump trucks. Clean soils were stockpiled at the southwestern corner of source area ST58 for backfilling. Buried debris were stockpiled for disposal by EA.

Soil excavation results are shown in Table 4.1. Approximately $700 \mathrm{yd}^{3}$ of soil were removed during excavation of the northcentral portion of source area ST58. Of the soil excavated, approximately $600 \mathrm{yd}^{3}$ were moderately or highly contaminated and transported to the soil composting demonstration site. The most contaminated soils were found adjacent to and beneath a 4-in. steel pipe, approximately $3 \mathrm{ft}$ bls near grid nodes 7D, 6E, 5F, 5E, and 5D. As depicted in the EMI survey (Figure 3.2), the piping ran southwest to northeast. The piping was also partially exposed during excavation of test pits 58TP01 and 58TP09 (Figure 3.9 and Table 3.4). Strong odors and fumes emanated from the soils surrounding the piping, and the piping was corroded. The condition of the piping and the highly contaminated soils suggest leaks occurred as a result of discontinuities and/or breaks in the underground piping (Figure 4.2). Excavation proceeded along the pipe trace, exposing approximately $30 \mathrm{ft}$ of piping, from grid nodes $7 \mathrm{D}$ to $6 \mathrm{E}$ and $6 \mathrm{E}$ to $5 \mathrm{D}$. Wood, cables, railroad ties, a railroad iron, and conduit were also found in the excavation. Ground water was evident at approximately $10 \mathrm{ft}$ bls and probably became contaminated through dissolution of the gasoline.

Excavation ceased after a sufficient volume of soils were transported to the soil composting demonstration site, as determined by EA. However, a significant amount of contaminated soil likely remains at source area ST58. Backfilling was performed after PNL demobilization. Backfill materials included stockpiled soils at the southwestern corner of the site and soils from an unidentified source. The clean backfill soils probably will become contaminated over time, given the residual contamination present. A remedial investigation/feasibility study will likely be required for source area ST58. A remedial investigation/feasibility study will likely be required for source area ST58.

- John Deere is a registered trademark of Deere and Company, Moline, Illinois. 


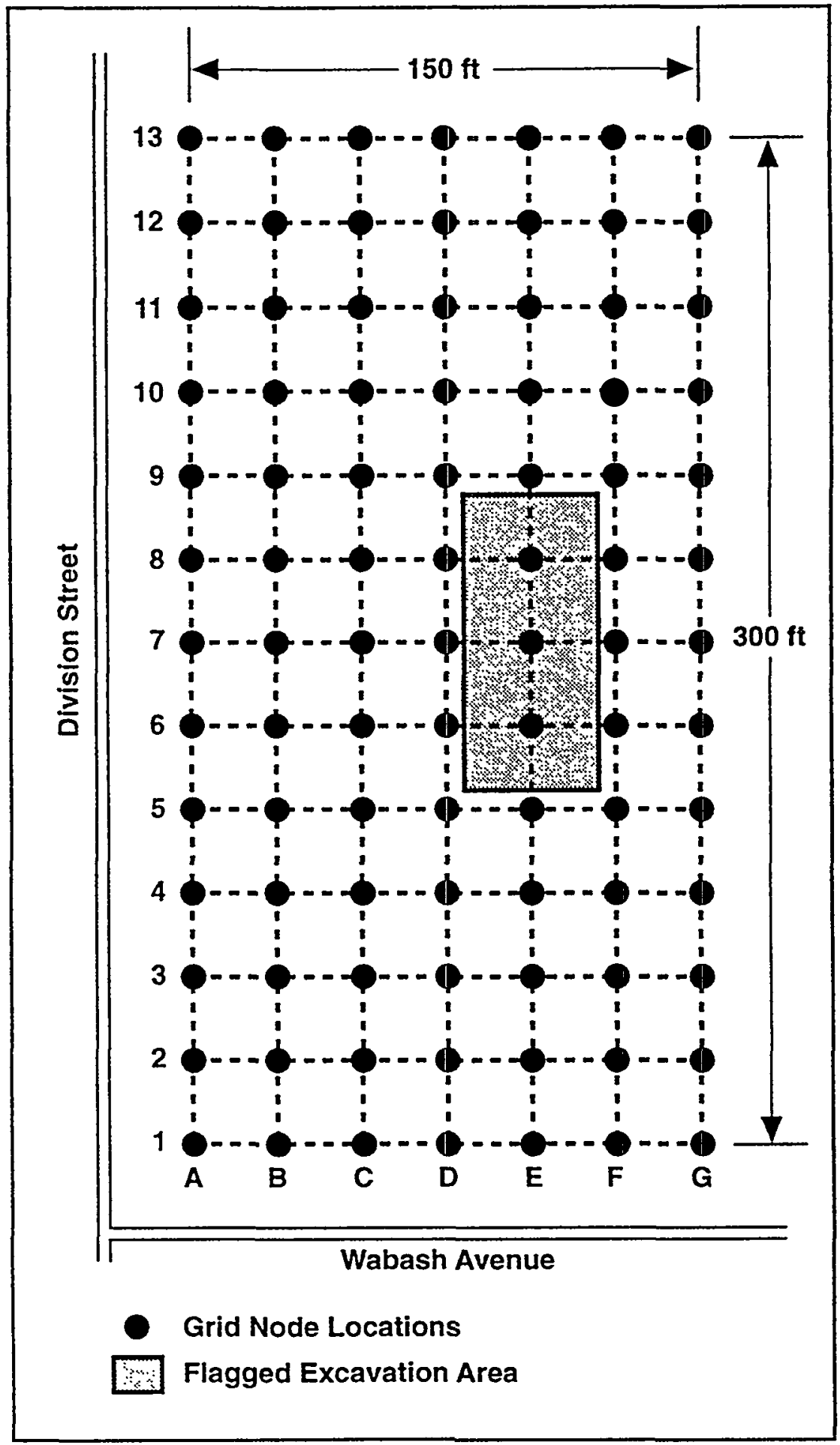

S9406010.10

Figure 4.1. Flagged Soil Excavation Area 
Table 4.1. Soil Excavation Results

\begin{tabular}{|c|c|c|c|c|c|c|}
\hline Date & $\begin{array}{c}\text { Depth } \\
\text { (ft) }\end{array}$ & $\begin{array}{l}\text { Grid } \\
\text { Node }\end{array}$ & $\begin{array}{l}\text { Reading } \\
\text { (PPMv) }\end{array}$ & $\begin{array}{l}\text { Time } \\
\text { (hrs) }\end{array}$ & $\begin{array}{c}\text { Color } \\
\text { Segregation }\end{array}$ & $\begin{array}{c}\text { Total Num. } \\
\text { of Loads }\end{array}$ \\
\hline \multirow[t]{5}{*}{ 24-Jun-93 } & $\begin{array}{l}0-2 \\
0-2\end{array}$ & $\begin{array}{l}7 \mathrm{~F}-7 \mathrm{D} \\
7 \mathrm{~F}-7 \mathrm{D}\end{array}$ & $\begin{array}{c}0 \\
33\end{array}$ & $\begin{array}{l}0830 \\
0855\end{array}$ & $\begin{array}{l}\text { Green } \\
\text { Green }\end{array}$ & 5 \\
\hline & $\begin{array}{l}2-3.5 \\
2-3.5 \\
2-3.5 \\
2-3.5 \\
3.5-5 \\
3.5-5 \\
3.5-5 \\
5-8 \\
5-8 \\
5-8 \\
5-8 \\
5-8 \\
5-8\end{array}$ & $\begin{array}{l}7 E-7 D \\
7 E-7 D \\
7 E-7 D \\
7 E-7 D \\
7 E-7 D \\
7 E-7 D \\
7 E-7 D \\
7 D-8 D \\
7 D-8 D \\
7 D-8 D \\
7 D-8 D \\
8 D-8 F \\
8 D-8 F\end{array}$ & $\begin{array}{c}107 \\
219 \\
310 \\
697 \\
100 \\
98 \\
510 \\
78 \\
80 \\
35 \\
80 \\
10 \\
72\end{array}$ & $\begin{array}{l}0920 \\
0935 \\
0935 \\
0940 \\
1000 \\
1010 \\
1017 \\
1035 \\
1045 \\
1053 \\
1101 \\
1125 \\
1146\end{array}$ & $\begin{array}{l}\text { Yellow } \\
\text { Yellow } \\
\text { Yellow } \\
\text { Yellow } \\
\text { Yellow } \\
\text { Yellow } \\
\text { Yellow } \\
\text { Yellow } \\
\text { Yellow } \\
\text { Yellow } \\
\text { Yellow } \\
\text { Yellow } \\
\text { Yellow }\end{array}$ & 15 \\
\hline & $\begin{array}{l}0-2 \\
0-2\end{array}$ & $\begin{array}{l}7 F-6 F \\
7 F-6 F\end{array}$ & $\begin{array}{l}0 \\
0\end{array}$ & $\begin{array}{l}1246 \\
1308\end{array}$ & $\begin{array}{l}\text { Green } \\
\text { Green }\end{array}$ & 5 \\
\hline & $\begin{array}{c}2-7 \\
2-7 \\
10 \\
7-10\end{array}$ & $\begin{array}{c}7 E-6 E \\
7 E-7 F \\
7 F-6 F \\
6 E\end{array}$ & $\begin{array}{c}74 \\
\text { NR } \\
\text { NR } \\
500\end{array}$ & $\begin{array}{l}1320 \\
1400 \\
1435 \\
1450\end{array}$ & $\begin{array}{l}\text { Yellow } \\
\text { Yellow } \\
\text { Yellow } \\
\text { Yellow }\end{array}$ & 10 \\
\hline & $\begin{array}{l}5-8 \\
8-10 \\
8-10 \\
0-5 \\
5-7\end{array}$ & $\begin{array}{l}7 D-6 D \\
7 D-6 D \\
7 D-6 E \\
7 D-6 E \\
7 D-6 D\end{array}$ & $\begin{array}{c}>2500 \\
>2500 \\
>2500 \\
1900 \\
>2500\end{array}$ & $\begin{array}{l}1516 \\
1523 \\
1532 \\
1600 \\
1622 \\
\end{array}$ & $\begin{array}{l}\text { Red } \\
\text { Red } \\
\text { Red } \\
\text { Red } \\
\text { Red } \\
\end{array}$ & 10 \\
\hline $25-J u n-93$ & $\begin{array}{c}5-8 \\
8-10 \\
5-8 \\
5-8 \\
8-10 \\
8-10 \\
5-9 \\
5-9 \\
8-10 \\
8-10 \\
8-10 \\
4-5 \\
3-7 \\
8-10 \\
3-7 \\
8-10\end{array}$ & $\begin{array}{c}6 E \\
6 E \\
6 E-6 D \\
6 E \\
6 E \\
6 E \\
6 E-5 F \\
6 E-5 F \\
6 E-5 F \\
6 E-5 F \\
6 E-5 F \\
6 E-5 F \\
5 F-5 E \\
5 F-5 E \\
5 F-5 E \\
5 F-5 E\end{array}$ & $\begin{array}{c}>2500 \\
>2500 \\
850 \\
>2500 \\
1906 \\
1280 \\
>2500 \\
>2500 \\
>2500 \\
2082 \\
2208 \\
800 \\
1180 \\
1533 \\
2100 \\
1603\end{array}$ & $\begin{array}{l}0835 \\
0852 \\
0904 \\
0916 \\
0929 \\
0947 \\
1041 \\
1059 \\
1106 \\
1128 \\
1150 \\
1203 \\
1300 \\
1320 \\
1347 \\
1400\end{array}$ & $\begin{array}{l}\text { Red } \\
\text { Red } \\
\text { Red } \\
\text { Red } \\
\text { Red } \\
\text { Red } \\
\text { Red } \\
\text { Red } \\
\text { Red } \\
\text { Red } \\
\text { Red } \\
\text { Red } \\
\text { Red } \\
\text { Red } \\
\text { Red } \\
\text { Red }\end{array}$ & 25 \\
\hline (1) $\mathrm{NR}=$ & & $\mathrm{g}$ instru & talfi & & - & \\
\hline
\end{tabular}




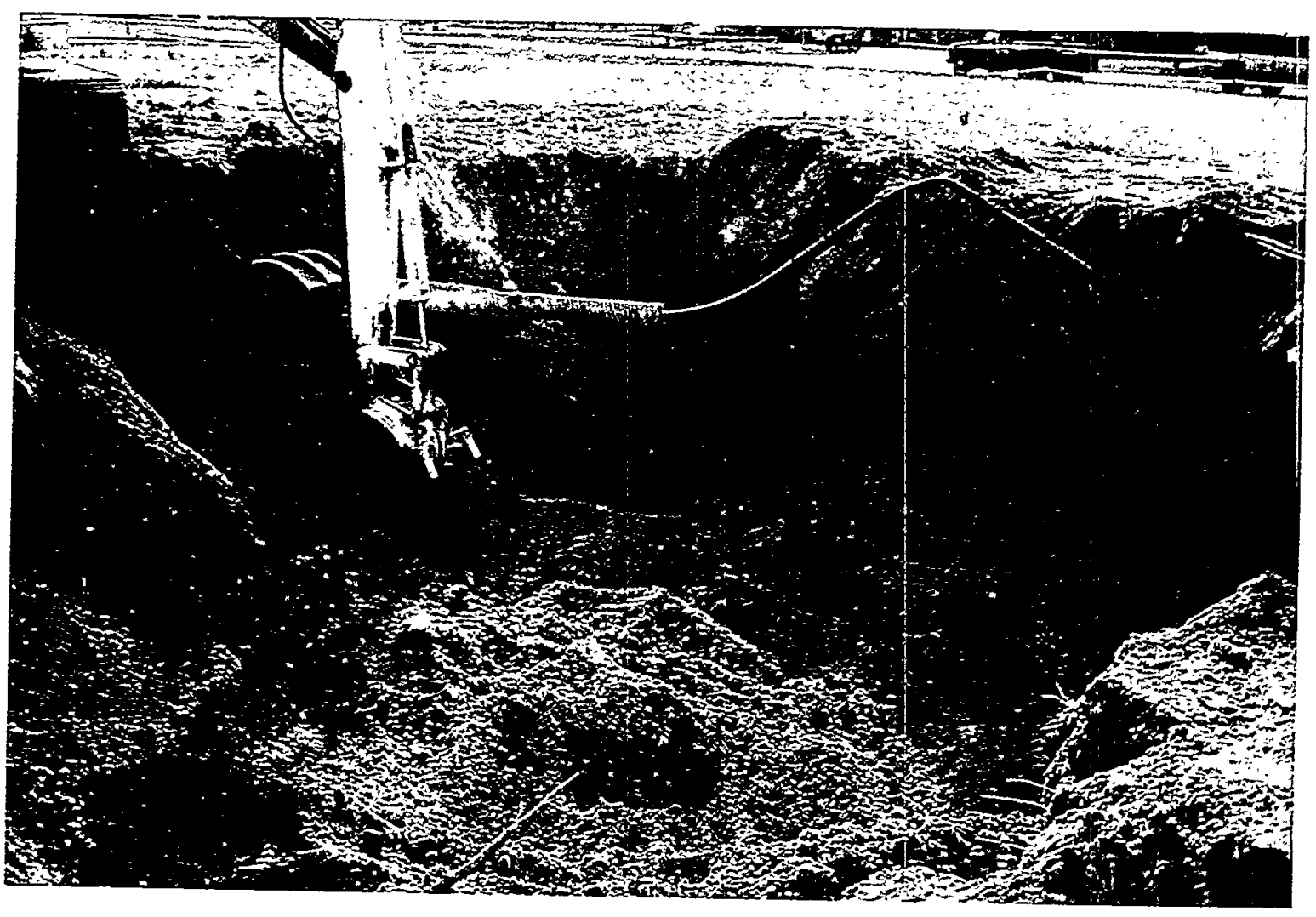

Figure 4.2. Soil Excavation Area and Underground Piping 


\subsection{Conclusions}

The conclusions from the work at source area ST58 are as follows.

1. EMI survey results corresponded very well to the AST piping locations indicated on the unscaled drawings and radiodetection unit survey. Signatures interpreted as AST piping were confirmed during test pit soil sampling and soil excavation. Survey results further indicated a significant amount of other buried material; this was also confirmed.

2. The radiodetection unit survey delineated the two main fuel feeder pipes entering the source area. In general, the signal was attenuated and became difficult to detect with increased distance and branching from the transmitter, probably as a result of discontinuities and/or breaks in the piping.

3. Soil gas results for the conventional gas extraction survey indicated close spatial correlation between field PID readings and gas chromatography analysis. Two locations containing high subsurface concentrations of gasoline were identified in the northcentral and northwestern parts of the source area. The high concentrations coincided with the unscaled drawings, April 1993 benzene concentrations in ground water, and EMI survey results. No other unusual compounds were detected.

4. The Petrex method results were comparable to the conventional gas extraction results, with gasoline determined as the main subsurface contaminant. Contaminant distributions for the two soil gas surveys appeared similar; however, the finer grid employed in the Petrex method produced better resolved contours. The two concentration centers were depicted as separate sources. Apparent TCE and PCE observations were associated with a hydrocarbon interference at those mass regions.

5. The two soil gas surveys produced high quality remote mapping of subsurface gasoline contamination. Both methods appear appropriate for other shallow applications in unconsolidated materials where contamination is known to exist.

6. Soils in the test pits were relatively similar across the site. A former soil horizon occurs at 5 to $6 \mathrm{ft}$ bls, confirming that the site was covered with approximately 3 to $4 \mathrm{ft}$ of fill. The former soil horizon contains organic matter, wood, and roots, and probably represents the land surface during operation of the old Quartermaster service station.

7. The test pit soil sample results generally support the contaminant distributions interpreted from the soil gas surveys. Good spatial correlation was also achieved between the head space and soil sample analyses. Significant concentrations of BTEX and TPH-G were found in the soils, - confirming gasoline as the main subsurface contaminant. The most contaminated soils were found in the northcentral part of the source area at the 4- to 5.5- and 9- to 10-ft sampling intervals. Typically, the contamination occurred near or below the former soil horizon in the clayey silt and gravelly sand, suggesting surface spills contributed to the contamination present. 
8. The high subsurface concentrations of gasoline detected in the northwestern corner of the source area during the soil gas surveys probably reflect ground-water contamination and/or possibly floating product.

9. Results from the lead analyses were significantly below the suggested EPA cleanup range. The contamination present is probably an artifact of paint-stained soil.

10. The source of lead contamination in the ground water cannot be determined from the available data. It may be the result of leaded gasoline having leaked from the underground piping.

11. Approximately $700 \mathrm{yd}^{3}$ of soil were removed during excavation of the northcentral portion of source area ST58. Of those, approximately $600 \mathrm{yd}^{3}$ were moderately or highly contaminated and transported to the soil composting demonstration site. The most contaminated soils were found adjacent to and beneath a 4-in. steel pipe, approximately $3 \mathrm{ft}$ bls.

12. The condition of the piping and the highly contaminated soils suggests leaks occurred as a result of discontinuities and/or breaks in the underground piping.

13. Ground water was evident in the excavation at approximately $10 \mathrm{ft}$ bls and probably became contaminated through dissolution of the gasoline.

14. A significant amount of contaminated soil likely remains at source area ST58. The clean backfill soils probably will become contaminated over time, given the residual contamination present.

15. A remedial investigation/feasibility study will likely be required for source area ST58. 


\subsection{References}

Shannon and Wilson, Inc. 1991. Geotechnical Investigation and Foundation Study Squadron Operations Facility Air National Guard Eielson Air Force Base, Alaska. Shannon and Wilson, Inc. Fairbanks, Alaska.

Shannon and Wilson, Inc. 1992. Geotechnical Investigation and Foundation Study Vehicle Maintenance Facility Air National Guard Eielson Air Force Base, Alaska. Shannon and Wilson, Inc. Fairbanks, Alaska.

U.S. Environmental Protection Agency. 1986. Test Methods for Evaluating Solid Waste Physical/Chemical Methods. SW-846, Third Edition, U.S. Environmental Protection Agency, Washington, D.C.

U.S. Environmental Protection Agency, Alaska Department of Environmental Conservation, and U.S. Air Force. 1990. Federal Facility Agreement Under CERCLA Section 120. 
Appendix A

Source Area Characterization Plan 


\section{SOURCE AREA CHARACTERIZATION PLAN SOURCE AREA ST58 \\ OLD QUARTERMASTER SERVICE STATION}

May 1993

Prepared for Eielson Air Force Base

Fairbanks, Alaska

\section{Prepared by} Battelle

Pacific Northwest Laboratories

Richland, Washington

A. 1 


\section{CONTENTS}

Page

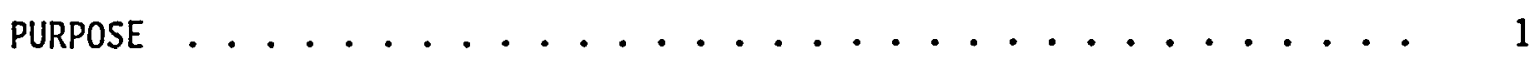

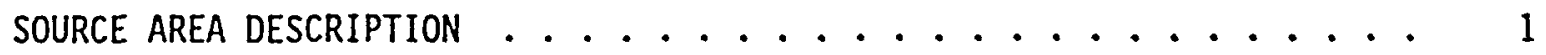

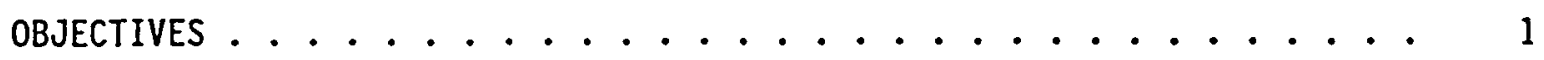

TASKS . . . . . . . . . . . . . . . . . . . 3

ASSUMPTIONS, CONDITIONS, AND DEFINITIONS . . . . . . . . . . . 3

RECORDS SEARCH ....................... 5

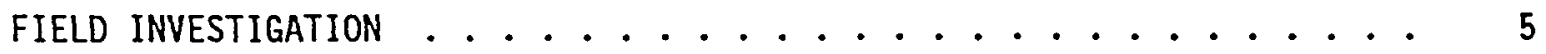

Surface Geophysical Surveys . . . . . . . . . . . . 5

Soil Gas Surveys . . . . . . . . . . . . . . 6

Contaminant Types, Concentrations, and Distributions . . . . . 7

SOIL EXCAVATION . . . . . . . . . . . . . . . . 7

Residual Product, AST Piping, and Free Product

Removal and Disposal .................. 7

SITE RESTORATION . . . . . . . . . . . . . . . . 7

EQUIPMENT DECONTAMINATION . . . . . . . . . . . . . . . 7

SAMPLE ANALYSIS PROTOCOL . . . . . . . . . . . . . 8

Sample Delivery, Holding, and Storage . . . . . . . . 8

Sample Analysis ................... 8

Sample Disposal . . . . . . . . . . . . . . . . 9

Quality Assurance and Control .............. 9

Period of Performance ................ . . 10

Reporting Requirements ................. 10

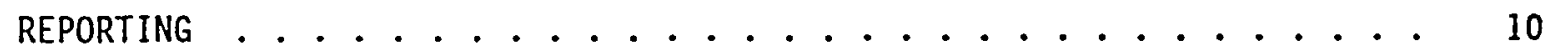

HEALTH AND SAFETY . . . . . . . . . . . . . . . . . . . . 11

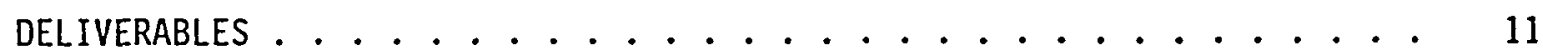


SCHEDULE . . . . . . . . . . . . . . . . . . . 11

\section{FIGURES}

Figure

Page

1.

Source Area ST58

\section{IABLES}

Table

Page

1. Division of Hork Between PNL, EA, and Eielson AFB ..... 4

2. Sample Anatysis Matrix for Source Area ST58 . . . . . . . 9

A.3 


\section{SOURCE AREA CHARACTERIZATION PLAN \\ SOURCE AREA ST58 \\ OLD QUARTERHASTER SERVICE STATION}

\section{PURPOSE}

The purpose of this work is for Battelle Pacific Northwest Laboratories (PNL) to assist Eielson Air Force Base (AFB) in the characterization of Source Evaluation Report (SER) source area ST58, the old Quartermaster service station. The work will require a field investigation to determine the nature and extent of soil and ground-water contamination present, excavation of those soils with the highest contamination, and site restoration. The field investigation will be coordinated with the PNL soil composting demonstration for remediation of hydrocarbon contamination.

\section{SOURCE AREA DESCRIPTION}

Source area ST58 is the site of the old Quartermaster service station. It is located on the northwest corner at the intersection of Division Street and Wabash Avenue (Figure 1). The service station covered approximately 1 acre (135 by 300 feet). The site is currentiy a flat, grassy field.

The service station was operated from 1970 to 1988 . The station utilized four 25,000 gallon above ground storage tanks (ASTs), containing motor gasoline (MOGAS) and diesel. Both leaded and unleaded MOGAS were used. Blueprints show an isopropyl alcohol AST; Ejelson AFB records indicate only MOGAS was stored in this tank. The ASTs and above ground piping were removed in August 1988; the underground piping was left in place.

No known spills have occurred at source area ST58. No service station maintenance records, observations during AST removal, or closure files are available. Geotechnical investigations conducted in November 1991 and February 1992 indicate the presence of benzene contamination in ground water immediately downgradient of source area ST58 (Figure 1). Concentrations above the maximum contaminant Teve] (MCL) of $5 \mathrm{ug} / \mathrm{L}$ range from 5.4 to $145 \mathrm{ug} / \mathrm{L}$. The MCL was exceeded in four we11s, 58MW03, 58MH04, 58MW05, and 58MH08. Benzene concentrations in the remaining wells were a 11 below detection. No chemical analyses were performed on the soils.

\section{OBJECTIVES}

The objectives of the work at source area ST58 are to:

- determine the contaminant types, concentrations, and distributions in the soil and ground water resulting from source area ST58

- excavate approximately 500 cubic yards of the most contaminated soil and transport it to the soil composting demonstration for remediation of hydrocarbon contamination 


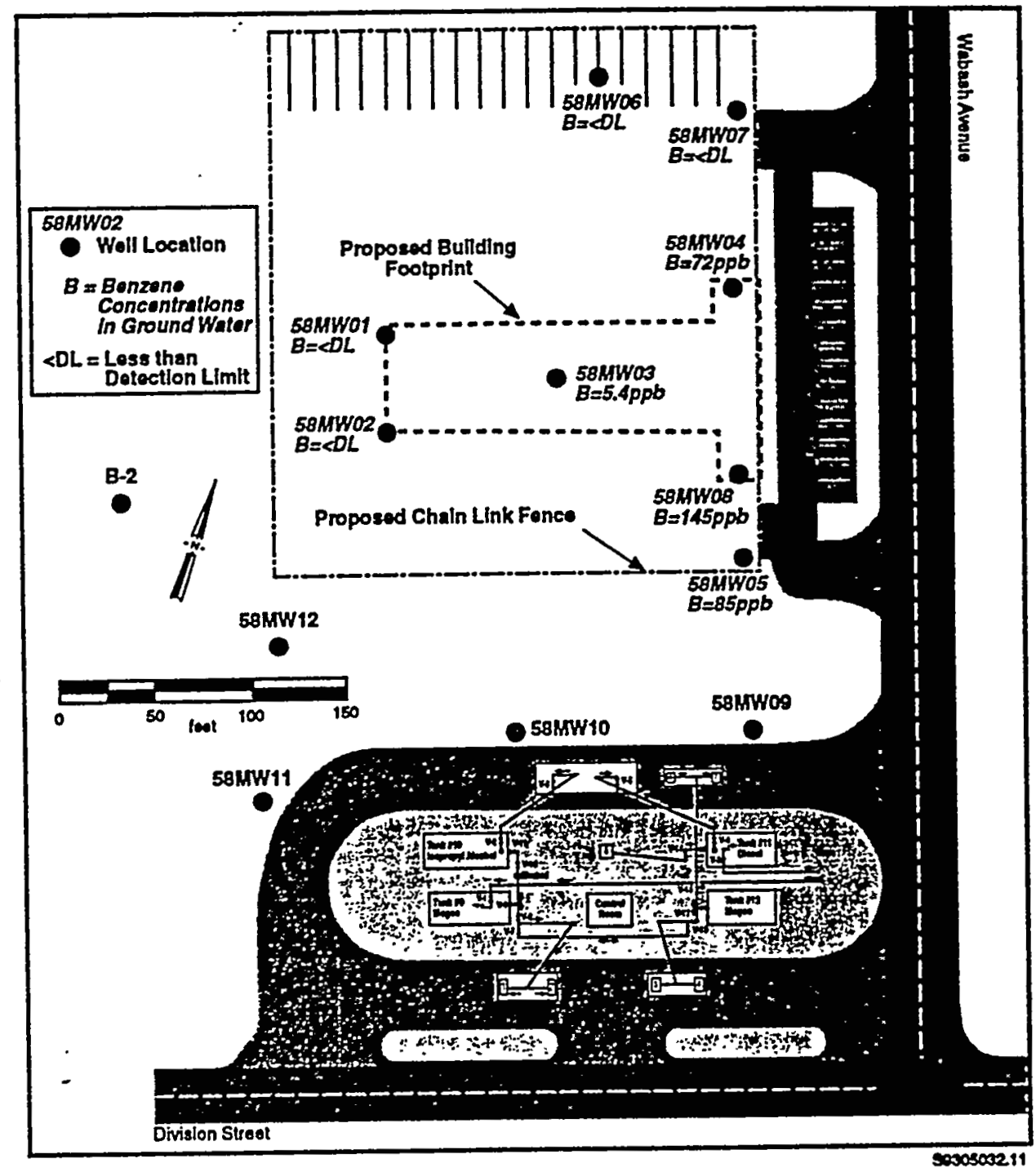

Figure 1. Source Area ST58. 
- backfill the excavation and restore the site to pre-work conditions.

\section{TASKS}

The work at source area ST58 will include the tasks listed below. The work will be performed by PNL, EA Engineering, Science, and Technology (EA), and Eielson AFB. Table 1 shows the division of work between PNL, EA, and Eielson AFB.

- determine the nature and location of any AST piping, Teaks, and/or spills through a records search

- survey the grid nodes for the geophysical and soil gas surveys

- further identify the location of the AST piping using surface geophysical surveys

- further estimate the contaminant types, concentrations, and distributions using soil gas surveys

- confirm the contaminant types, concentrations, and distributions through test pit soil sampling and analysis

- excavate approximately 500 cubic yards of the most contaminated soil and transport it to the soil composting demonstration

- remove and dispose of any residual product from the AST piping

- remove and dispose of the AST piping from the excavation

- backfill the excavation with clean soil and restore the site to pre-work conditions.

\section{ASSUMPTIONS, CONDITIONS, AND DEFINITIONS}

The work at source area ST58 will be performed under the following assumptions and conditions:

- access around utilities or other restrictions will be coordinated with Eielson AFB by means of a Base Civil Engineering Hork Clearance Request; the work clearance request will be completed by EA and posted in the field

- traffic/pedestrian controls will be coordinated with Eielson AFB 


\begin{tabular}{|c|c|}
\hline \multirow[t]{7}{*}{ PNL } & Perform Records Search \\
\hline & Grid Surface Geophysical Surveys \\
\hline & Grid, Perform, and Interpret Soil Gas and Petrex Surveys \\
\hline & Perform Test Pit Soil Sampling \\
\hline & Recommend Soil Excavation Area \\
\hline & Perform Laboratory Analyses* \\
\hline & Complete and Submit Technical Report \\
\hline \multirow[t]{2}{*}{ EA } & Operate Backhoe and Dump Truck for Soil Excavation \\
\hline & $\begin{array}{l}\text { Perform Residual Product, AST Piping, and Free } \\
\text { Product Removal and Disposal }\end{array}$ \\
\hline \multirow[t]{4}{*}{ Eielson AFB } & Perform Location Surveying \\
\hline & Perform and Interpret Surface Geophysical Surveys \\
\hline & Operate Backhoe for Test Pit Soil Sampling \\
\hline & Perform Site Restoration \\
\hline
\end{tabular}

- field screening will be used during the field investigation and soil excavation; field screening pertains to the use of monitoring instruments [ie., flame ionization detector (FID), photoionization detector (PID), colorimetric tube, and/or explosimeter] to help determine health and safety precautions, monitor potential exposures, and identify contaminant sources.

- $\quad$ work will be performed in level $D$ personal protective equipment (PPE); level C PPE will be used if concentrations in the breathing space with the monitoring instrument exceed background concentrations by 10 parts per million (ppm) for 5 minutes

- soil will be considered contaminated if a head space analysis with the monitoring instrument indicates greater than $10 \mathrm{ppm}$ volatile organic compounds (VOC)

- a head space analysis pertains to holding the sample inlet of the monitoring instrument in a plastic bag filled with a soil sample and taking an instrument reading

- a backhoe will be used for the test pit soil sampling; the backhoe will be decontaminated using a high pressure washer before and after sampling

- the high pressure washer and site will be provided by Eielson AFB

- test pit soil sampling equipment will be new or decontaminated using soap and water scrub with distilled water rinse before each sample is collected

- decontamination water used for the test pit soil sampling equipment will be contained, treated, sampled, and analyzed before discharge to the Eielson AFB sanitary sewer system 
- treated water wil. be discharged to the Eielson AFB sanitary sewer system when sample analyses are less than 10 parts per billion (ppb) total benzene, toluene, ethylbenzene, and xylene (BTEX) and $5 \mathrm{ppb}$ benzene

- sample analyses will be performed using Environmental Protection Agency (EPA) or equivalent procedures; analyses will be performed on a rapid turnaround basis

- a backhoe and dump truck will be used for the soil excavation; the backhoe and dump truck will be decontaminated using the high pressure washer before and after excavation

- backfill soils to be used for the site restoration will be provided by Eielson AFB.

\section{RECORDS SEARCH}

A search will be conducted to locate service station as-built drawings, maintenance records, and closure files for source area ST58. This information will be used to help identify the location of the ASTs and associated piping, determine if any leaks and/or spills were documented, and guide the field investigation, soil excavation, and site restoration. Suspected locations of the AST piping, leaks, and/or spills will be staked in the field.

\section{FIELD INVESTIGATION}

\section{Surface Geophysical Surveys}

Magnetometer and if necessary, ground penetrating radar (GPR) surveys will be performed to supplement the records search in identifying the location of the AST piping. These surveys are useful in locating buried objects. The magnetometer measures the strength of the earth's magnetic field and buried metal objects will appear as magnetic anomalies. GPR pulses are reflected back to the surface when an interface such as a buried object is encountered.

A grid encompassing the suspected piping Tocation will be determined and set up in the field. Magnetometer measurements will be taken at each node within the grid and mapped in the field. The GPR survey will be run along the grid lines to provide continuous digital and analog readouts. Initial results may be used to optimize additional measurements and runs.

In the event existing records are insufficient, a 150 by 300 -foot grid with 25-foot nodes will be set up, with the 150-foot axis parallel. to Wabash Avenue. Magnetometer measurements will be taken at each node for a total of 91 measurements. The GPR survey will be run along the grid iines for a total of 20 runs. Initial results may be used to optimize additional measurements and runs. 
Suspected AST piping locations will be staked based on the results of the surface geophysical surveys to optimize residual product and AST piping removal. Grid node locations will be surveyed for mapping and reporting. The need for a GPR survey will be determined in the field by the PNL Field Team Leader.

\section{Soil Gas Surveys}

Conventional gas extraction and the passive Petrex method will be used to supplement the records search in estimating the contaminant types, concentrations, and distributions resulting from source area ST58. These surveys are useful in measuring VOC present in the vadose zone or ground water. Conventional gas extraction involves physically removing a gas sample from the vadose zone. The passive Petrex method involves burying absorbent material in the vadose zone and physically sorbing the VOC present.

A grid encompassing the suspected contaminant locations will be determined and set up in the field. Conventional gas extraction probes will be installed at each node within the grid at a depth of approximately 4 feet with an air hammer. The probes will be allowed to equilibrate overnight. Samples will be drawn using a vacuum pump and analyzed for VOC on a rapid turnaround basis. Duplicate samples will be drawn at approximately 5 percent of the nodes. Initial-results may be used to optimize additional sampling.

The Petrex method samplers will be installed adjacent to each conventional gas extraction probe within the grid at a depth of approximately 18 inches with a tractor mounted auger. Duplicate samplers will be installed at approximately 5 percent of the nodes. The samplers will be left in the ground for approximately 1 week. Following retrieval, the samplers will be placed in sealed tubes and sent to the manufacturer for VOC analysis.

A direct comparison will be made between the conventional gas extraction and Petrex method results.

In the event existing records are insufficient, the 150 by 300 -foot grid used for the surface geophysical surveys will also be used for the soil gas surveys. Conventional gas extraction probes will be installed at 50-foot nodes within the grid for a total of 28 probes. Duplicate samples will be drawn at approximately 5 percent of the nodes. The Petrex method samplers will be installed at 25-foot nodes within the grid for a total of 91 samplers. Duplicate samplers will be installed at approximately 5 percent of the nodes. Initial results may be used to optimize additional sampling.

Estimated contaminant locations will be staked based on the results of the soil gas surveys to optimize residual product removal and soil excavation. Grid node locations will be surveyed for mapping and reporting. 
Contaminant Types, Concentrations, and Distributions

The contaminant types, concentrations, and distributions resulting from source area ST58 will be confirmed through soll sampling and analysis. Soll samples will be collected from 15 test pits using a backhoe. Three soil samples will be collected from each test pit, approximately 0.5 feet and 4 feet below 7 and surface and just above the water table. Head space analyses will be performed and mapped as sampling progresses.

Test pit soil samples will be collected from the point of highest contamination and below the AST locations and pump islands. Samples will be collected below each 25-foot'length of AST piping with emphasis on joints and elbows. Samples will also be collected outside the perimeter and below the bottom of the plume(s) to confirm the horizontal and vertical extent of contamination. The samples will be analyzed for VOC, total petroleum hydrocarbons (TPH), and lead on a rapid turnaround basis.

\section{SOIL EXCAVATION}

Information from the records search and field investigation will be used to optimize soil excavation. Approximately 500 cubic yards of the most contaminated soil will be excavated and transported to the soil composting demonstration site for remediation of hydrocarbon contamination. Head space analyses will be performed and mapped as excavation progresses:

\section{Residual Product, AST Piping, and Free Product Removal and Disposal}

Information from the records search and field investigation will be used to optimize residual product, AST piping, and free product removal. Residual product within the AST piping in the excavation will be removed using a peristaltic or vacuum pump and disposed. The AST piping will be removed using a backhoe and disposed. Free product, if present in the excavation, will be removed using a peristaltic or vacuum pump and disposed.

\section{SITE RESTORATION}

Source area ST58 will be backfilled with clean soil provided by Eielson AFB and restored to pre-work conditions.

\section{EQUIPMENT DECONTAMINATION}

The backhoes and dump truck will be decontaminated using a high pressure washer before coming onsite and after completion of work. The high pressure washer and site will be provided by Eielson AFB. 
Test pit soil sampling equipment will be new or decontaminated using soap and water scrub with distilled water rinse before each sample is collected.

Decontamination water used for the sampling equipment will be contained and treated using the PNL waste-water treatment system, as in the 1991 and 1992 field investigations. The treated water will be sampled and analyzed for VOC on a rapid turnaround basis. The treated water will be discharged to the Eielson AFB sanitary sewer system when sample analyses are less than $10 \mathrm{ppb}$ total BTEX and $5 \mathrm{ppb}$ benzene.

One equipment blank will be collected after decontamination of the test pit soil sampling equipment. The equipment blank will be analyzed for VOC on a rapid turnaround basis.

\section{SAMPLE ANALYSIS PROTOCOL}

\section{Sample Delivery, Holding, and Storage}

The conventional gas extraction samples will be analyzed in a field laboratory. The test pit soil samples will be shipped to PNL via Federal Express. The Petrex method samplers will be shipped to the manufacturer via Federal Express. All samples will be packed in blue or bagged ice and sealed in coolers.

Upon receipt, the laboratory will check the condition of the samples (ie., temperature, breakage, leaks, etc.) and verify that the accompanying chain of custody is in agreement with the sample labels. The laboratory will then sign the chain of custody.

If any discrepancies in the accompanying documentation are noted and/or the integrity of the samples have been compromised, the laboratory will immediately notify the PNL Analytical Contact for resolution. These discrepancies will be noted on the chain of custody. The samples will be stored at $4^{\circ} \mathrm{C} \pm 2^{\circ} \mathrm{C}$ until extraction for analysis.

\section{Sample Analysis}

The conventional gas extraction samples, soil samples, duplicates, and equipment blank will be analyzed for selected constituents as shown in the sample matrix in Taḅle 2.

The conventional gas extraction samples will be analyzed for VOC using PNL Technical Procedure PNL VOA-2, Volatile Organic Compounds in Water by Purge and Trap Capillary Column Gas Chromatography with Dual Electron Capture and Flame Ionization Detectors.

Alcohol extracts from the test pit soil samples will be analyzed for VOC using Modified PNL Technical Procedure PNL VOA-3 EPA Method 502.2, Volatile Organic Compounds in Water by Purge and Trap Capillary Column Gas Chromatography with Photoionization and Electrolytic Conductivity Detectors in Series. 


\begin{tabular}{|c|c|c|c|c|c|}
\hline \multirow[b]{2}{*}{$\begin{array}{c}\text { Sample } \\
\text { Type } \\
\end{array}$} & \multicolumn{3}{|c|}{ VOC } & \multirow{2}{*}{$\begin{array}{c}\text { TPH } \\
\text { EPA Method } \\
8015 / 8020\end{array}$} & \multirow{2}{*}{$\begin{array}{l}\text { Lead } \\
\text { EPA Method } \\
\text { TCLP 7421 }\end{array}$} \\
\hline & PNL VOA-2 & $\begin{array}{c}\text { PNL VOA-3 } \\
\text { EPA Method } 502.2\end{array}$ & $\begin{array}{c}\text { Manufacturer } \\
\text { Analysis }\end{array}$ & & \\
\hline $\begin{array}{l}\text { Conventional Gas } \\
\text { Extraction } \\
\end{array}$ & $x$ & & & & \\
\hline Petrex Method & & & $x$ & & \\
\hline Test Pit Soil & & $\mathrm{x}$ & & $\mathrm{x}$ & $x$ \\
\hline $\begin{array}{l}\text { Water-Treatment } \\
\text { System }\end{array}$ & & $\mathrm{x}$ & & & \\
\hline Equipment Blank & & $x$ & & & \\
\hline
\end{tabular}

The water-treatment system samples and equipment blank will be anaiyzed for VOC using PNL Technical Procedure PNL VOA-3 EPA Method 502.2, Volatile Organic Compounds in Water by Purge and Trap Capillary Column Gas Chromatography with Photoionization and Electrolytic Conductivity Detectors in Series.

The test pit soil samples will be analyzed for TPH using EPA Method 8015/8020, gas and diesel ranges, and Tead using EPA Method 7421.

\section{Sample Disposal}

The laboratory will dispose of all residual samples.

\section{Quality Assurance and Control}

This work will be performed under the PNL-MA-70 Quality Assurance Plan No. EES-102, Rev. 0, for Eielson AFB, Source Area ST58, dated May 1993.

Departures from the 1 isted methods will be documented as part of the laboratory record. Departures affecting the quality of the anaiytical results wiTl be reported to the PNL Analytical Contact for approval before performing the analyses.

Analytical test conditions, sample preparation information, and related data for conducting the analyses will be documented as part of the laboratory record and traceable to the original sample numbers and analytical results.

The laboratory will use the original chain of custody to track each sample and return these documents with the analytical results.

One field duplicate, method blank, and matrix spike sample will be analyzed for every 20 samples from a particular medium. One equipment blank will be analyzed after decontamination of the test pit soil sampling equipment. Performance requirements for quality control samples are specified below. 
Accuracy (SR) : 75-125\%

Precision (RD) $\pm 20 \%$

\section{Period of Performance}

The samples will be.collected in May and June 1993. The samples will be delivered to the field laboratory on the day of collection or shipped to PNL via Federal Express within one day of collection. The Petrex method samplers will be shipped to the manufacturer via Federal Express within one day of retrieval.

\section{Reporting Requirements}

All samples, with the exception of the Petrex method samplers, will be analyzed on a rapid turnaround basis. Analytical results including sample numbers, date and time of analysis, results in ppb, original chain of custody forms, and any departures from the 1 isted procedures will be reported to the PNL Analytical Contact within 24 hours of sample receipt. The Petrex method samplers will be analyzed on a normal turnaround basis.

\section{REPORTING}

A technical report will be submitted following completion of the field investigation, soil excavation, and site restoration for source area ST58. The report will include as a minimum:

- a discussion of the source area history and conditions resulting in initiation of the source area characterization plan

- source area maps showing boundaries, roads, buildings, AST and associated piping locations, and other relevant structures

- survey data for grid node locations

- a description of the surface geophysical surveys and resuits

- a description of the soil gas surveys, including laboratory data

- descriptions of the contaminant types, concentrations, and distributions, including laboratory data

- descriptions of the hydrogeology

- a description of the soil excavation, including excavated soil volumes

- a description of the residual product, AST piping, and free product removal and disposal

- a description of the site restoration, including backfill materials and quantities 
- a copy of the work clearance request.

\section{HEALTH AND SAFETY}

The work at source area ST58 will be performed under the Health and Safety Plan Addendum (Appendix F) in the Final Operable Units 3, 4, and 5 Management Plan dated October 1992. This plan references the Health and Safety Plan (Appendix C) in the Site Management PIan for Eielson AFB dated Apri1 19, 1992.

Work will be performed in 1eve1 D PPE. Level C PPE will be used if concentrations in the breathing space with the monitoring instrument exceed background concentrations by 10 parts per million (ppm) for 5 minutes. Colorimetric tubes will be used to identify specific contaminants.

\section{DELIVERABLES}

Deliverables for the work at source area ST58 include:

- source area characterization plan

- technical report.

\section{SCHEDULE}

The schedule for the work at source area ST58 is:

- Apri1 30, 1993

- May 3, 1993

- May 14, 1993

- May 18, 1993

- May 19, 1993

- May 28, 1993

- June 1, 1993

- June 11, 1993

- June 14,1993

- June 18, 1993 submit source area characterization plan to Eielson AFB

submit source area characterization plan to Ejel son AFB, EPA, and Alaska Department of Environmentat Conservation (ADEC)

obtain Base Civil Engineering Work Clearance Request

stake and survey grid node locations

commence surface geophysical surveys

complete surface geophysical surveys

commence soil gas surveys

complete soil gas surveys

commence test pit soil sampling

complete test pit soil sampling

11 
- June 28,1993 :

commence soil excavation

- JuTy 2, 1993

complete soil excavation

- July 7, 1993

commence site restoration

- July 9, 1993

complete site restoration

- October 1, 1993

submit technical report. 


\section{Appendix B}

\section{Letter from A. E. Schumacher to D. W. Glover,}

Dated January 6, 1993, Subject History of Old Quartermaster Service Station 


\section{Sultelle}

Pacific Northwest Laboratories

Date January 5, 1993

To Andy Schumake of

From

Don Gloverifuty

Subject History of Old Quartermaster Service Station
Projeot Number

Intornal Distribution

File/LB

The following are questions that we discussed briefly. Any information you could furnish on these items would be appreciated and would be helpful in formulating a more detailed approach for surveying the area and clean-up if indicated.

1. Dates of operation (from-to)

2. Operated by? (AF - Contractor)

3. Fuels used by? (AF - Private etc.)

4. Storage tanks (removed, dates)

5. Piping removed? (yes-no, dates)

6. Types of gas (leaded-unieaded-aviation etc.)

7. Any known leaks? (documentation on file)

8. Known spills? (documentation on file)

9. Maintenance records (repairs-modifications etc.)

10. Observations during AST removal

11. Official closure files or records (availability)

12. Maps-Drawings-As builts (original and modifications)

13. Previous investigations (samples-results-etc.)

14. Storage of other than gasoline, diesel and isopropyl alcohol if any, what type material (solvent-motor oil etc.)

15. What was isopropyl alcohol used for?

$: \lg$

B.1 
FROM: 343 CES/CEO

2258 Central Ave Ste 1

Eielson AFB AK 99702-2225

SUBJ: History of Old Quartermaster Service Station

T0: Don Glover

Battelle Pacific Northwest Laboratories

P 0 Box 999

Richland WA 99352

1. The following are answers to questions, in the order asked, from your letter dated 5 Jan 93.

Question 1. From 1970 to 1988.

Question 2. A1r Force personne1.

Question 3. Air Force and dependents until 1975. Air Force vehicles only after 1975.

Question 4. Removed August 1988.

Question 5. Aboveground piping removed only in August 1988.

Question 6. Leaded, unleaded, and diesel.

Question 7. The pipeline was suspected of leaking at the intersection of Industrial $\mathrm{Dr}$ and Division St.

Question 8. No known spills.

Question 9. No records avallable.

Question 10. No records available.

Question 11. No records available.

Question 12. See blueprints enclosed.

Question 13. Dave Blevens of the Environmental Flight will supply sample results if they exist. Dave can be reached at 377-5159.

Question 14. Two barrels of motor oil where stored on site to issue to customers.

Question 15. An isopropyl tank $\# 10$ is shown on the blueprint, but to the best of our knowledge, only MOGAS was stored in it.

2. This is about all I have on this site, let me know if I can be of further help.

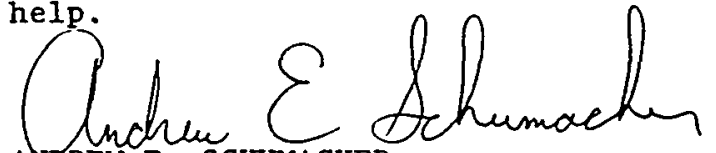

AHOREW E. SCHUMACHER

Deputy Chief of Operations 
Appendix C

April 1993 Analytical Results 


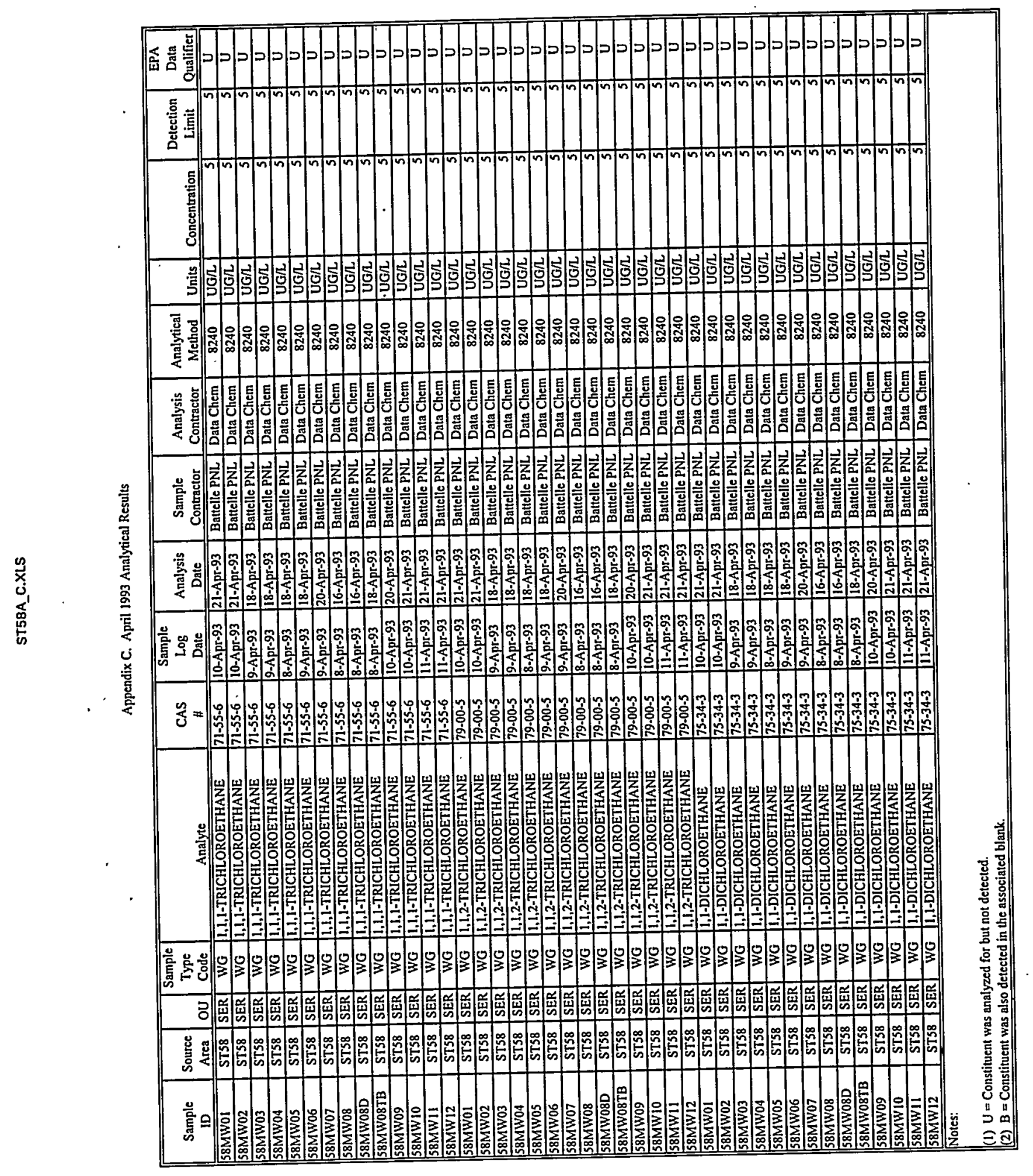

C. 1 


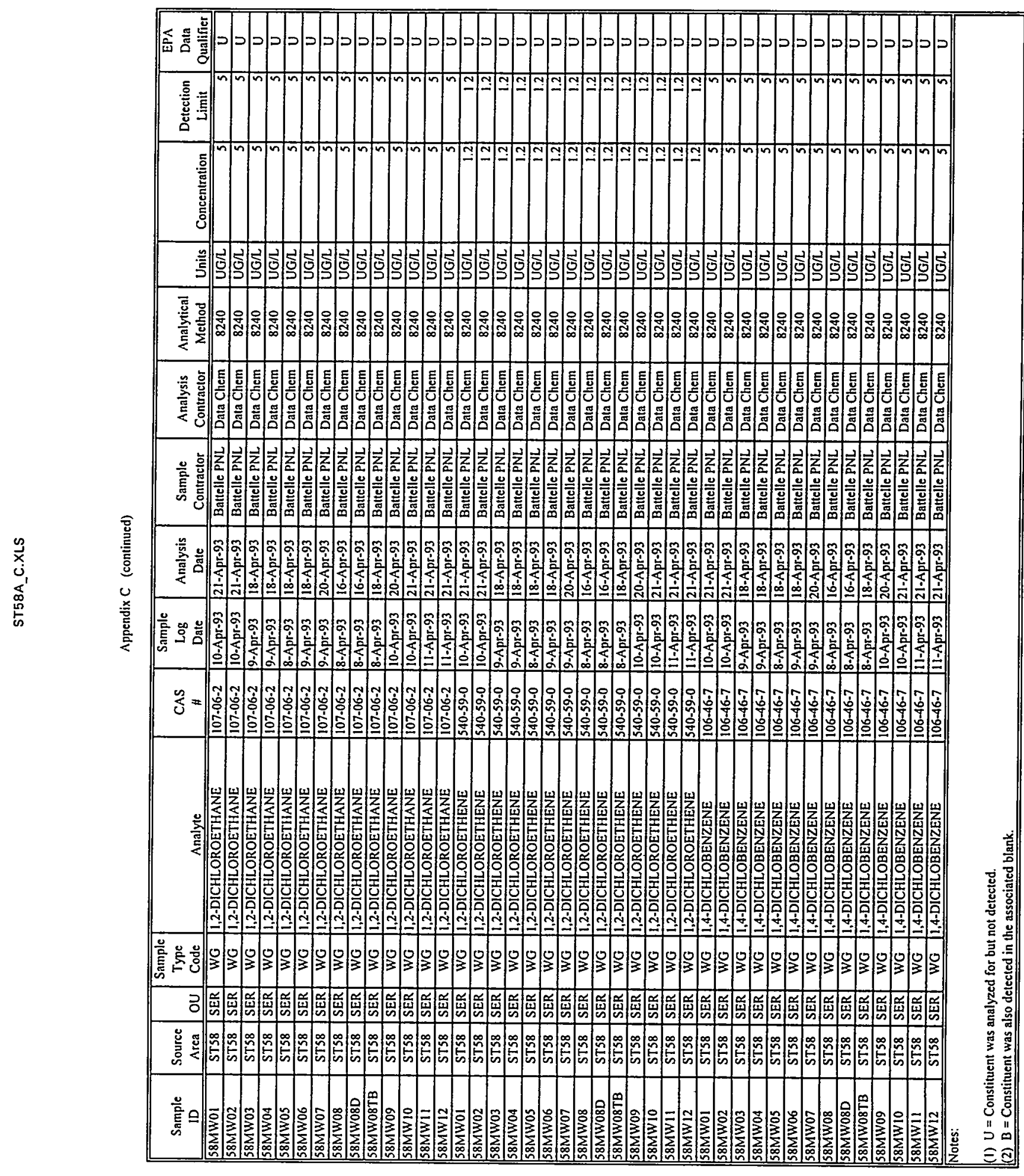

C. 2 


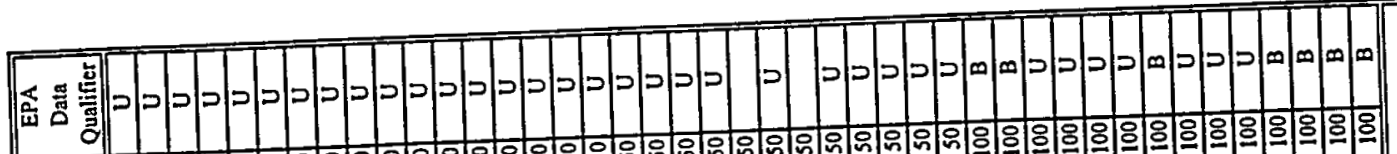

$$
\begin{array}{||l}
\hline \\
\hline \\
\hline
\end{array}
$$

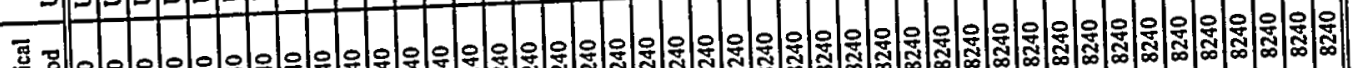

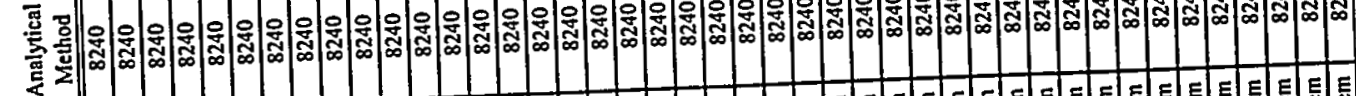
号 竞 E

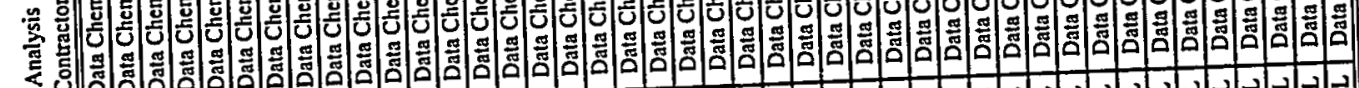
烈

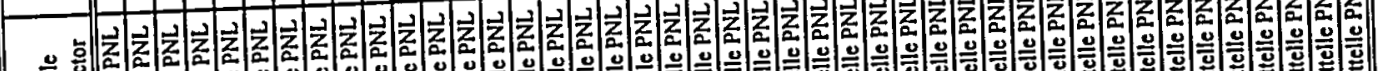
空

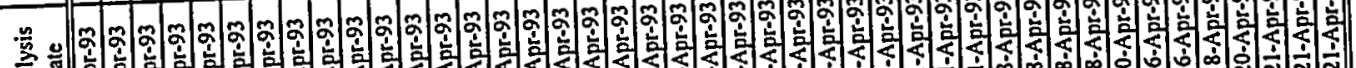

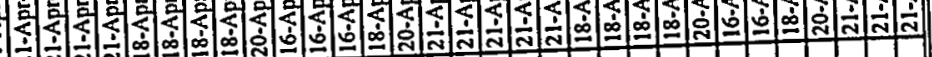

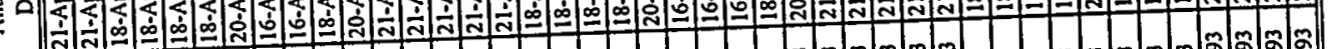
을

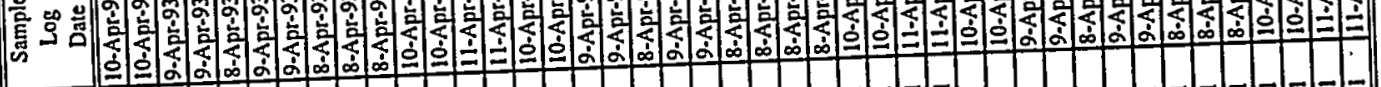
至

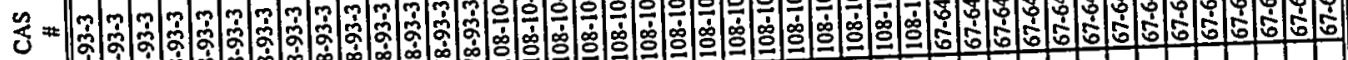

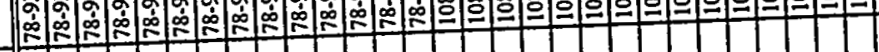

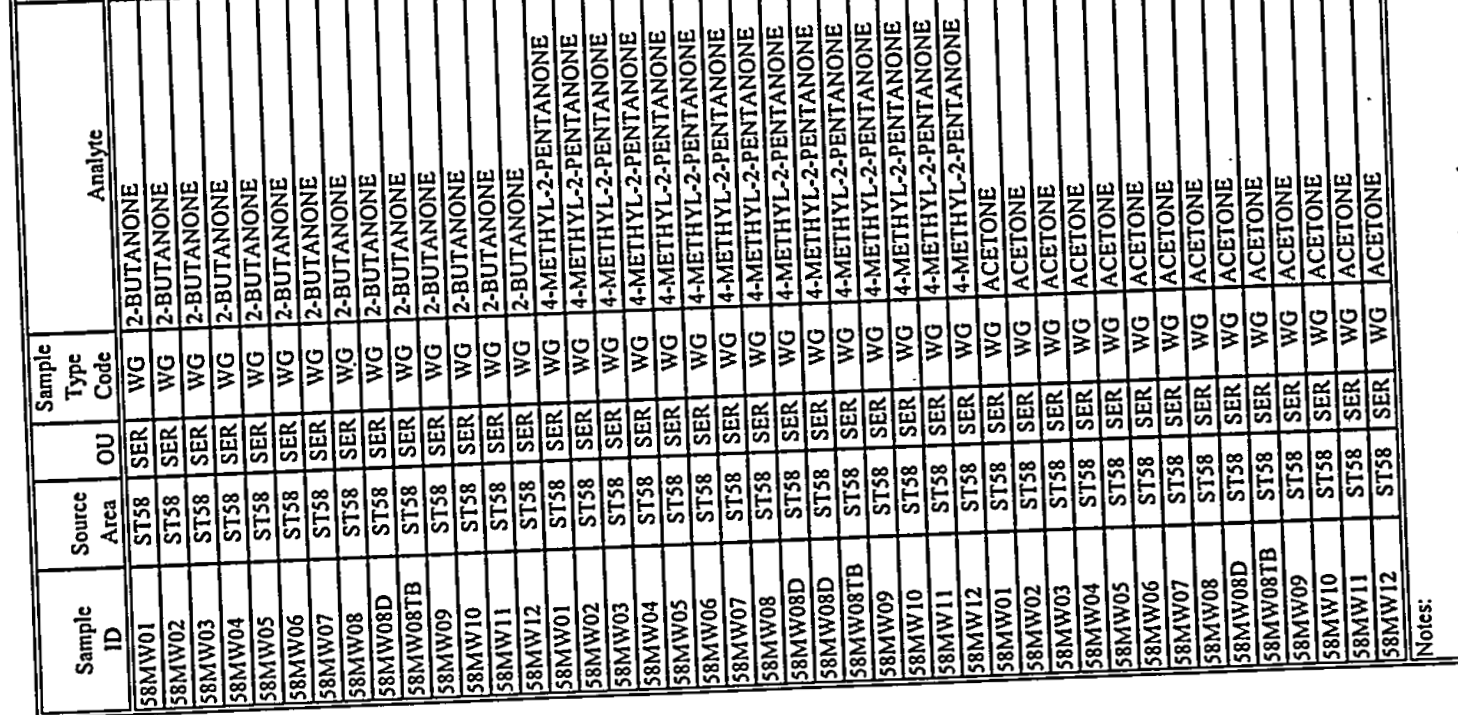




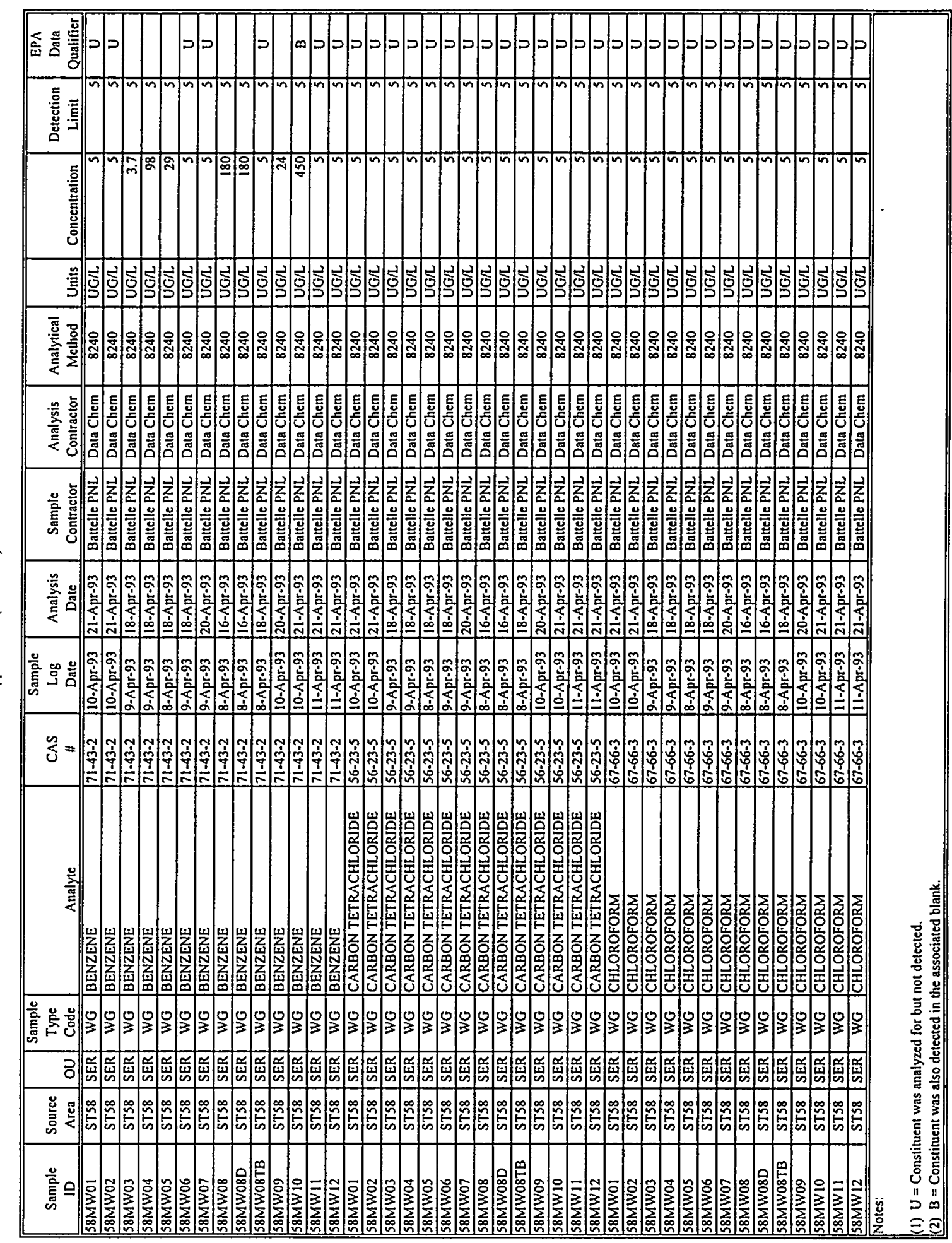

C. 4 


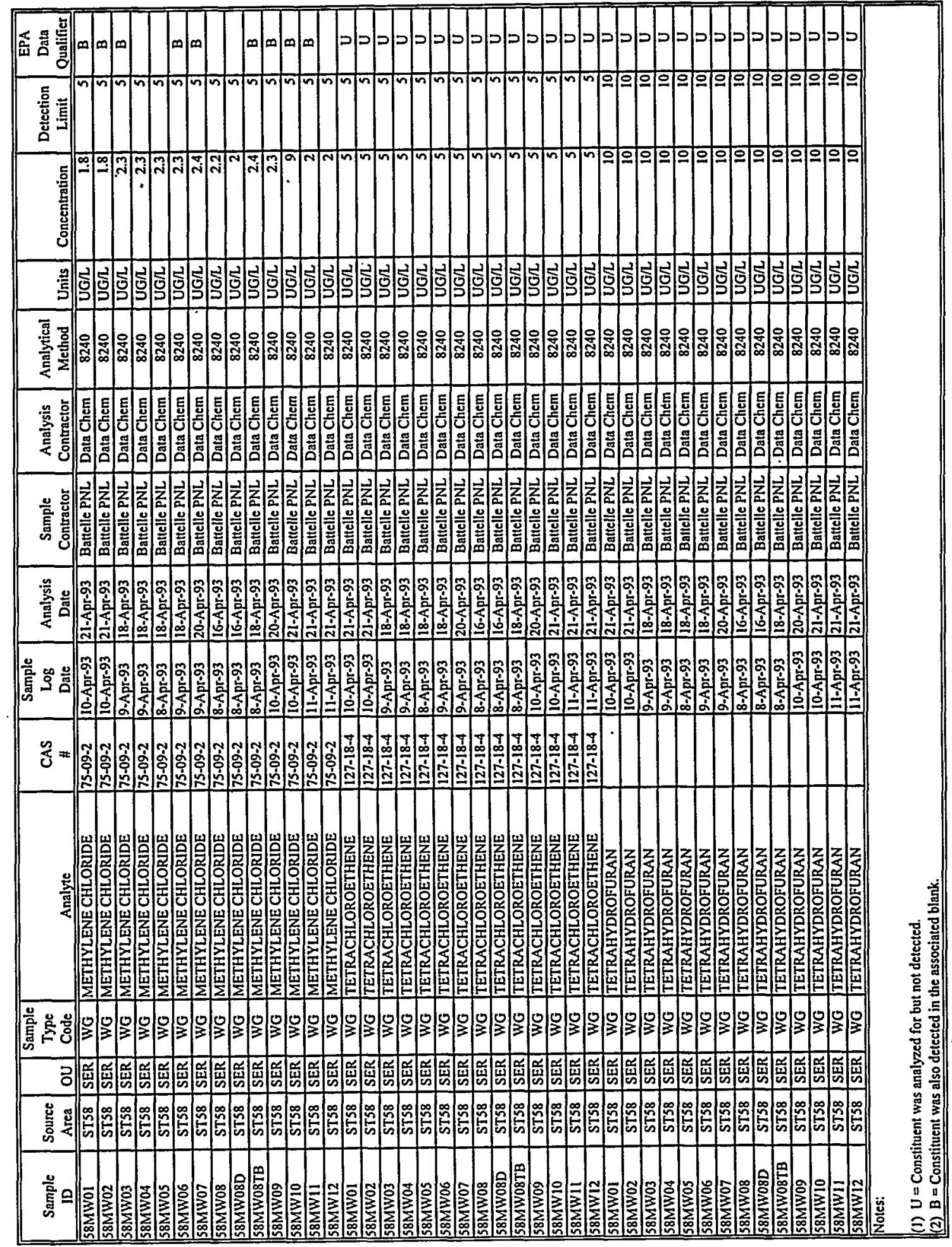




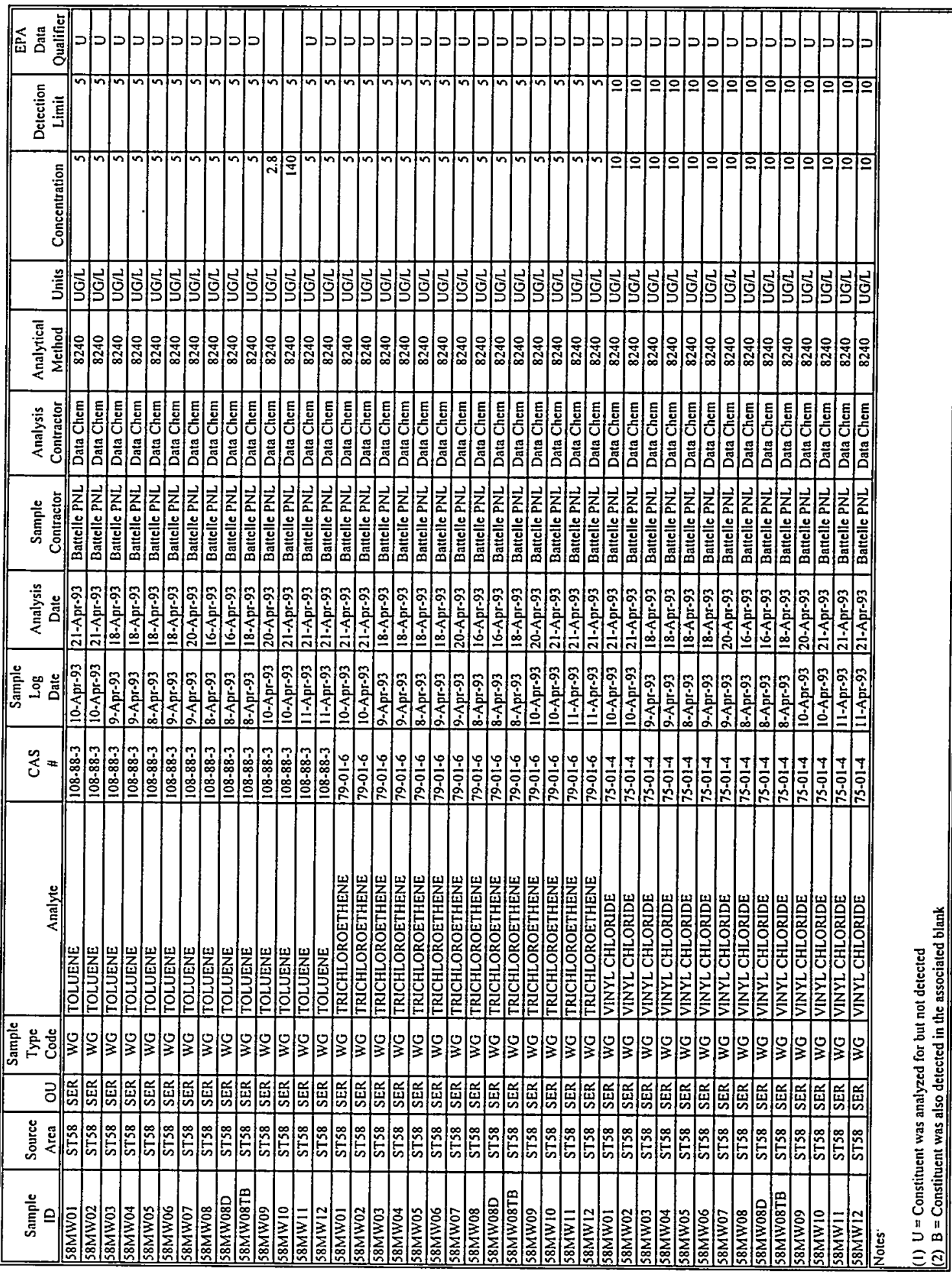

C. 6 


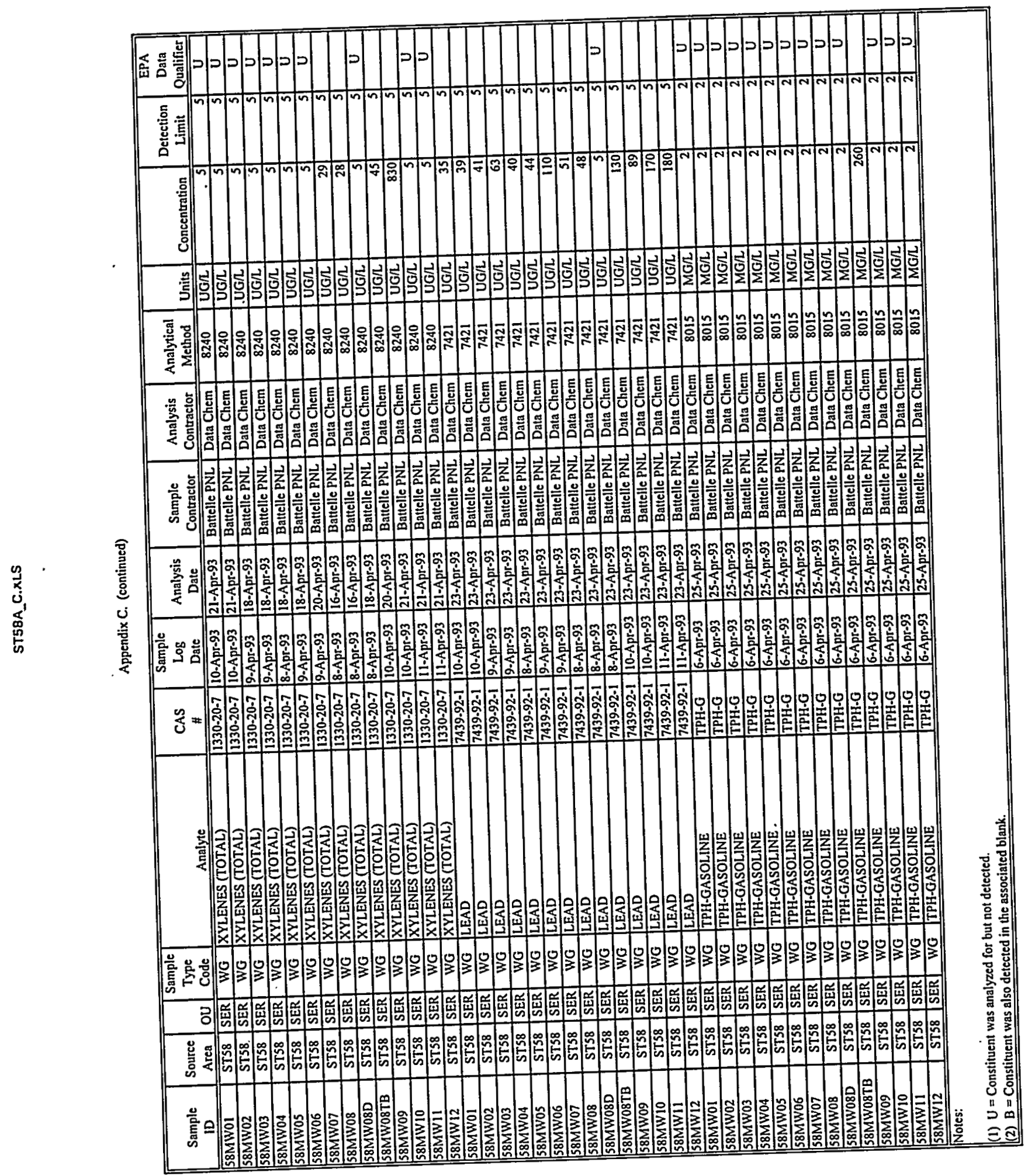




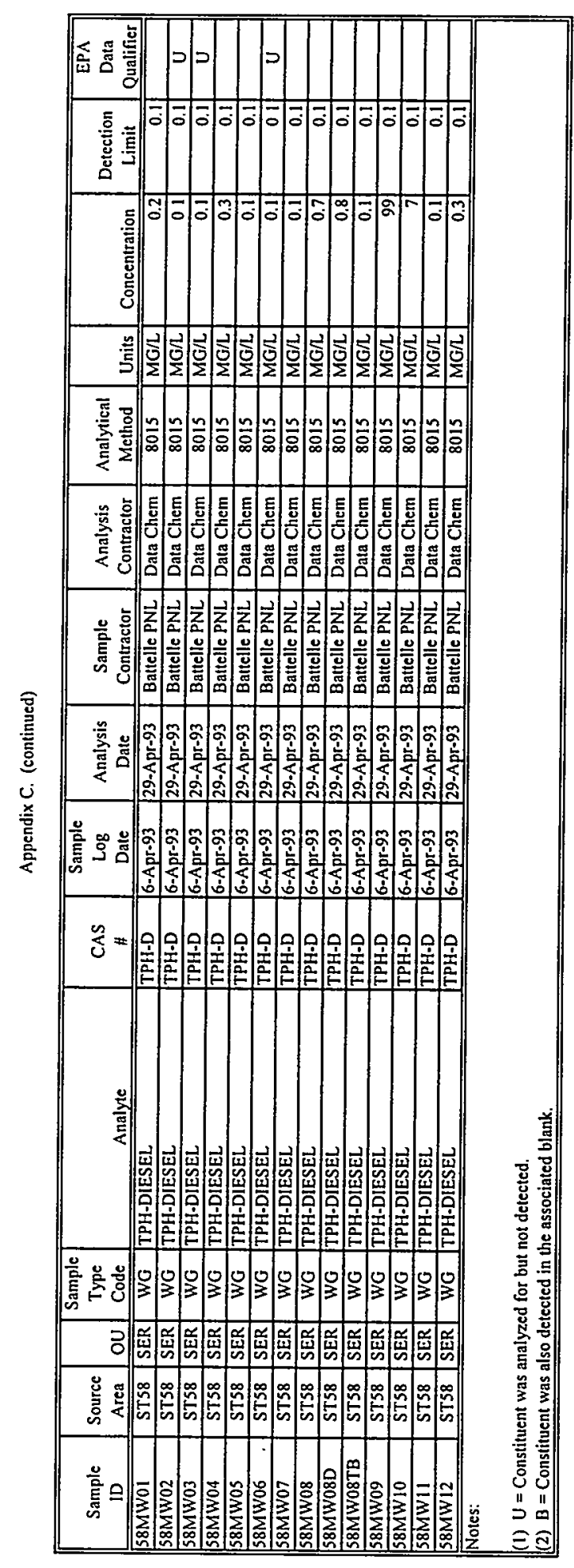

C. 8 


\section{Appendix D}

\section{Base Civil Engineering Work Clearance Request}




\begin{tabular}{|c|c|c|c|c|}
\hline \multicolumn{4}{|c|}{ BASE CIVIL ENGINEERING WORK CLEARANCE REQUEST } & DATE FREPARED \\
\hline \multicolumn{5}{|c|}{ 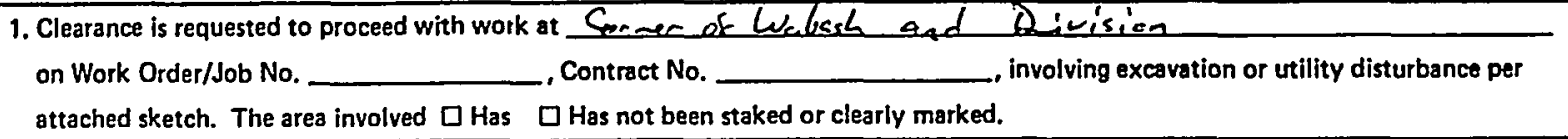 } \\
\hline \multicolumn{5}{|c|}{ VED } \\
\hline A. PAVEMENTS & $\begin{array}{l}\text { - DAATHAGE } \\
\text { SYSTKMS }\end{array}$ & $\begin{array}{l}\text { C. RAILROAD } \\
\text { TRACKS }\end{array}$ & $\begin{array}{l}\text { D. FIRE DETECTION } \\
\text { AND PMOTEC. } \\
\text { TION SYSTEMS }\end{array}$ & $\begin{array}{l}\text { E. UTILITY } \\
\text { D OVERHEAD } \\
\text { D UNDEROMOUND }\end{array}$ \\
\hline $\begin{array}{l}\text { F. COMM. } \\
\text { प OVERHEAD } \\
\text { U UNDERGROUND }\end{array}$ & $\begin{array}{l}\text { C. AIRCRAFT OR } \\
\text { VEHICULAR } \\
\text { TRAFFIC FLOW }\end{array}$ & H. SEcunity & 1. OTHER (SpeeIfy) & \\
\hline
\end{tabular}

3. INSTRUCTIONS: The BCE work clearence request is used for any work (contrect or In house) that may distupt alreraft or vehicular traffic flow, base utility services, protection provided by fire end intruslon alerm system, or routine activities of the Instaliation. Thls form is used to coordinate the required work with key base activities and keep customer Inconvenlence to a minimum. It is also used to identify potentially hazardous work conditlons in an sttempt to prevent accidents. The work clearance request la processed just prior to the start of work. If delays are encountered and the conditions at the fob site change (or may have changed) this work clearence request must be reprocessed.

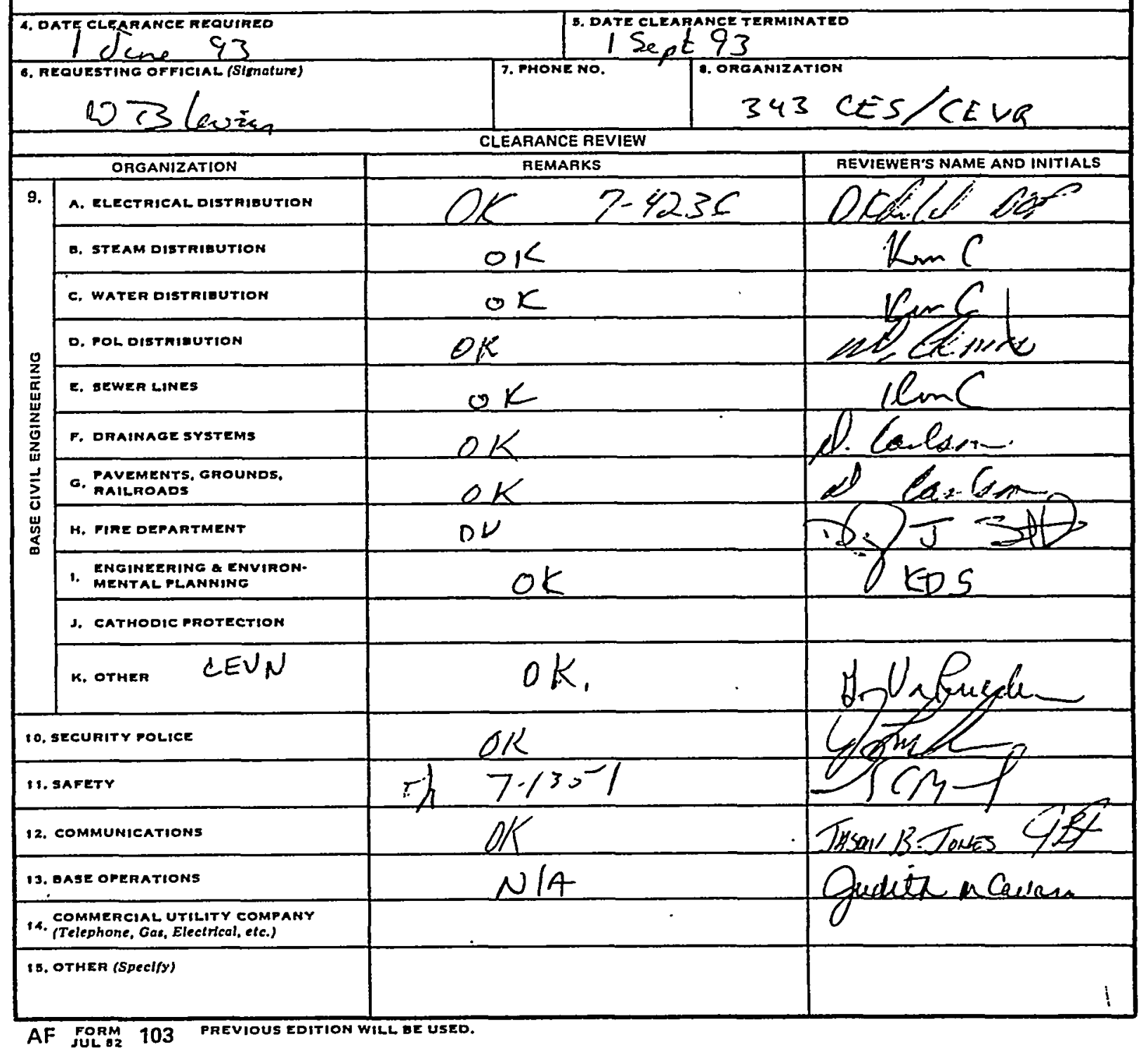


16. REMARKS (This section must descrbe apectfe precautfonary measures to be taken before and during work aecompluhment. 8pectfle comments concerrs. ine the ogproved method of excavation, hand or powered equipment thould be (ncluded.)

\begin{tabular}{|l}
\hline REQUESTED CLEARANCE \\
\hline DATE \\
1
\end{tabular}

\section{2}



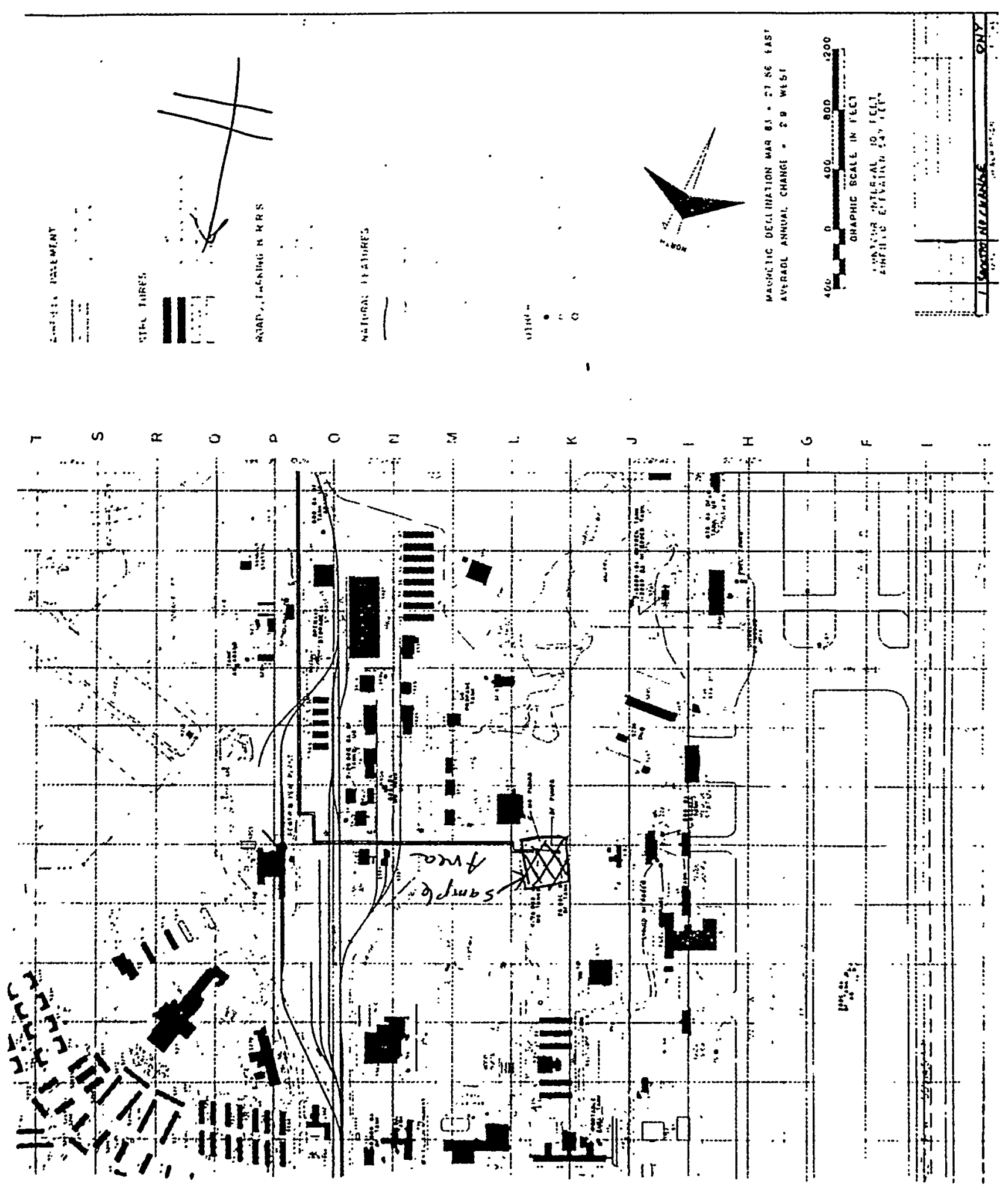


\section{Appendix E}

Surveyor's Report 
KALEN \& ASSOCIATES, INC.

1041 Chena Ridge Road FAIRBANKS, ALASKA 99709

\section{(907) $479.2628 \quad 479.2656$}

то Butrilicimuminath Aenues lisanicakeze Geleme AFE, At
WE ARE SENDING YOU Attached $\square$ Under separate cover via
$\square$ Shop drawings
ㅁ Prints
$\square$ Plans
C Change order
$\square$ Copy of letter
ㅁ.

LEUTER @F TRANSMUTTAL

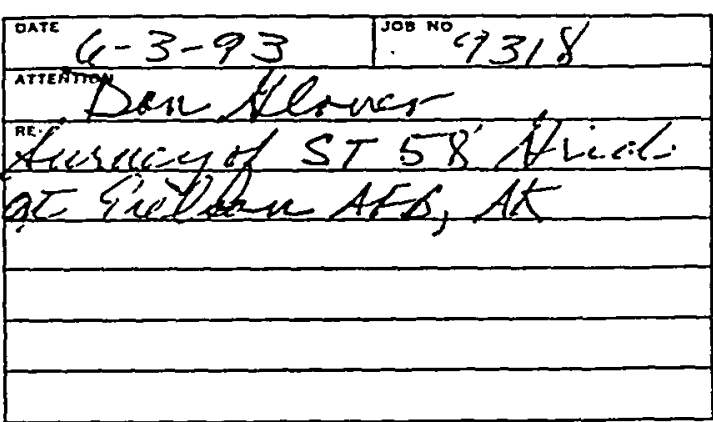

the following items:

$\square$ Specifications

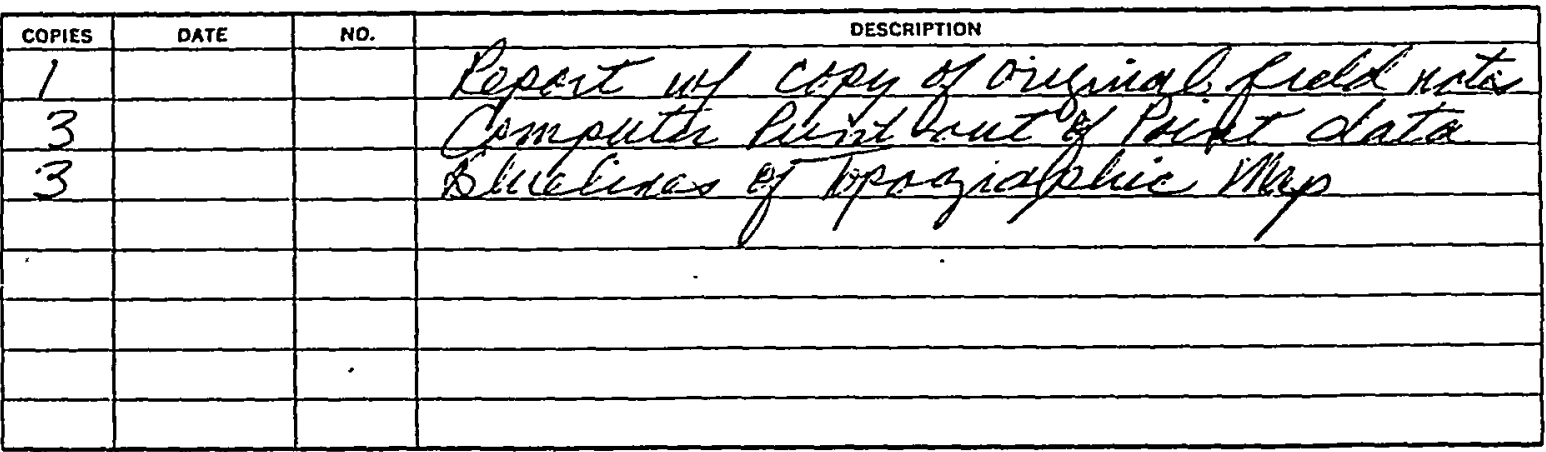

THESE ARE TRANSMITTED as checked below:

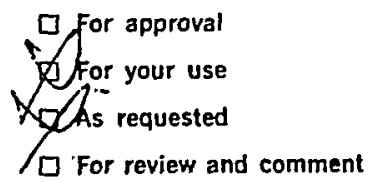

$\square$ FOR BIDS DUE $\square$ Approved as submitted

$\square$ Approved as noted

$\square$ Returned for corrections $\square$
Resubmit___copies for approval

口 Submit___ copies for distribution

$\square$ Return corrected prints 19 $\square$ PRINTS RETURNED AFTER LOAN TO US REMARKS

COPY TO

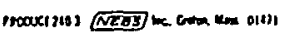

SIGNED:

If enclosures sere not es moted, kindly notify us at ones.

E. 1 


\title{
KALEN \& ASSOCIATES, Inc.:
}

Engineers \& Surveyors

Land Surveys - Mineral Surveys - Subdivisions Civil Engineering - Forensic Expertise • CADD

\author{
SURVEYOR'S REPORT \\ SURVEY OF ST 58 GRID \\ EIELSON AIR FORCE BAGE, ALABKA
}

BATTELLE ENVIRONMENTAL SERVICES ORGANIZATION

$\therefore$

June 3,1993

Kalen \& Associates, Inc. performed the topographic survey of 91 flagged locations at site ST58 at Eielson AFB, Alaska on May 28 , 1993. The locations were taken on a grid. of 300 feet by 150 feet. Vertical elevations were taken to the nearest 0.1 foot and horizontal coordinates to the nearest 0.02 foot. Field work was accomplished with a Hewlett-Packard 3820A Total station and TDS-500 Data collector.

The data for all locations was then processed using softdesk Engineering software, and the topographic map prepared using AutoCAD Release 11 working with Softdesk.

This Report includes a print-out of the Northing, Easting, and elevation for all points, a topographic map showing point numbers, elevations, descriptions, and their relationship to control points EF 12 and EF 26, which are U.S. Army Corps of Engineers brass cap control monuments at Eielson $A F B$, and copies of original field notes.

I CERTIFY that the information shown on the computer print-out and the topographic map is a true and accirate representation of the survey as performed under my direct supervision.

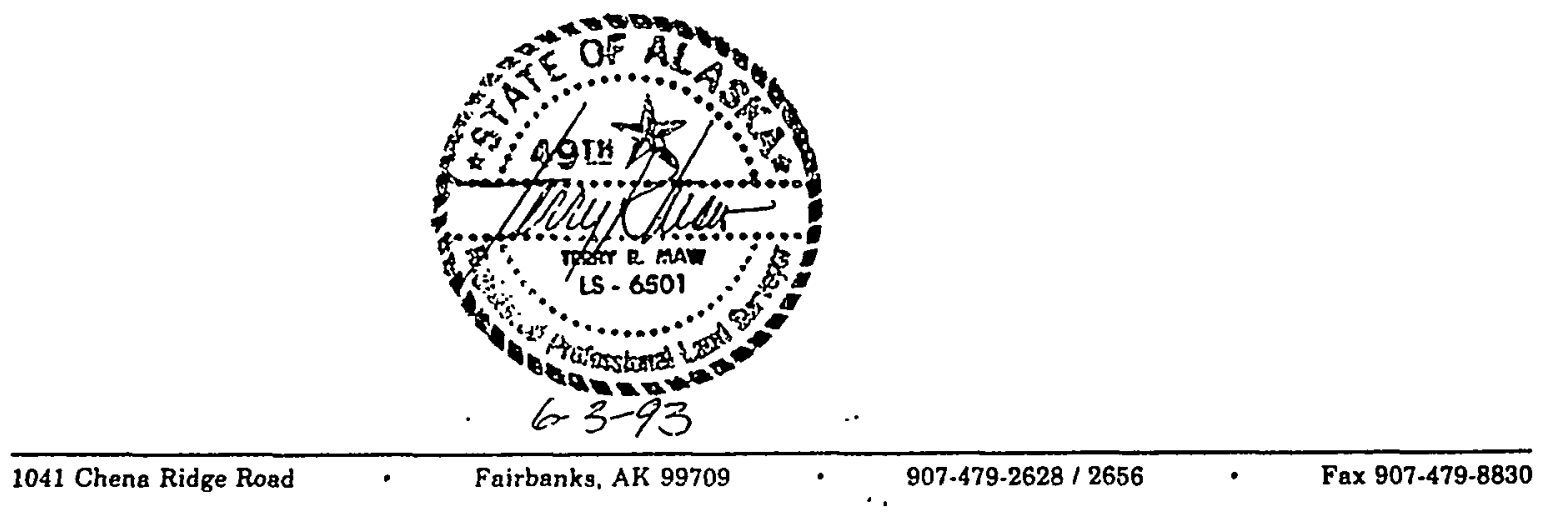


Kalen \& Associates, Inc.

1041 Chena Ridge Road

Fairbanks, Ak 99701

$907-479-265$.

Site st58 Grid

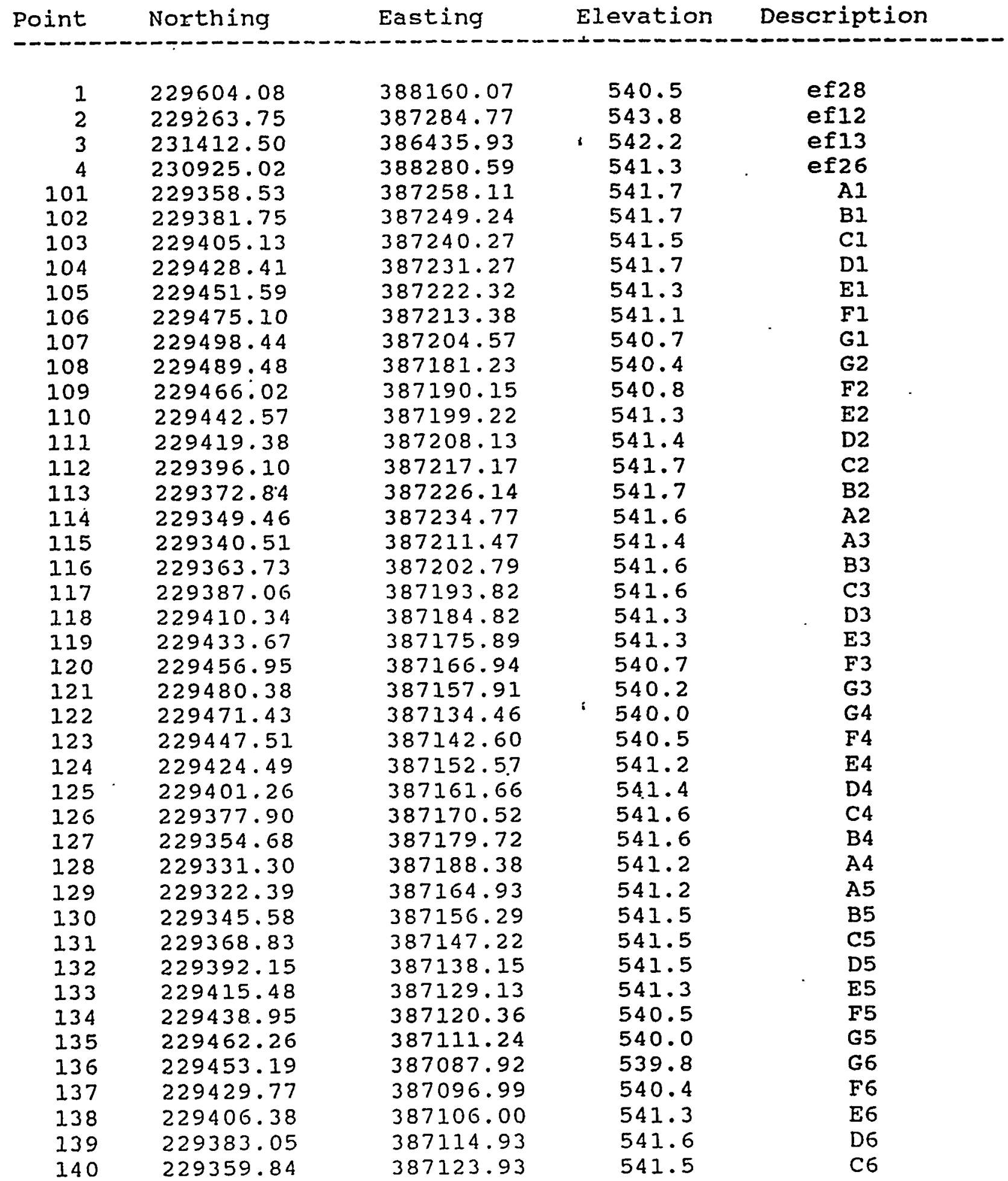

E.3 
Site ST58 Grid

Page 2

$\begin{array}{ll}141 & 229336.51 \\ 142 & 229313.34 \\ 143 & 229304.17 \\ 144 & 229327.45 \\ 145 & 229350.78 \\ 146 & 229374.07 \\ 147 & 229397.36 \\ 148 & 229420.72 \\ 149 & 229444.05 \\ 150 & 229434.97 \\ 151 & 229411.57 \\ 152 & 229388.11 \\ 153 & 229364.96 \\ 154 & 229341.59 \\ 155 & 229318.40 \\ 156 & 229295.18 \\ 157 & 229285.97 \\ 158 & 229309.35 \\ 159 & 229332.78 \\ 160 & 229355.86 \\ 161 & 229378.93 \\ 162 & 229402.54 \\ 163 & 229425.82 \\ 164 & 229416.93 \\ 165 & 229393.51 \\ 166 & 229370.16 \\ 167 & 229346.74 \\ 168 & 229323.57 \\ 169 & 229300.35 \\ 170 & 229277.03 \\ 171 & 229267.76 \\ 172 & 229291.38 \\ 173 & 229314.70 \\ 174 & 229337.86 \\ 175 & 229361.11 \\ 176 & 229384.35 \\ 177 & 229407.68 \\ 178 & 229398.78 \\ 179 & 229375.41 \\ 180 & 229352.00 \\ 181 & 229328.72 \\ 182 & 229305.62 \\ 183 & 229282.35 \\ 184 & 229258.86 \\ 185 & 229249.64 \\ 186 & 229273.27 \\ 187 & 229296.72 \\ 188 & 229319.51 \\ 189 & 229342.75 \\ 190 & 229366.16 \\ 191 & 229389.52\end{array}$

387132.97

541.5

B6

387141.73

541.3

C6

387118.36

541.3

541.5

541.6

541.6

541.2

540.5

539.8

387064.66

387041.29

387050.48

387059.32

387068.47

387077.37

387086.44

387095.22

387071.47

387062.93

387054.08

387045.11

387036.02

387026.99

387018.15

386994.73

387003.93

387012.90

387021.85

387030.90

387039.57

387048.29

387025.20

387016.43

387007.51

386998.52

386989.46

386980.54

386971.73

386948.28

386957.14

386966.25

386975.37

386984.21

386993.04

387002.00

386978.72

386969.94

386960.73

386952.16

386942.98

539.5

540.4

541.1

541.5

541.5

541.5

541.2

541.1

541.4

541.4

541.2

540.7

540.0

539.0

A7

B7

C7

D7

E7

F7

G7

G8

F8

E8

D8

C8

B8

A8

A 9

B9

C9

D9

E9

538.6

F9

G9

539.6

G10

540.5

F10

E10

540.8

D10

541.1

541.0

540.9

ClO

B10

A10

540.5

AII

540.6

BII

540.4

C11

540.4

DII

540.0

E11

F11

538.3

G11

537.7

G12

538.7

F12

539.3

E12

539.5

D12

539.4

C12

539.8

B12

540.0

A12

539.5

A 13

539.1

B13

538.3

C13

538.4

D13

386933.94

386924.78

537.8

E13

F13

537.6

G13

E. 4 


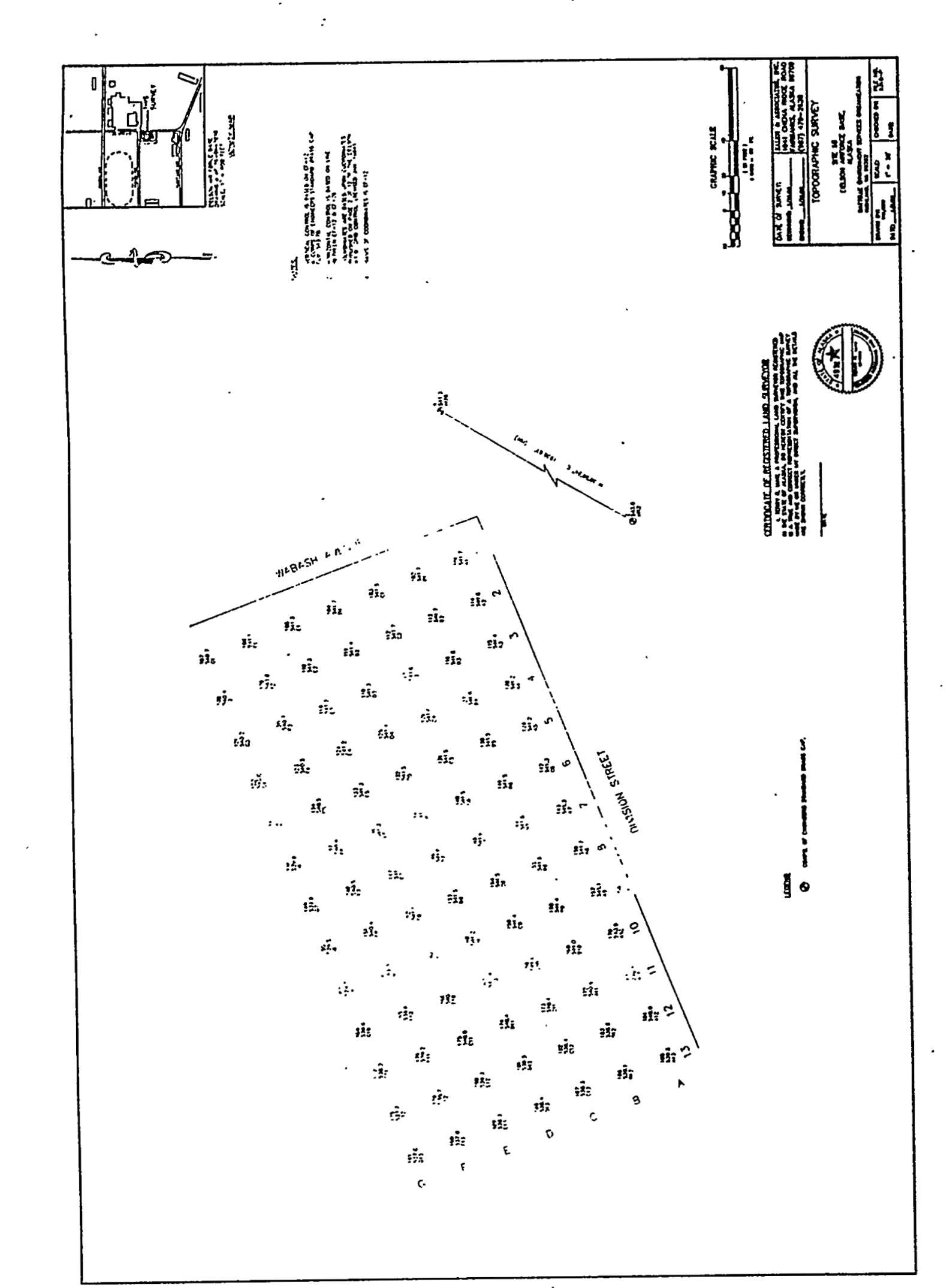




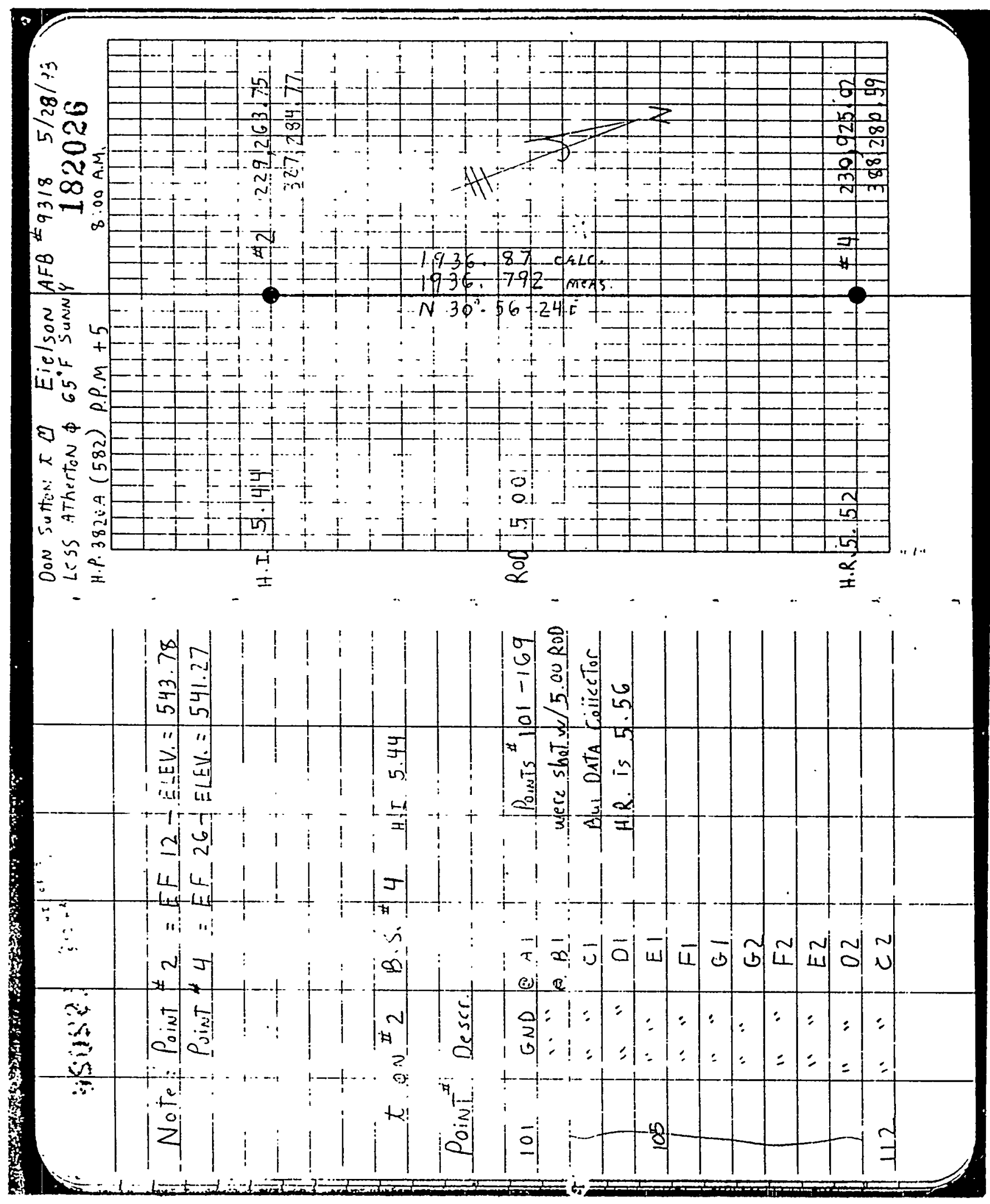




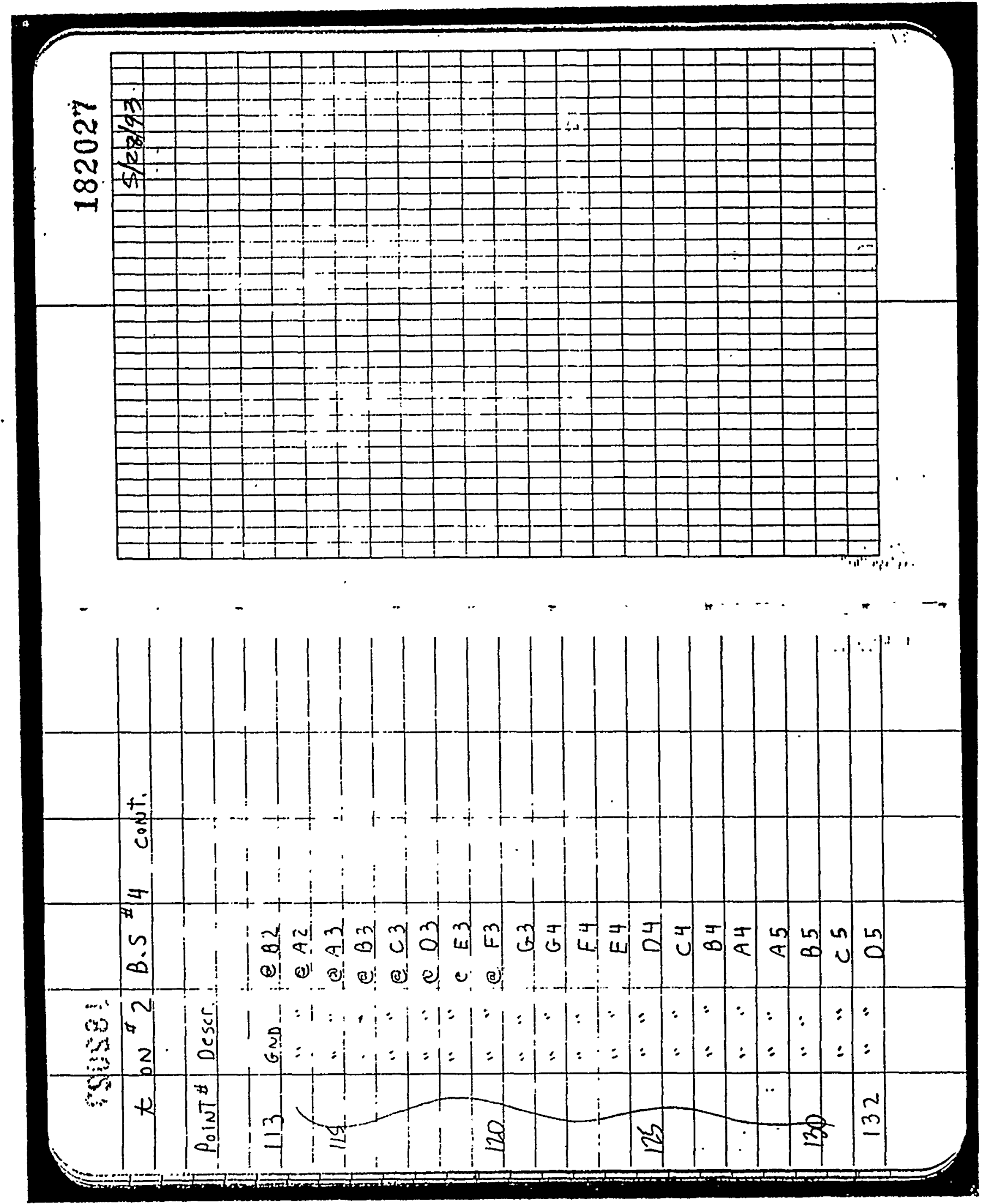

E.7 


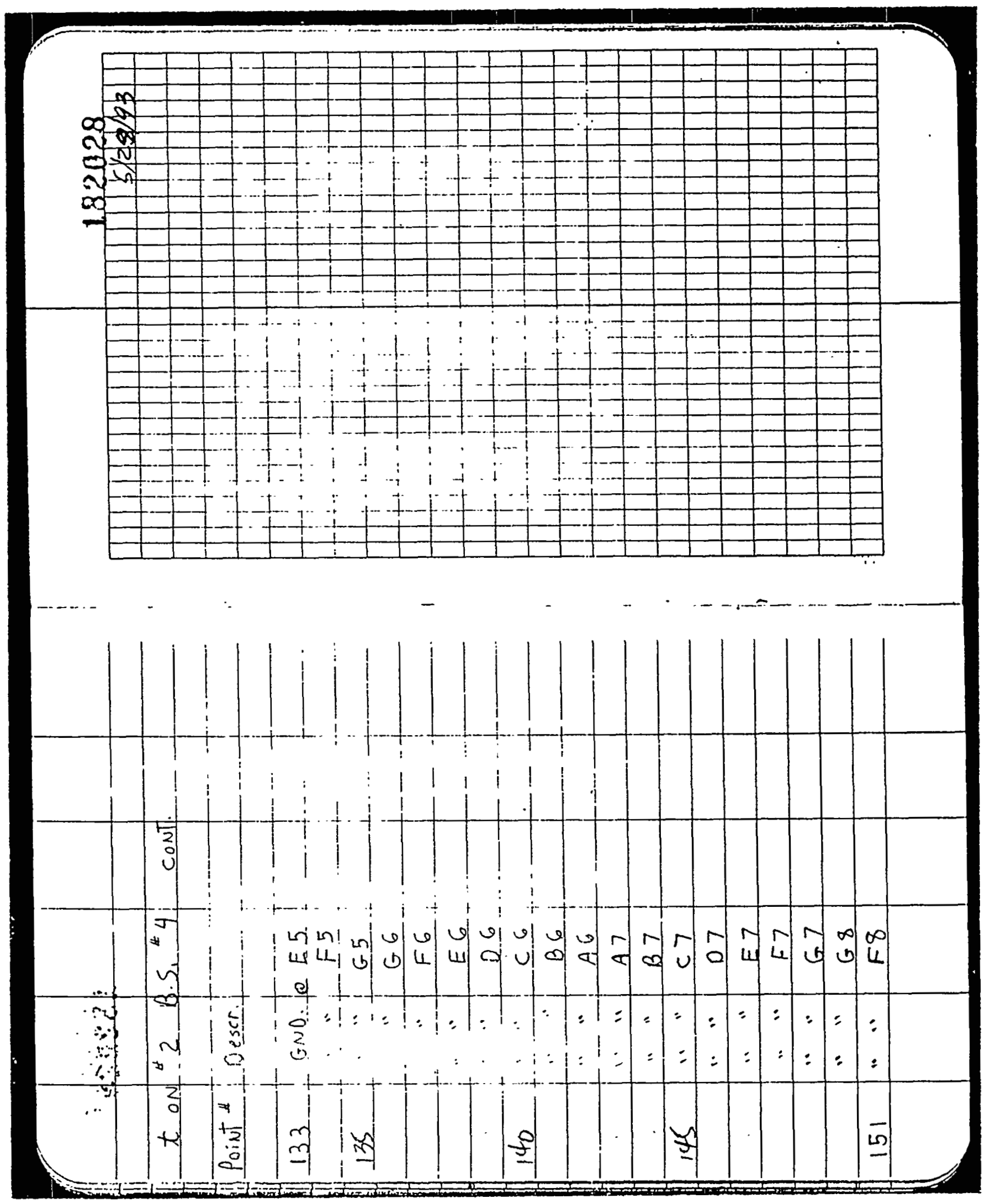

E. 8 


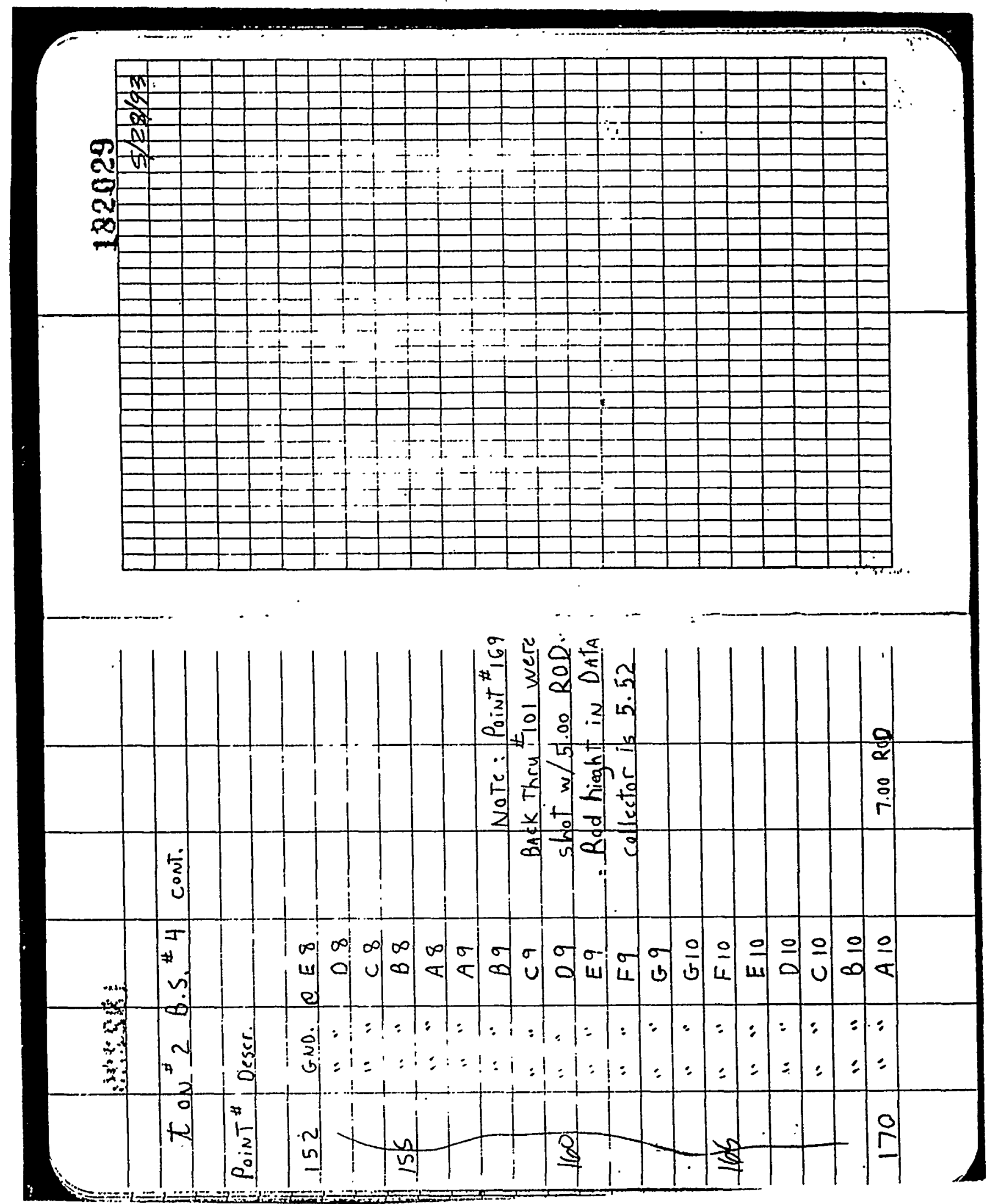




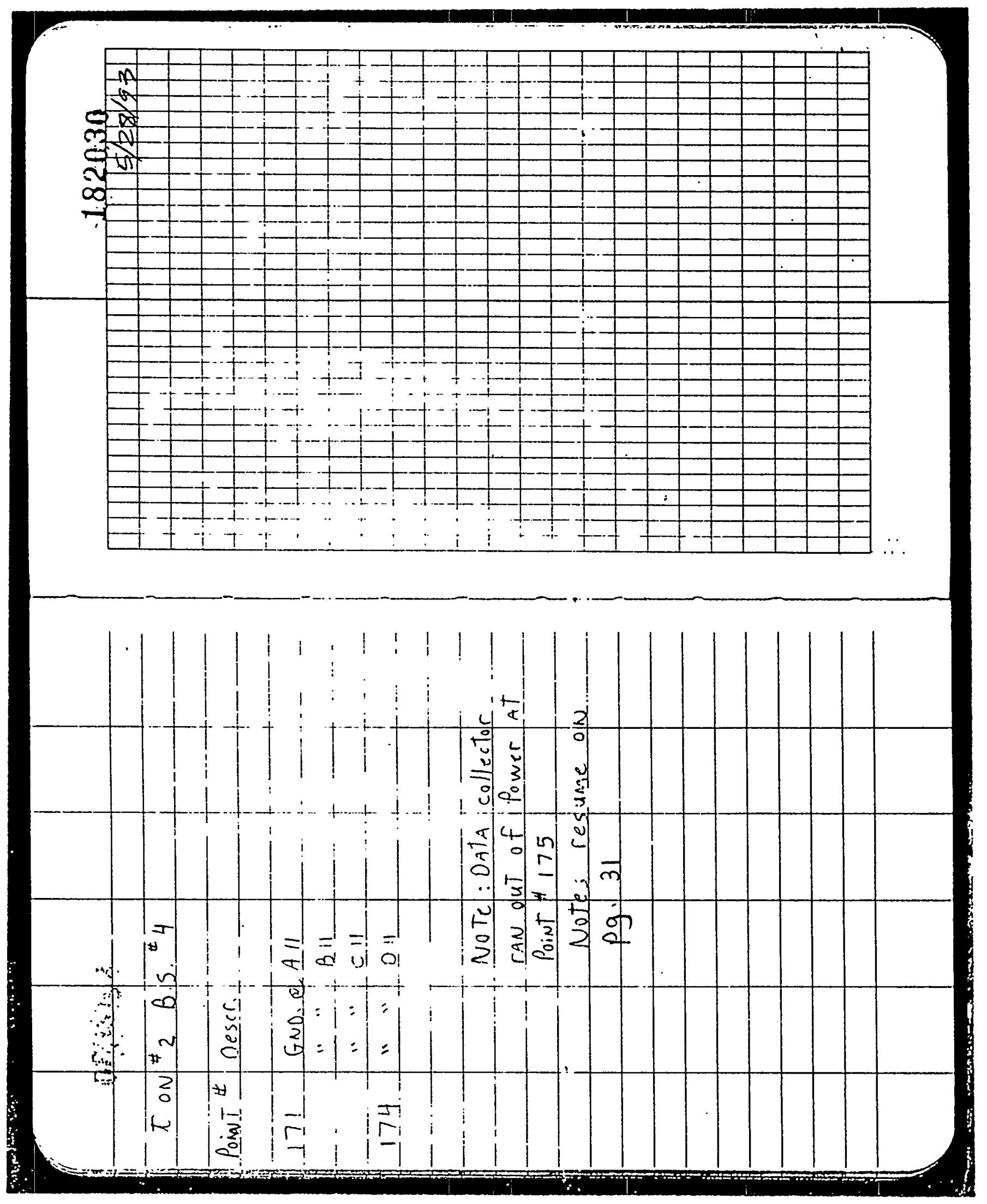

E. 10 


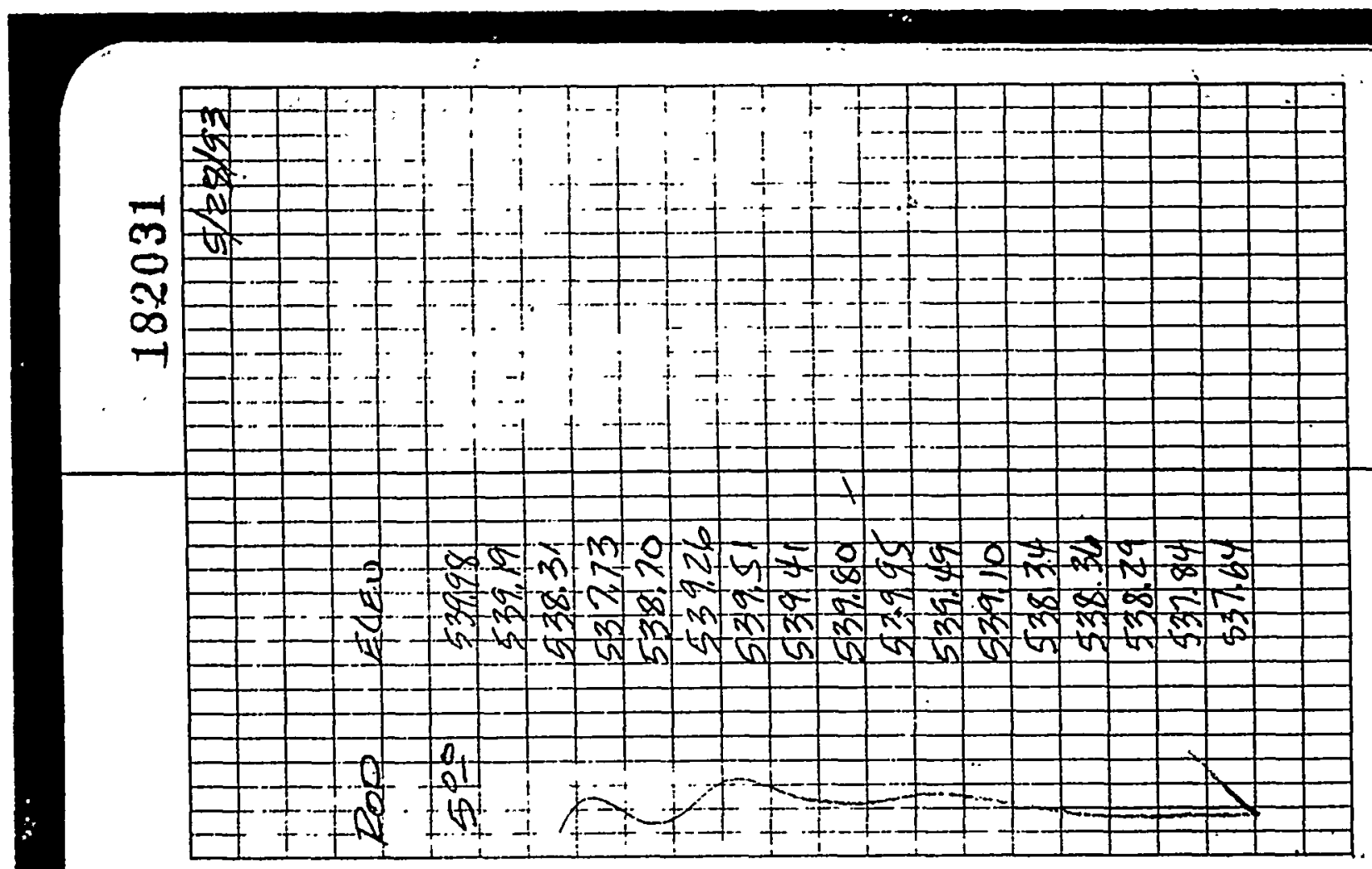

A 10

it

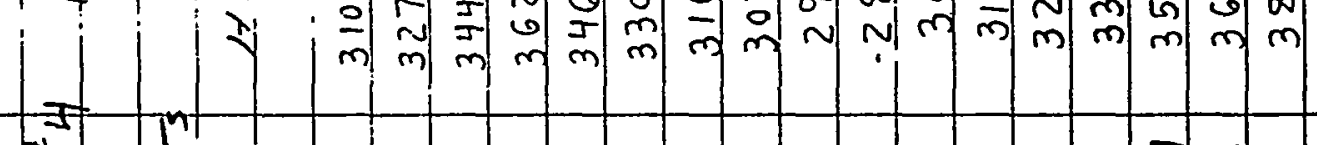

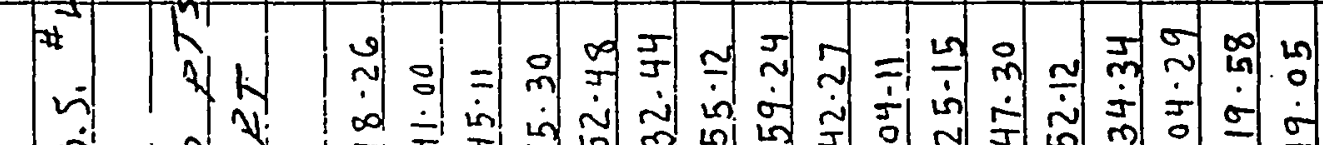

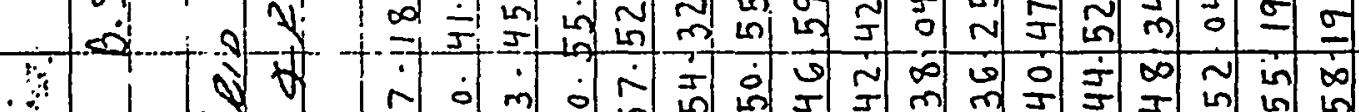

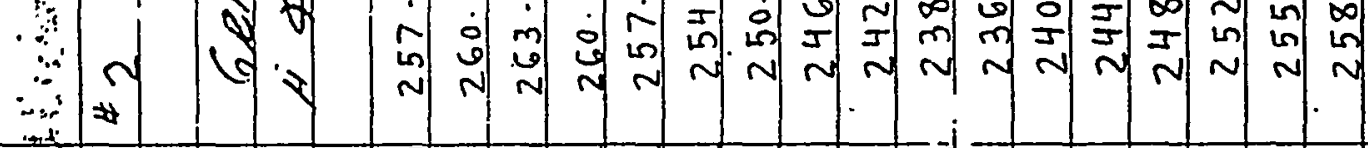

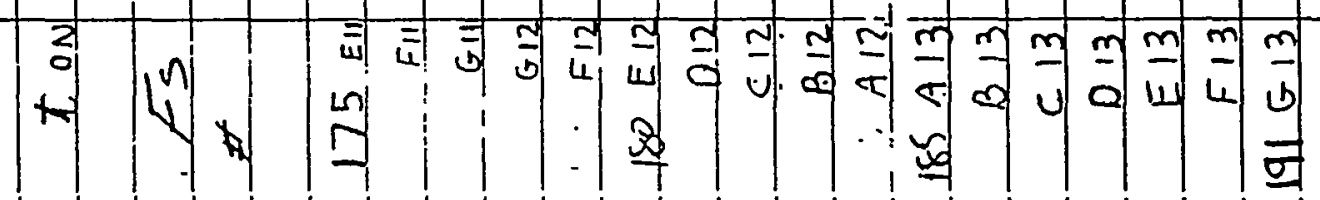


Appendix F

Surface Geophysical Surveys Report 


\section{SURFACE GEOPEYSICS EVALUATION OF SOURCE AREA ST58 OLD QUARTERMASTER SERVICE STATION}

\section{PURPOSE}

A shallow electromagnetic survey was performed by Battelle Pacific Northwest Laboratories (PNL) at source area ST58, the old Quartermaster service station, to help locate underground piping in support of the Source Area Characterization Plan (PNL May 1993). In addition, a radio wave pipe survey was conducted by Eielson Air Force Base (AFB) to aid in this task. The suspected underground piping locations were staked to optimize residual product and piping removal.

\section{INSTRUMENT OPERATING PRINCIPIE}

The electromagnetic investigation was performed using a Geonics, Ltd. EM-31 instrument. The EM-31 measures ground conductivity non-invasively by inducing circular eddy currents in the subsurface from a transmitter coil on one end of the instrument. The underground current loops, of which the magnitudes are directly proportional to terrain conductivity, generate a secondary magnetic field. This magnetic field is intercepted and measured by a receiver coil on the other end of the instrument. The output voltage measured by the receiver is linearly related to the terrain conductivity.

Two components of the induced magnetic field are measured and digitally displayed by the EM-31: the quadrature and in-phase components. The quadrature phase component gives the ground conductivity measurement while the in-phase component is used primarily for calibration purposes, but is very sensitive to large metaliic objects.

The EM-31 is very sensitive to lateral changes in terrain conductivity in the top three meters of the subsurface. Therefore, when the tool is passed over an underground metallic object, which is a very good electrical conductor, a significant deflection will occur on the digital meter display. If the tool crosses a length of buried pipe with the tool's long axis perpendicular to the pipe axis the reading profile will be characterized by two maxima on either side of the pipe and a minimum directly above the pipe. It is then possible to accurately determine the location and strike of the buried pipe by making a traverse with the EM-31 pointed in the direction of the pipe axis. Now the meter reading will be a positive maximum when the instrument is both directly over the pipe and pointing along it's axis. However, this profile will be complicated by the proximity of adjoining and nearby pipes. Nevertheless, the presence of any significant buried metallic object in the top 
three meters of the ground will produce a recognizable anomaly in the readings.

The radio wave pipe survey carried out by Eielson AFB uses a radio transmitter and receiver. The transmitter is attached to an above surface section of the pipe whose underground location is being targeted. The pipe then acts as an antenna which transmits the radio signals. The stand-alone, hand-held receiver measures the intensity of the transmitted radio signals using an analog meter. Maximum readings should occur directly above the pipe of interest.

\section{SURYEY PROCEDURES}

\section{Initial Investigation}

Prior to any measurements a $300 \mathrm{ft}$ by $150 \mathrm{ft}$ grid was surveyed onto the site. Grid nodes were staked every $25 \mathrm{ft}$. For the initial investigation in-phase and quadrature phase measurements were taken at every grid node with the tool facing parallel to Wabash Ave. General regions on the grid where anomalous readings occurred were demarcated from this initial data set.

At this time personnel from Eielson AFB also performed their radio wave pipe survey. They attached the radio transmitter to a pipe inlet across Wabash Ave. from the site. By locating points of maximum measure signal with their receiver they were able to delineate several sections of buried feeder pipe.

Eollow-up Investigations

The first follow-up was to take measurements at the grid points in the anomalous regions with the tool facing perpendicular to wabash Ave. (90 degrees to the initial tool orientation). This helped to clarify the orientation of buried metal objects.

It was decided that the spacing of the data points was not providing enough resolution for the very sensitive measurements so readings were taken halfway between the grid nodes. The higher resolution data helped to identify the location of maxima and minima readings on the grid.

A final follow-up investigation was performed to try to determine the strike of possible buried pipes and to walk along their lengths. This was accomplished by finding a minima measurement point and rotating the tool on that point to find the orientation that gave the highest reading. If the buried object was a pipe then the tool direction was parallel to the pipe length. 


\section{CONCTUSIONS}

A non-invasive surface geophysical investigation was performed at source area ST58, the old quartermaster service station, to help identify the location of underground piping before soil sampling and excavating were carried out.

The radio wave pipe survey completed by Eielson AFB was able to delineate the two main feeder pipes entering the site under wabash Ave., but lost the radio signal from there.

The EM-31 electromagnetic survey completed by PNL identified regions in the site where buried metallic material is likely present. A contour map representation of the conductivity results is. shown in Figures 1 and 2 . A number of particular buried pipe sections were also traced. The location of underground piping interpreted from the EM-31 measurements is shown in Figure 3 .

\section{UNCERTAINTIES}

The EM-31 measures subsurface conductivity to a depth of no more than 3 meters. If the measurement profile across a buried metal object is clean the lateral resolution of the tool is very good, on the order of one foot. However, if the object has an abnormal shape or orientation, or is surrounded by other metallic objects, the lateral resolution is decreased. This occurs because the tool starts measuring the effects of a large buried conductor as much as 10 feet before crossing it. From the large, wide anomalies in the EM-31 data the ST58 site appears to contain a significant amount of buried metallic debris. This made it difficult to identify singular pipes. The pipe locations that were delineated from the data seemed to have distinctive signatures, but it is entirely possible that some of these locations were misinterpreted due to the complex interaction of many anomalies.

The radio signals transmitted in a radio wave pipe survey attenuate and become harder to detect with distance and branching of the pipe. Also, discontinuities or breaks in the pipe will severely hinder transmission of the radio signals making detection of the pipe very difficult. 

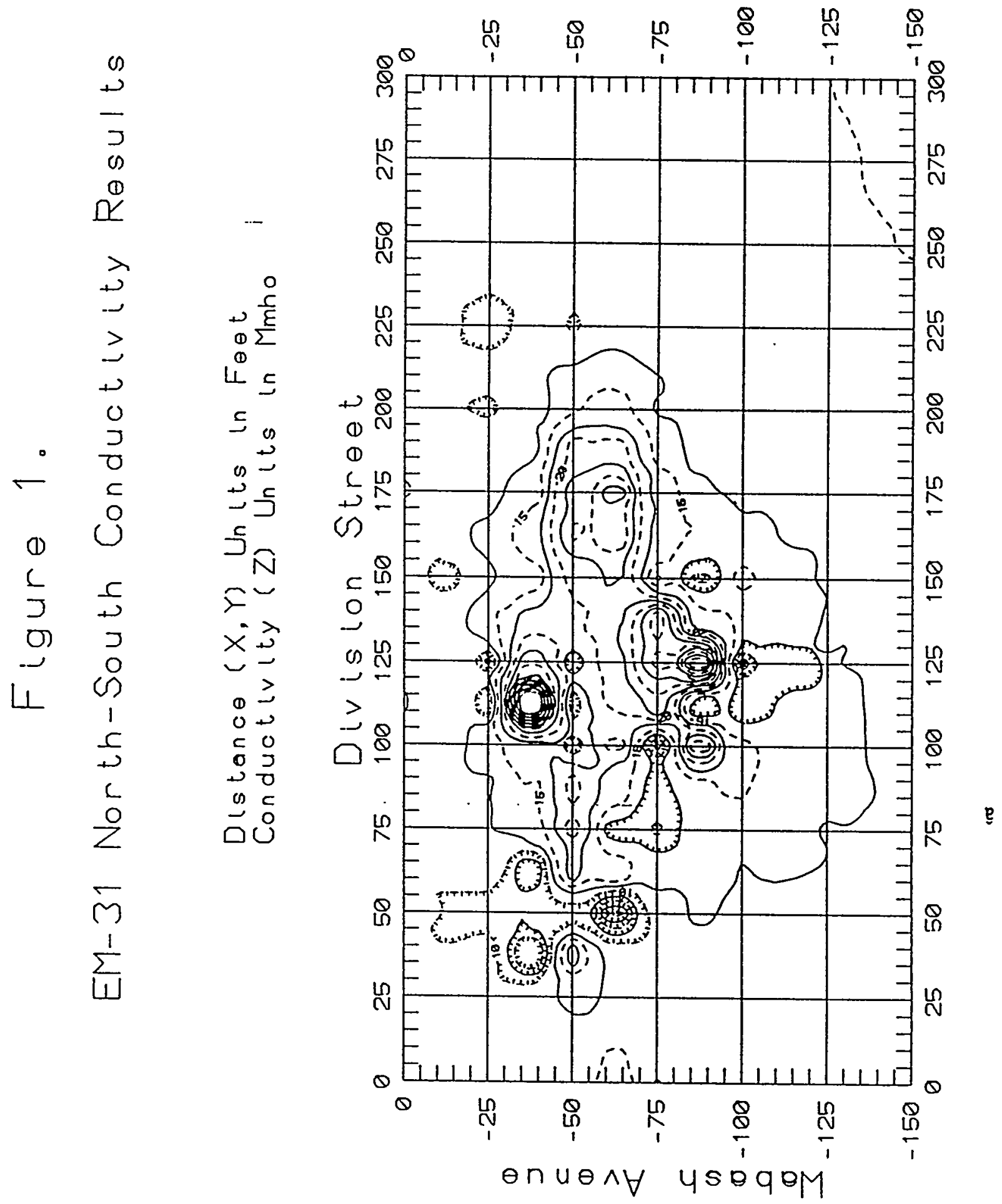

F. 4 


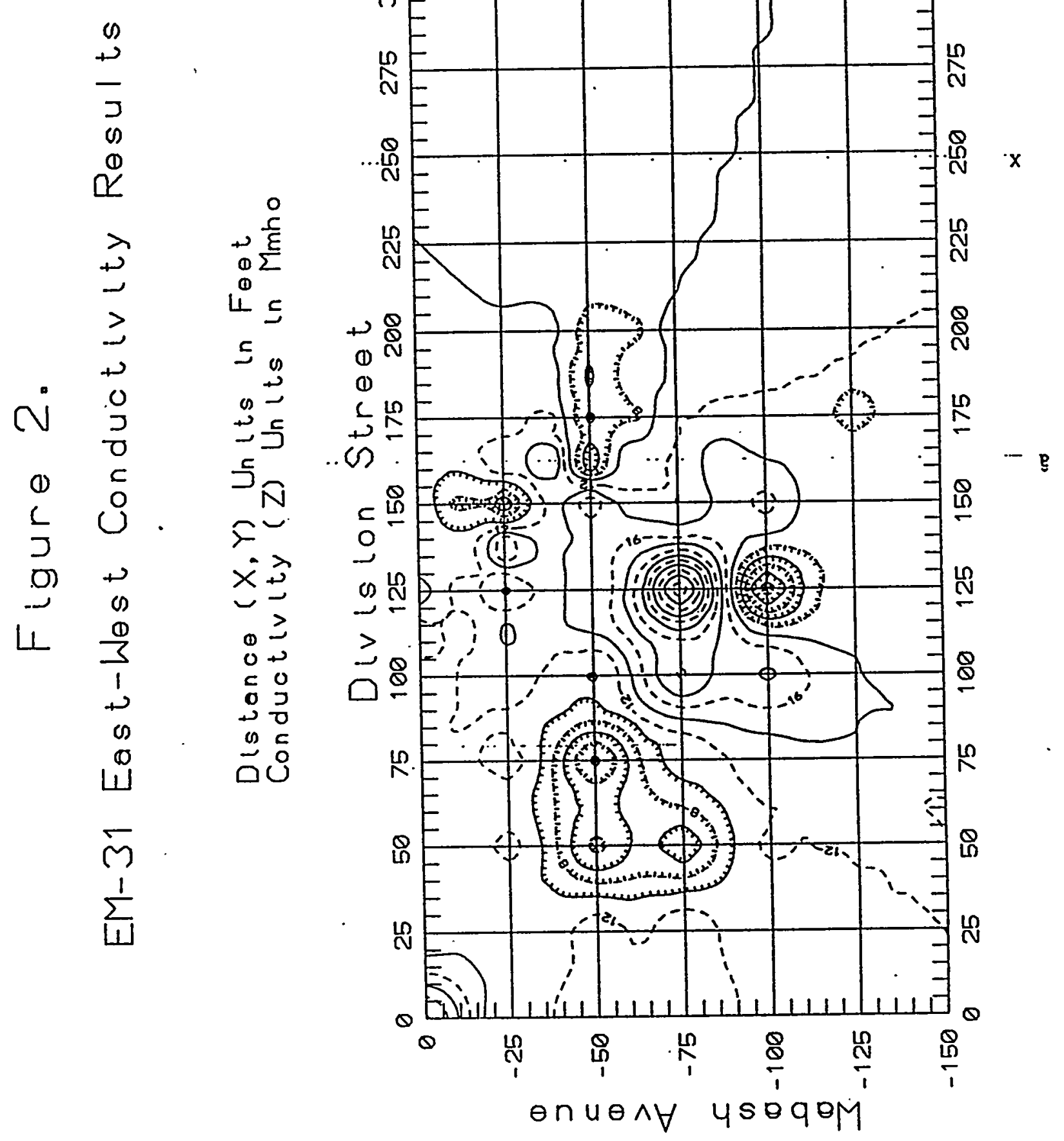

F.5 


\section{EM-31 Electromagnetic Survey Results With Interpreted}

Underground Pipe Locations at ST58

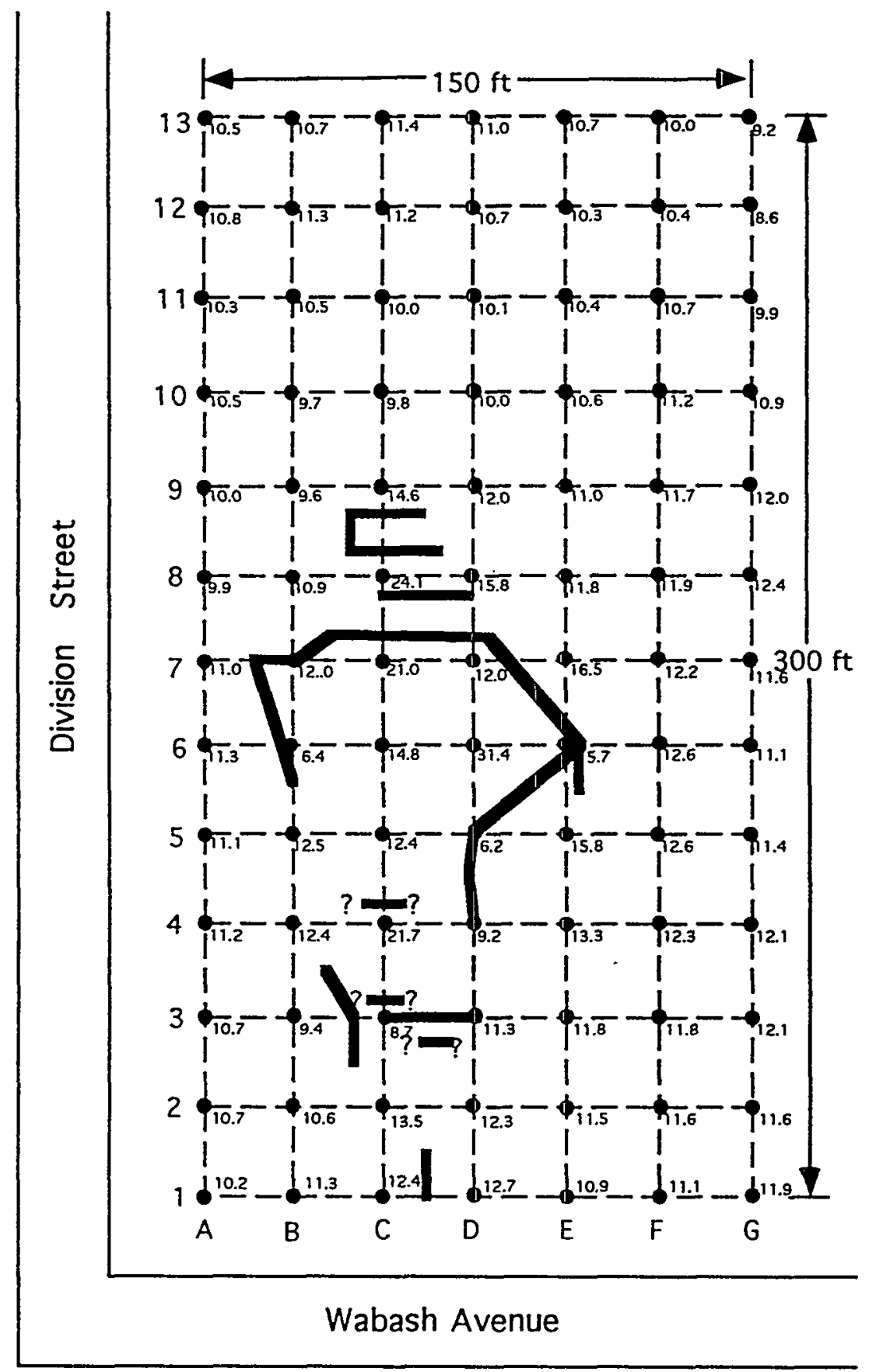

- EM-31 Conductivity Measurements (in Mmho) With Tool Axis Parallel to Wabash Ave.

- Interpreted Underground Pipe Locations

Figure 3. 
Appendix G

Petrex Method Report 
FINAL REPORT

ON THE FINDINGS OF THE PETREX SOIL GAS SURVEY

PERFORMED AT EIELSON AIR FORCE BASE

IN ALASKA

PREPARED FOR:

Battelle PaCific NoRThwest Laboratories

Prepared By:

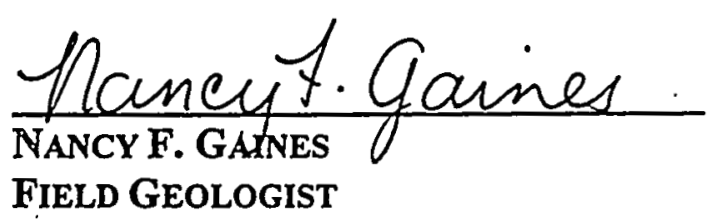

APPROVED BY:

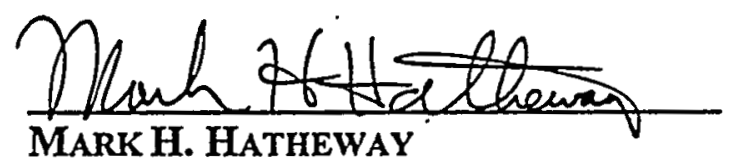

MANAGER OF ENVIRONMENTAL OPERATIONS
DATE:

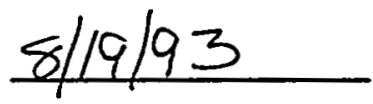

DATE:

$8 / 19 / 93$

NORTHEAST RESEARCH INSTITUTE, INC. 309 FARMINGTON AVENUE, SUITE A-100

FARMINGTON, CONNECTICUT 06032-1943

TELEPHONE (203) 677-9666

FAX (203) 677-7008

August 19, 1993

FR1894e

G.1 


\section{TABLE OF CONTENTS}

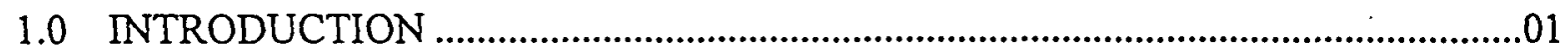

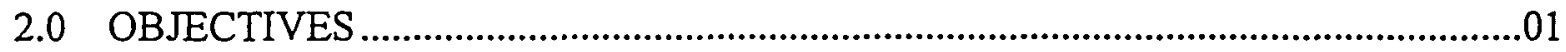

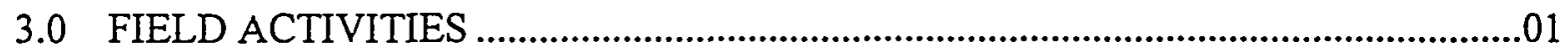

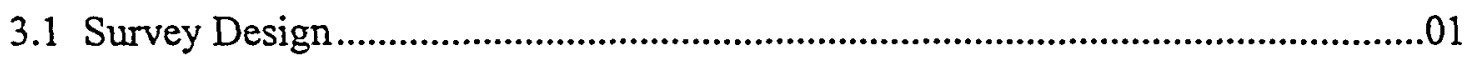

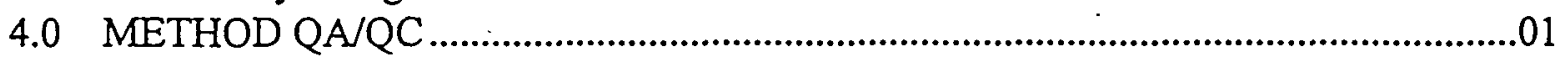

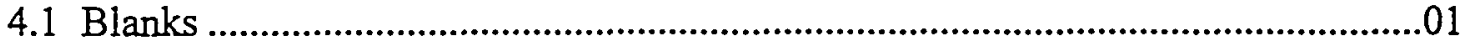

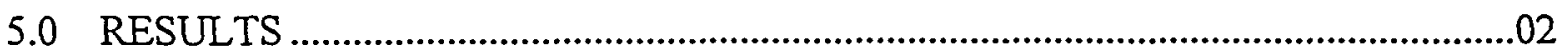

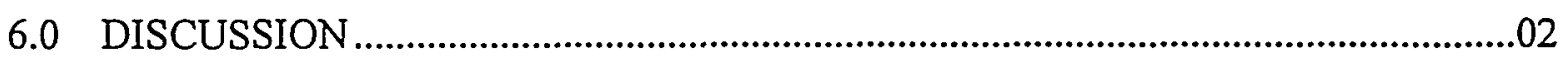

6.1 BTEX Relative Response Map .................................................................03

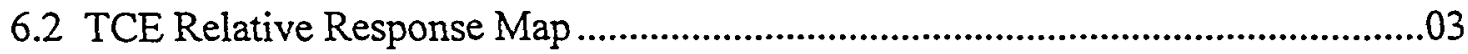

6.3 Cycloalkanes/Alkenes Relative Response Map.................................................03

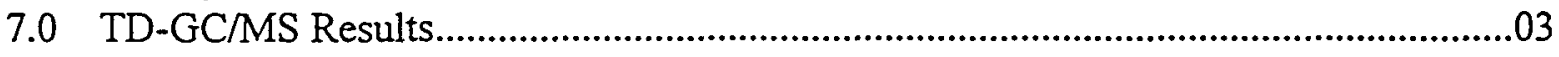

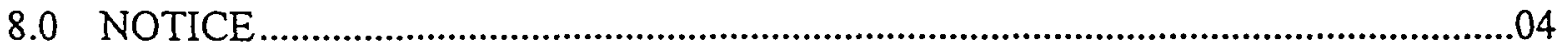

Appendix A: Petrex Protocol

Appendix B: Relative Response Maps, Plates 1-4

Appendix C: Mass Spectra

Appendix D: Table of Data 


\subsection{INTRODUCTION}

Battelle Pacific Northwest Laboratories has conducted a Petrex soil gas survey at Eielson Air Force Base in Alaska utilizing samplers provided by Northeast Research Institute, Inc. (NERI). The purpose of this survey was to screen the site for volatile organic compounds and semivolatile organic compounds (VOCs and SVOCs) which may be present in the soil gas as constituents of fuel products such as gasoline and arctic diesel. The results will be used to assess the presence or potential for soil and/or groundwater contamination and to determine the magnitude and areal extent of any contamination detected.

\subsection{OBJECTIVES}

The objectives of this soil gas survey were to:

1. Collect and report VOCs and SVOCs in the soil gas;

2. Map the areal extent of reported compounds; and

3. Attempt to indicate source areas and migration/dispersion pathways.

\subsection{FIELd ACtivitiES}

All field work was conducted by Battelle Pacific personnel. A description of typical field methods is provided in the Petrex Protocol, Appendix A.

\subsection{METhod QA/QC}

A description of the Petrex QA/QC procedures is provided in Appendix A in the Petrex Protocol.

\subsection{Travel Blanks}

Two Petrex samplers, which remained sealed, traveled with the survey samplers to the field and back to the laboratory. These two travel blanks were analyzed concurrently with the survey samplers under the same operating conditions on the mass spectrometer: Results of analysis of the travel blanks showed no ion counts present other than normal atmospheric compounds and instrument noise. 


\subsection{RESULTS}

All samplers were analyzed by NERI's standard method of Thermal Desorption/Mass Spectrometry (TD-MS). The results are summarized on the plates listed below which are located in Appendix B.

Plate 1: Sample Numbers and Locations Map

Plate 2: Benzene, Toluene, Ethyl Benzene/Xylenes (BTEX) Relative Response Map

Plate 3: Trichloroethene (TCE) Relative Response Map

Plate 4: Cycloalkanes/Alkenes Relative Response Map

The mass spectra are provided in Appendix $\mathrm{C}$.

These VOCs were found to be the most prominent compounds in the soil gas. In order to map the reported compounds, mass spectral peaks indicative of the compounds were selected and their corresponding ion counts were summed and plotted. Table 1 lists the reported compounds and their selected indicator peaks.

\section{TABLE 1}

Reported Compounds and Their Indicator Peak(s)

\begin{tabular}{ll} 
Reported Compound & Indicator Peak(s) \\
\hline BTEX & $78,92,106$ \\
TCE & 130 \\
Cycloalkanes/Alkenes & $84,98,112,126$
\end{tabular}

\subsection{Discussion}

The soil gas response levels discussed in the following section are described as high and moderate relative to the entire data set. The ion count values that have been reported represent qualitative soil gas values that were evaluated relative to the other sampler locations.

Ion count values are the unit of measure generated by the mass spectrometer to illustrate the relative intensities associated with each of the reported compounds. These response levels do not represent an actual concentration of the reported compounds but are used to differentiate source areas from migration/dispersion pathways.

For a complete discussion of relative response map evaluation, please refer to the Petrex Protocol, Appendix A. 


\subsection{Benzene, Toluene, Ethyl Benzene/Xylenes (BTEX) Relative Response Map}

Plate 2 represents the survey response for the presence of BTEX in the soil gas. Areas of high response appeared near the northeastern corner and near the center of the survey area. A small area of high response appeared along the south central edge of the survey area. Areas of more moderate response surrounded these zones. Another area of moderate response appeared in the northwestern corner of the survey area. Smaller areas of more moderate response appeared along the east central edge and the west central edge of the survey area. The source area for BTEX appeared near the center and near the northeastern corner of the survey area. A specific migration pathway is not evident from the soil gas data.

\subsection{Trichloroethene (TCE) Relative Response Map}

Plate 3 represents the survey response for the presence of TCE in the soil gas. Areas of high response appeared near the center and near the northeastern comer of the survey area. Areas of more moderate response uniformly surrounded these zones. A small area of moderate response appeared along the south central edge of the survey area. The source areas for TCE appeared to be near the center and near the northeastern corner of the survey area. A specific migration pathway is not evident from the soil gas data. Batelle had reported that TCE may have been an additive to arctic diesel.

\subsection{Cycloalkanes/Alkenes Relative Response Map}

Plate 4 represents the survey response for the presence of cycloalkanes/alkenes in the soil gas. Areas of high response appeared near the center, near the northeast corner, near the northwestern corner and along the south central edge of the survey area. Areas of more moderate response surrounded these zones. Additional small areas of moderate response appeared along the northwestern edge, northwest of the center, southwest of the center, in the southwestern corner, and near the southeastern corner. The source areas for cycloalkanes/alkenes appeared near the center and near the northeastern corner of the survey area. A specific migration pathway is not evident from the soil gas data.

\subsection{Thermal'Desorption-Gas Chromatography/Mass SPECTROMETRY RESUlts}

The second soil gas collector wire from samplers $39,48,49,55,57,65,80,81$, and 93 were analyzed by TD-GC/MS. This analysis was performed to confirm the compounds which were reported from the TD-MS analysis, to identify unknowns, and to clarify interfering compounds. 
The TD-GC/MS analysis method consisted of passing the desorbed gases through a chromatographic column prior to introduction into the mass spectrometer. This process separated the individual compounds and identified peaks without interference from co-occurring peaks. After all the data were recorded, compounds were identified by a computerized comparison to an internal library of compounds.

The results of the TD-GC/MS analysis are provided in a Table of Data in Appendix D. TDGC/MS results can only be compared to the TD-MS results in terms of presence or absence of particular compounds. Since they are two different analysis methods, they cannot be compared in terms of ion count levels. The TD-MS analysis is generally more sensitive than the TDGC/MS analysis, thus compounds which showed low ion count levels may not be detected by TD-GC/MS.

Overall, the results of the TD-GC/MS analysis confirm what was count in the TD-MS analysis. Moderate to high levels of several benzene isomers, pentane isomers, hexane isomers, Heptane isomers and cycloalkanes/alkenes were seen in samples $39,49,55,80$, and 81 . Sample 39 also showed high levels of toluene, xylene, trimethyl decane, methyl propyl nonane, isooctane, and trimethyl octane. Sample 49 showed high levels of toluene, ethyl benzene, naphthalene, methyl propyl nonane, octane, and methyl octane. Sample 55 showed high levels of xylenes and methyl dodecane. Sample 81 showed high levels of xylenes and ethyl benzene, and low levels of toluene. Sample 80 showed moderate to high levels of ethyl benzene, xylenes, and naphthalenes, and low levels of toluene and octane.

Sample 48 showed low levels of benzene and a few benzene isomers. Sample 57 showed moderate levels of a few hexane isomers and pentane isomers, and low levels of benzene, toluene, and xylenes. Sample 65 showed low levels of benzene and toluene. Sample 93 showed low levels of toluene and methyl naphthalene.

\subsection{NOTICE}

In connection with this survey and associated interpretation, only a limited scope of work was performed by NERI. Therefore, NERI maintains that it has not defined the scope of the environmental condition of the site. Professional judgements made within the context of this report are based on technical data made available to NERI as well as data gathered during on-site activities performed by Battelle Pacific Northwest Laboratories. NERI assumes no responsibility for conditions which did not come to its actual knowledge, or conditions not generally recognized as environmentally unacceptable at the time this report was prepared. 


\section{APPENDIX A PETREX PROTOCOL}

G.7 
REVISED AUGUST 1992

\section{PETREX ENVIRONMENTAL SOIL GAS PROTOCOL}

\section{INTRODUCTION}

The Petrex Technique provides a means by which trace quantities of gases from subsurface derived organic contaminants can be detected and collected at the earth's surface. The Technique is integrative, thereby eliminating the short-term variations associated with other gas/vapor detection methods. The Petrex Technique directly collects and records a broad range of organic compounds emanating from subsurface sources.

\section{SOIL GAS COULECTOR PREPARATION}

Adsorption collector wires (after construction) are cleaned by heating to $358^{\circ} \mathrm{C}$ in a high vacuum system.

Wires are packed under an inert atmosphere in glass culture tubes.

One collector out of every batch of thirty is checked for cleanliness by mass spectrometry. Another collector from the batch is checked for adsorptive capability. Based on the results, the batch of collectors is approved for release into the field.

\section{SOIL GAS SAMPLER INSTALLATION}

The sampler consists of two collectors, each a ferromagnetic wire coated with an activated carbon adsorbent in a screw top glass culture tube. Each sampler is typically placed in a shallow hole, 14-18 inches deep. The hole is backfilled and the location is marked. The sampler is left in the ground from one to thirty days, then retrieved and sealed for transportation back to the laboratory for analysis.

The Petrex soil gas sampling technique is adaptable to various surface conditions commonly encountered within survey areas. These surfaces typically include concrete, asphalt, grass, and gravel. Two installation methods are routinely utilized to adapt to these surface conditions.

The first method utilizes a coring shovel for sampler installations in grass or otherwise loosely consolidated soil conditions. The shovel cores a 14 inch deep by 2 inch diameter hole in the surface soils. 
Petrex soil gas samplers are placed (open end down) at the bottom of each core hole. The samplers are then backfilled with an aluminum foil plug and the original excavated soil. To complete installation, sample locations are marked with ribbon flagging and a numbered pin flag, as well as entered into a field notebook and plotted on a field map.

The second method of sampler installation utilizes an electric rotary hammer, equipped with an 18 inch by 1.5 inch diameter drill bit, for sampler installations under concrete, asphalt, or otherwise consolidated conditions. A hole is drilled through the surface to the dimensions of the drill bit equipped to the rotary hammer.

Petrex soil gas samplers are placed at the bottom of each drilled hole. For retrieval purposes, a cleaned galvanized steel wire is attached to each sampler. Aluminum foil is used to plug each hole to approximately two inches below grade. Then each hole is capped to grade with hydraulic cement. The hydraulic cement serves as protection from the external surface environment.

To complete sampler installation, sampler locations are marked with paint (where applicable), entered into a field notebook, and plotted on a field map.

\section{SOIL GAS SAMPLER RETRIEVAL}

Petrex soil gas samplers are retrieved following a time period that has allowed for the soil gas emanating from the subsurface environment of a survey area to equilibrate with the installed Petrex samplers. This time integration period is determined for each Petrex soil gas survey based on time calibration data or site conditions.

Retrieval operations are dependent on surface conditions and routinely consist of the following two methods.

The first method applies to grass covered or loosely consolidated soil conditions. A trowel is utilized to expose the backfilled samplers; then with a pair of tongs, the samplers are brought to the surface. At the surface, the samplers are sealed, cleaned, and labeled. Following retrieval, all debris are gathered and the core hole is backfilled with original material.

The second method applies to concrete, asphalt, or other consolidated surface conditions. A hammer and chisel is utilized to remove the hydraulic cement plug and expose the sampler. By means of the pre-attached retrieval wire, the sampler is brought to the surface. At the surface, the retrieval wire is removed and the sampler is sealed, cleaned, and labeled.

Following retrieval, each drill hole is backfilled and patched with cement or asphalt. 


\section{TIME CALIBRATION SAMPLERS}

Time calibration samplers are included in Petrex soil gas surveys, as appropriate. These samplers are included as a means of monitoring the loading rates of volatile and semivolatile organic compounds (VOCs and SVOCs) emanating from the soil gas at a survey area onto the Petrex collectors.

During Petrex sampler installation, two sets of three to five time calibration samplers are also installed at survey sample locations that best represent the range of soil gas response for the survey area. These representative locations are determined based on previous soils and/or groundwater studies and other site specific conditions such as gradient and potential source areas.

The first set of time calibration samplers are generally retrieved within a week or less following the initial installation and the second set one week later. Often, permanent on-site personnel are instructed to perform time calibration sampler retrieval.

Lengths of exposure periods of the survey samplers for each survey are determined based on the results of each respective set of time calibration samplers. Time calibration samplers are usually analyzed within 24 hours upon receipt at the laboratory. At the first indication of significant relative ion count intensities and significant total ion count values, the decision is made to retrieve the entire complement of survey samplers.

If there are no significant relative ion count intensities detected from the second set of time calibration samplers, then the survey samplers are allowed to equilibrate in the field for a maximum time period of up to 30 days. The average environmental Petrex soil gas survey requires a collector integration period of one day to two weeks.

\section{METHOD OA/OC}

Within every survey sampler, two or more collector wires should have adsorbed identical compounds. Like compounds on separate collectors relate an acceptable quality assurance (QA) during the survey's analysis. The first wire is analyzed by Thermal Desorption/Mass Spectrometry (TD/MS). The data from the first wire is reported on the relative response maps. The second wire is retained for analysis by Thermal Desorption-Gas Chromatography/Mass Spectrometry (TD-GC/MS), if warranted by the initial TD/MS analysis of the second wire.

Approximately ten percent of the total Petrex survey samplers contain three collector wires. The third collector wire, a QC collector wire, is used by the operator to test the mass spectrometer's operating conditions prior to survey analysis. Some of these quality control $(\mathrm{QC})$ collectors are also used to check the mass spectrometer sensitivity during survey analysis. In addition, the QC collector may be used to compare the reproducibility of-the detected VOCs. 


\section{TRAVEL BLANKS}

Two Petrex samplers, each containing a single collector wire, are included with each Petrex soil gas survey as travel blanks. These blanks are analyzed with the survey samplers to indicate whether there may have been contamination introduced to the survey samplers during installation or shipment. If compounds other than normal atmospherics (e.g., $\mathrm{CO}_{2}, \mathrm{H}_{2} \mathrm{O}, \mathrm{N}_{2}$, and $\mathrm{Ar}$ ) are detected on the blanks, then blank subtraction may be performed on the survey's data set. This process, an initial step to data interpretation, involves the correction of ion flux values of the detected blank contaminants from the entire survey's data set. The resulting ion flux values are provided on the relative response maps.

\section{MASS SPECTROMETER TUNING}

An Extranuclear Quadrupole Mass Spectrometer or similar instrument, equipped with a Curiepoint pyrolysis/thermal desorption inlet, is used for collector analysis. Mass assignment and resolution are manually adjusted using a Perfluorotributylamine (PFTBA) standard or a built-in tuning program, depending on the instrument. A linear correction, based on the known spectrum of PFTBA, is calculated. This correction is applied to a second PFTBA spectrum. If correct mass $(M / Z)$ values are obtained, the operator proceeds to the next tuning step. If not, Step 1 is repeated until correct masses are obtained.

Peak intensity ratios are set from the major peaks in the PFTBA spectrum using the following values:

$\begin{array}{lll}\text { Mass } & & \begin{array}{l}\text { Spectrum } \\ \text { (M/Z) }\end{array} \\ 69 & = & \text { Intensities } \\ 131 & = & 48 \% \\ 219 & = & 50 \% \pm 5 \%\end{array}$

During tuning, the ion signal for mass (M/Z) 69 of PFTBA is measured at a preset sample pressure and detector voltage and compared to previous values at the same setting.

Electron energy is set to 70 electron volts. All other operating parameters, such as scans, scan range, and mass offset, are established in the computer program. These values may only be changed by the laboratory manager.

Tuning is performed at the beginning of a run so that an individual survey is analyzed at the same set of instrument conditions. The samplers are analyzed in random order. 


\section{LABORATORY ANALYSIS}

Periodic machine background and blank Petrex collector analyses are performed to assure that there is no carry-over between successive samplers. If there are peaks present which are not related to atmospheric gases, the supervisor is notified and the mass spectrometer is shut down and cleaned as necessary.

A written sample number record is kept during the analysis to prevent accidental cross numbering.

The mass spectrometer control program contains appropriate "flag statements" that prompt the operator with a warning if an input sample number has already been analyzed. The operator then checks the current number, along with the disk storage location of the previously entered number to identify the true numbering situation.

\section{COMPOUND IDENTIEICATION}

Compound identification is based on molecular weight, compound fragmentation, and isotope distribution, as applicable. Each VOC exhibits a unique mass spectral signature. NERI maintains a large library of spectra of individual compounds, accessible by computer. In addition, the company maintains a large library of mass spectra of commonly used chemical mixtures; e.g., gasolines, diesels, industrial oils and solvents, coatings, plastics, etc. These are used to assist in both compound and mixture identifications.

The ion count response of an indicator peak(s), representative of the compound and away from interference by other compounds, is extracted for data presentation and mapping.

\section{INTERPRETATION OF SOIL GAS DATA}

Soil gas data (including Petrex) reflect volatile and semivolatile organics collected at a point in the near surface. The sources of these volatile organics may be in the stratigraphic column and/or in groundwater below the collection point. Thus, the organics can be derived from surface spills, deposition, or migration into the deeper vadose zone, and groundwater. The soil gas survey reveals the areal extent of contamination and is the optimum guide in identifying areas in order to develop a vertical profile, including the drilling of soil borings and monitoring wells.

Soil gas data are always semi-quantitative in that multiple sources in soil and/or groundwater cannot be differentiated. However, the higher ion responses are representative of higher concentrations in the subsurface, given that geologic conditions are relatively consistent.

Due to chemical differences between individual compounds, including their ability to both adsorb and desorb from the charcoal Petrex collector element, it is invalid to compare the compound ion count at one sampling location to that of another compound. 
Patterns of compound distribition in the soil gas, as detected at the surface, can be strongly influenced by irregularities in the near surface and subsurface environment through which the soil gas diffuses. These irregularities include subsurface man-made structures, such as concrete foundations, drainage systems, and wells, and such naturally occurring structures.as fractured and unfractured bedrock, clay, and shale lenses.

Other factors influencing the soil gas signal include ground and surface water, the free carbon content of soils, microbiotic activity in the soil, and natural and synthetic ground cover.

All of these factors indicate that the most powerful use of soil gas data is in reconnaissance; identifying and mapping the relative abundance of the widest array of chemical species and mixtures. Efforts to relate soil gas response directly to groundwater or soil contaminant concentrations is generally not regarded as productive owing to the assumptions that are required - for heterogeneity and source distribution.

\section{RELATIVE RESPONSE DETERMINATION AND MAPPING}

The relative response values are reported as the ion counts of indicator peaks for any given compound or mixture. Sample locations on a base map are digitized as X-Y coordinates and ion counts for the reported compounds are plotted at respective locations.

Mapping of the ion counts occurs after contour intervals for each compound or component class are determined. In order to establish the contour intervals, factors such as statistical analysis of ion count distribution, physiochemical considerations, and component-source material relationships (if known) are taken into account for each compound or class, in each area, on an individual basis. Each map is then contoured by hand. The resultant contour zones for each compound or component class in each area are color coded on a relative basis depending on whether the data are interpreted to be of high, moderate to high, moderate, etc., intensity. The response values found on each of the response maps are color coded and contoured on this basis. 
APPENDIX B

RELative ResPonse MAPS, Plates 1-4

G.14 


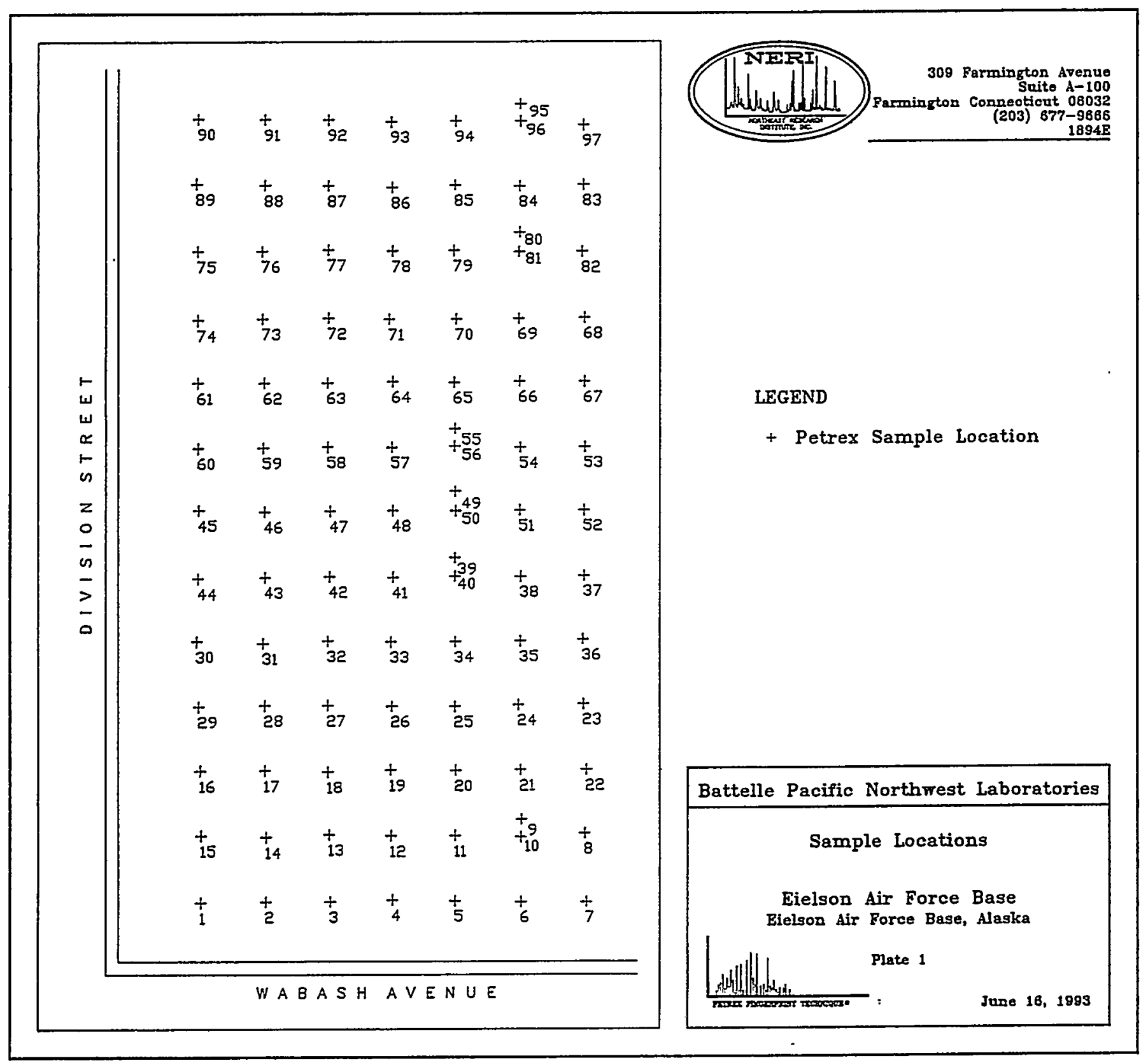

\section{G.15}




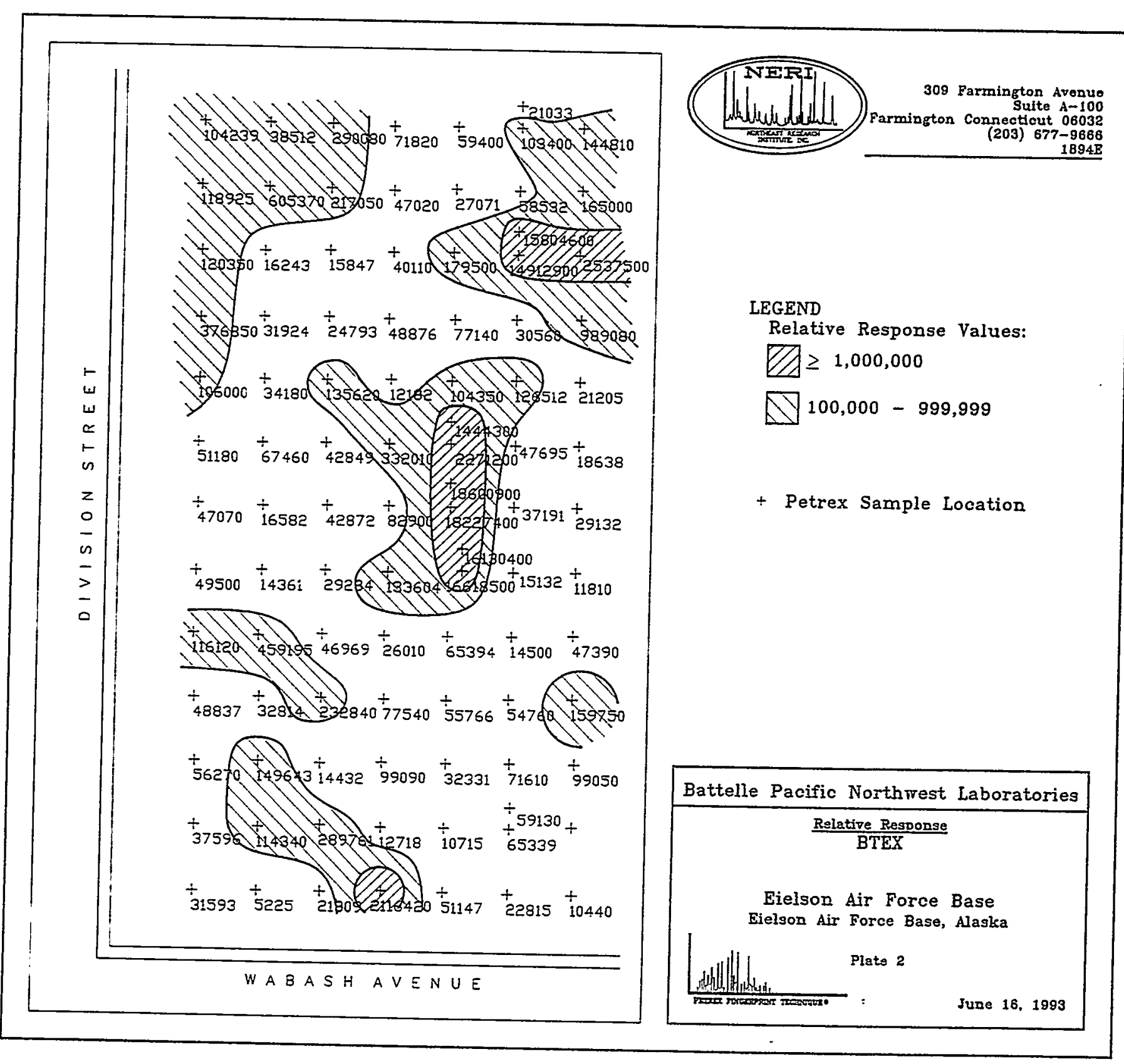

G.16 


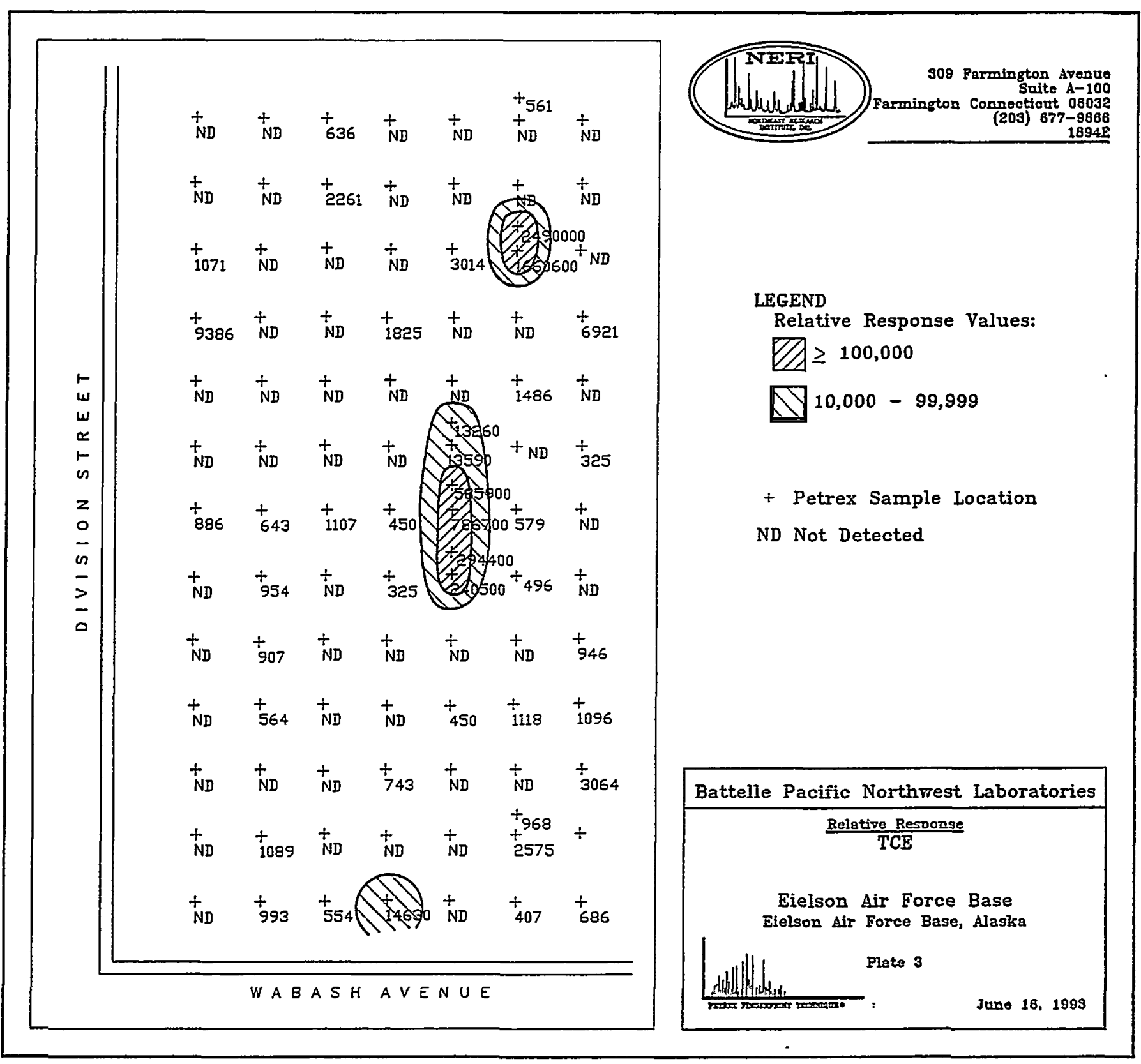

G.17 


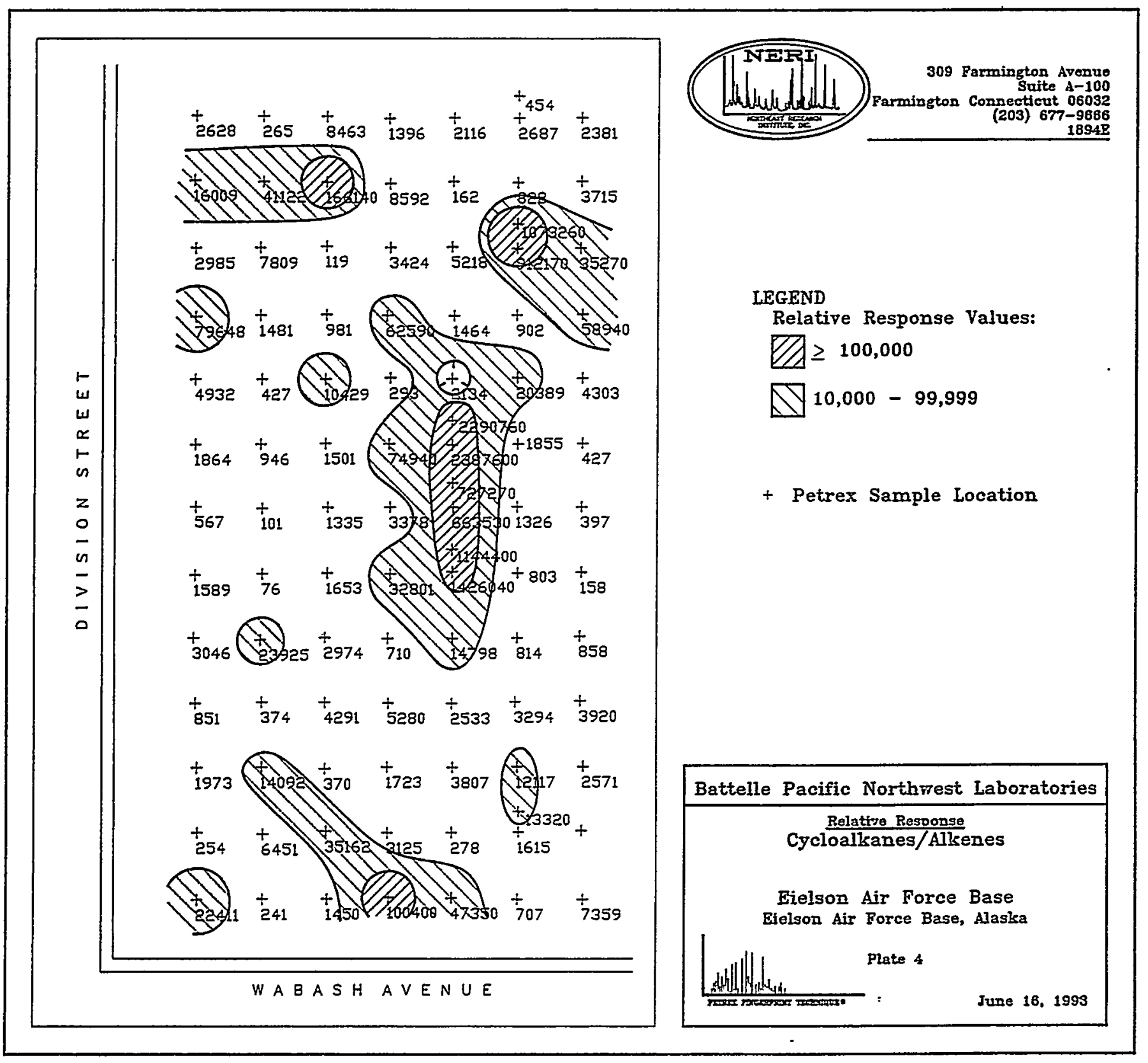

G.18 
APPENDIX C

MASS SPECTRA

G.19 


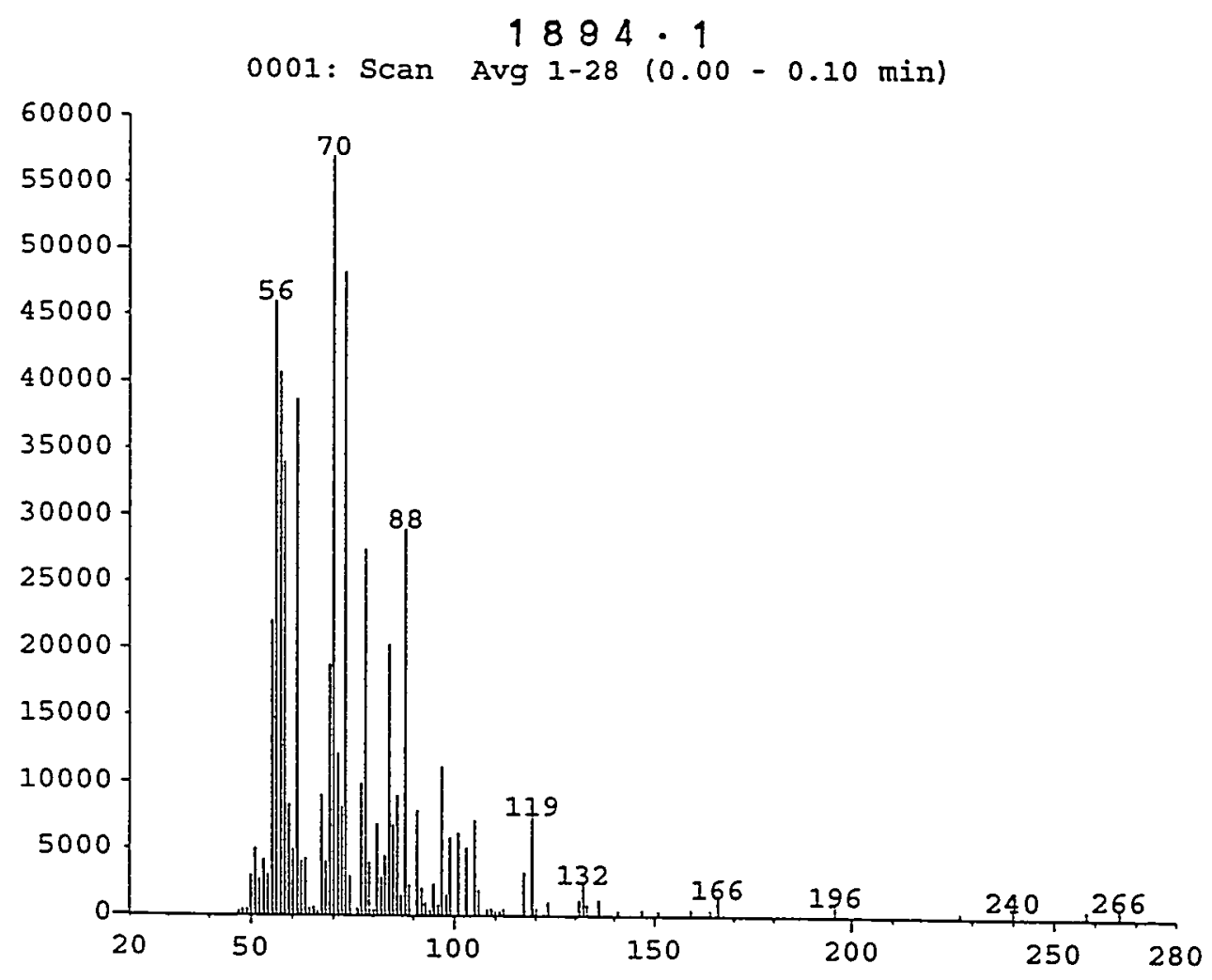

PlotData

Page: 1

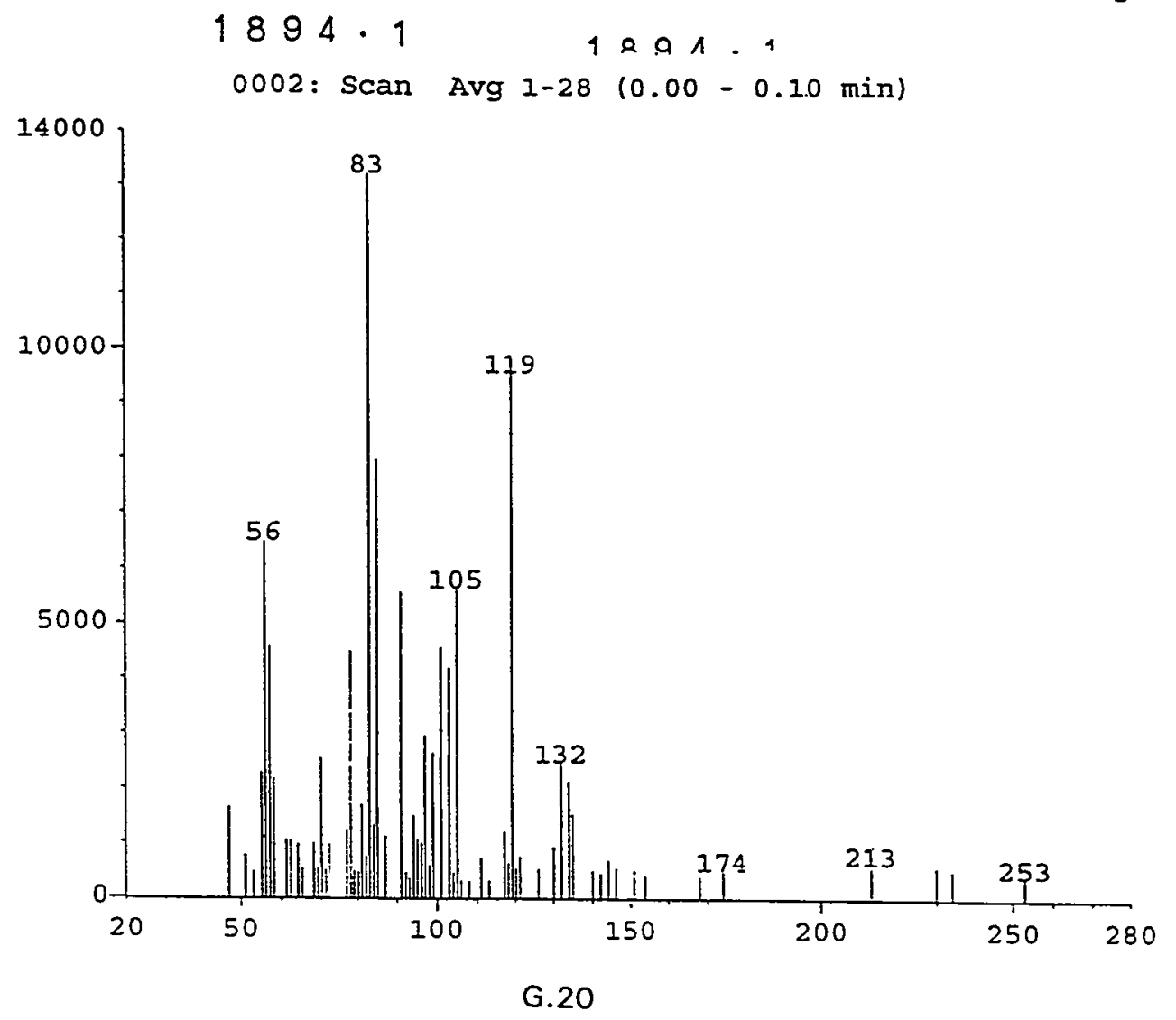


PlotData

$\therefore \quad 1884 \cdot 1$

Page: 1

$0003:$ Scan Avg 1-28 (0.00-0.10 min)

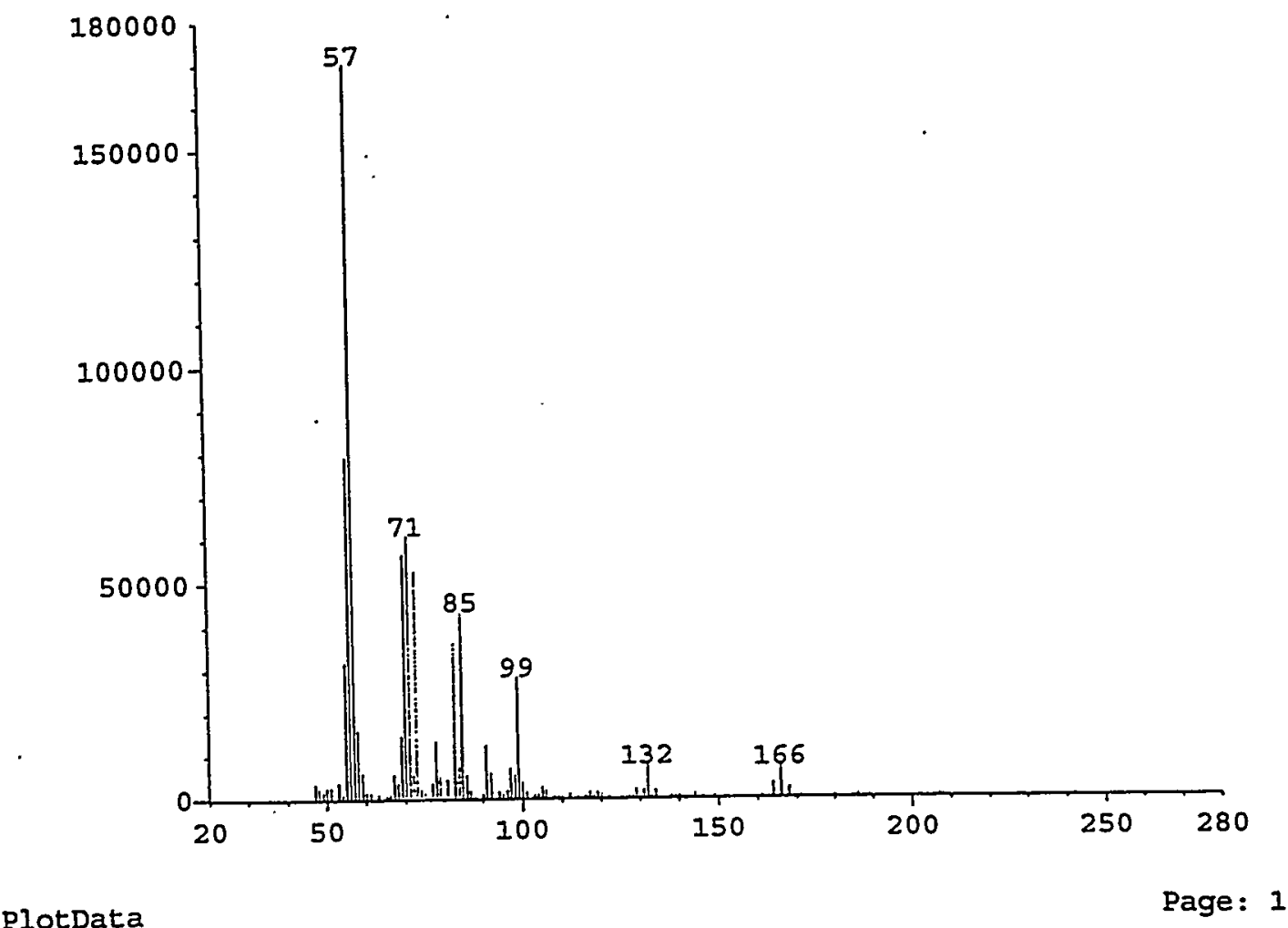

PlotData

$1894 \cdot 1$

$0004:$ Scan Avg 1-28. $(0.00-0.10 \mathrm{~min})$

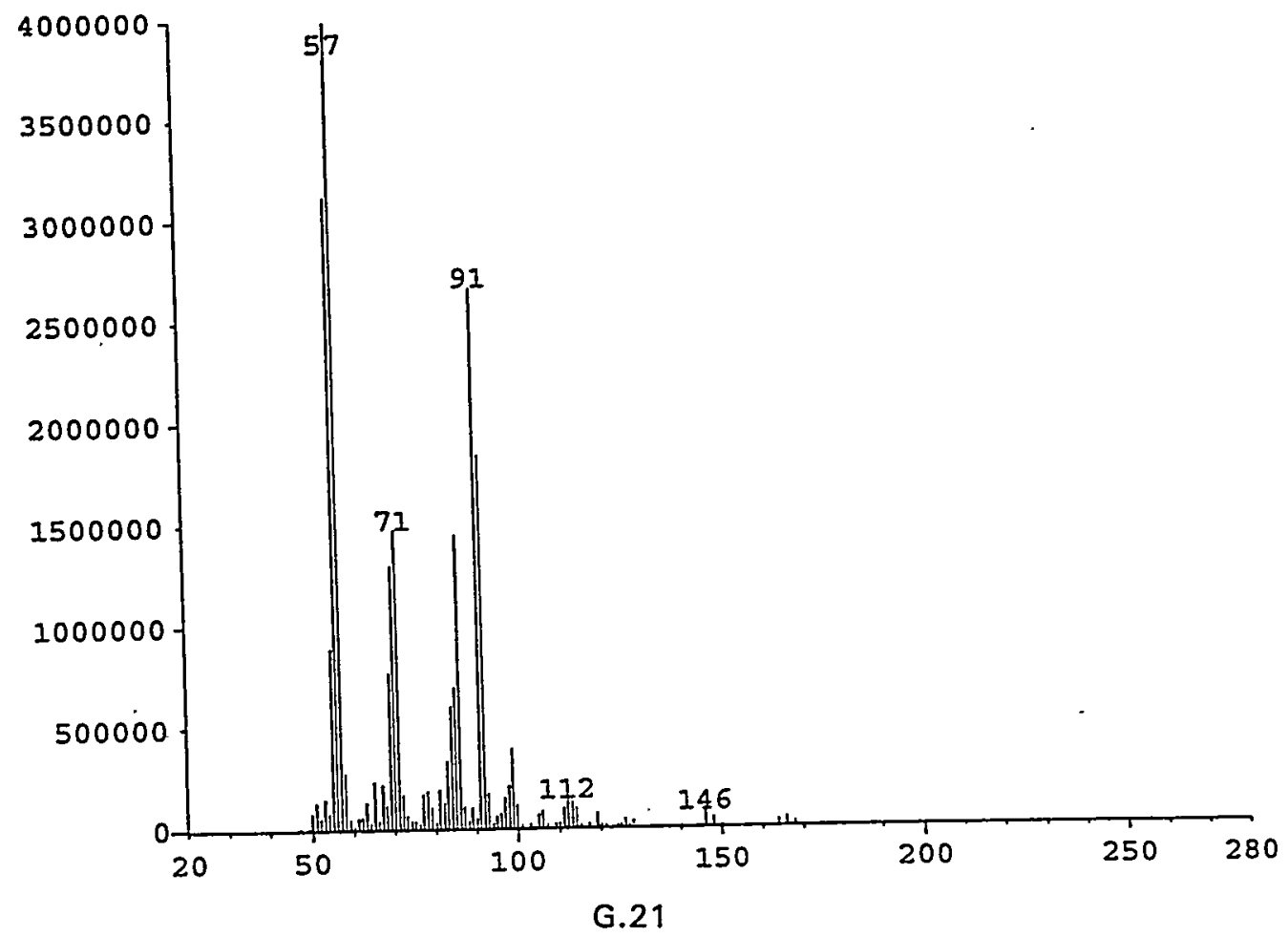


plotData

Page: 1

$1894 \cdot 1$

0005 : Scan Avg 1-28 (0.00-0.10 min).

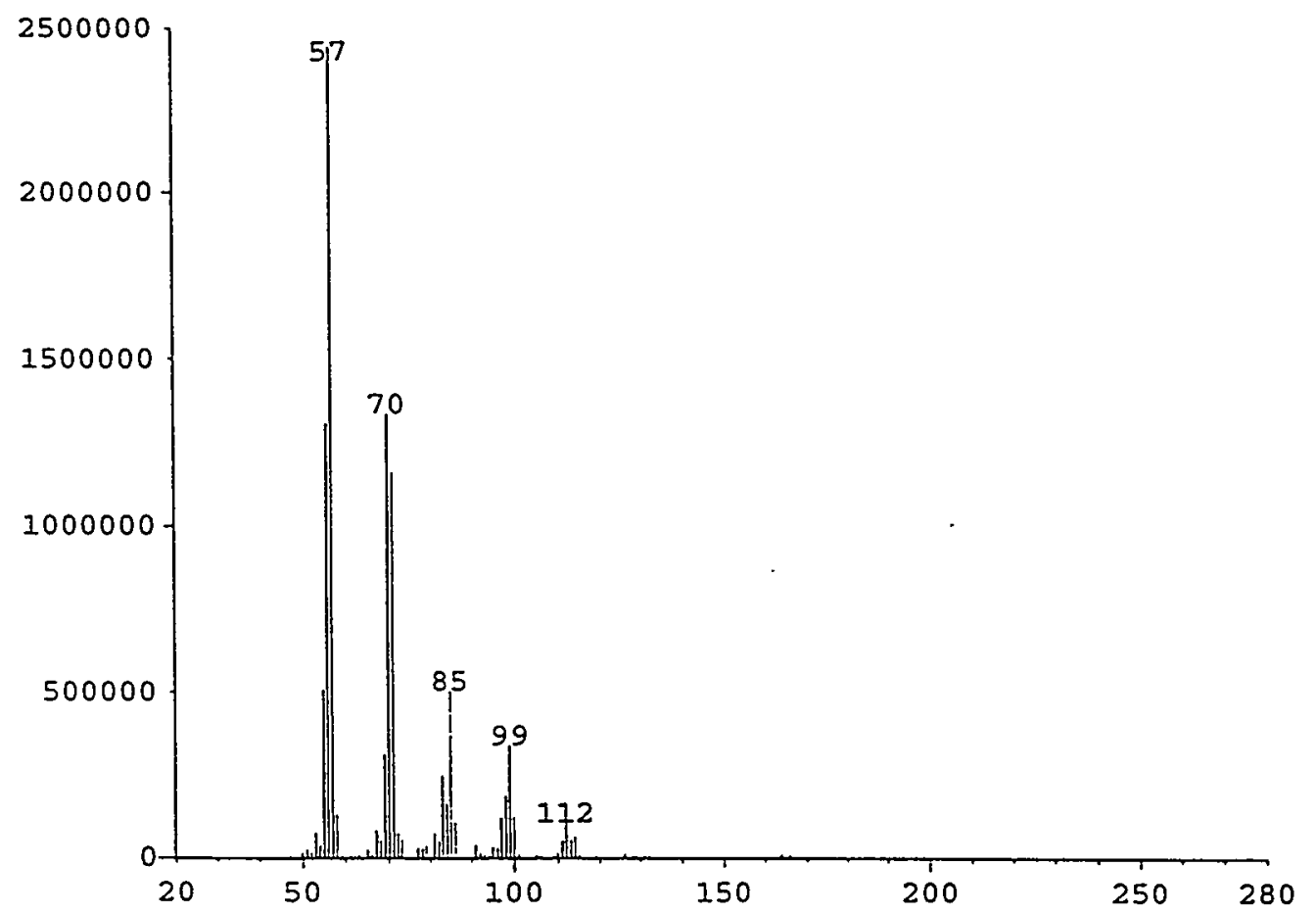

PlotData

$1894 \cdot 1$

Page: 1

0006: Scan Avg 1-28 (0.00-0.10 min)

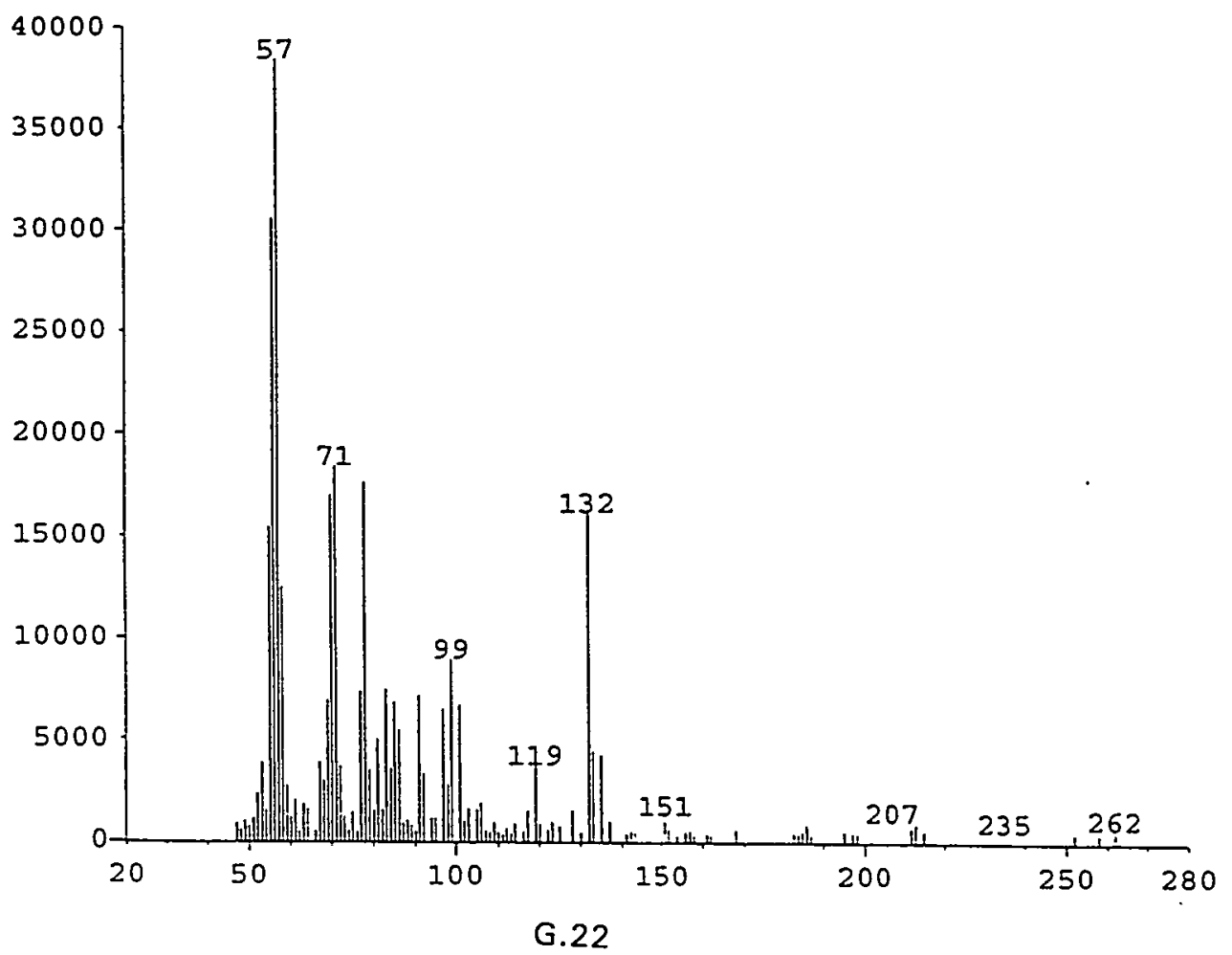


PlotData

Page: 1

$1894 \cdot 1$

0007 : Scan Avg $1-28(0.00-0.10 \mathrm{~min})$

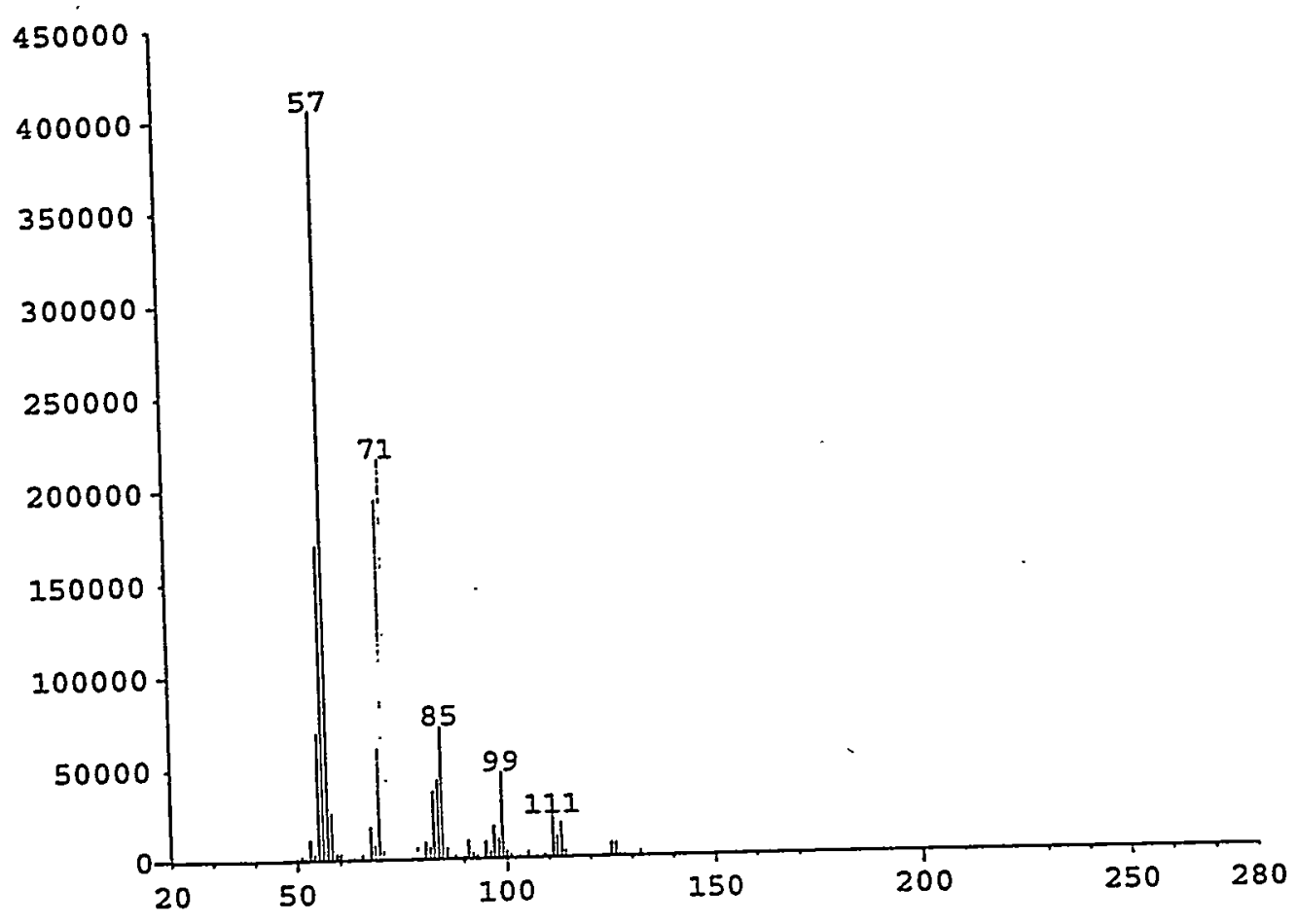

plotData

Page: 1

$1894 \cdot 1$

$0009:$ Scan Avg 1-28 (0.00-0.10 min)

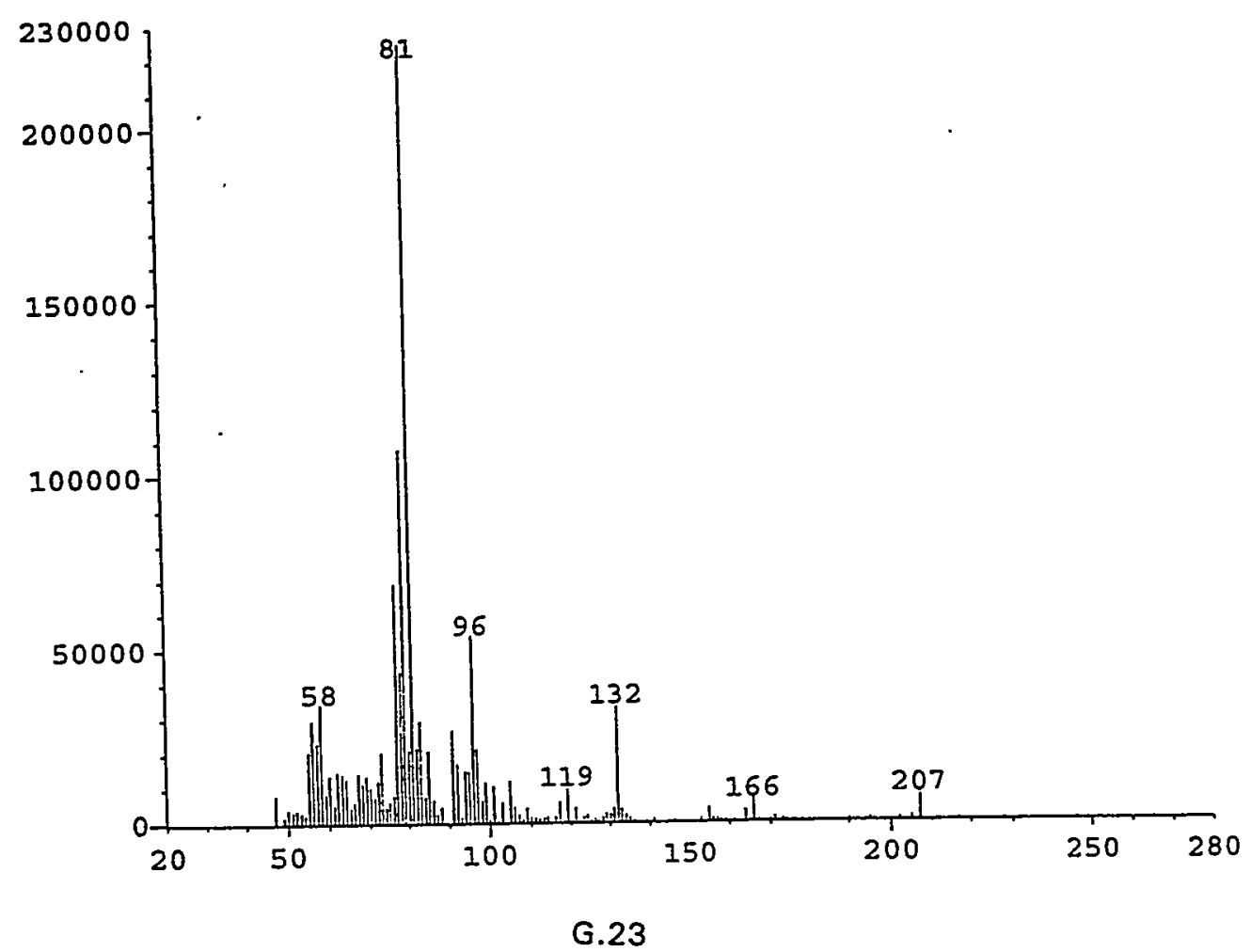


PlotData

Page: 1

$1894 \cdot 1$

0010: Scan Avg 1-28 (0.00-0.10 min)

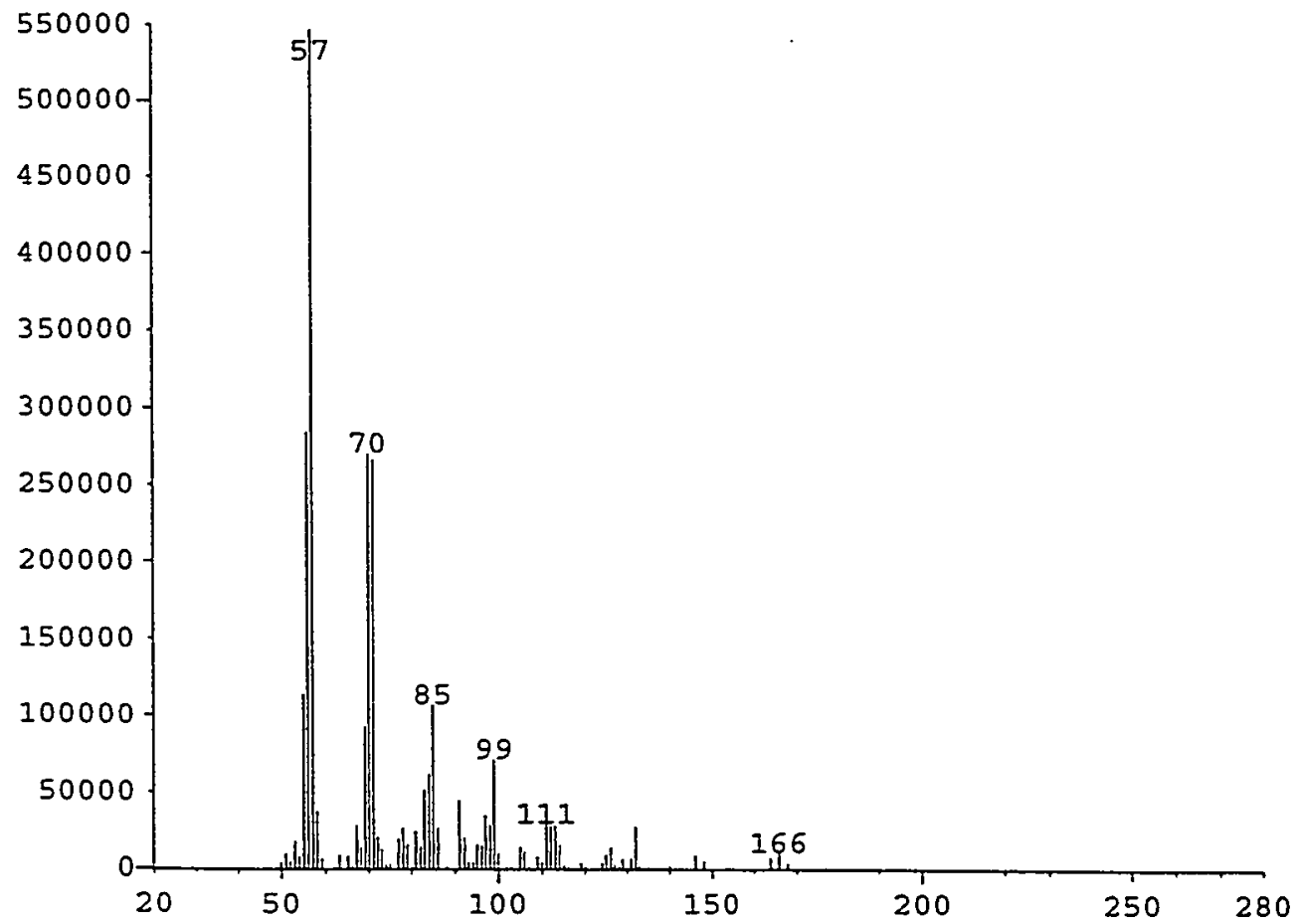

PlotData

$1894 \cdot 1$

Page: 1

0011: Scan Avg 1-28 (0.00-0.10 $\mathrm{min})$

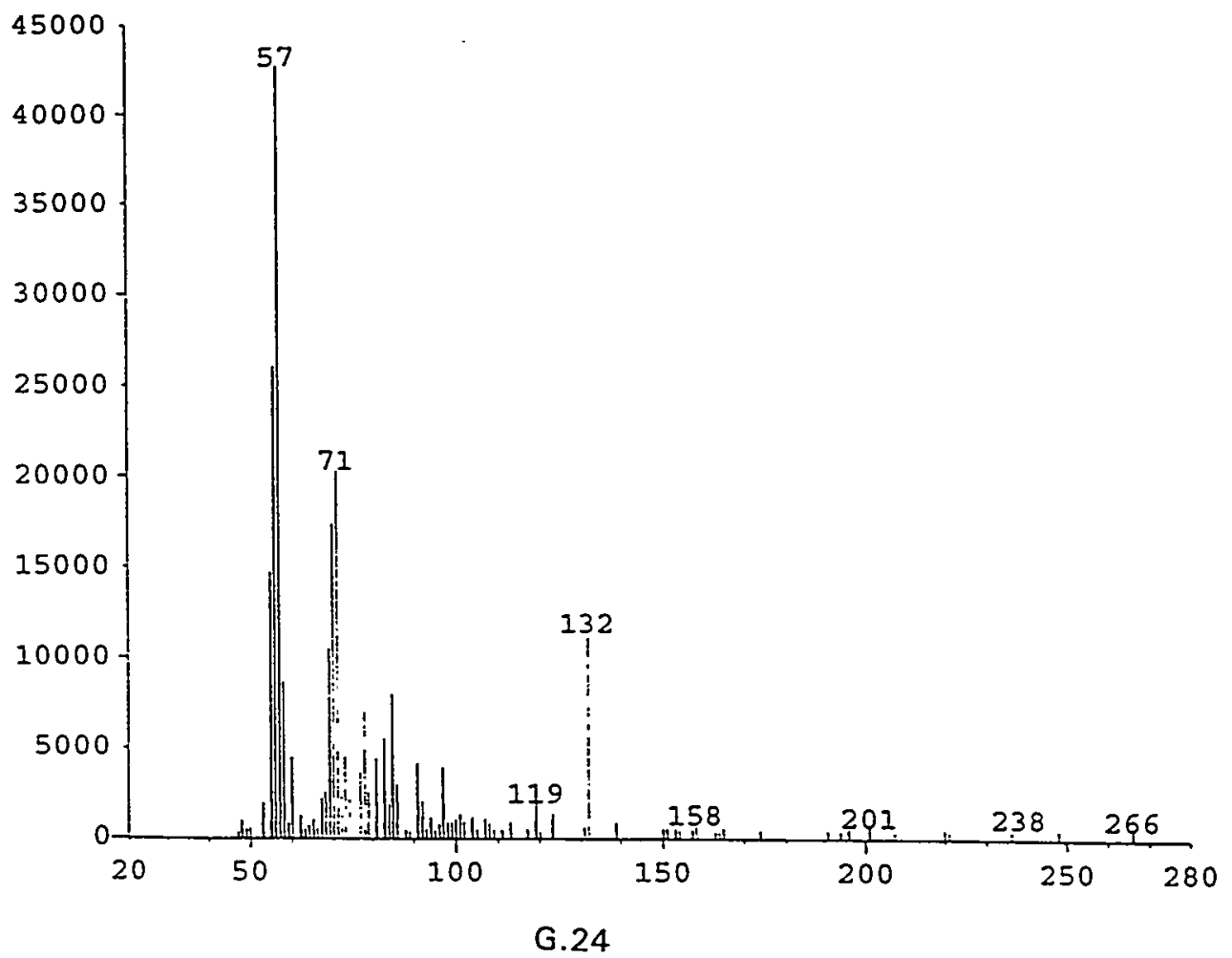




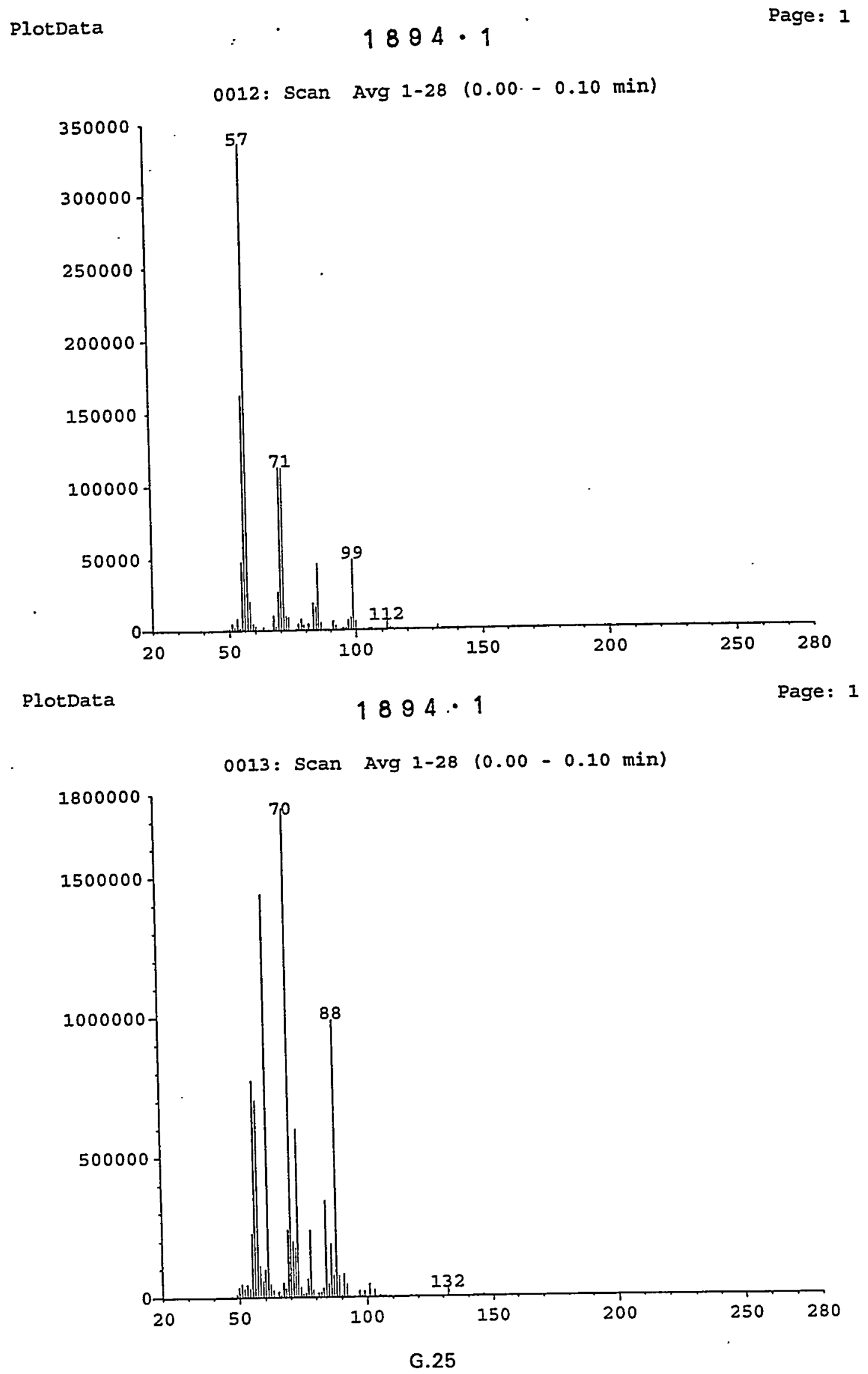


PlotData

Page: 1

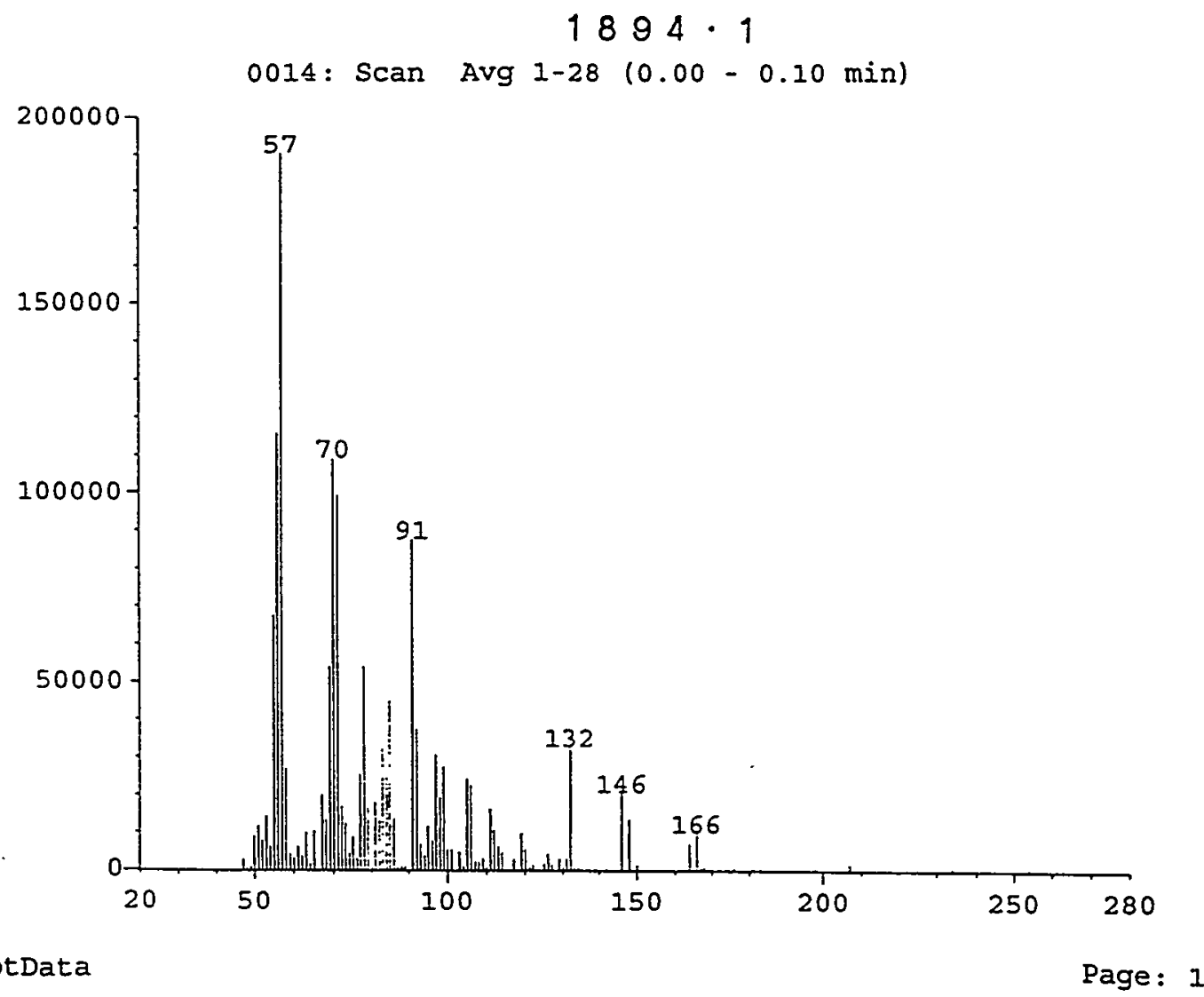

PlotData

$1884 \cdot 1$

0015: Scan Avg 1-28 (0.00-0.10 min)

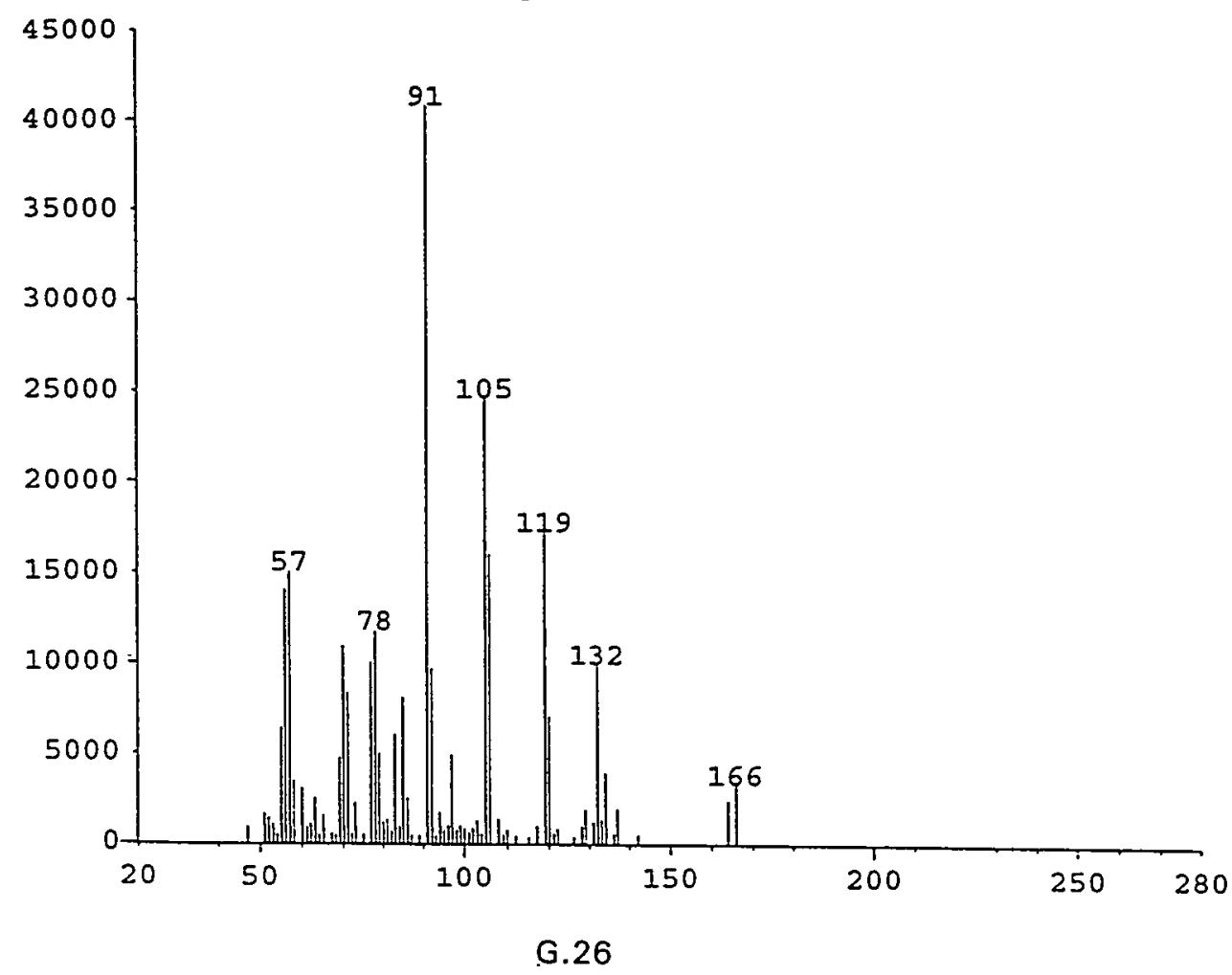




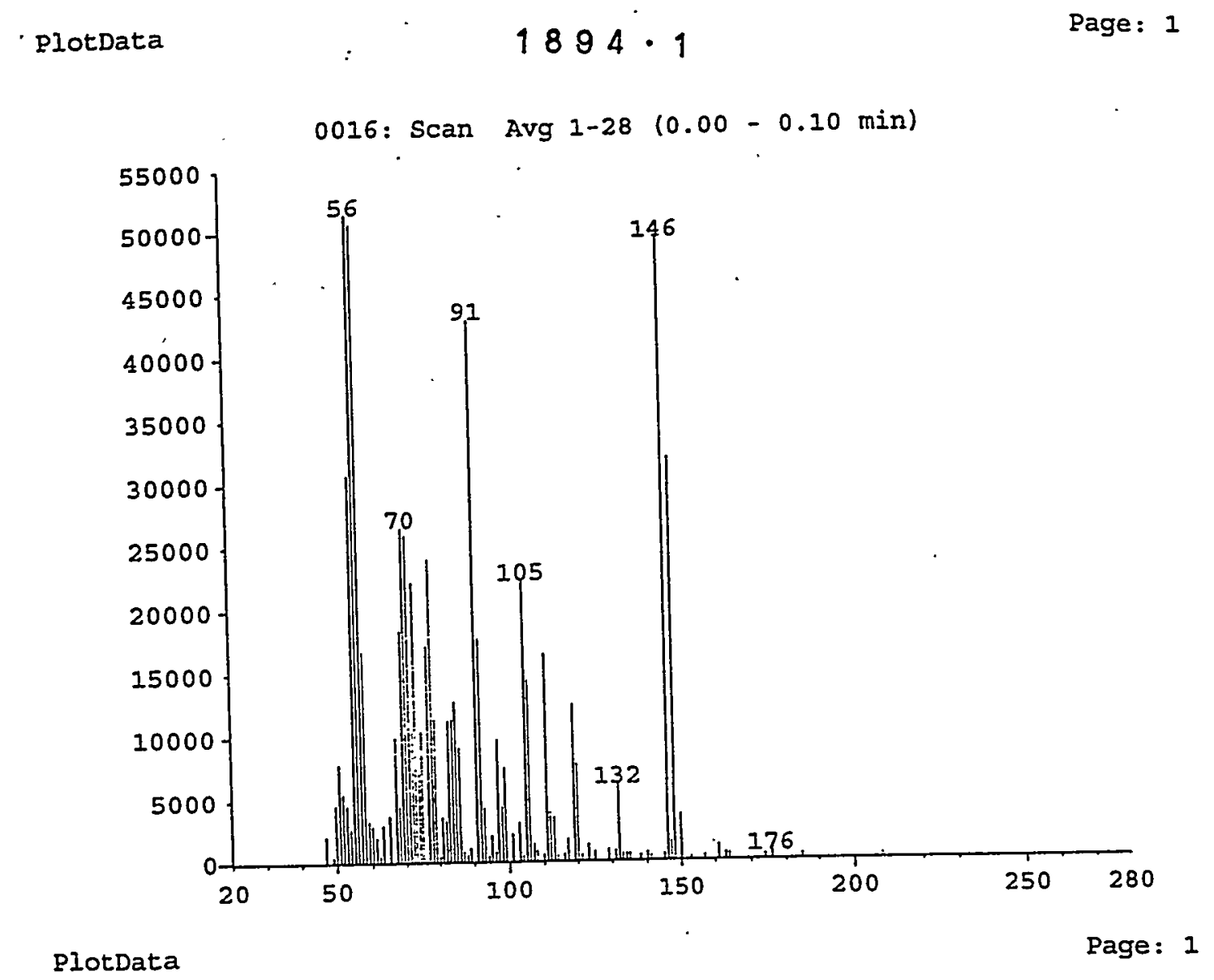

$1894 \cdot 1$

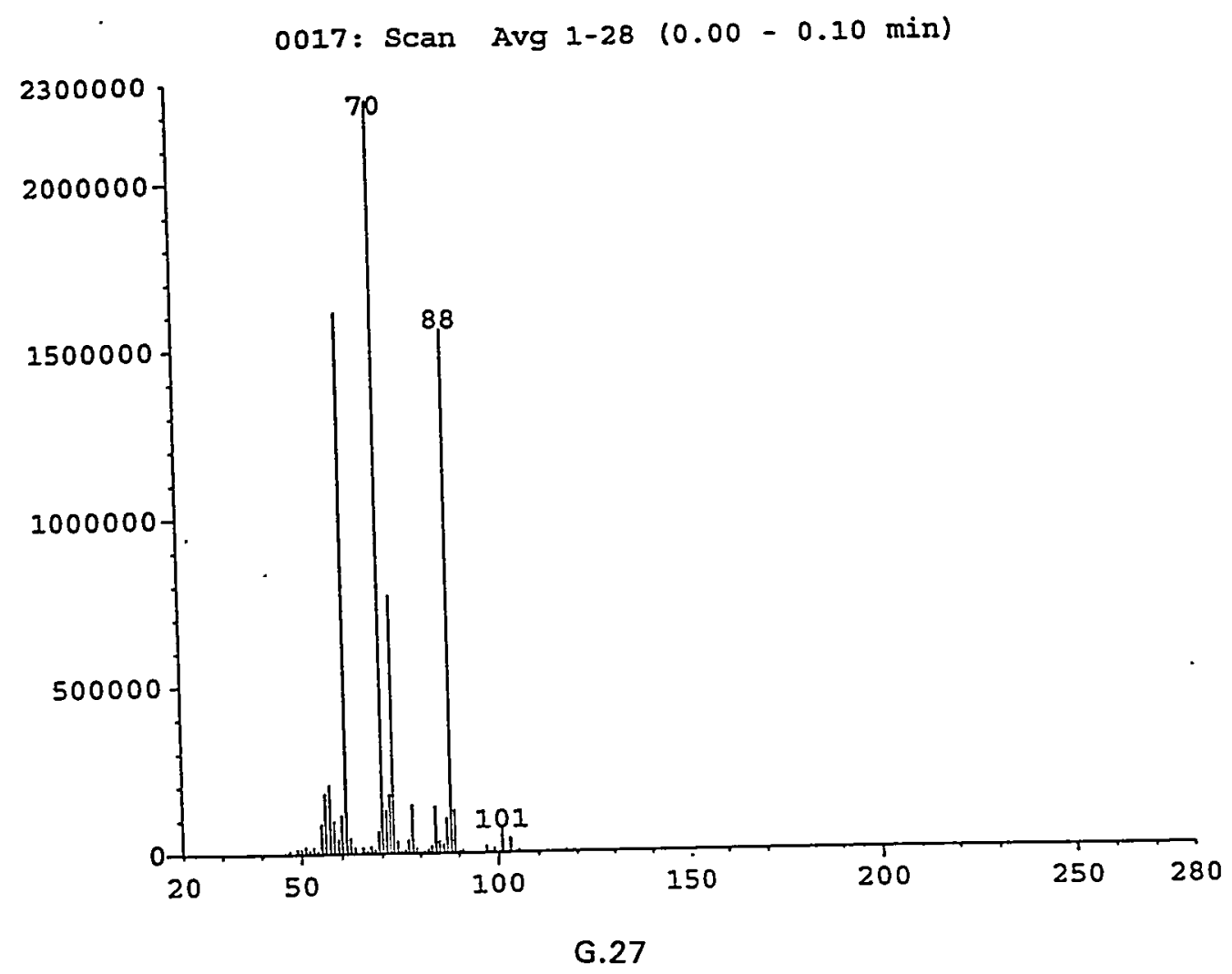


PlotData

Page: 1

$1894 \cdot 1$

0018 : Scan Avg 1-28 (0.00-0.10 min)

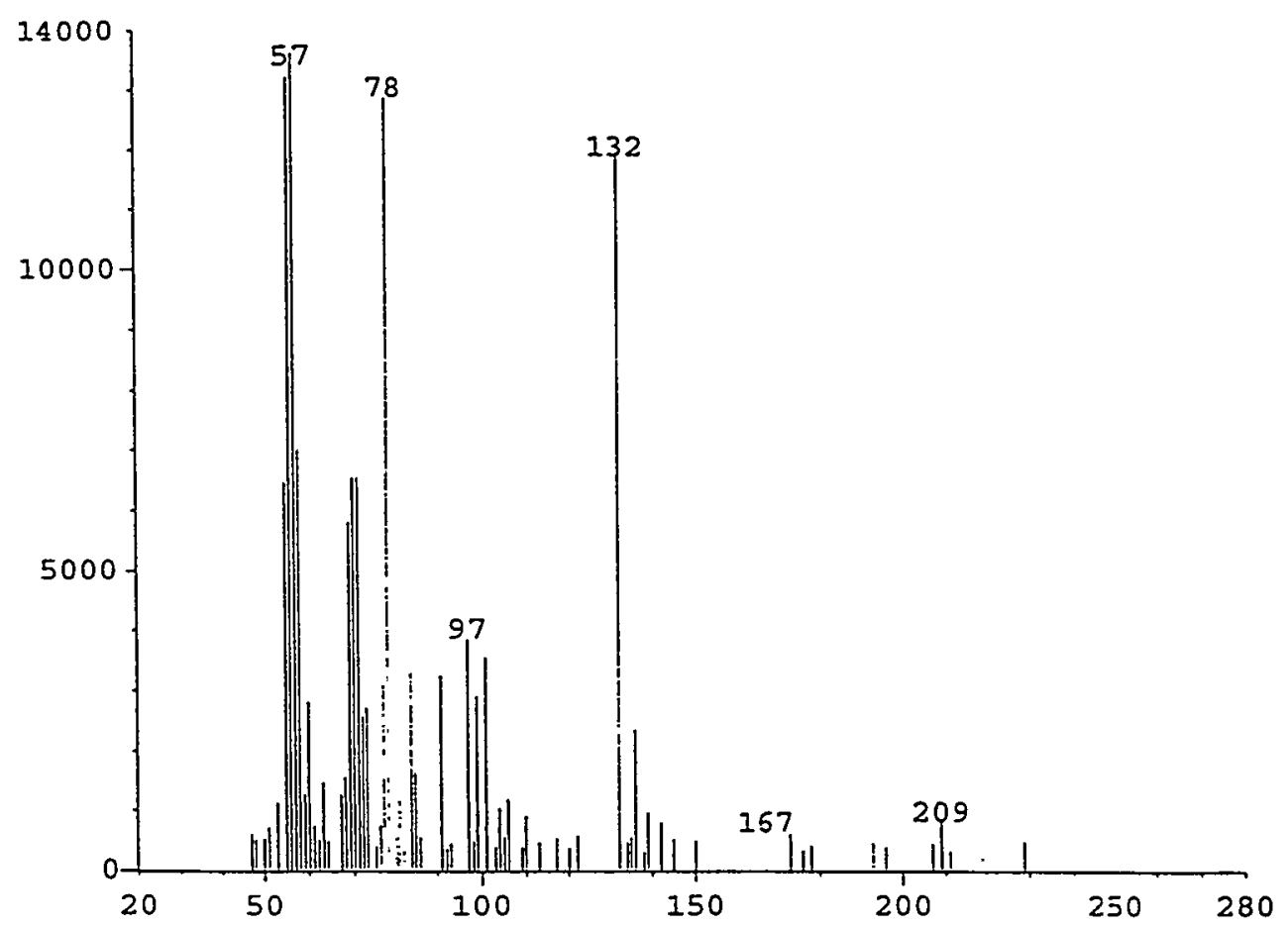

PlotData

$1894 \cdot 1$

Page: 1

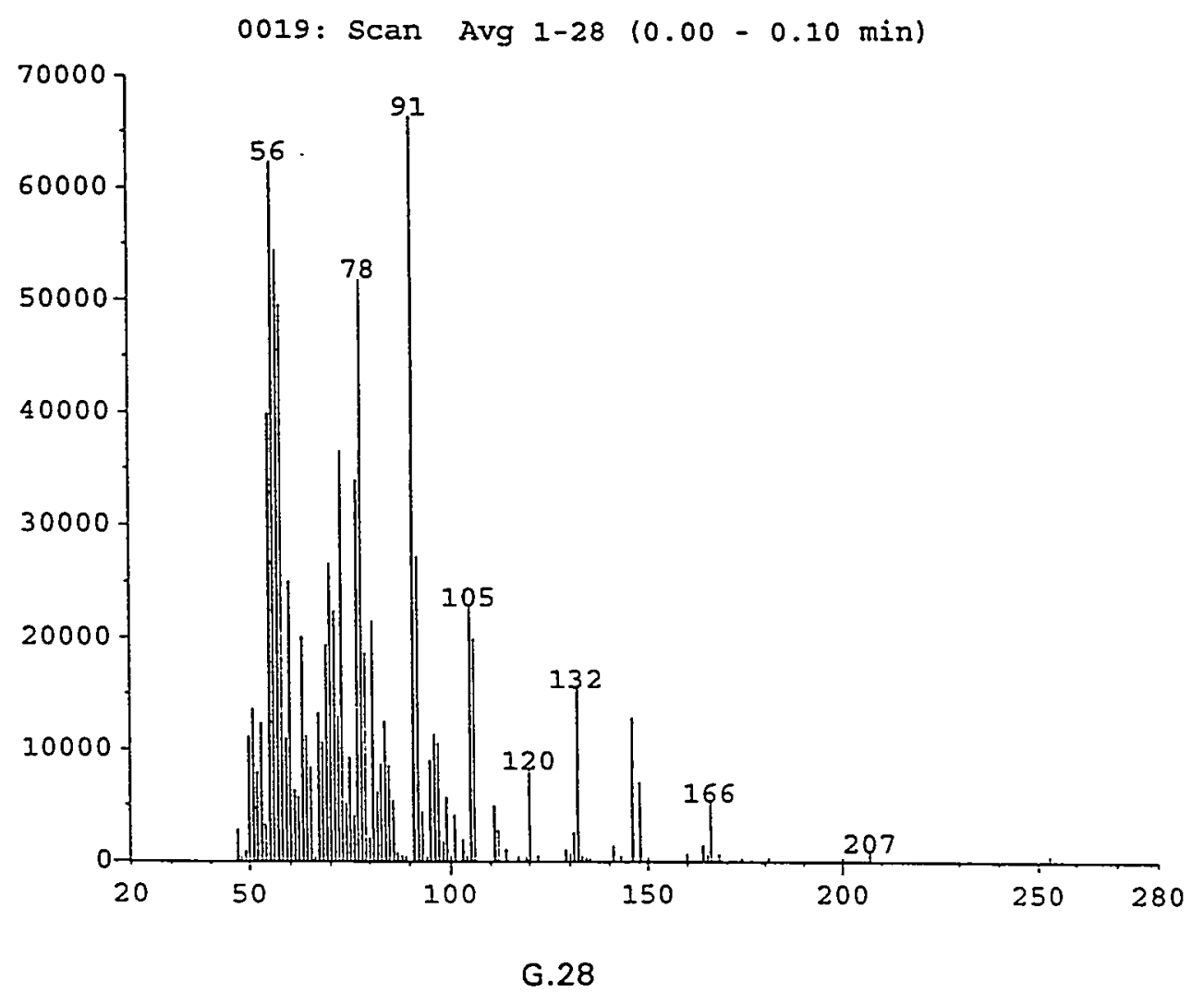


PlotData

Page: 1

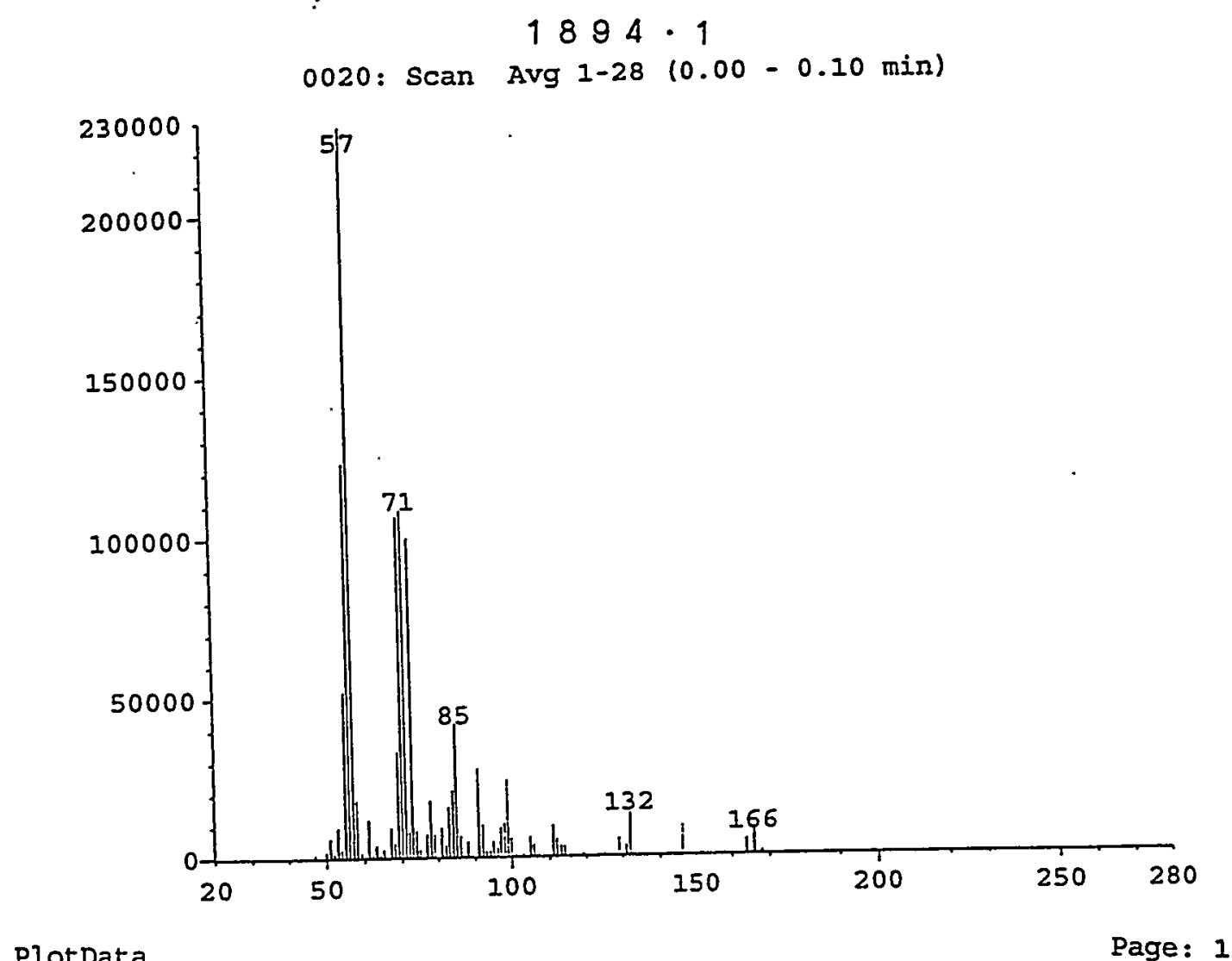

PlotData

Page: 1

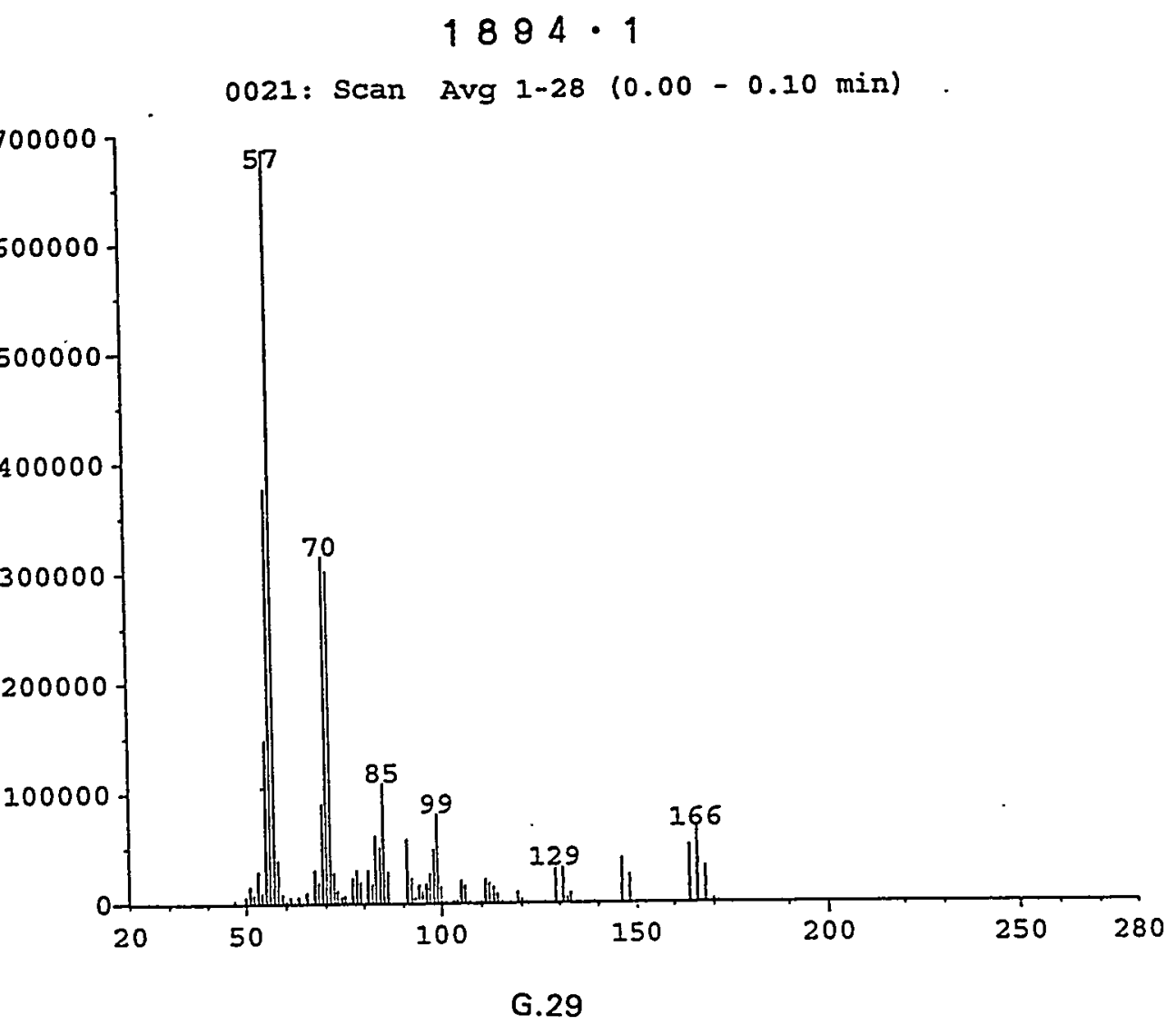


PlotData

$1894 \cdot 1$

0022: Scan Avg 1-28 (0.00-0.10 min)

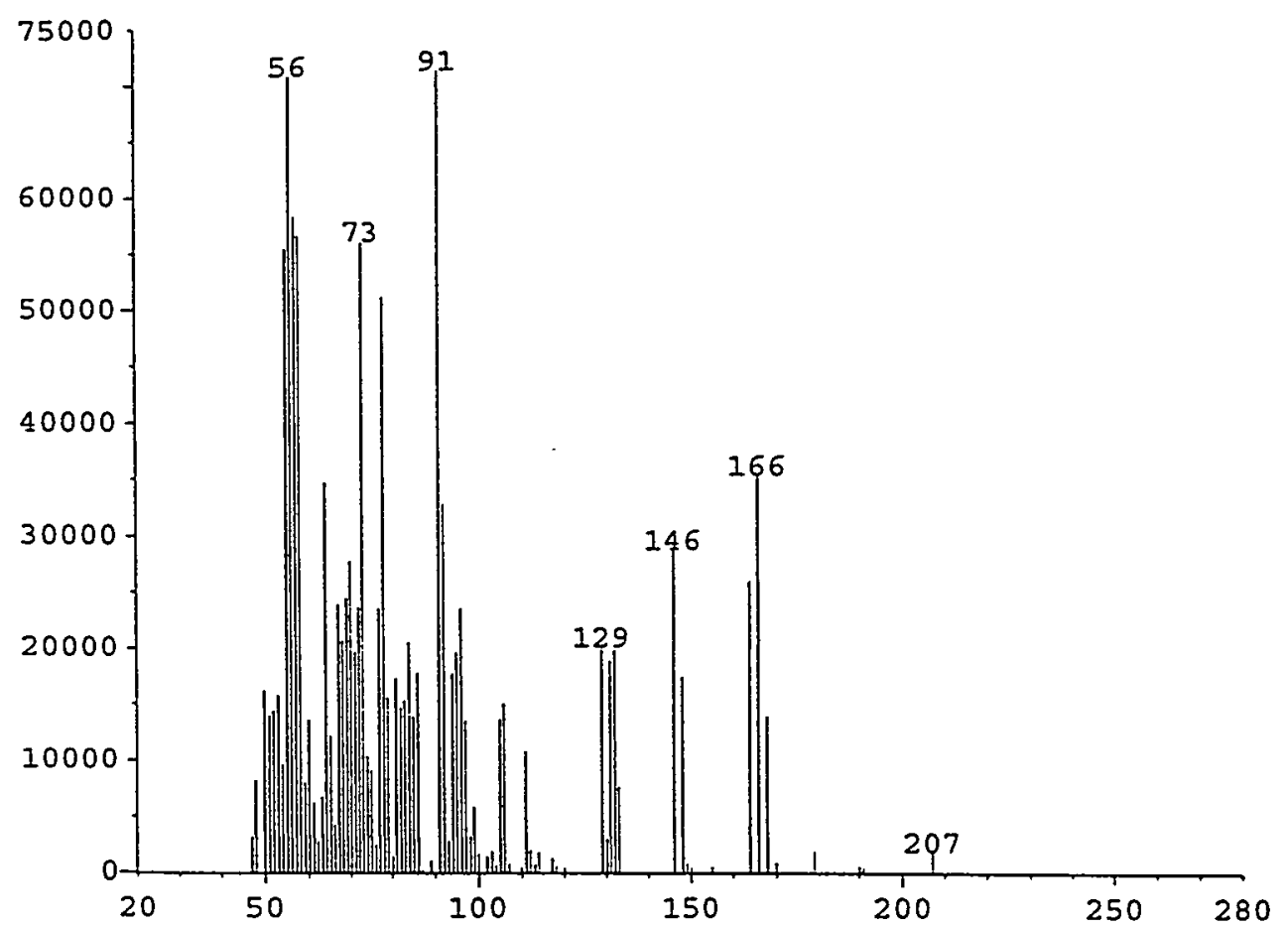

PlotData

$1884 \cdot 1$

0023 : Scan Avg 1.-28 (0.00 - $0.10 \mathrm{~min})$

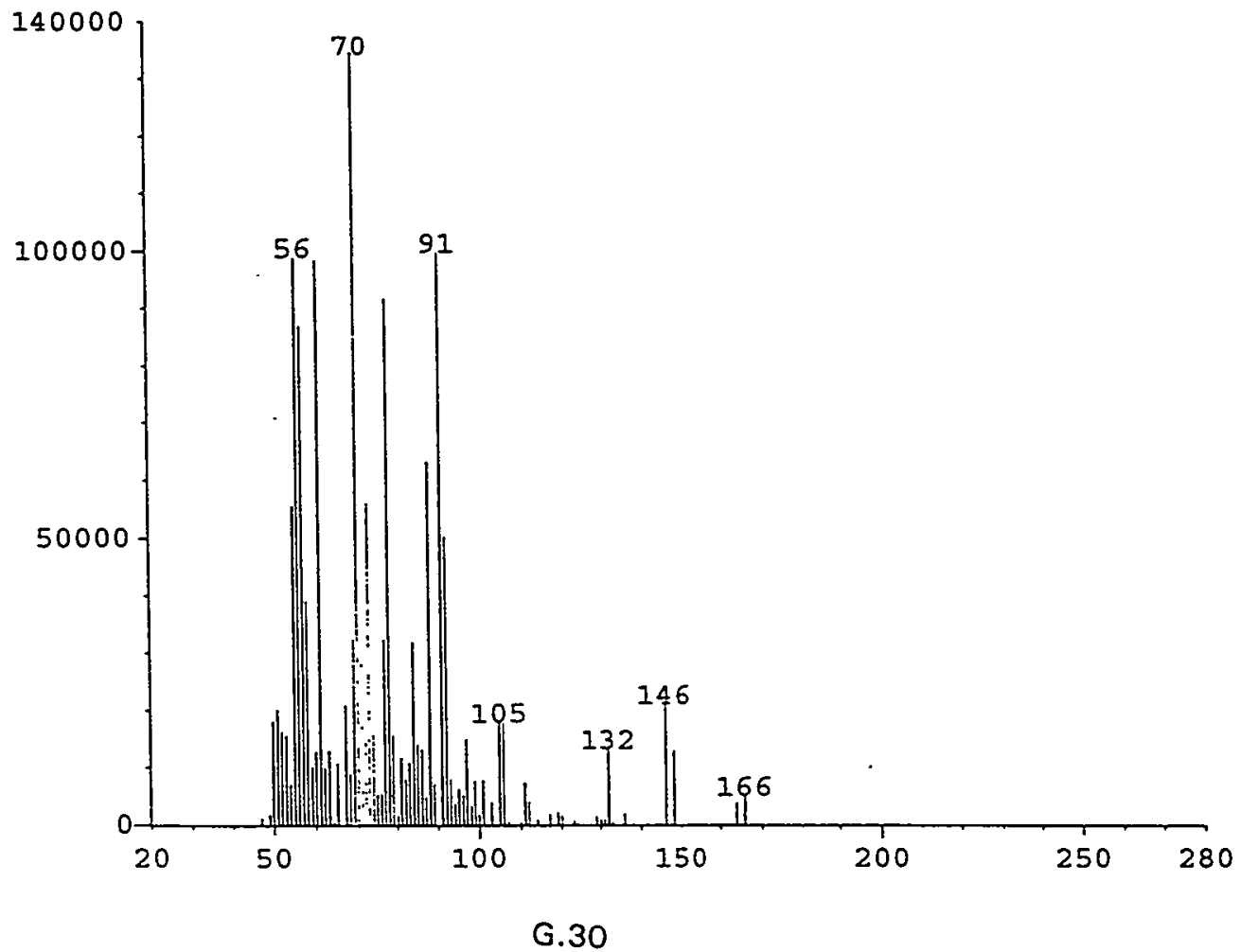


PlotData

$1894 \cdot 1$

Page: 1

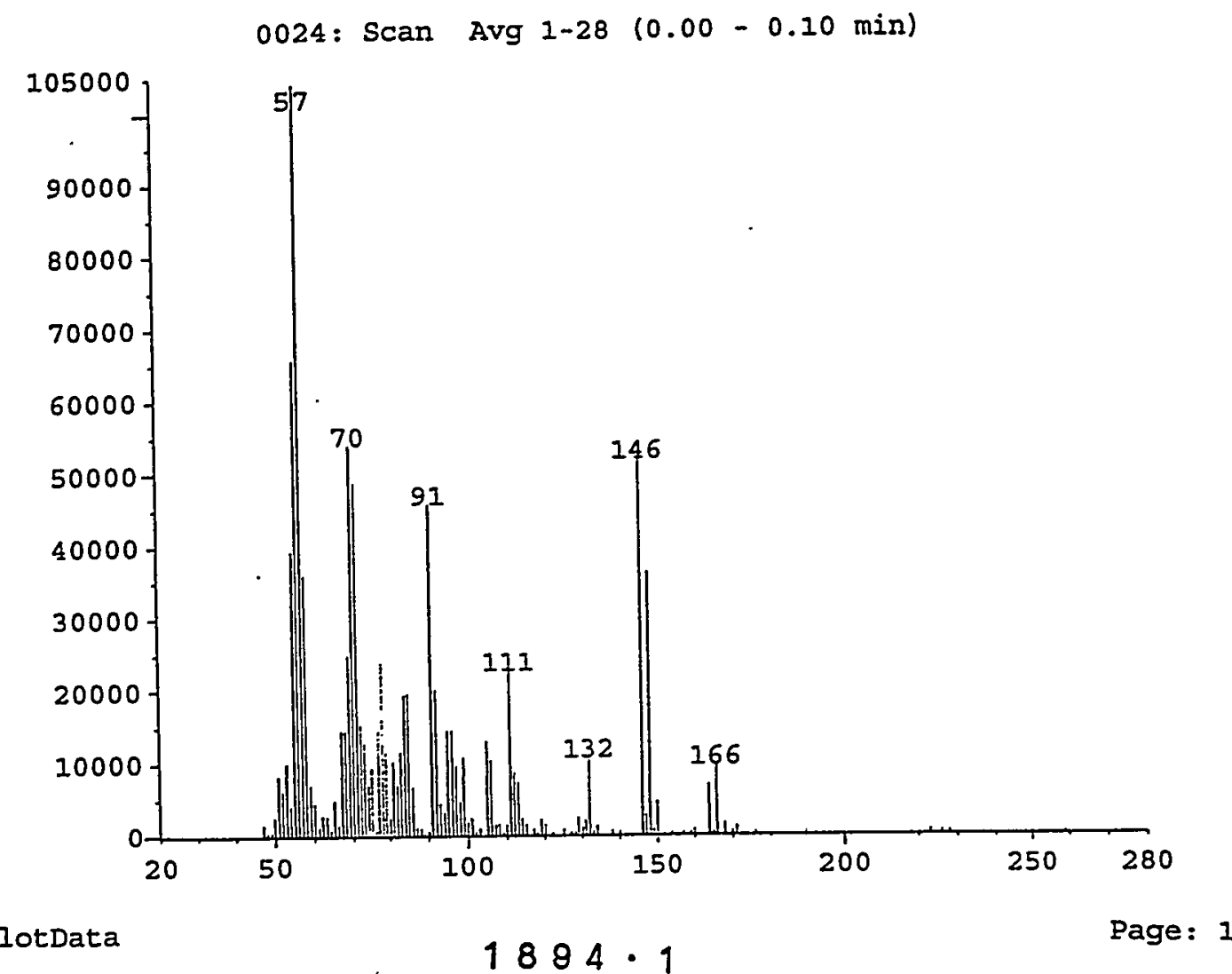

PlotData

$0025:$ Scan Avg 1-28 (0.00 $-0.10 \mathrm{~min})$

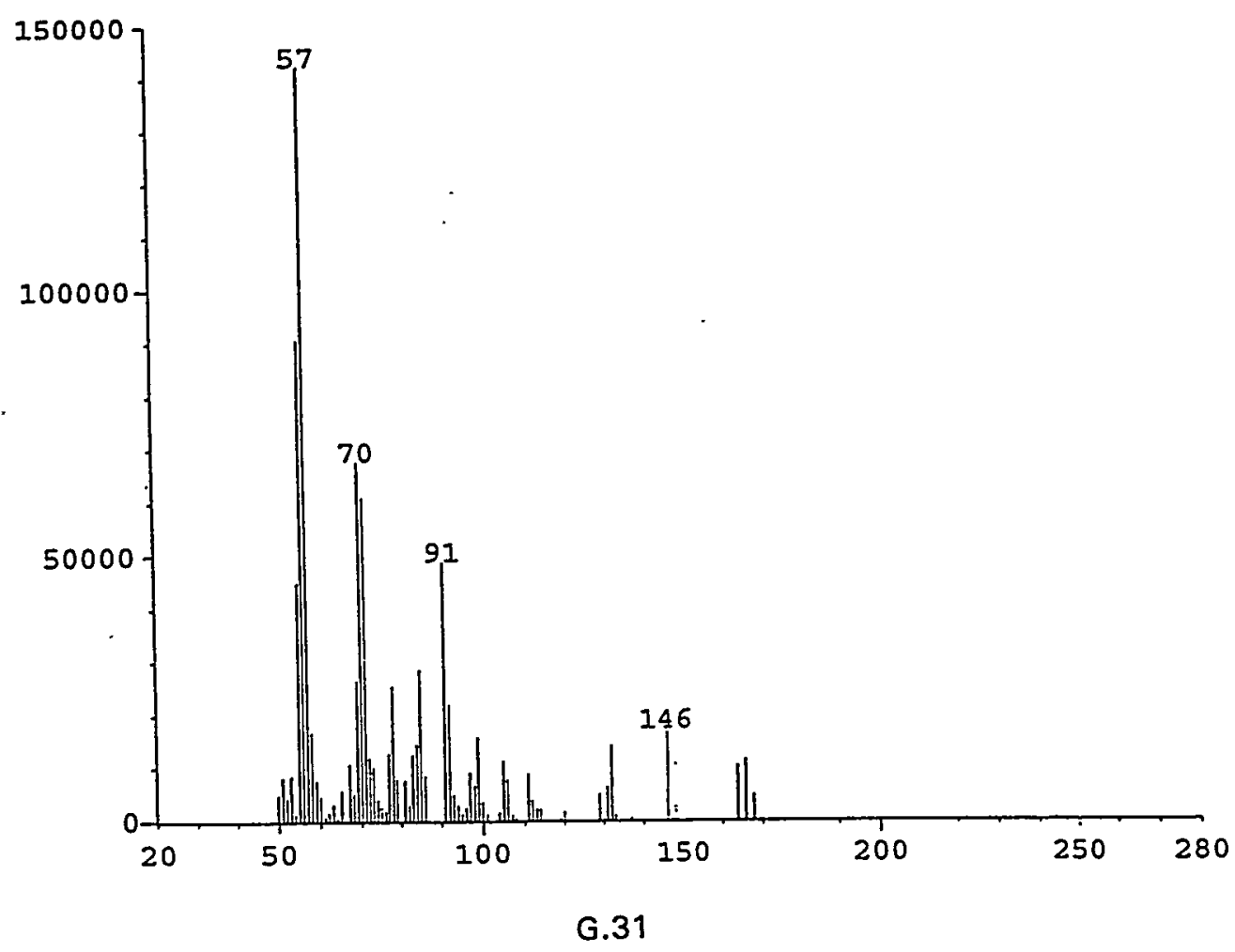


PlotData

$1894 \cdot 1$

Page: 1
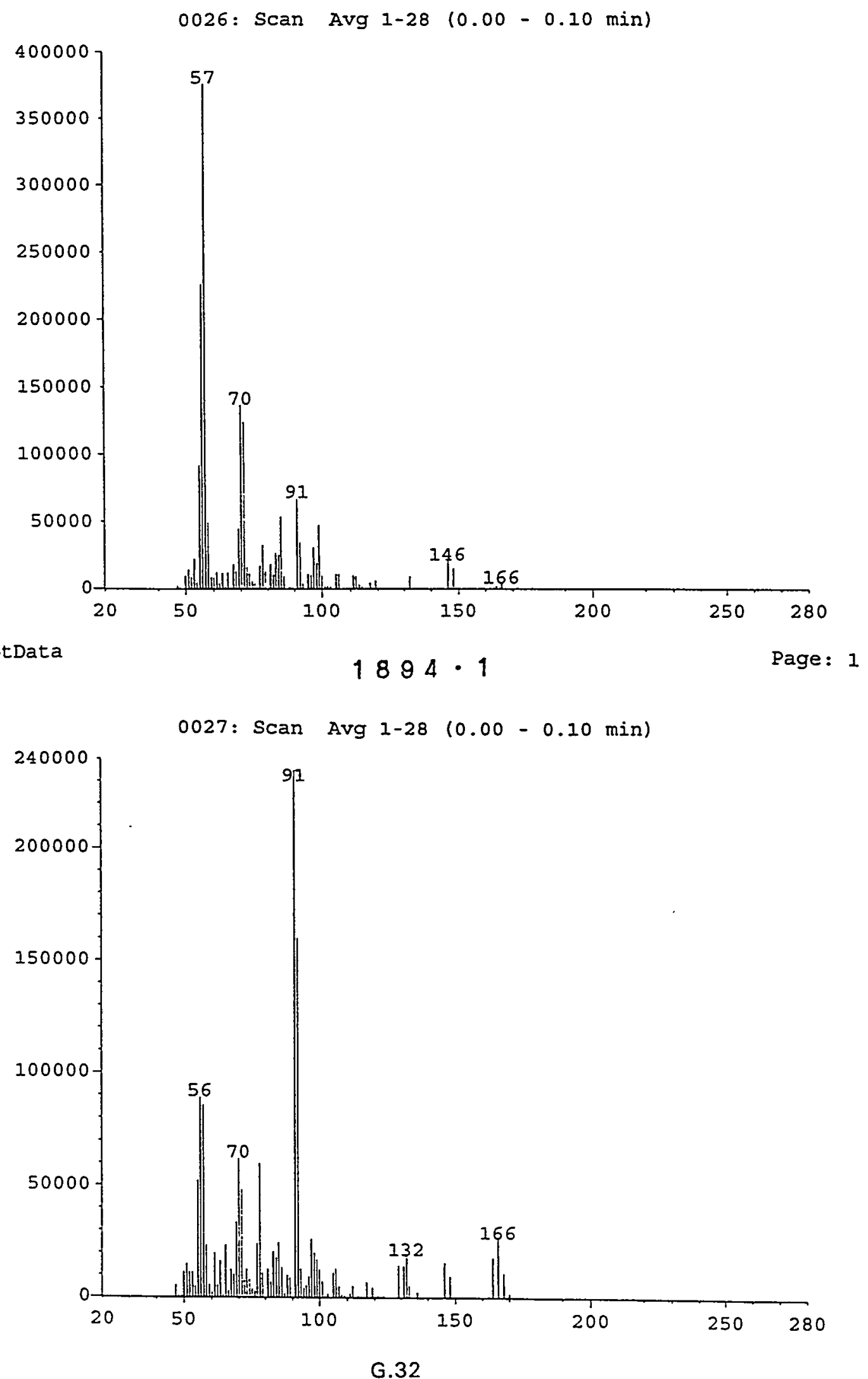
plotData

$1894 \cdot 1$

Page: 1

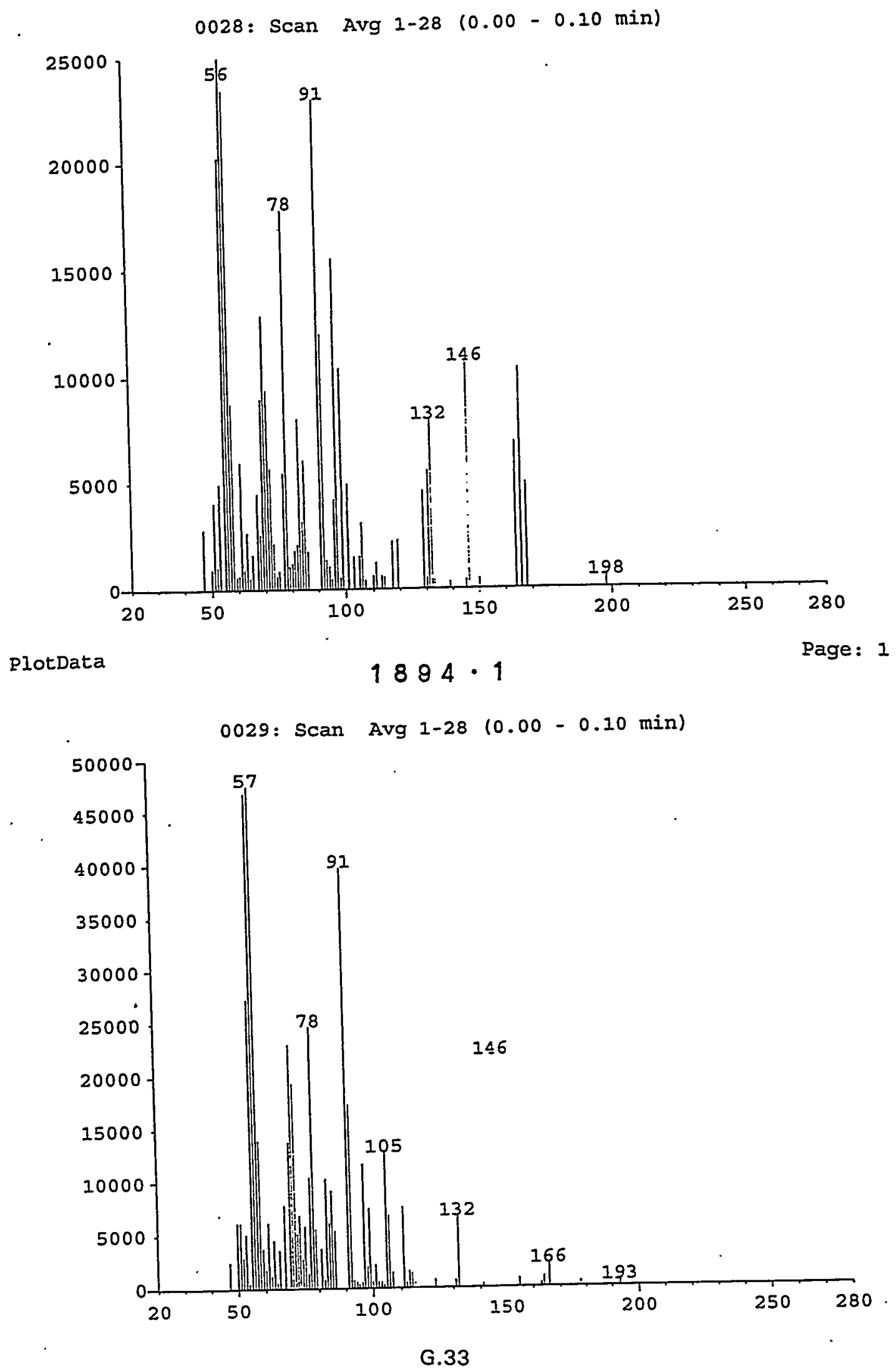


PlotData

$1894 \cdot 1$

Page: 1

$0030:$ Scan Avg 1-28 (0.00-0.10 min)

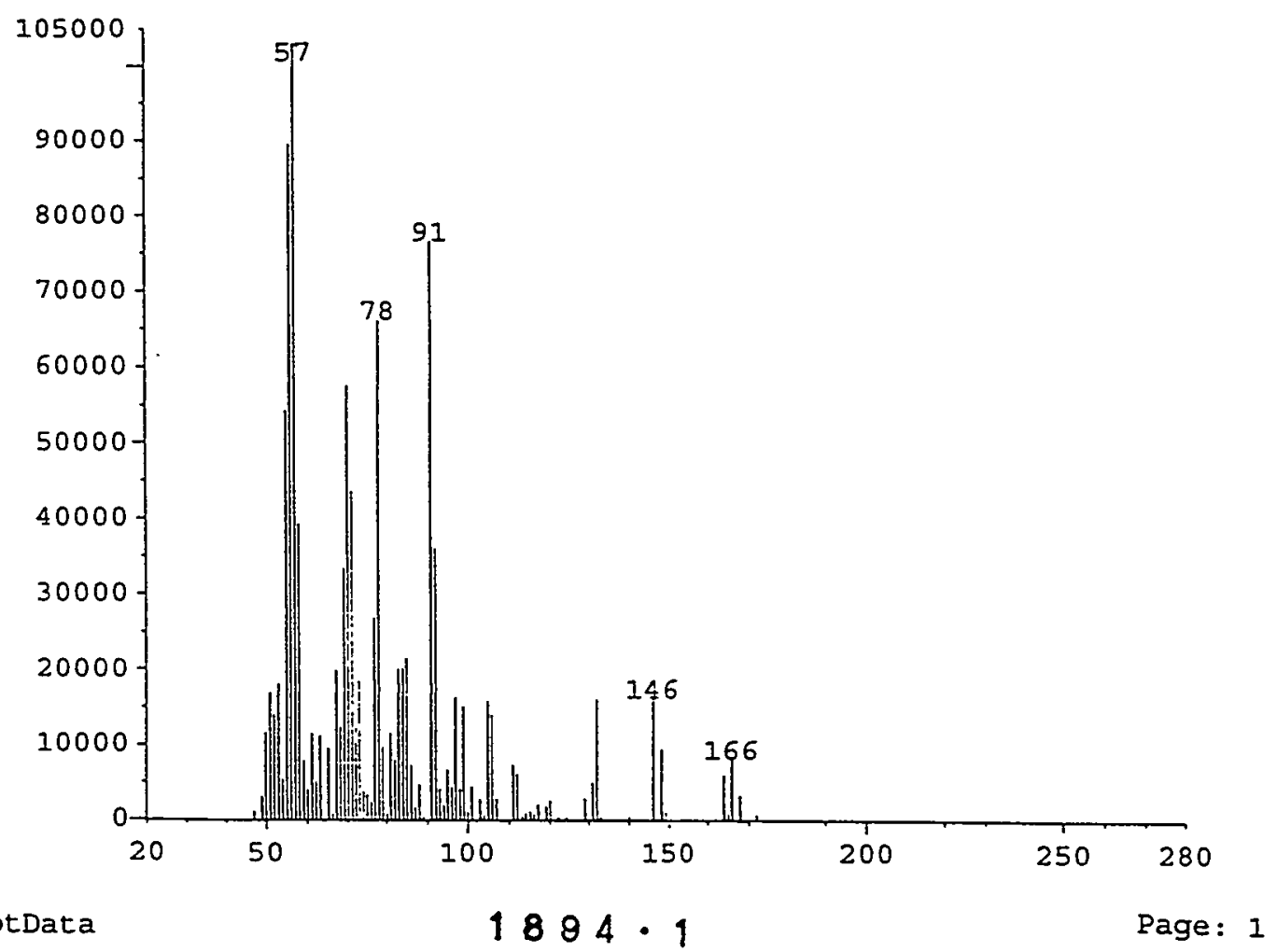

0031: Scan Avg 1-28 (0.00-0.10 min)

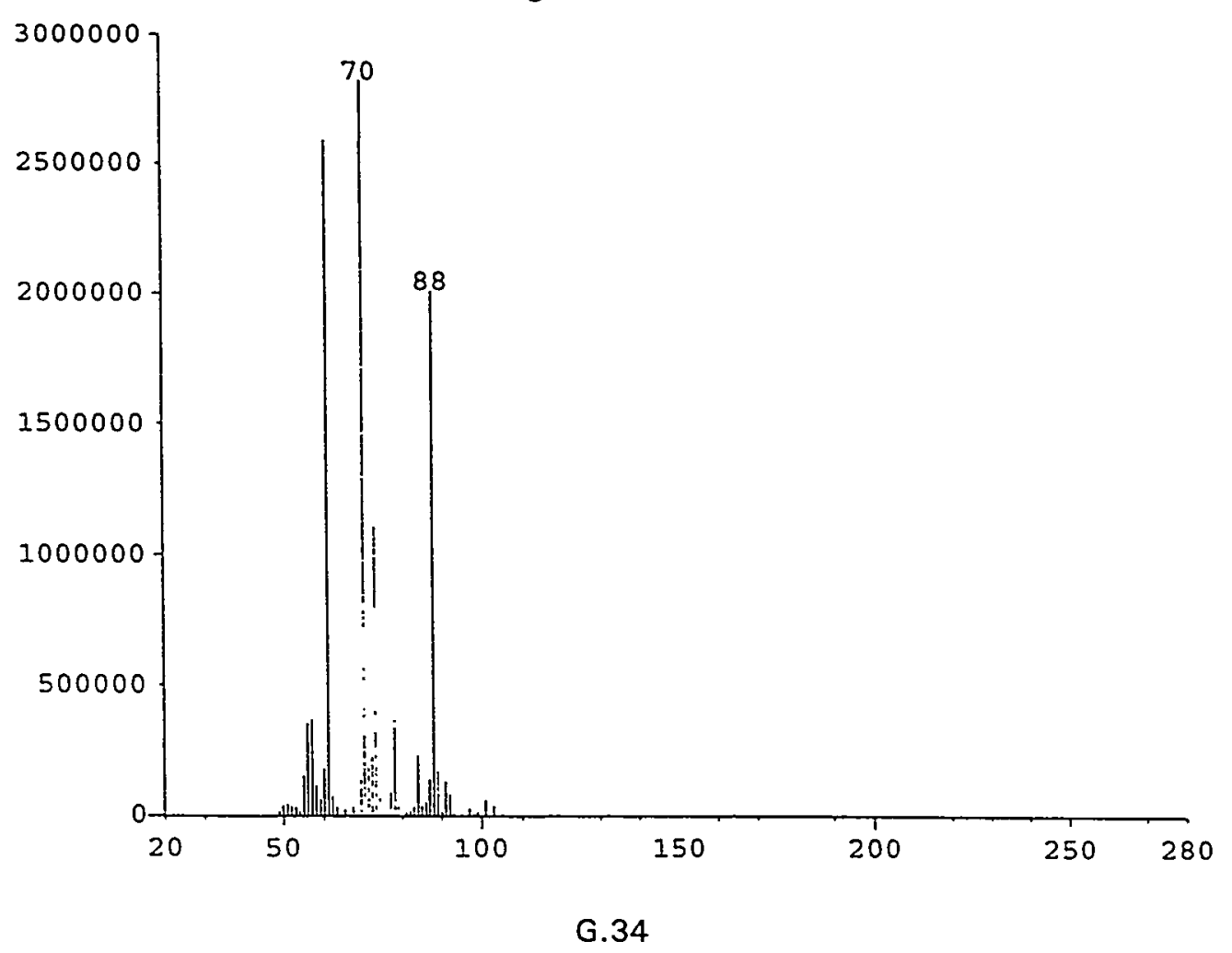


PlotData

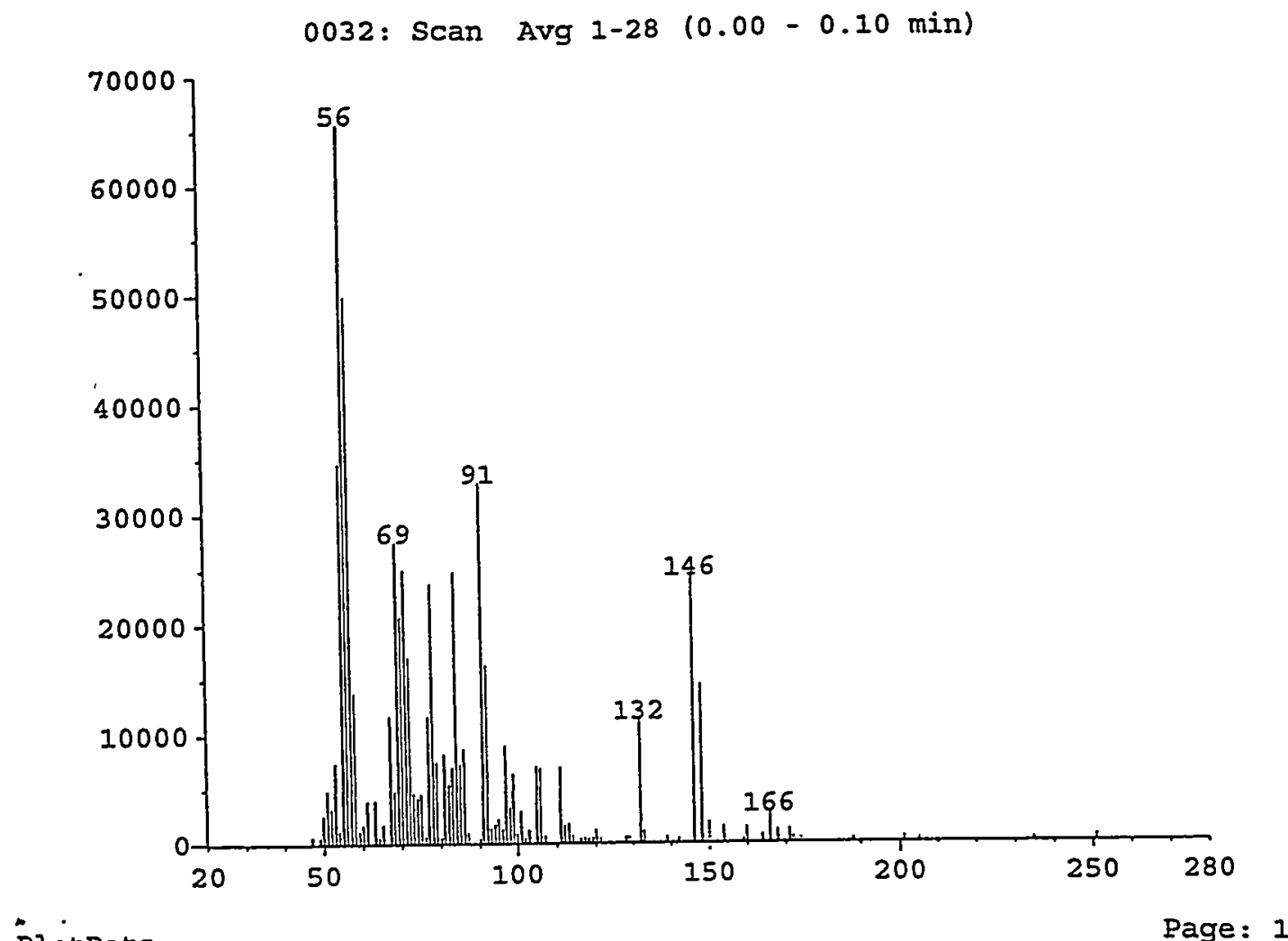

Page: 1
$1894 \cdot 1$

Page: 1

PlotData

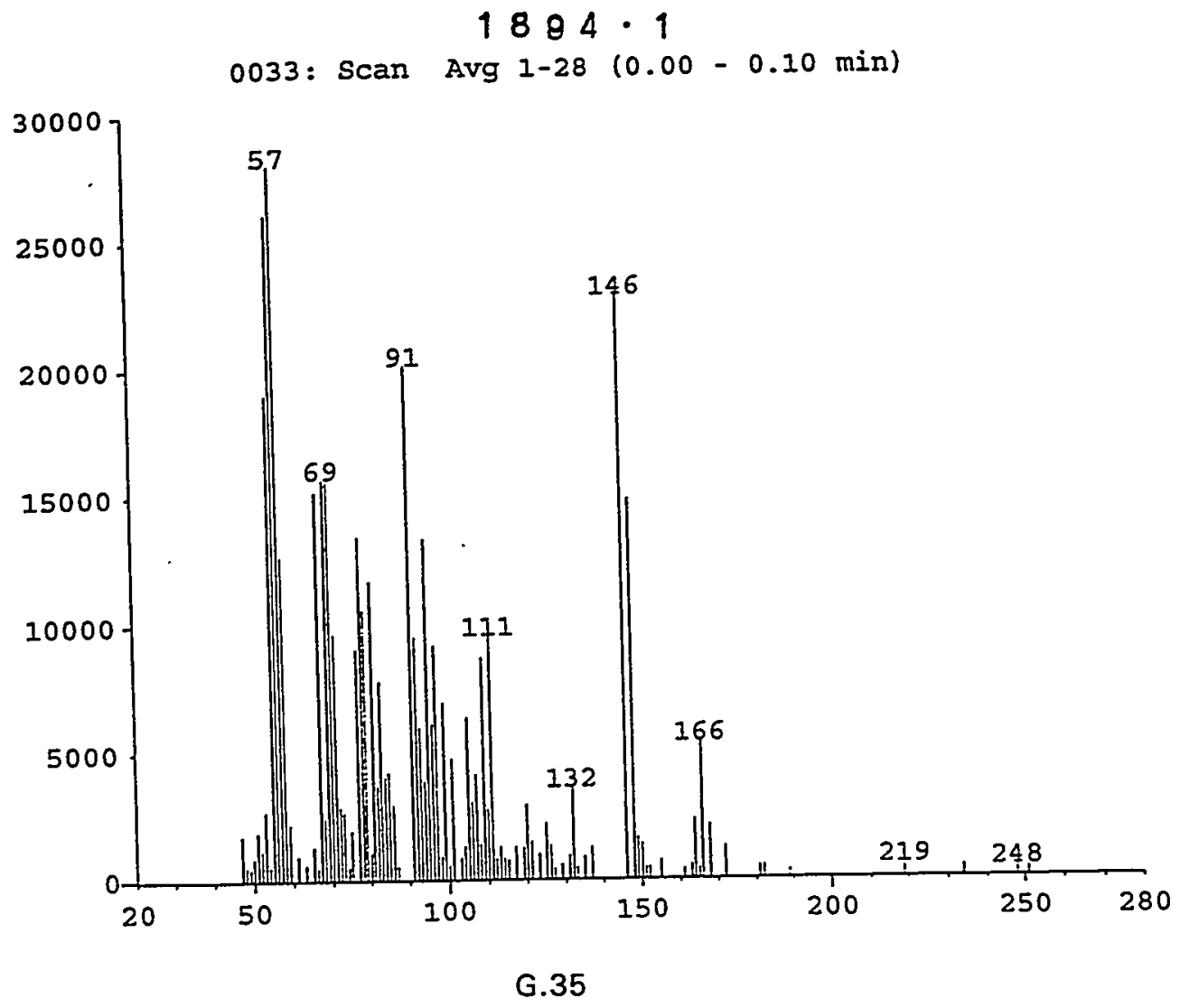


PlotData

$1894 \cdot 1$

Page: 1

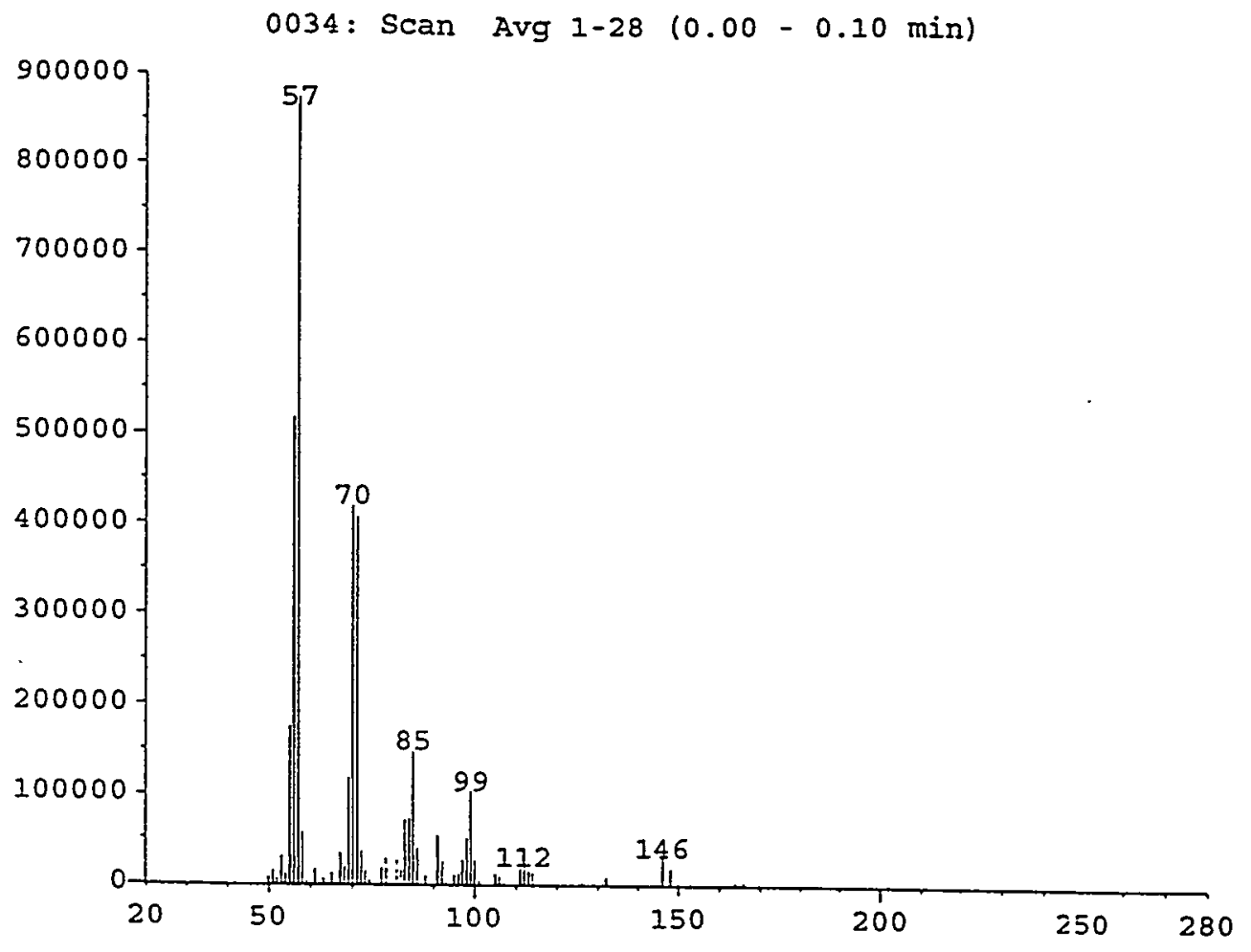

PlotData

$1894 \cdot 1$

Page: 1

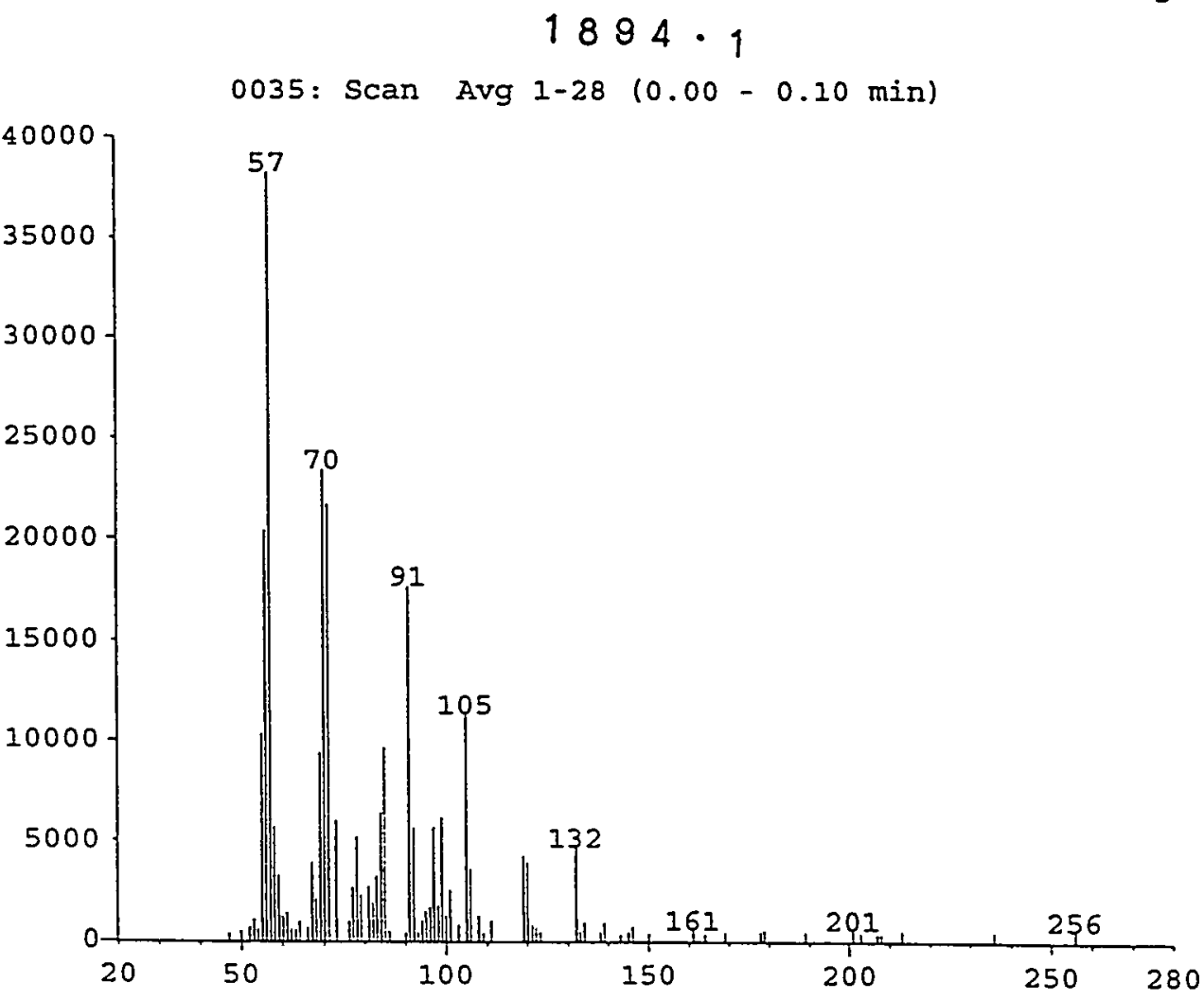

G.36 
PlotData

$1894 \cdot 1$

Page: 1

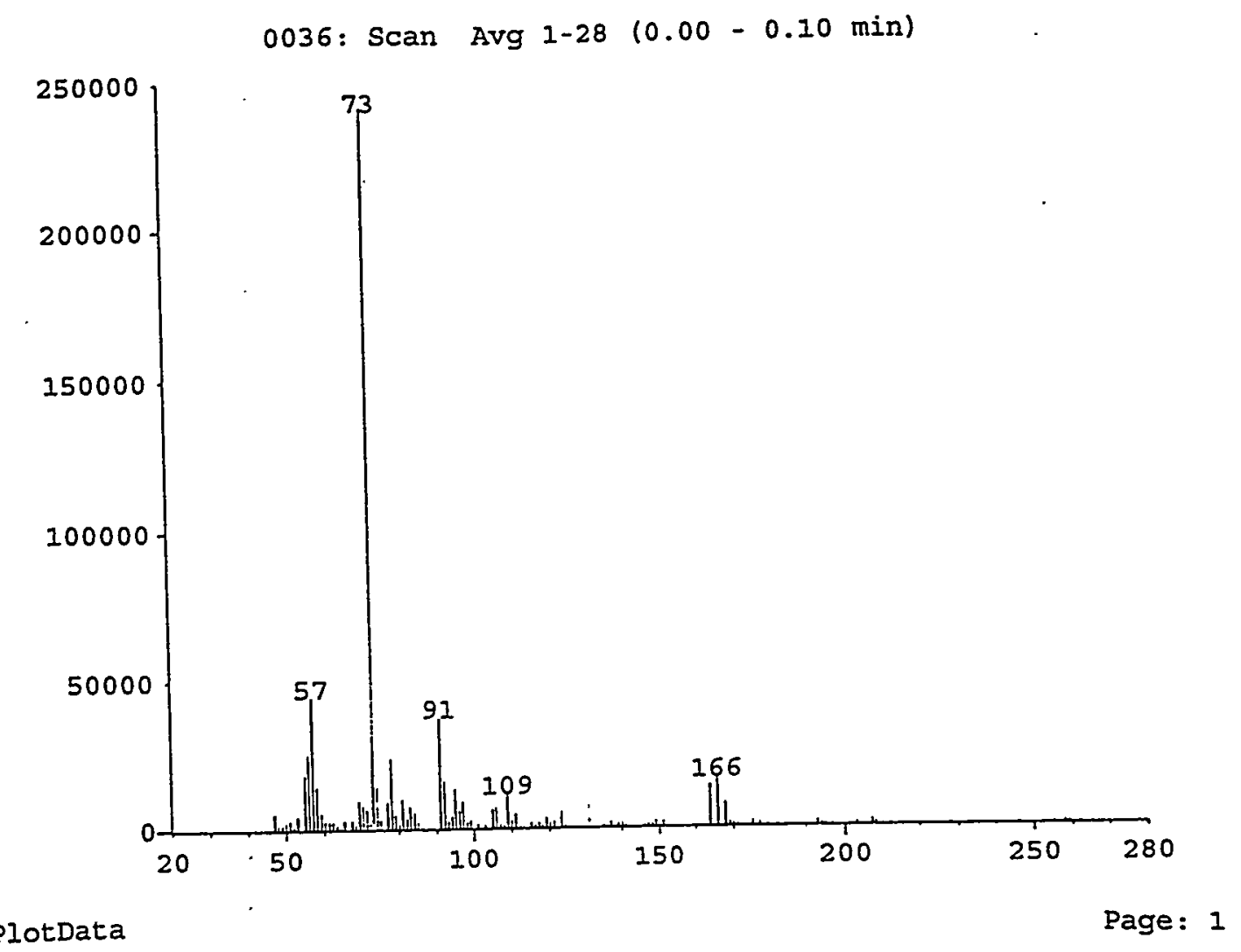

PlotData

$1894 \cdot 1$

0037: Scan Avg 1-28 (0.00-0.10 min)

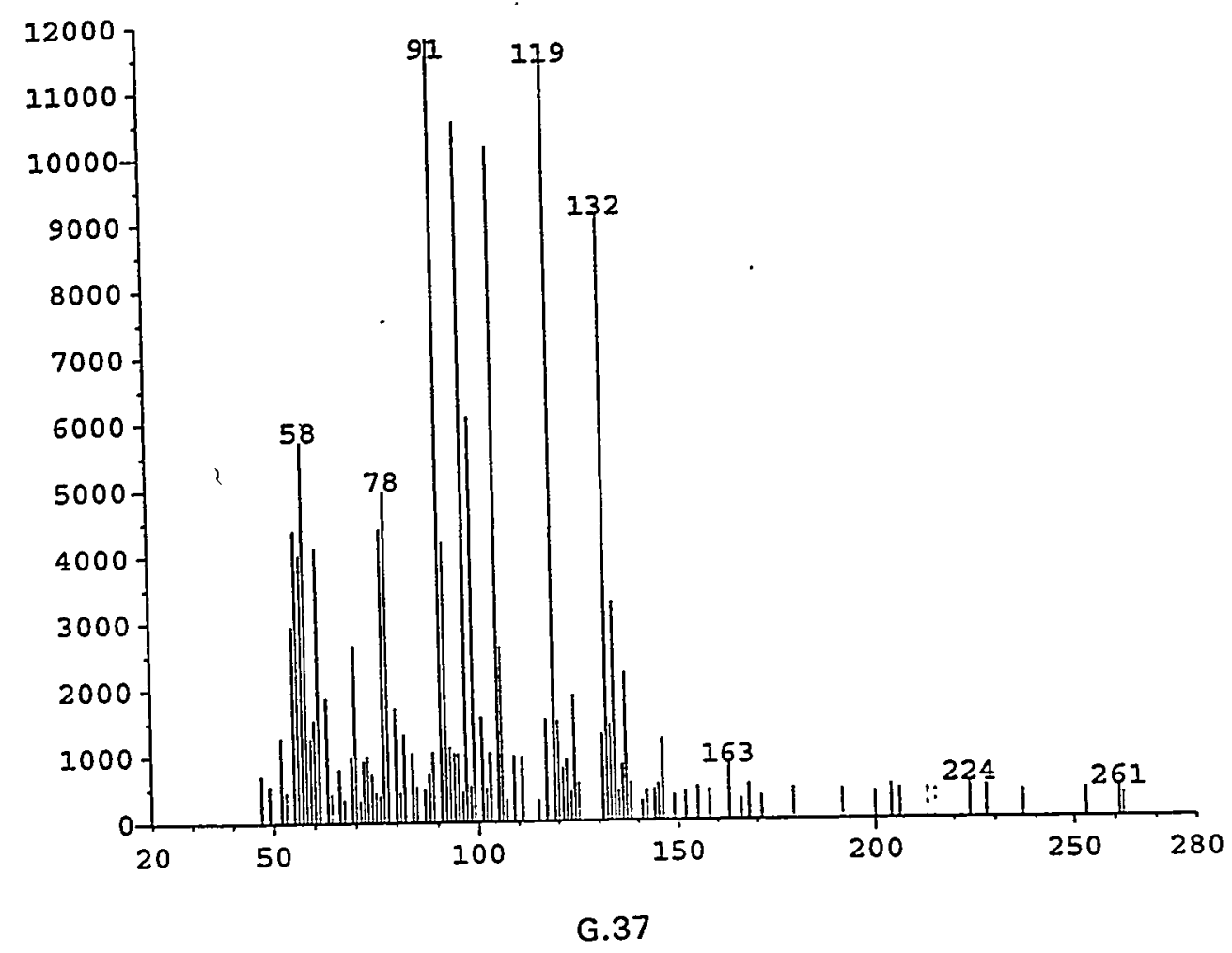


PlotData

Page : 7

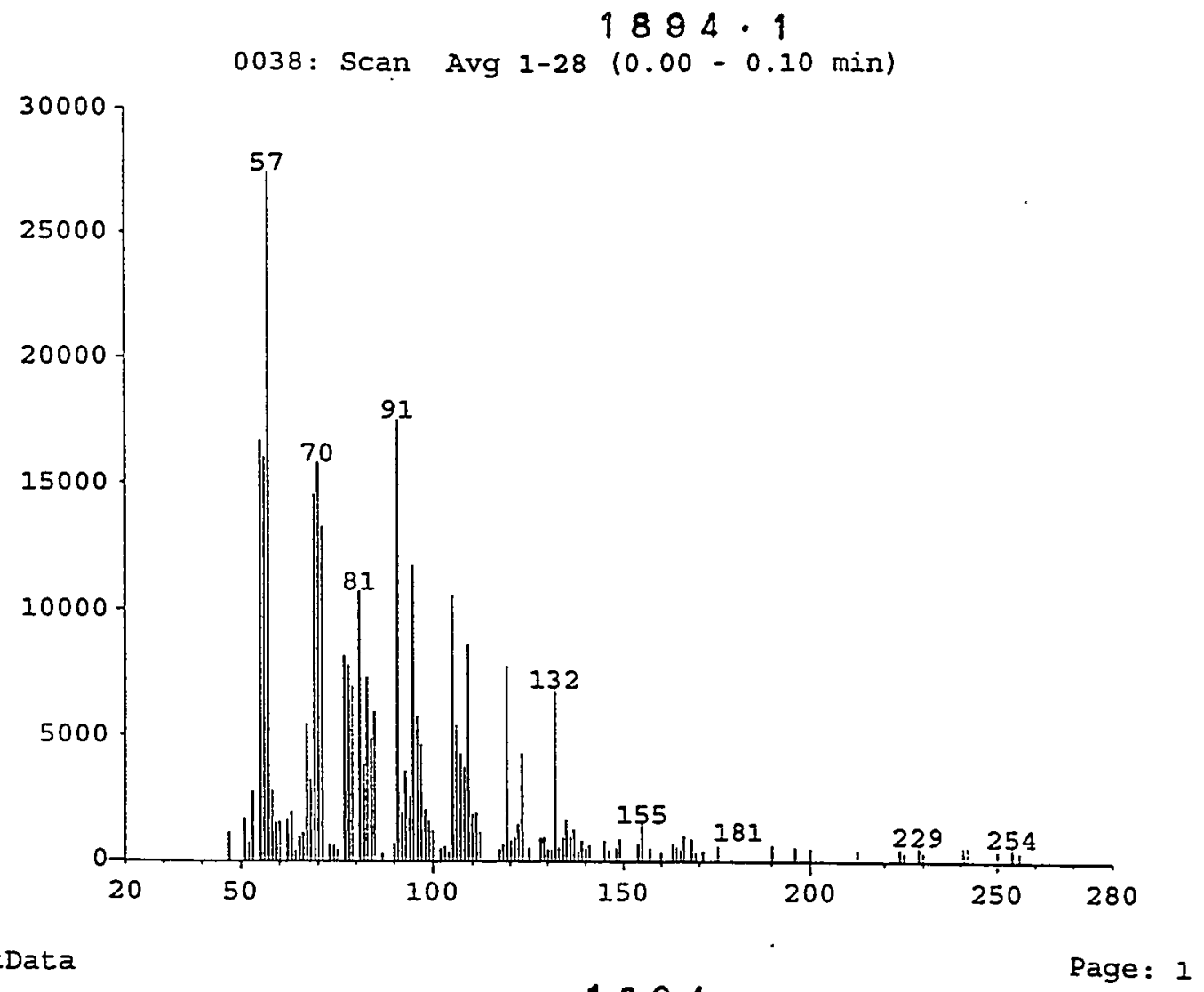

PlotData

$1884 \cdot 1$

0039: Scan Avg 1-28 (0.00 - 0.10 min)

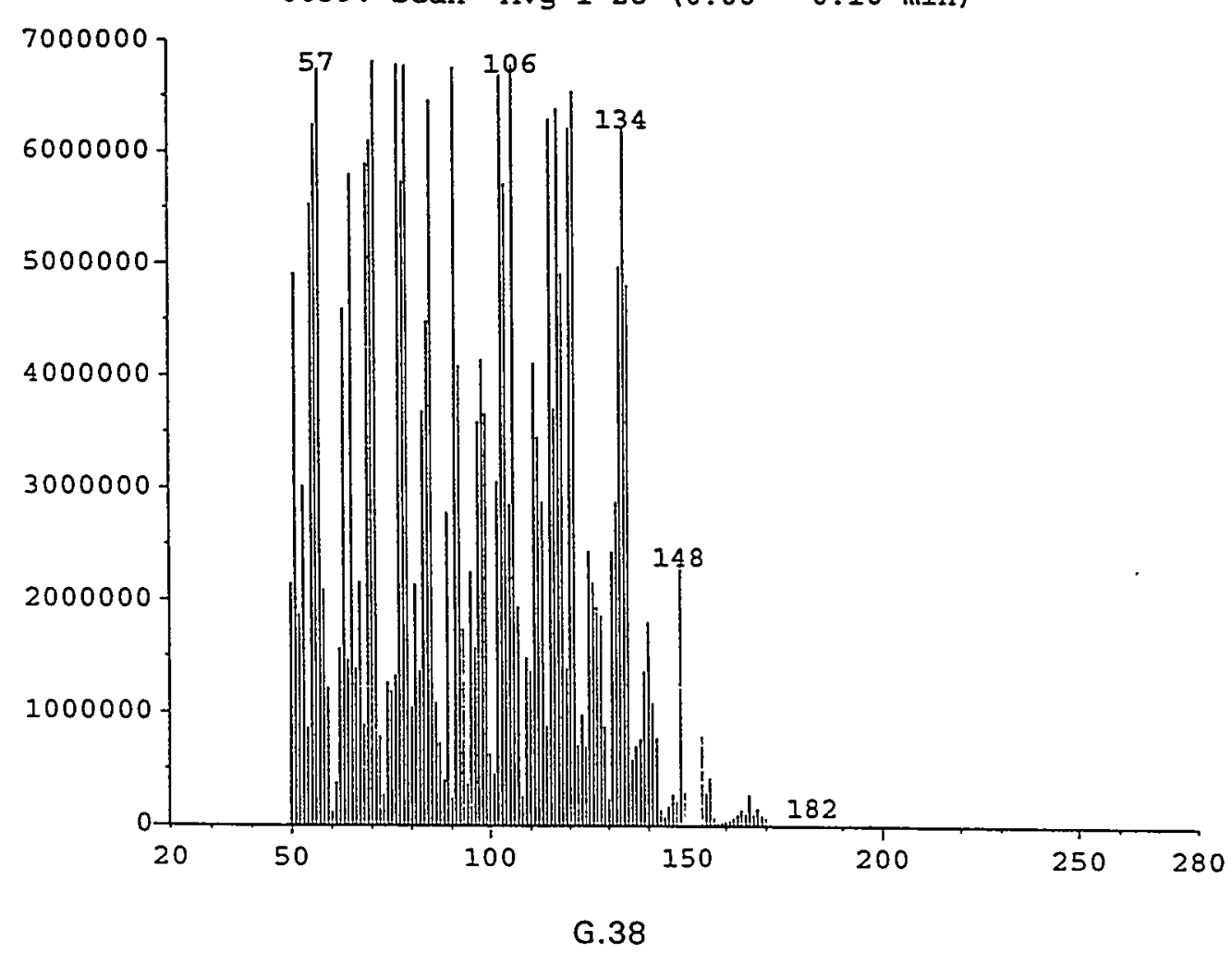


PlotData

$1894 \cdot 1$

$0040:$ Scan Avg 1-28 (0.00-0.10 min)

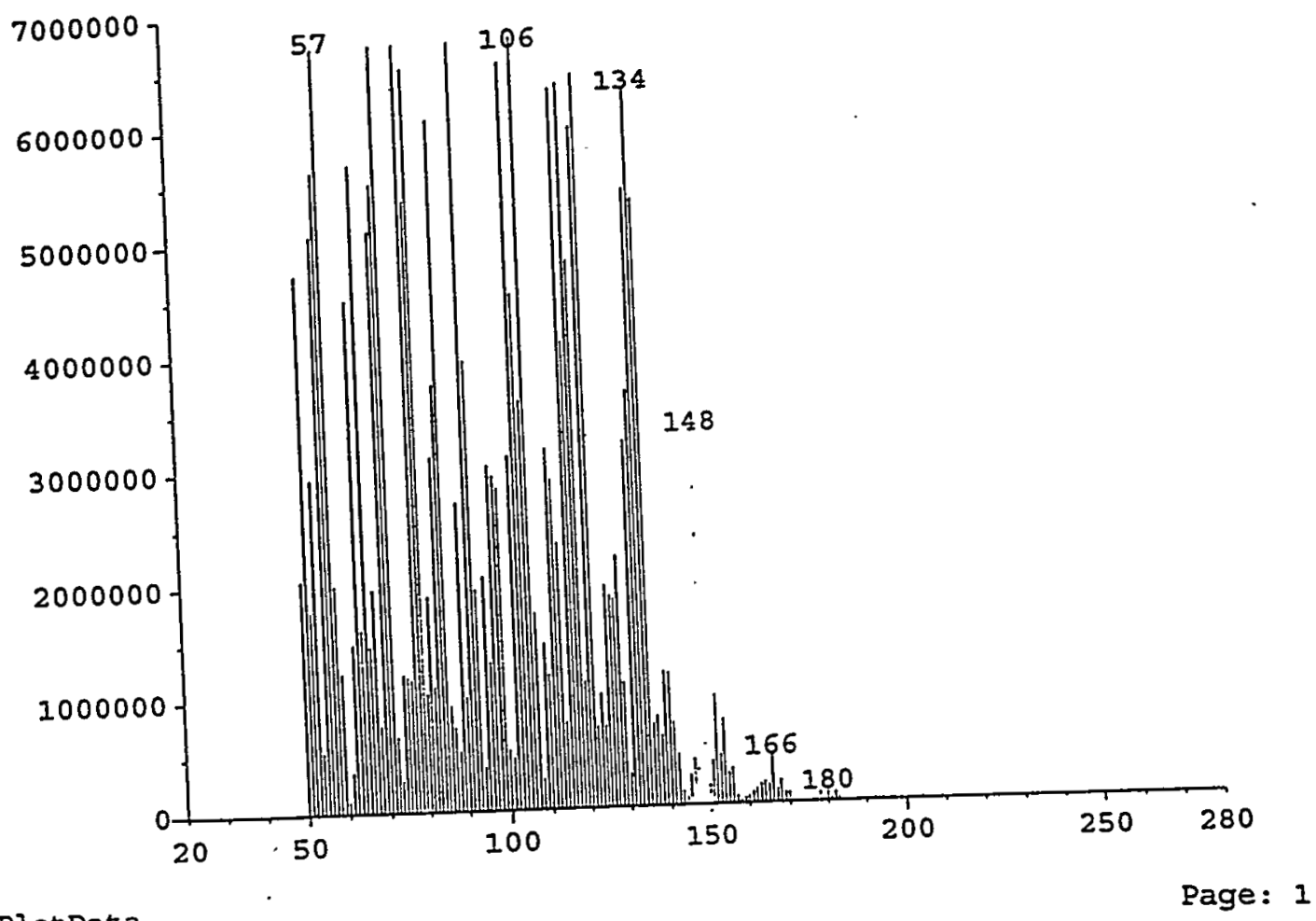

PlotData

$1884 \cdot 1$

0041: Scan Avg 1-28 (0.00-0.10 min)

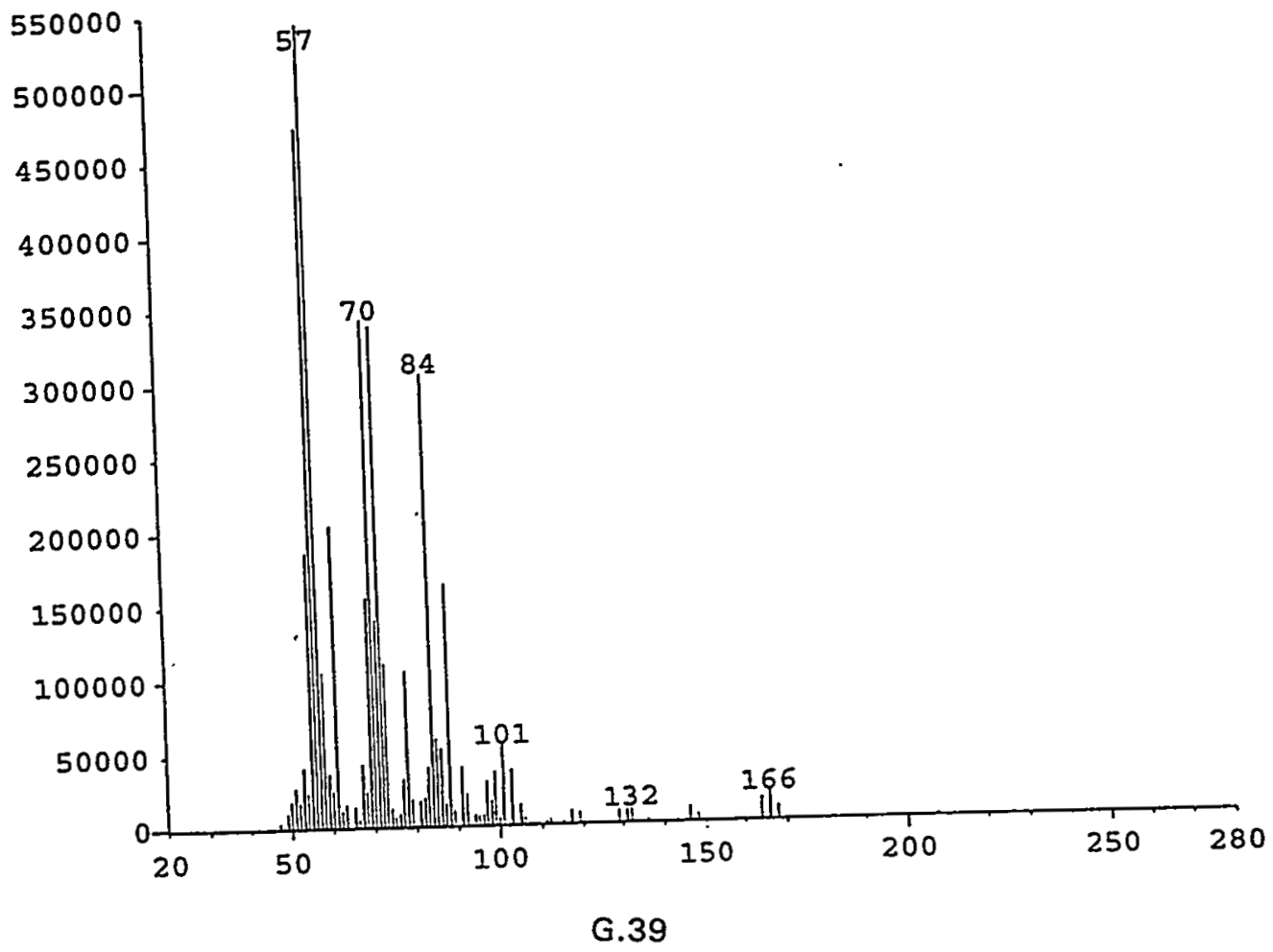




$$
1894 \cdot 1
$$

$0042:$ Scan Avg 1-28 (0.00-0.10 min)

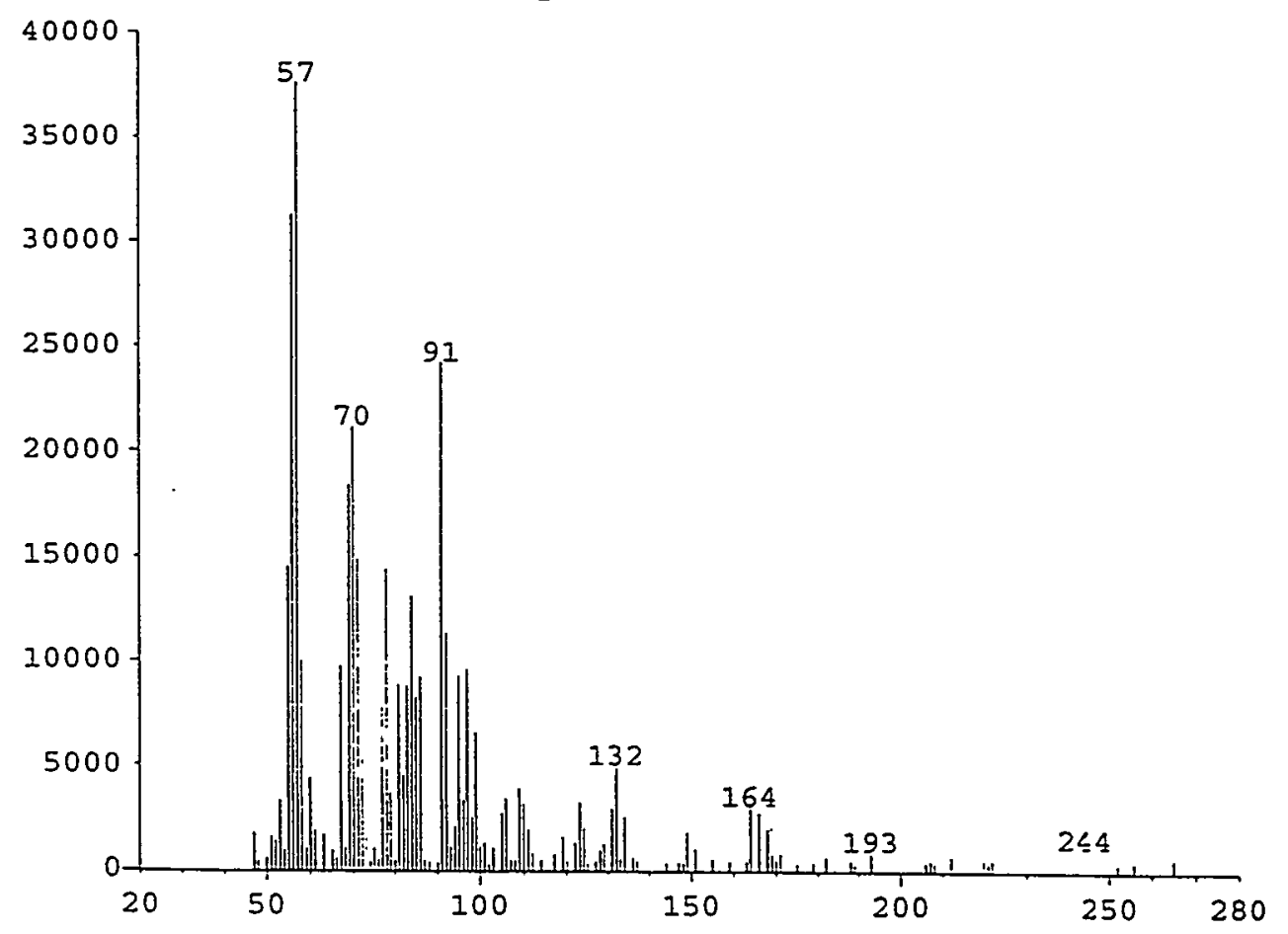

PlotData

$1894 \cdot 1$

Page: 1

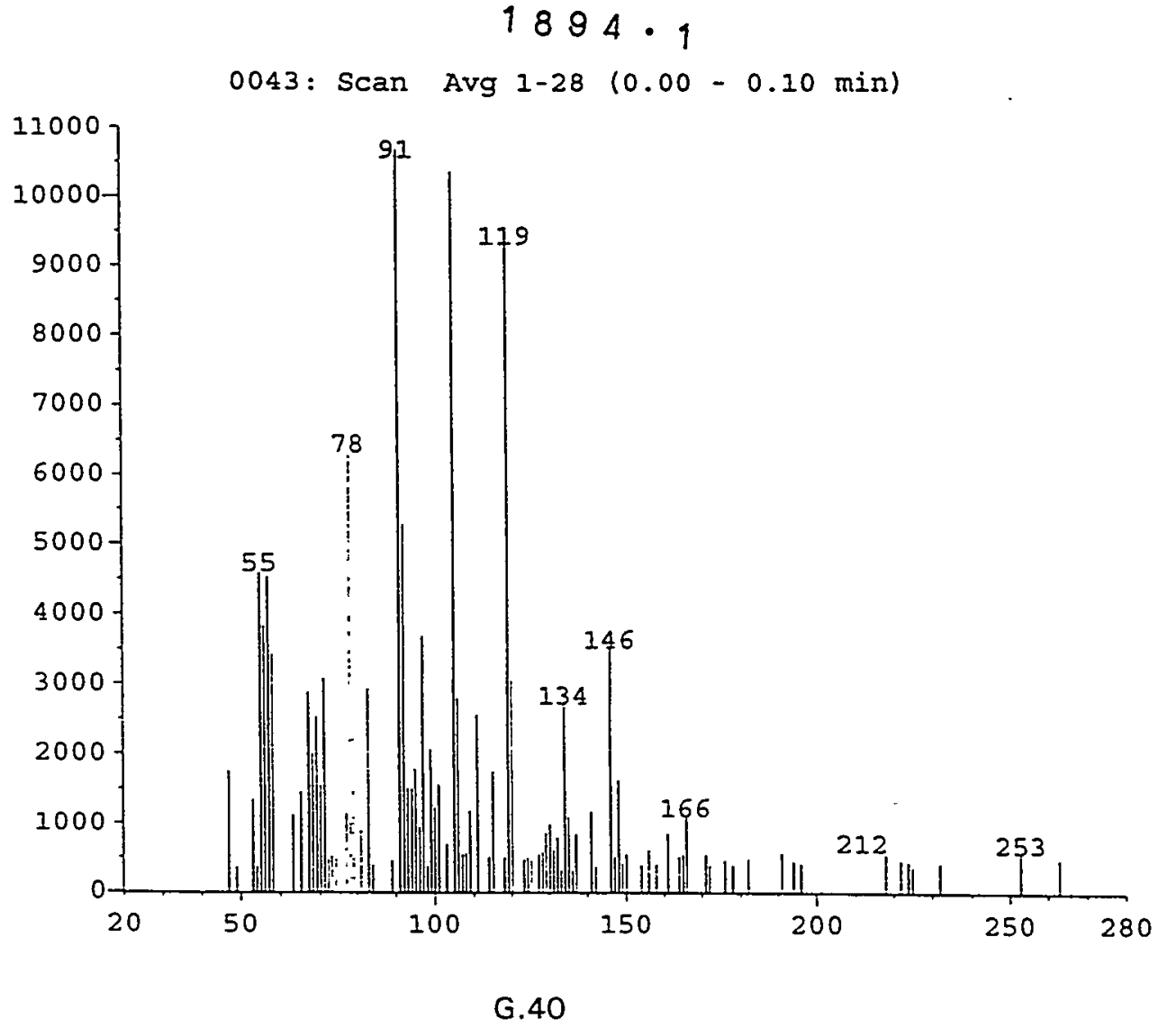




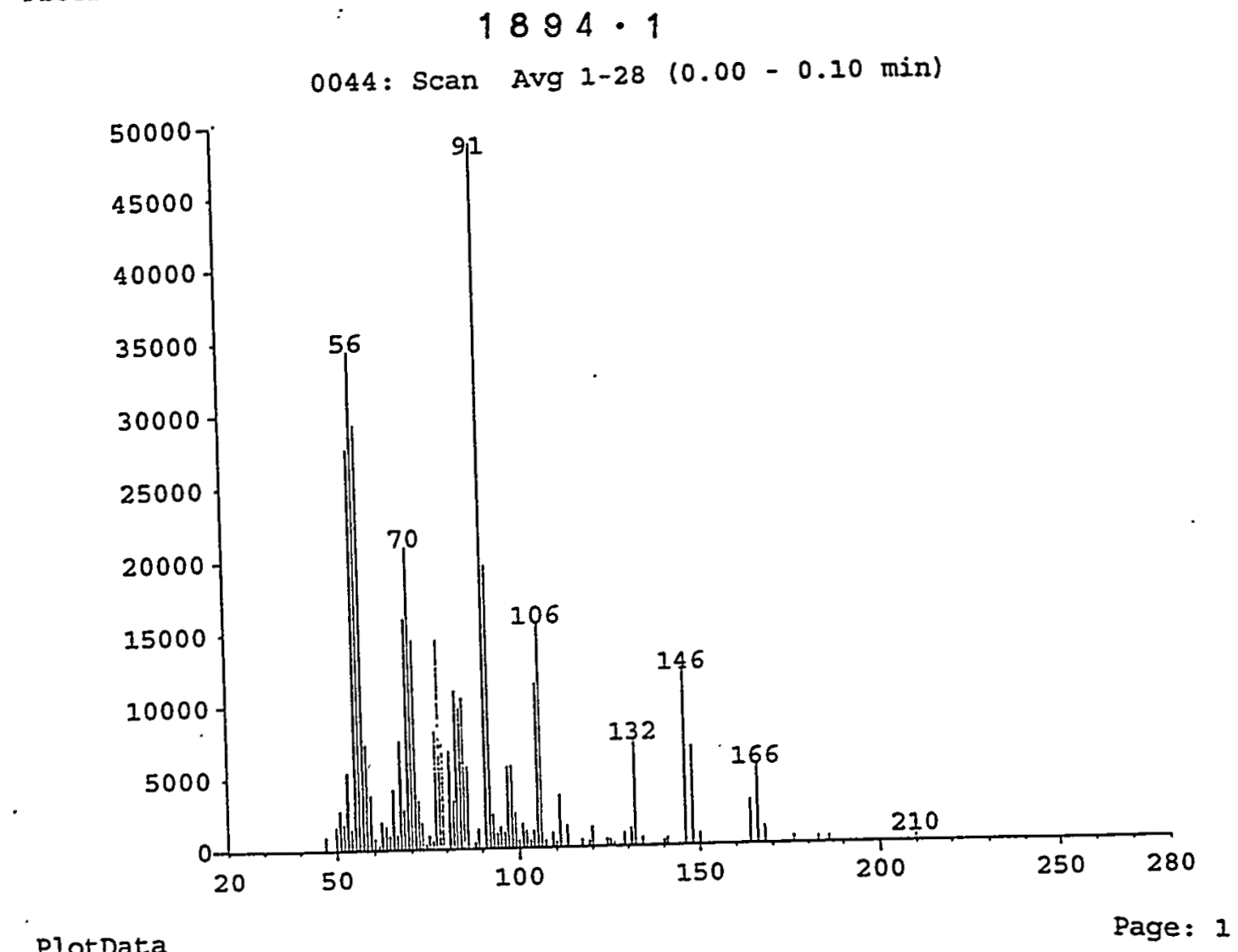

PlotData

$1894 \cdot 1$

0045: Scan Avg 1-28 (0.00-0.10 min)

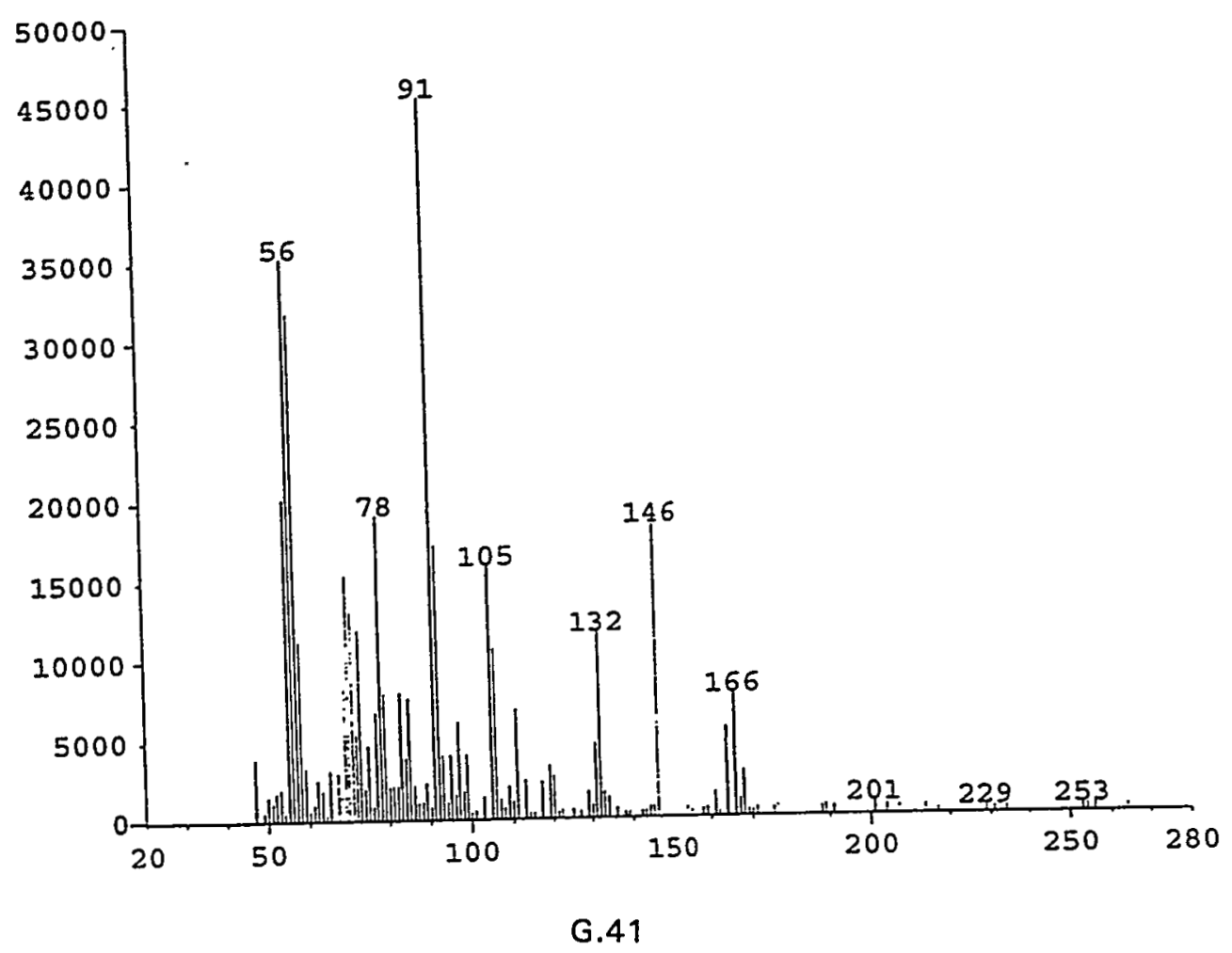



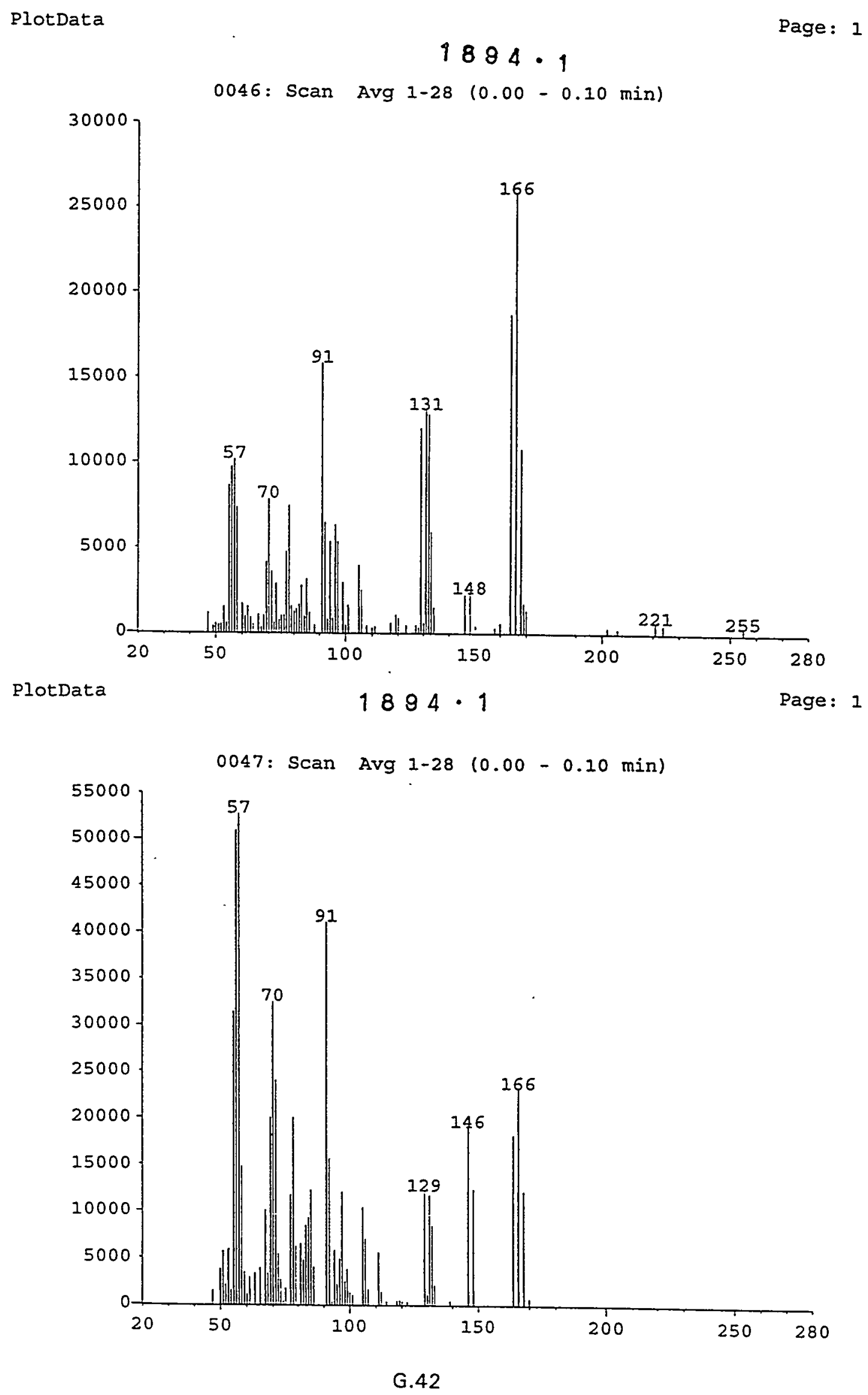

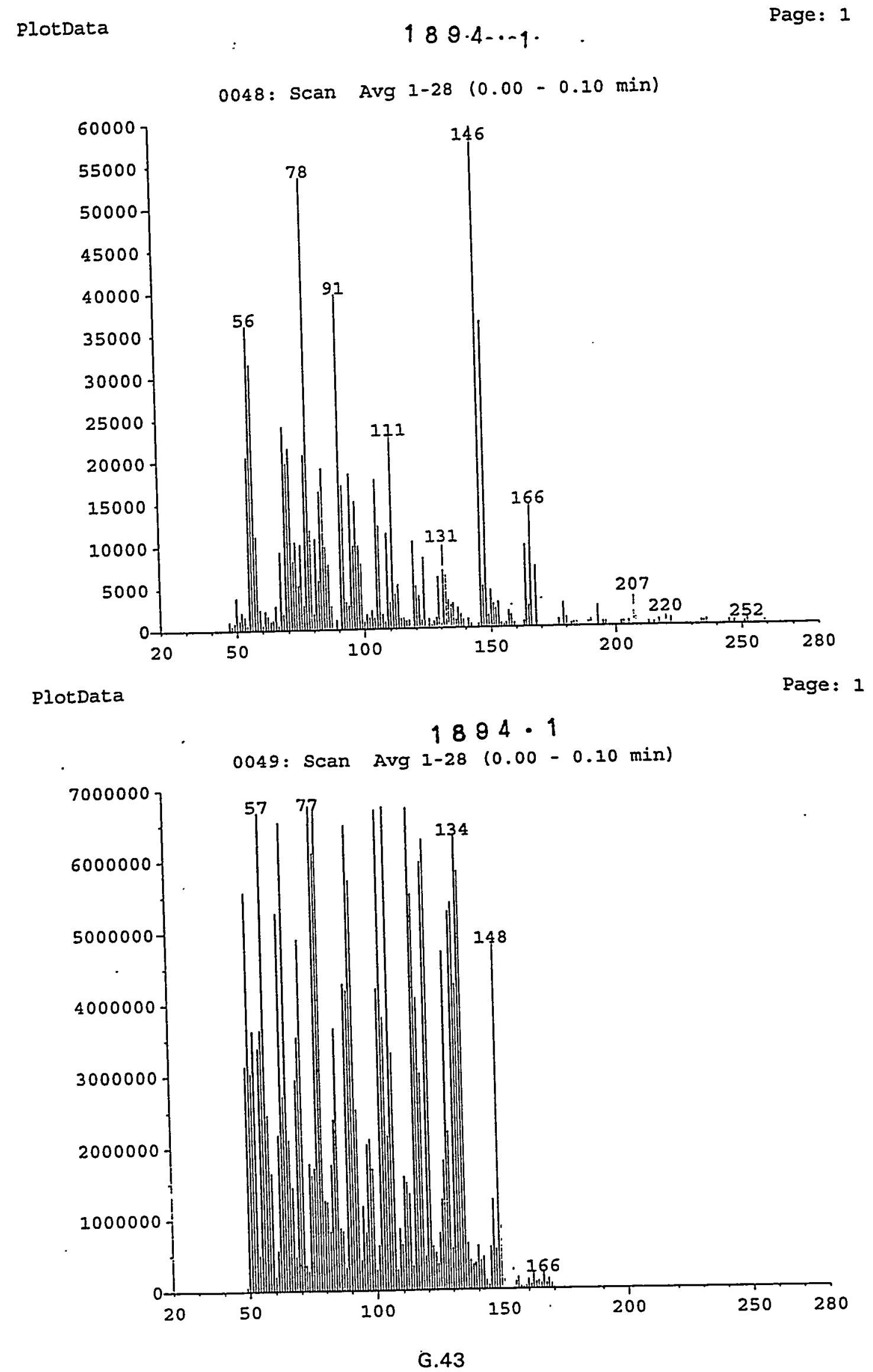


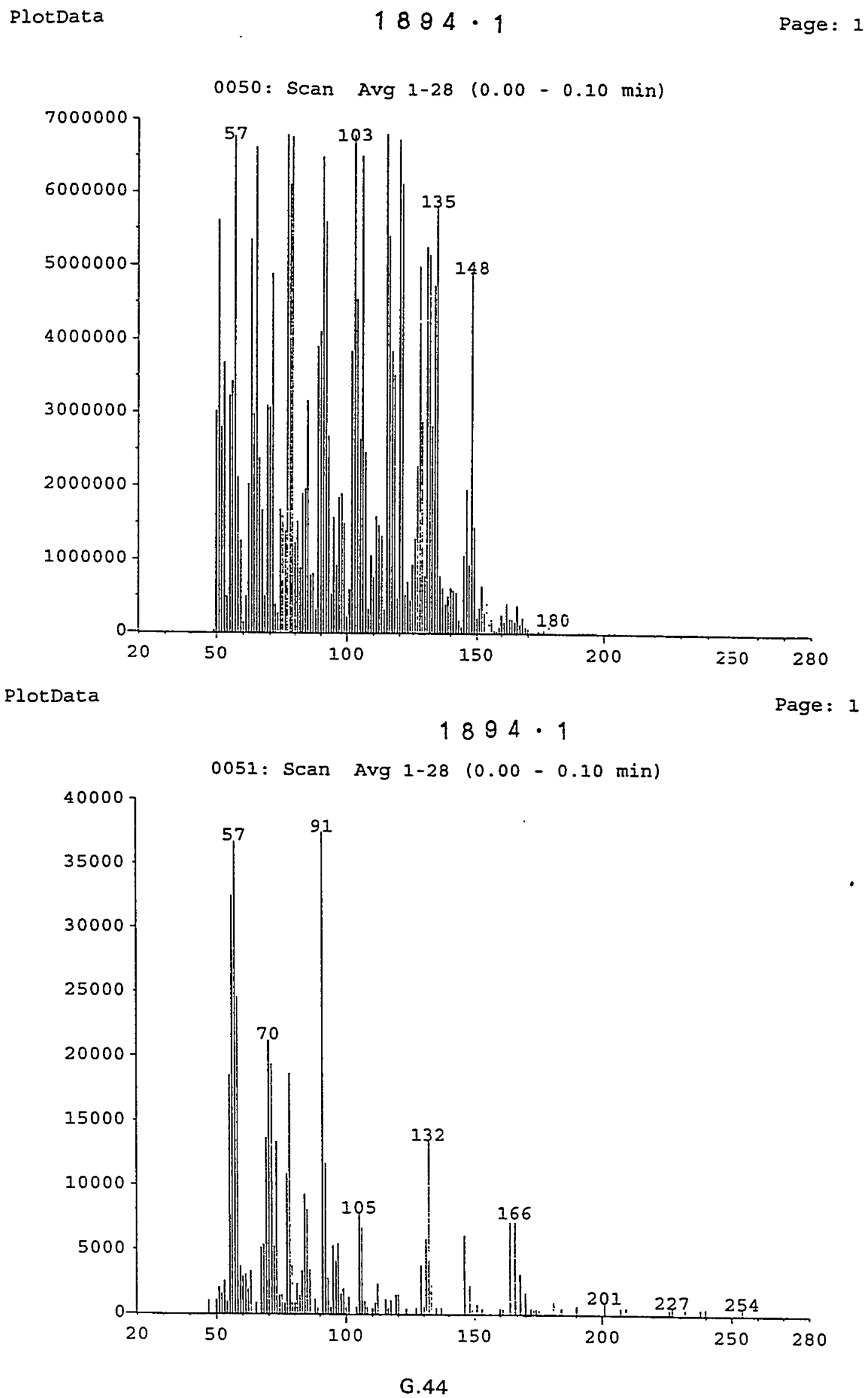




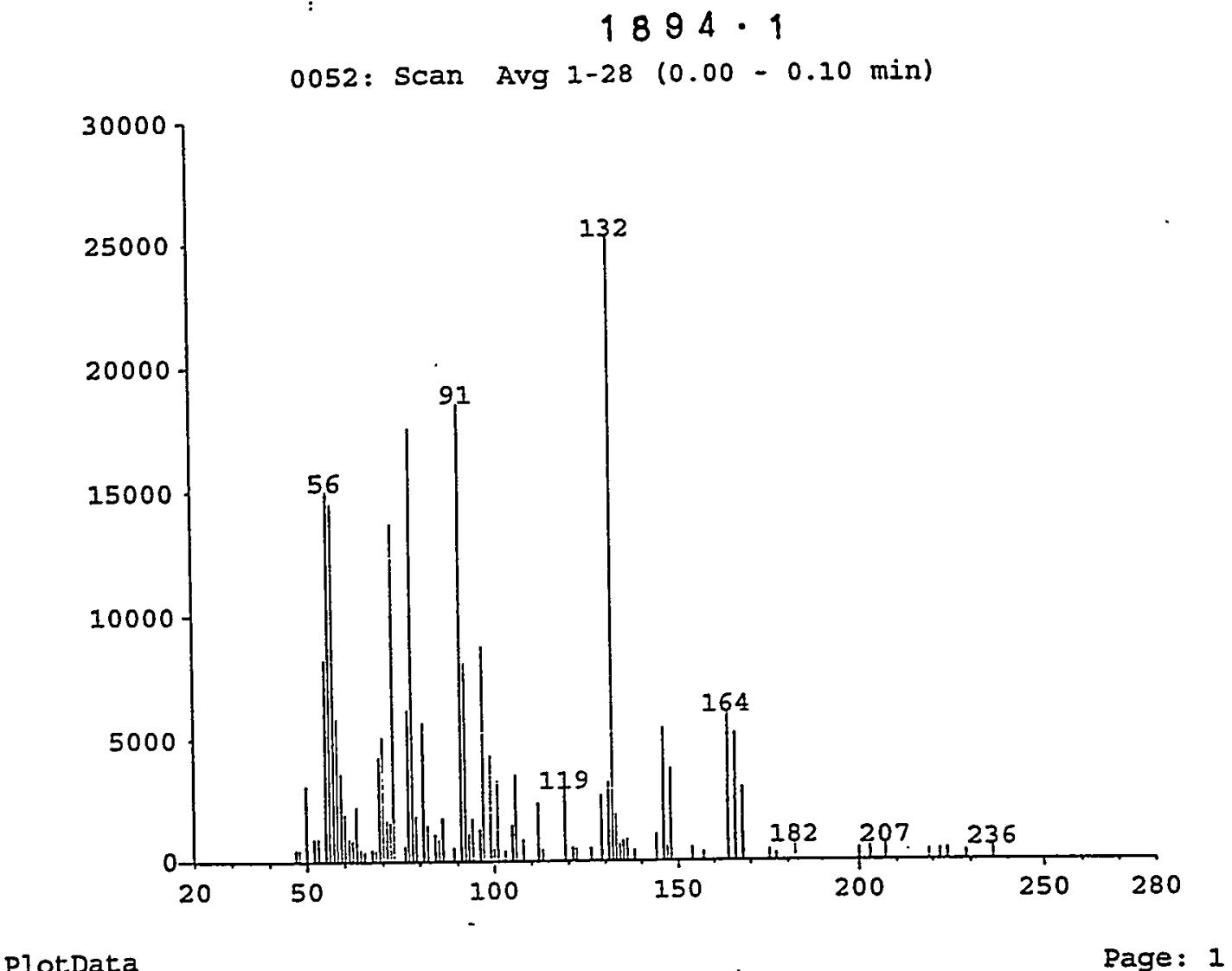

PlotData

$1894 \cdot 1$

0053 : Scan Avg 1-28 (0.00-0.10 min)

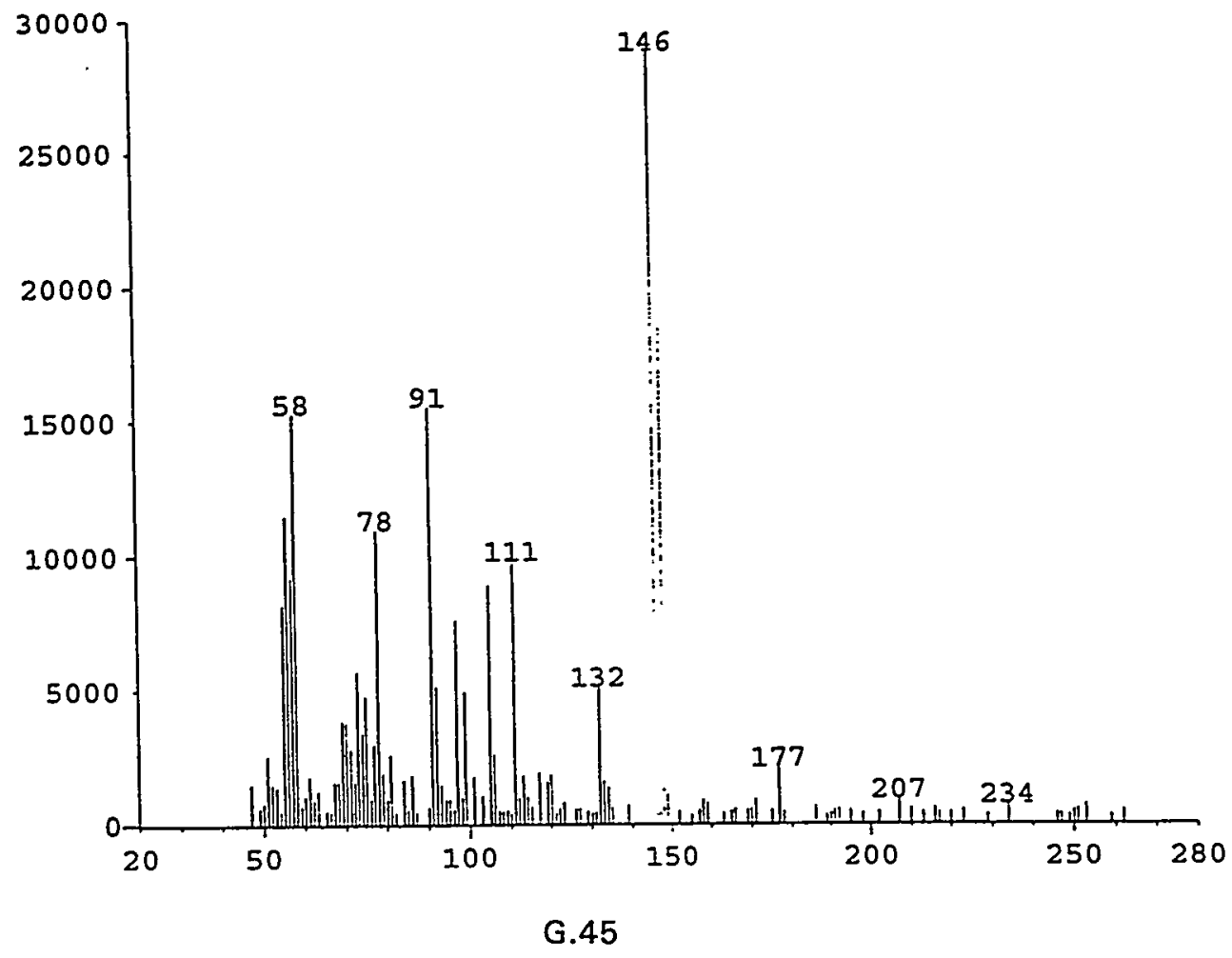


$1894 \cdot 1$

0054: Scan Avg 1-28 (0.00-0.10 min)

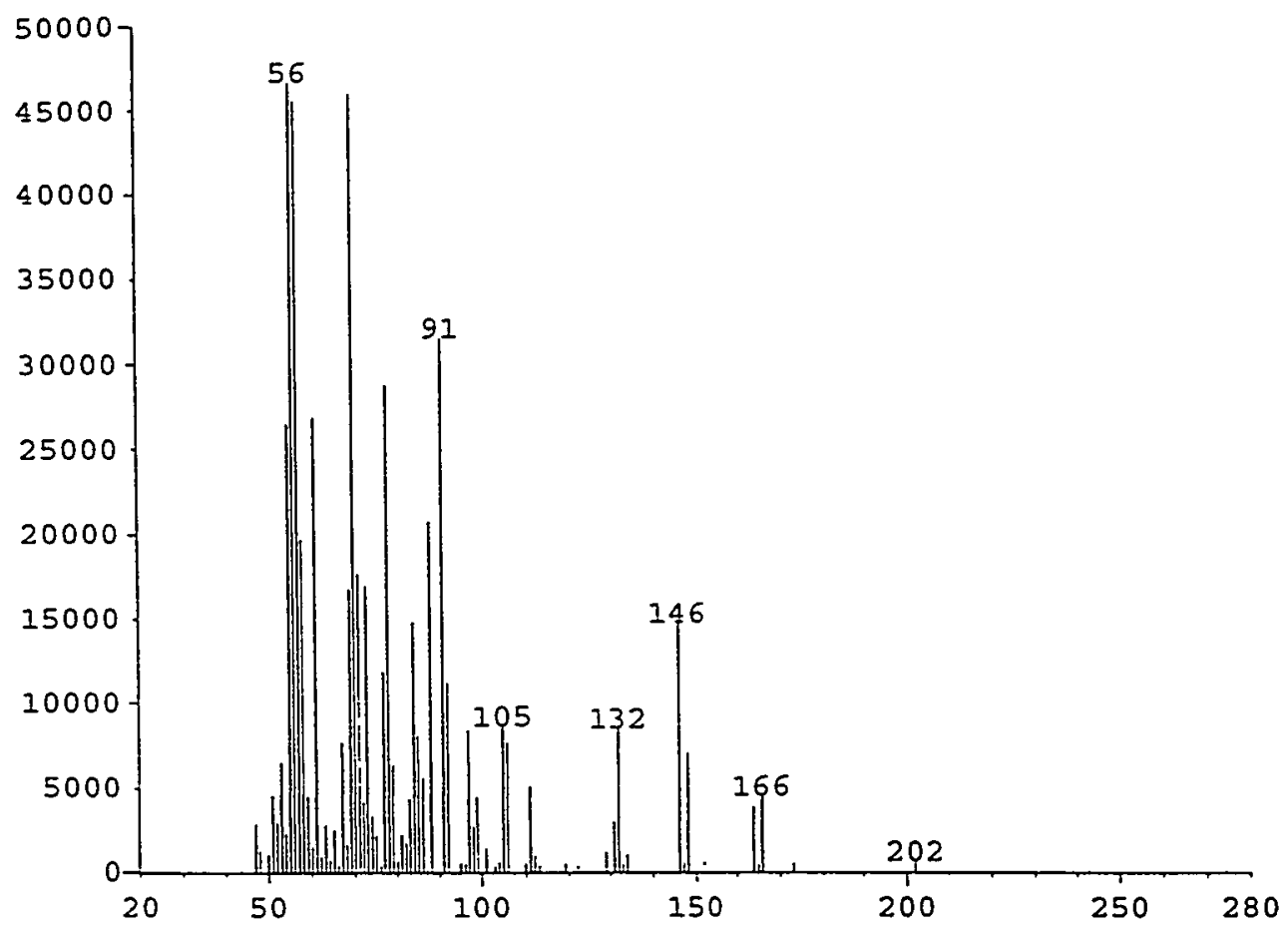

PlotData

$1894 \cdot 1$

$0055:$ Scan Avg 1-28 (0.00-0.10 min)

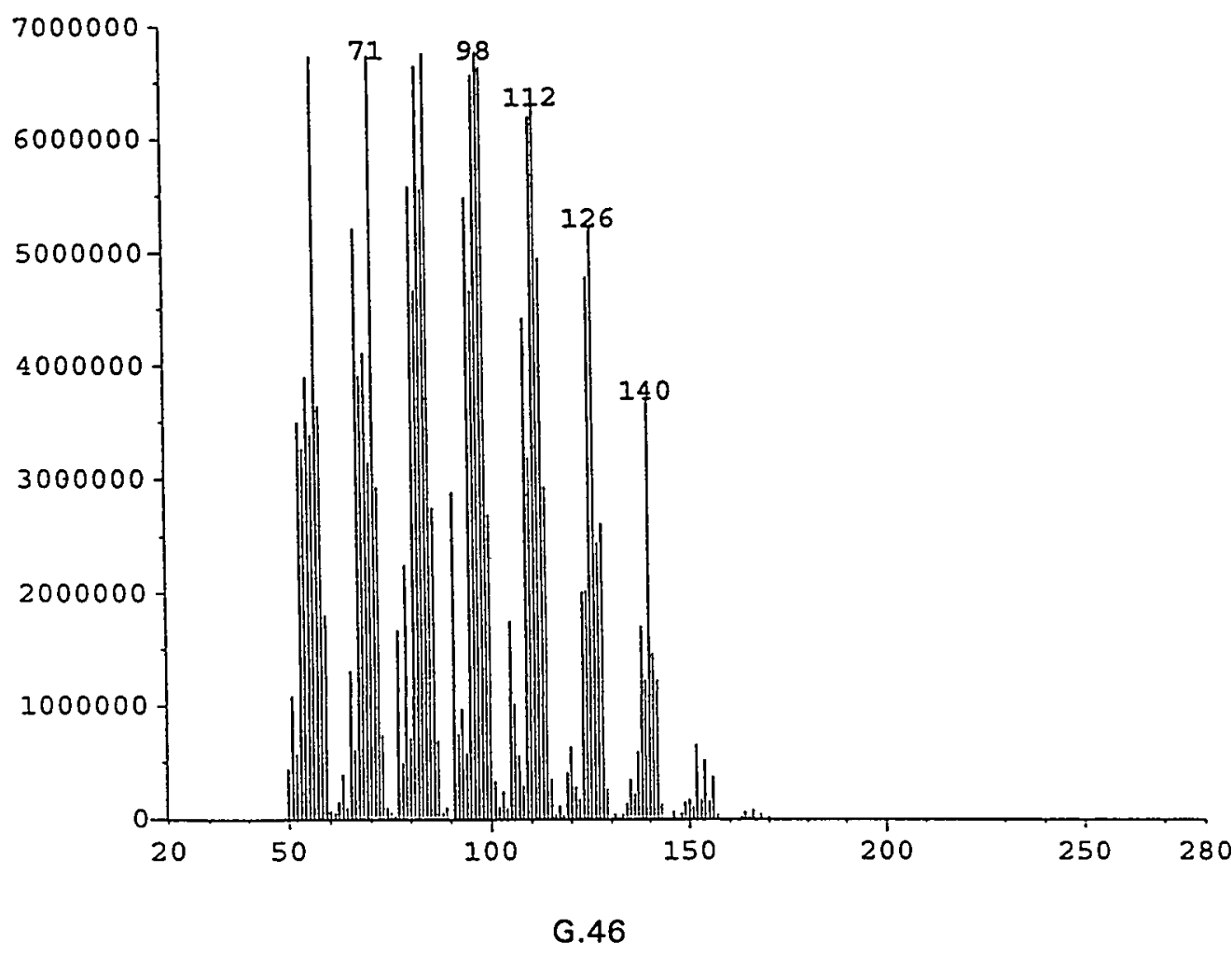




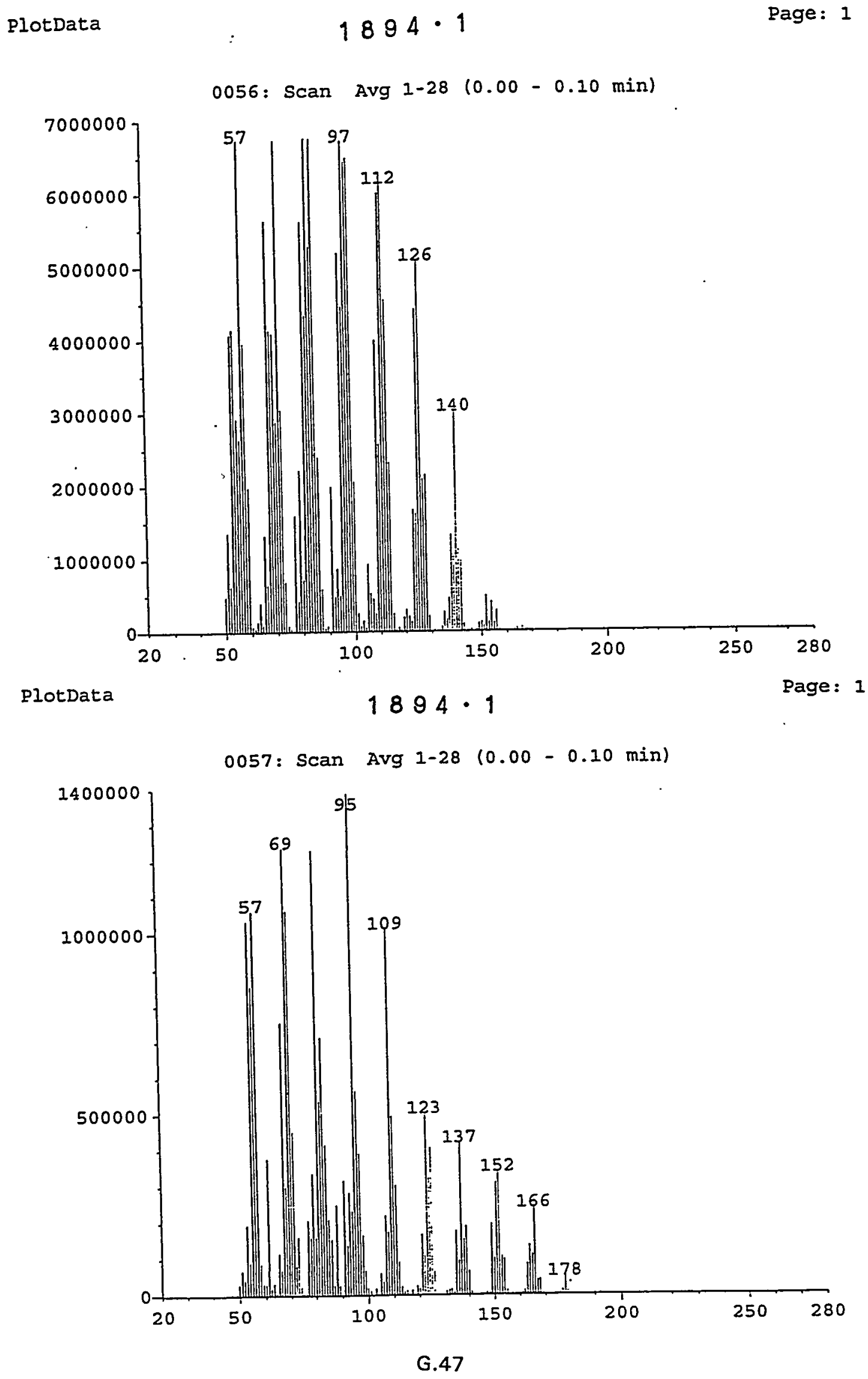




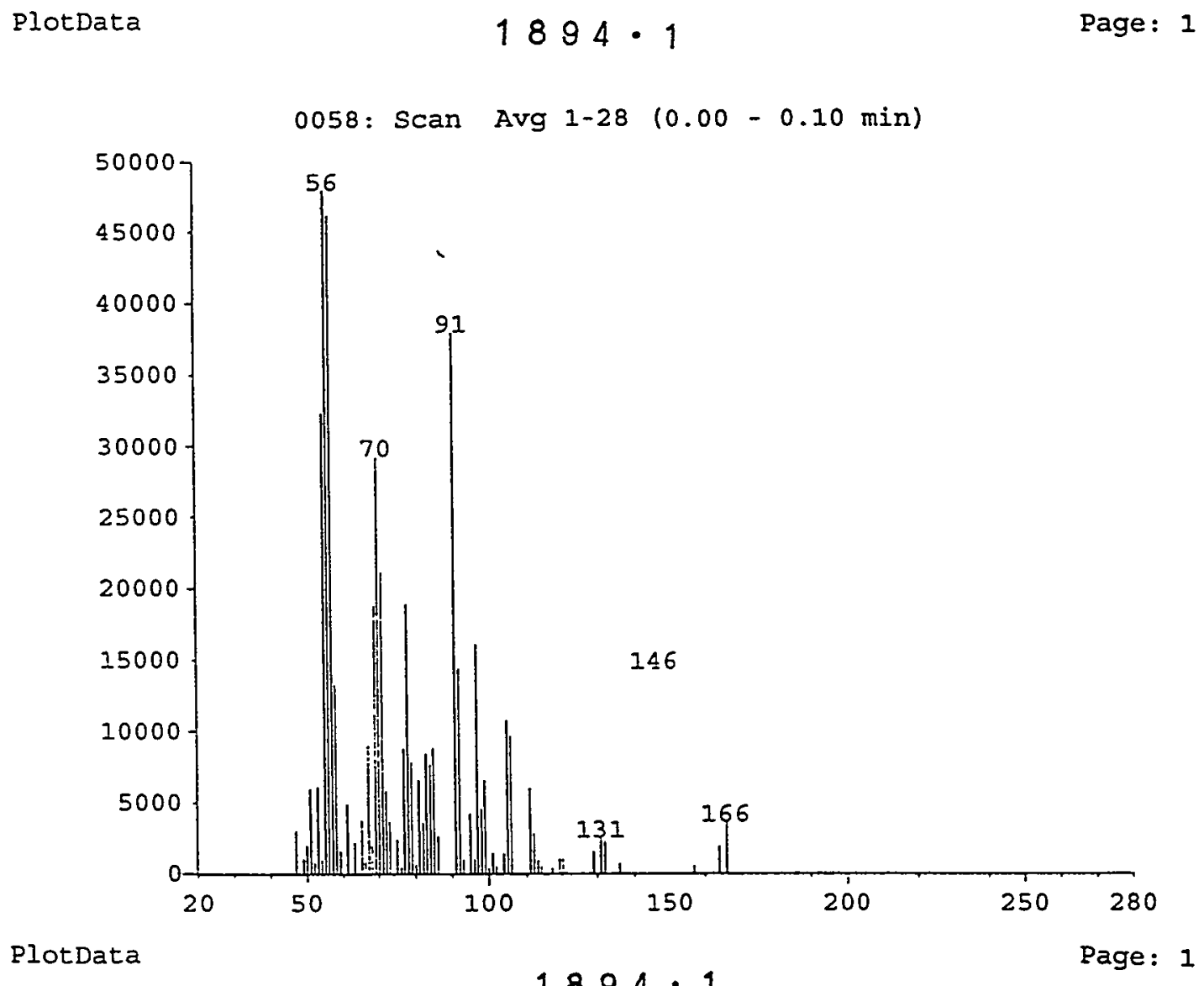

$1894 \cdot 1$

0059 : Scan Avg $1-28(0.00-0.10 \mathrm{~min})$

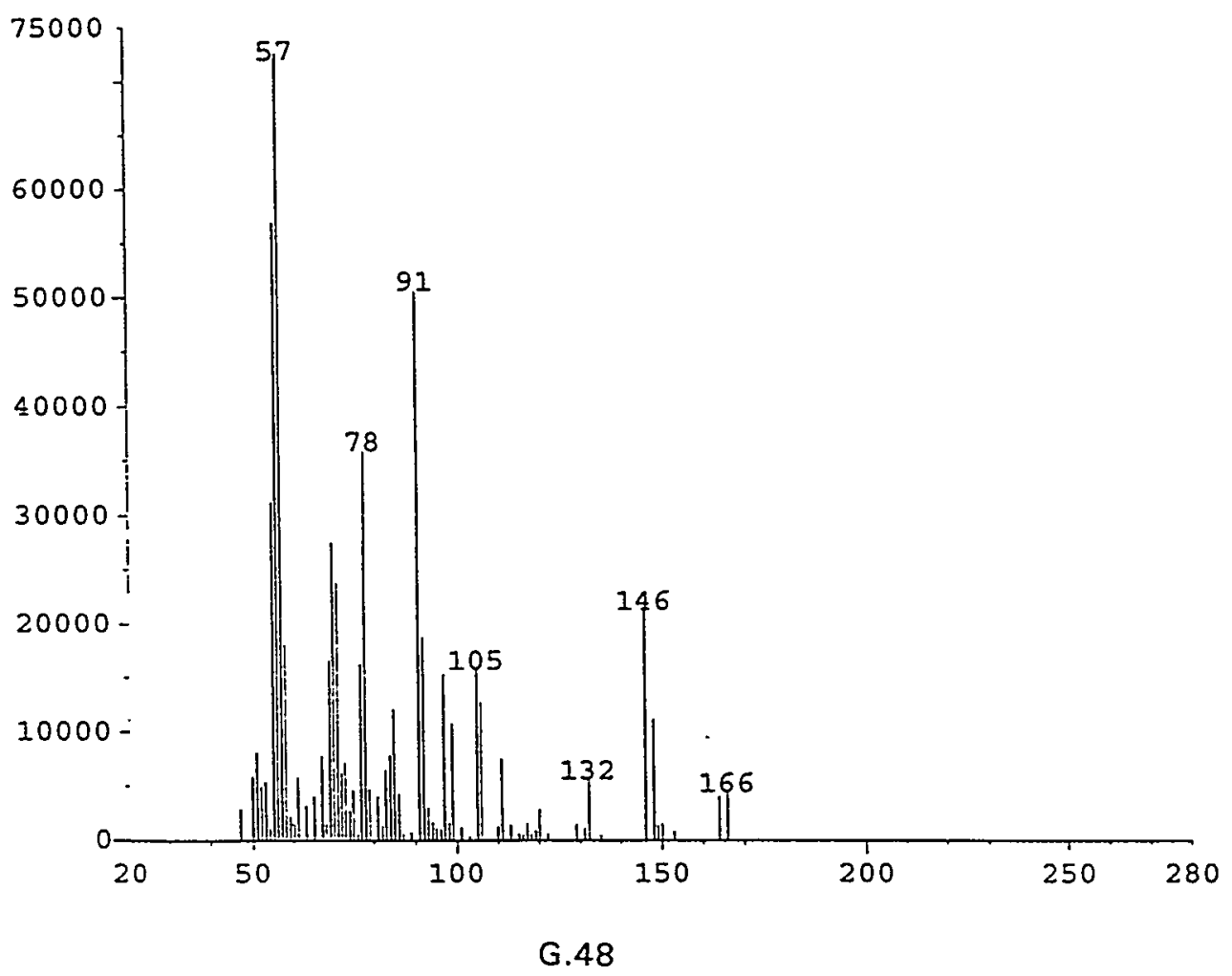




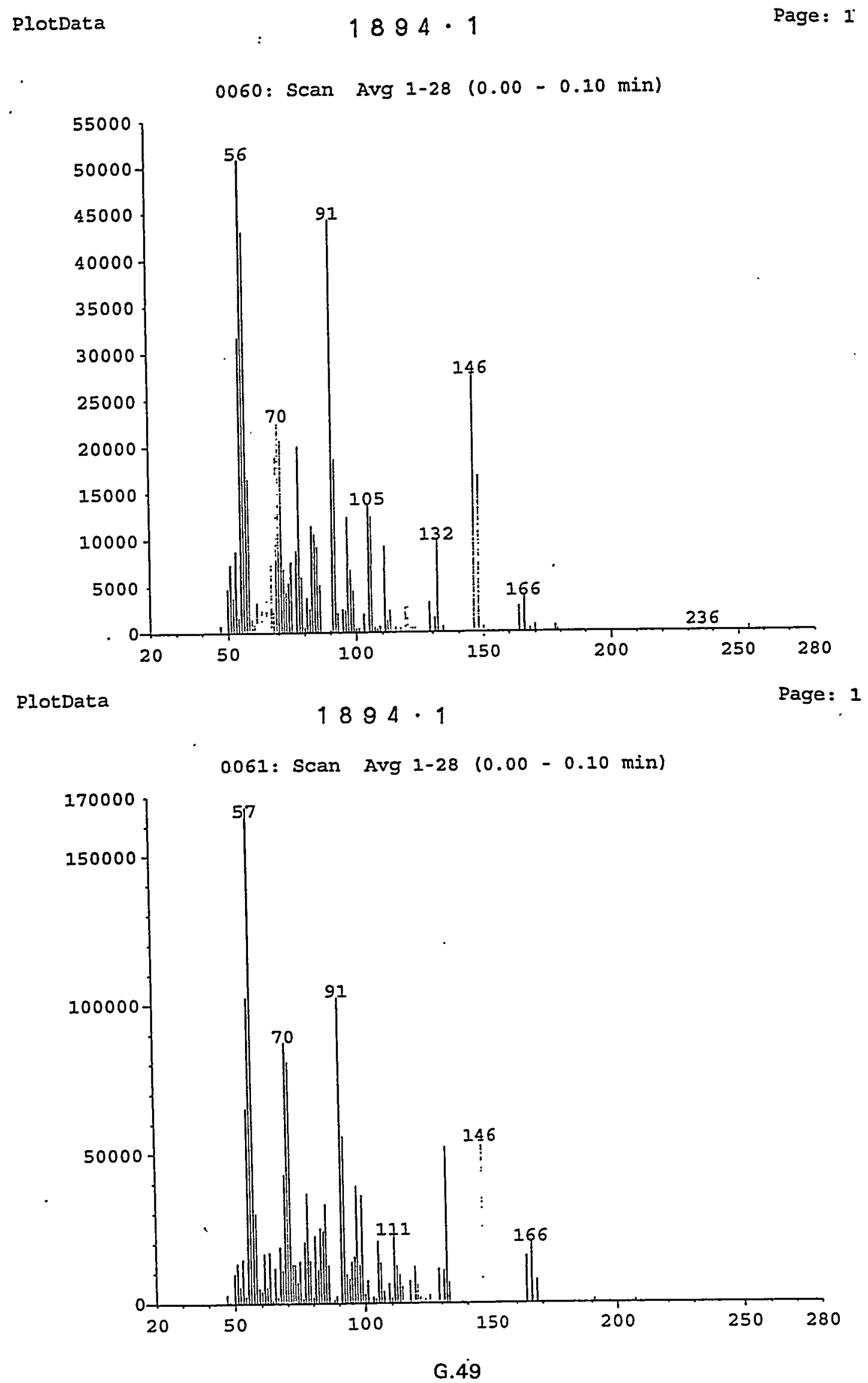



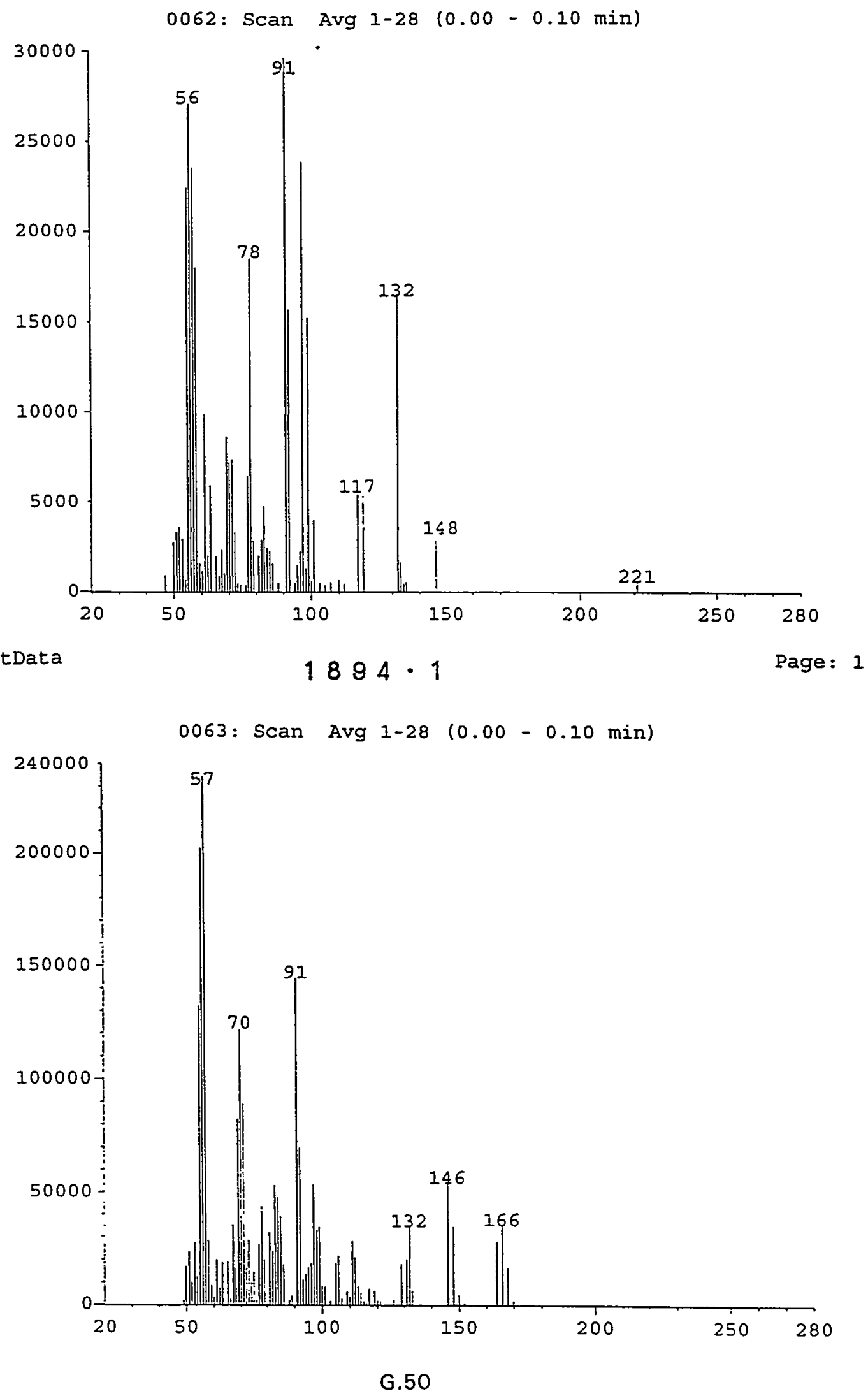


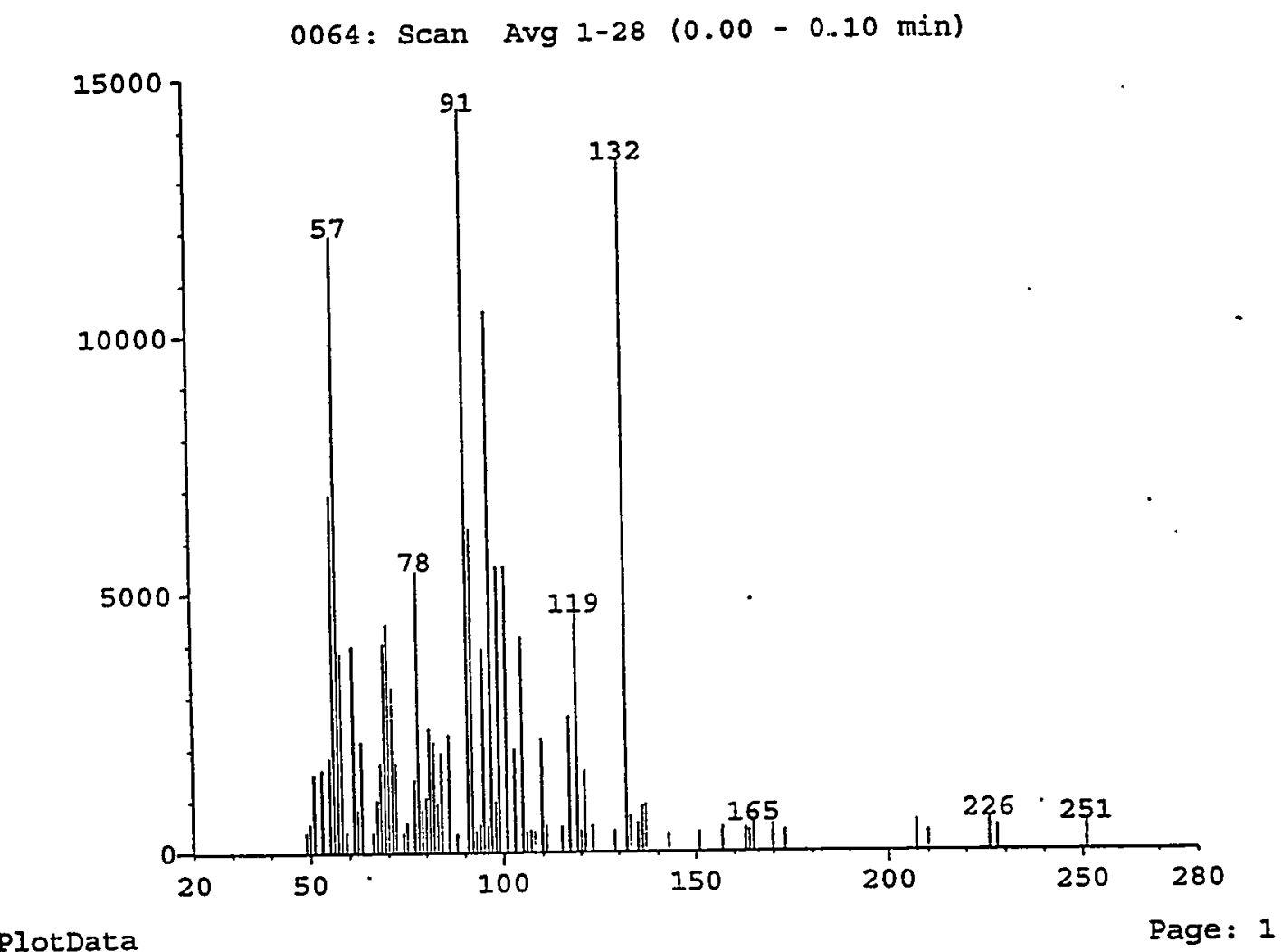

PlotData

$1894 \cdot 1$

$0065:$ Scan Avg 1-28 (0.00-0.10 min)

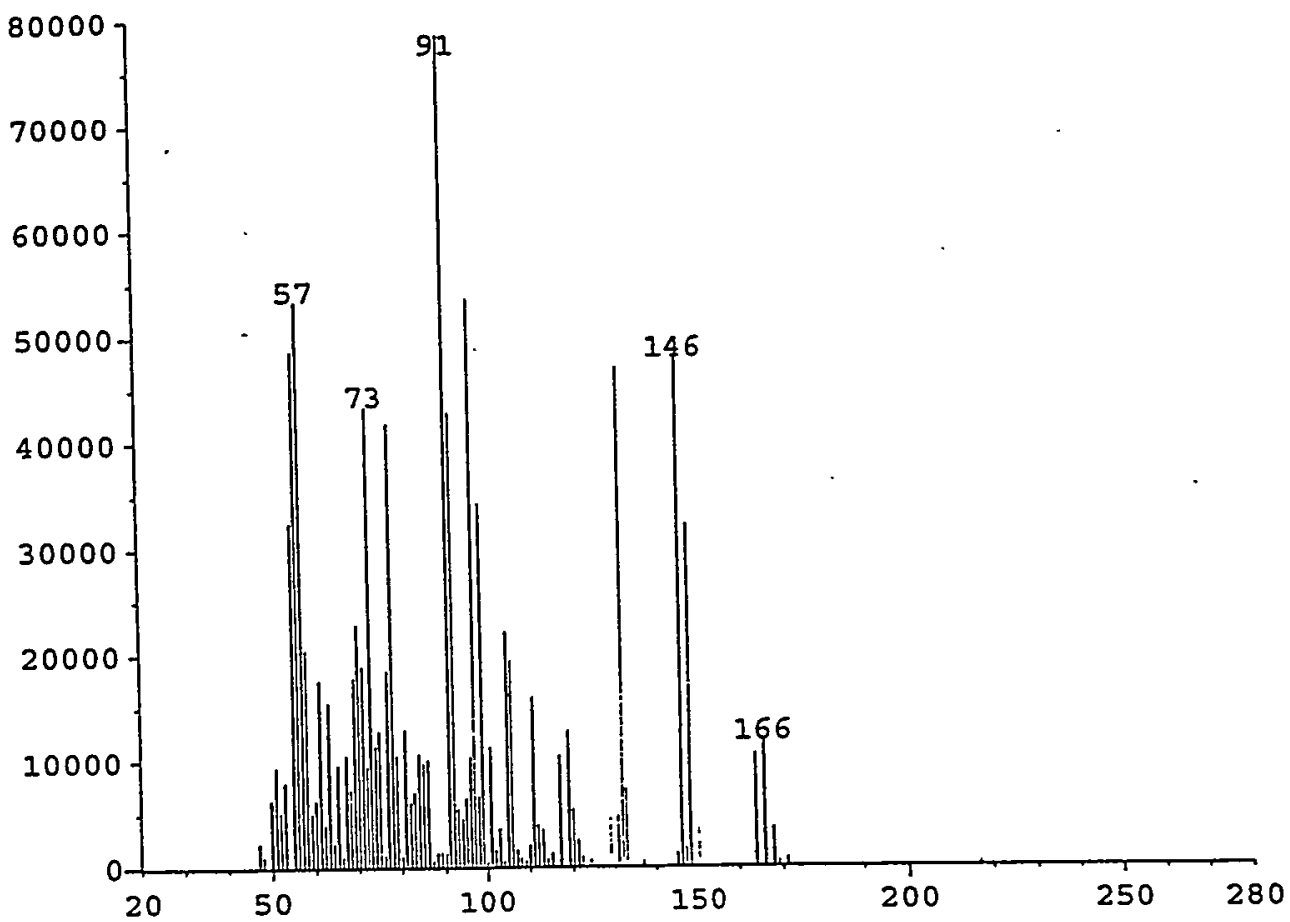




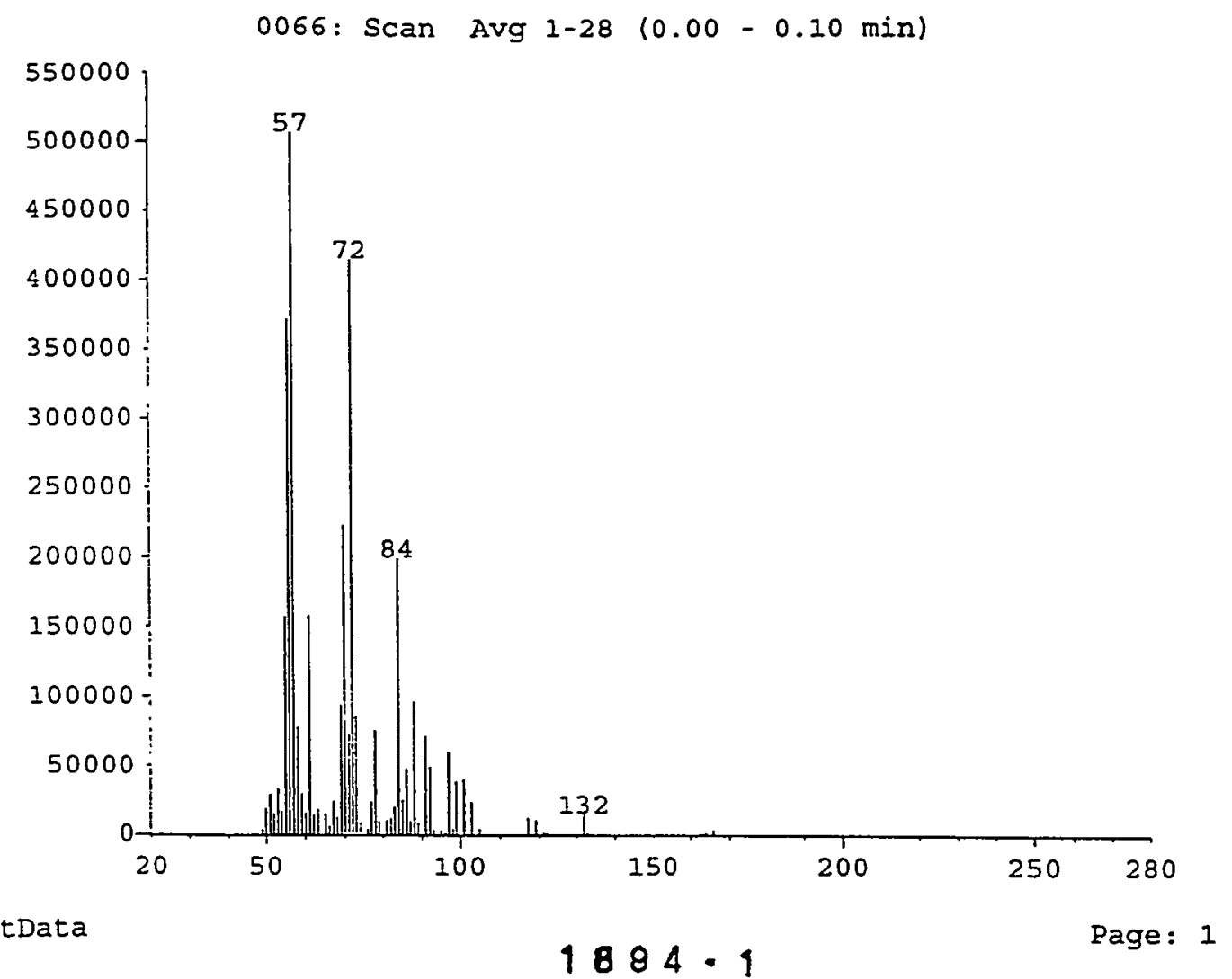

PlotData

$1884 \cdot 1$

0067: Scan Avg 1-28 (0.00-0.10 min)

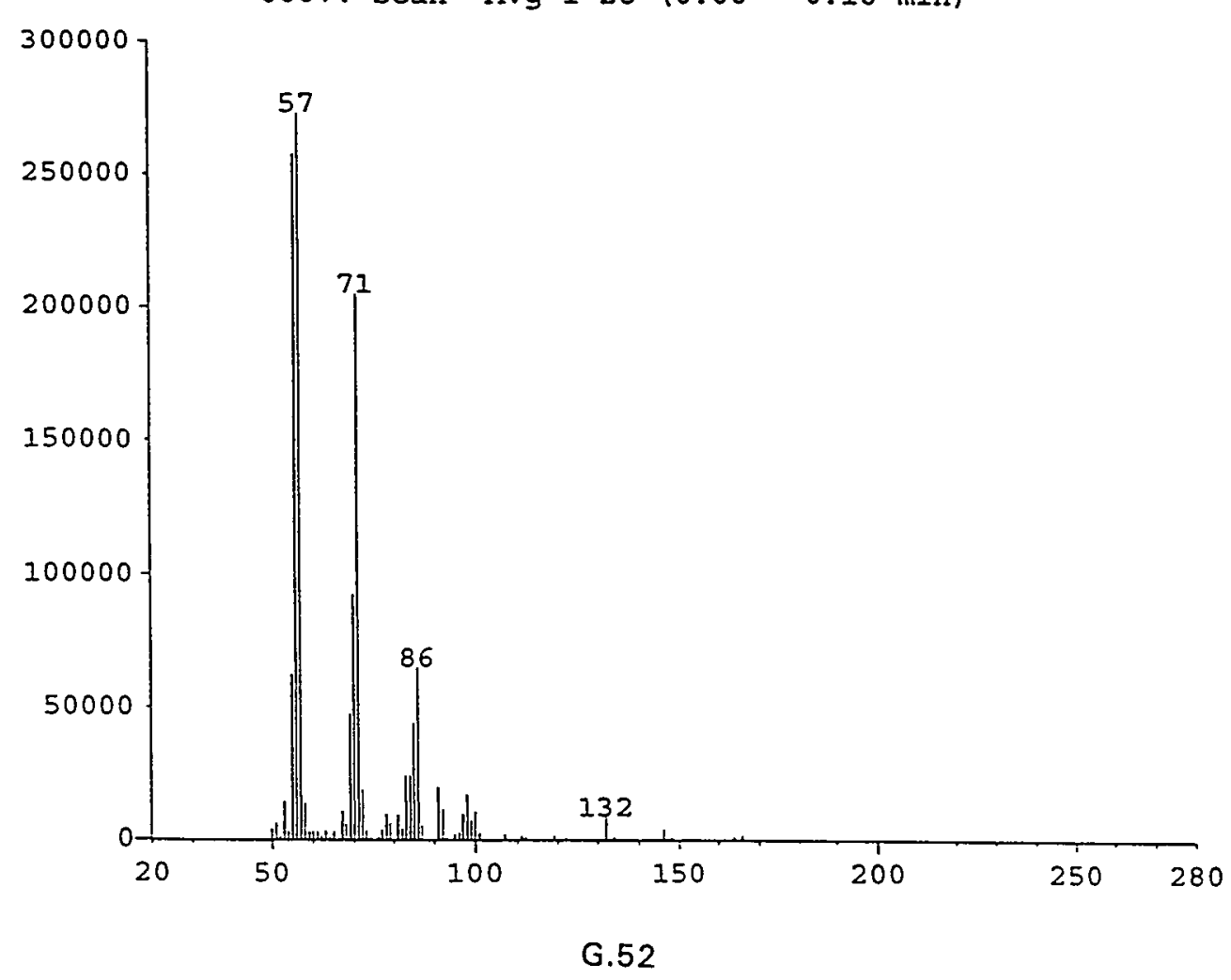


PlotData

$1894 \cdot 1$

0068: Scan Avg 1-28 (0.00-0.10 min)

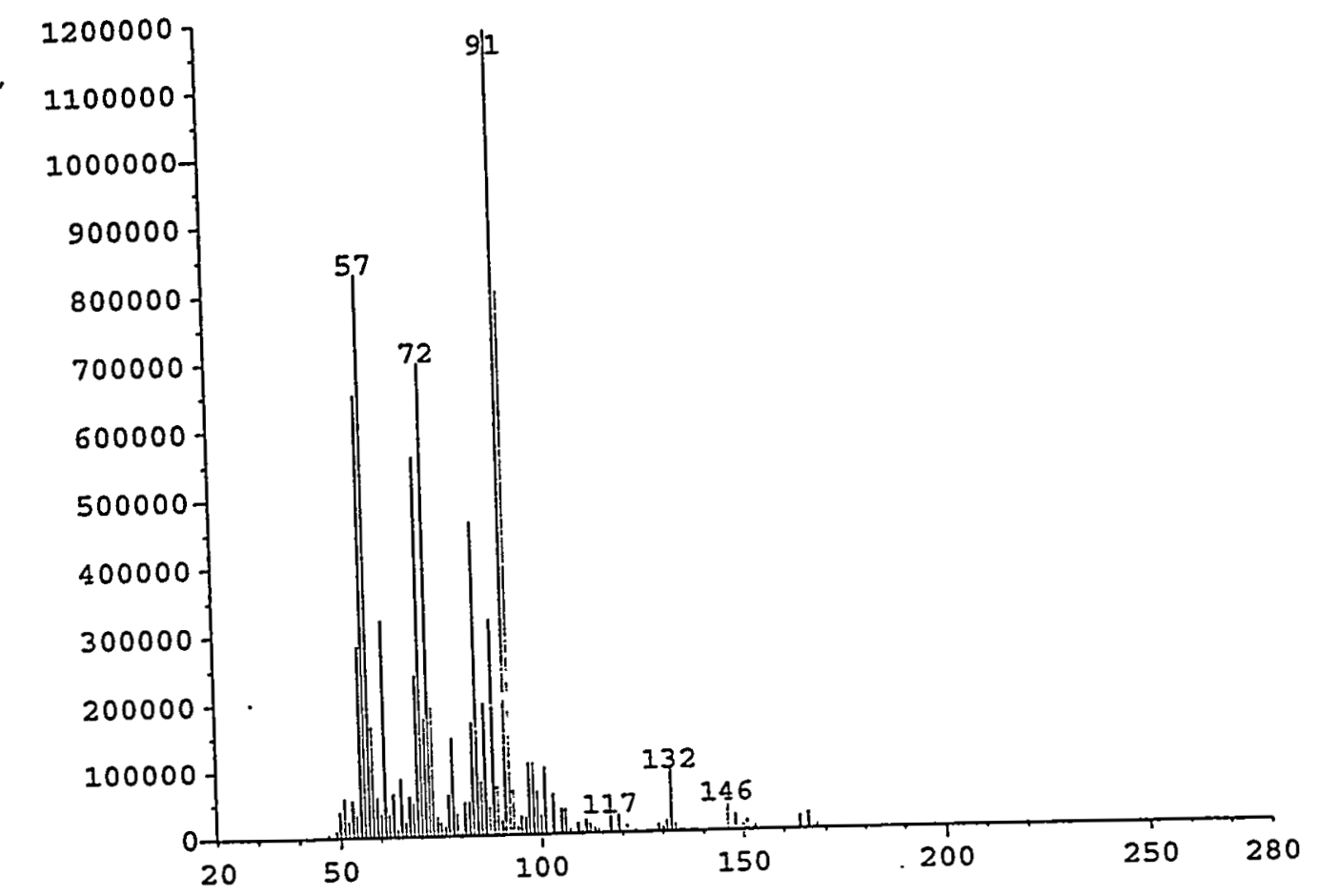

PlotData

Page: 1

$1884 \cdot 1$

0069: Scan Avg 1-28 (0.00-0.10 min)

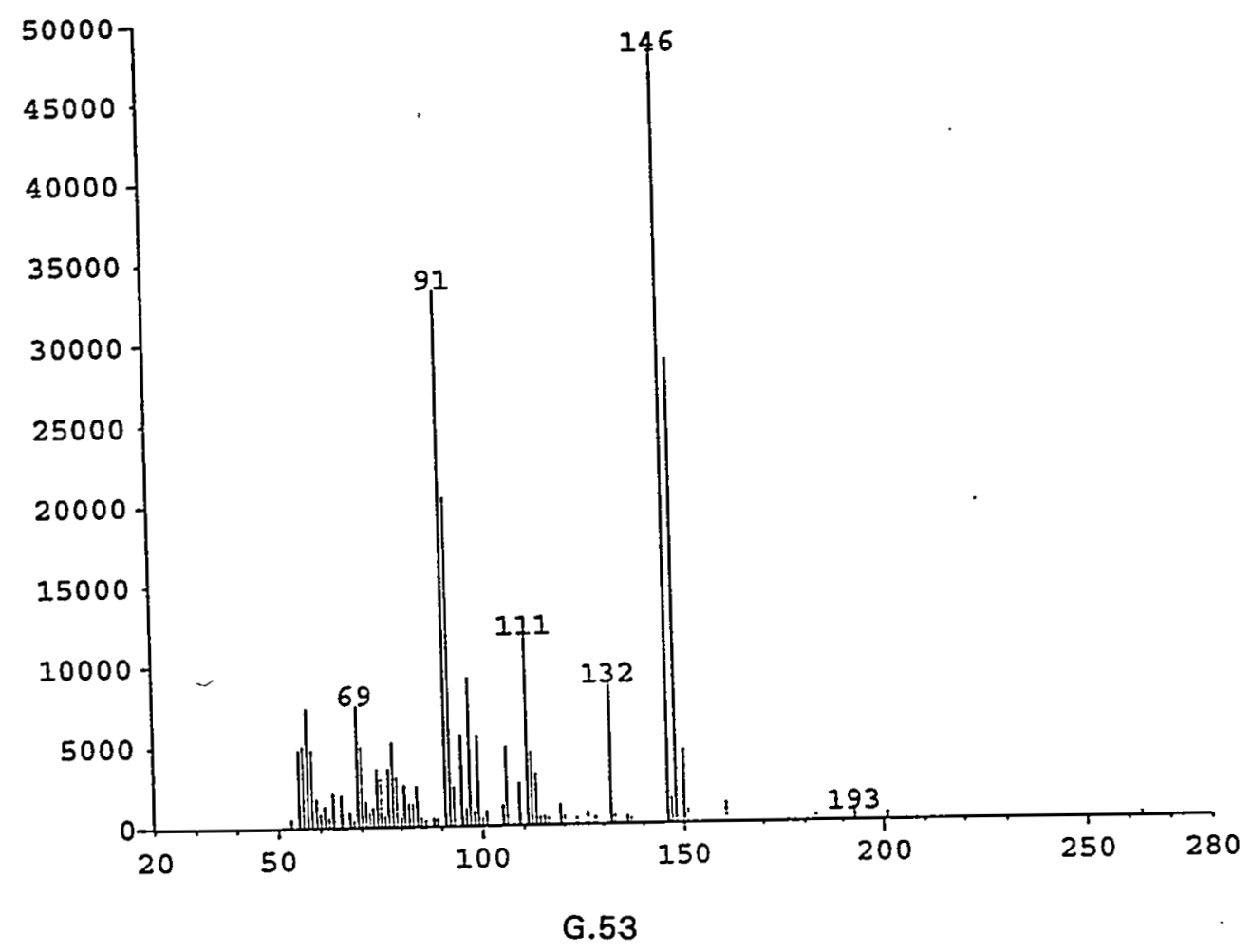


PlotData

Page: 1

$1894 \cdot 1$

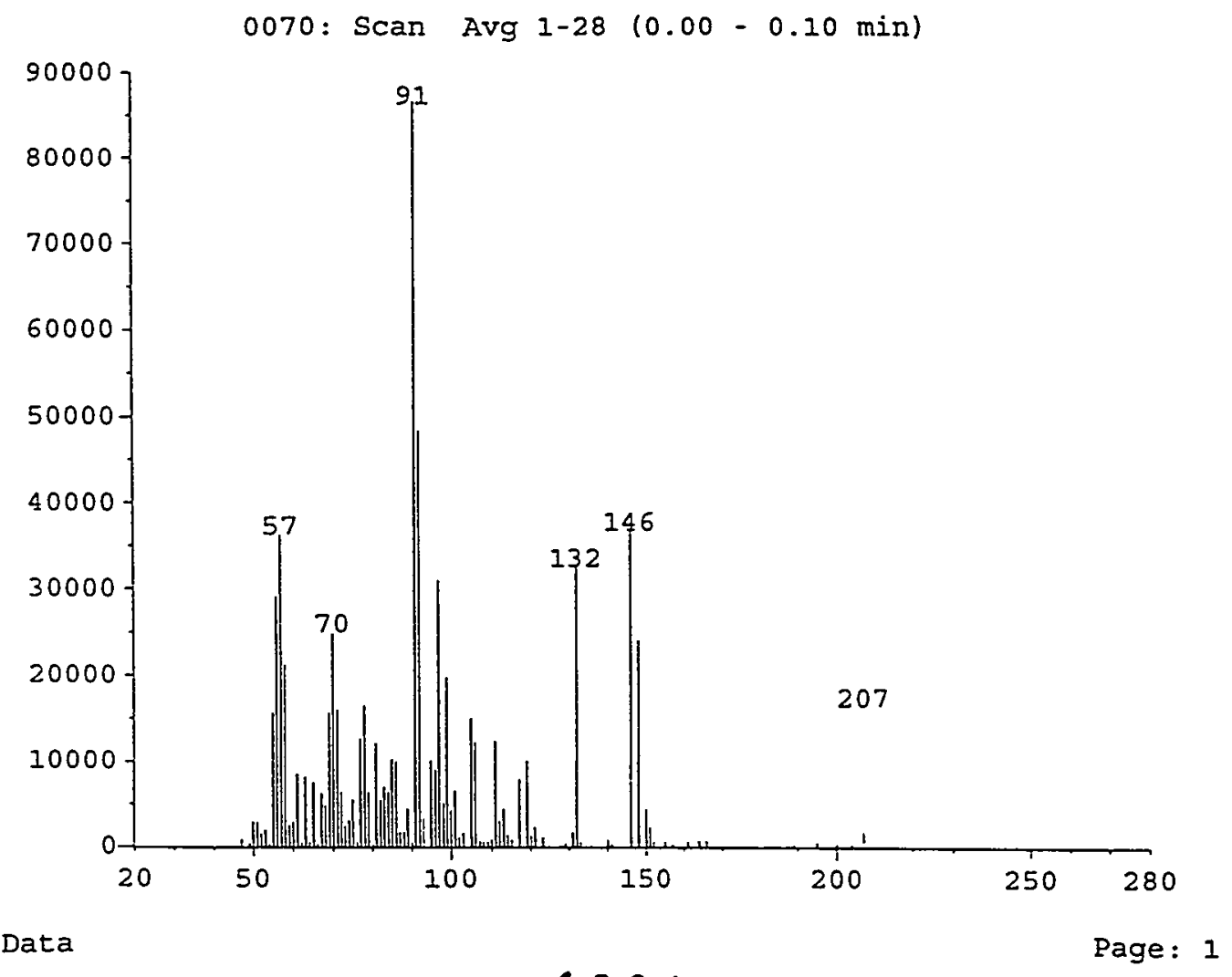

PlotData

$1884 \cdot 1$

0071: Scan Avg 1-28 (0.00-0.10 min)

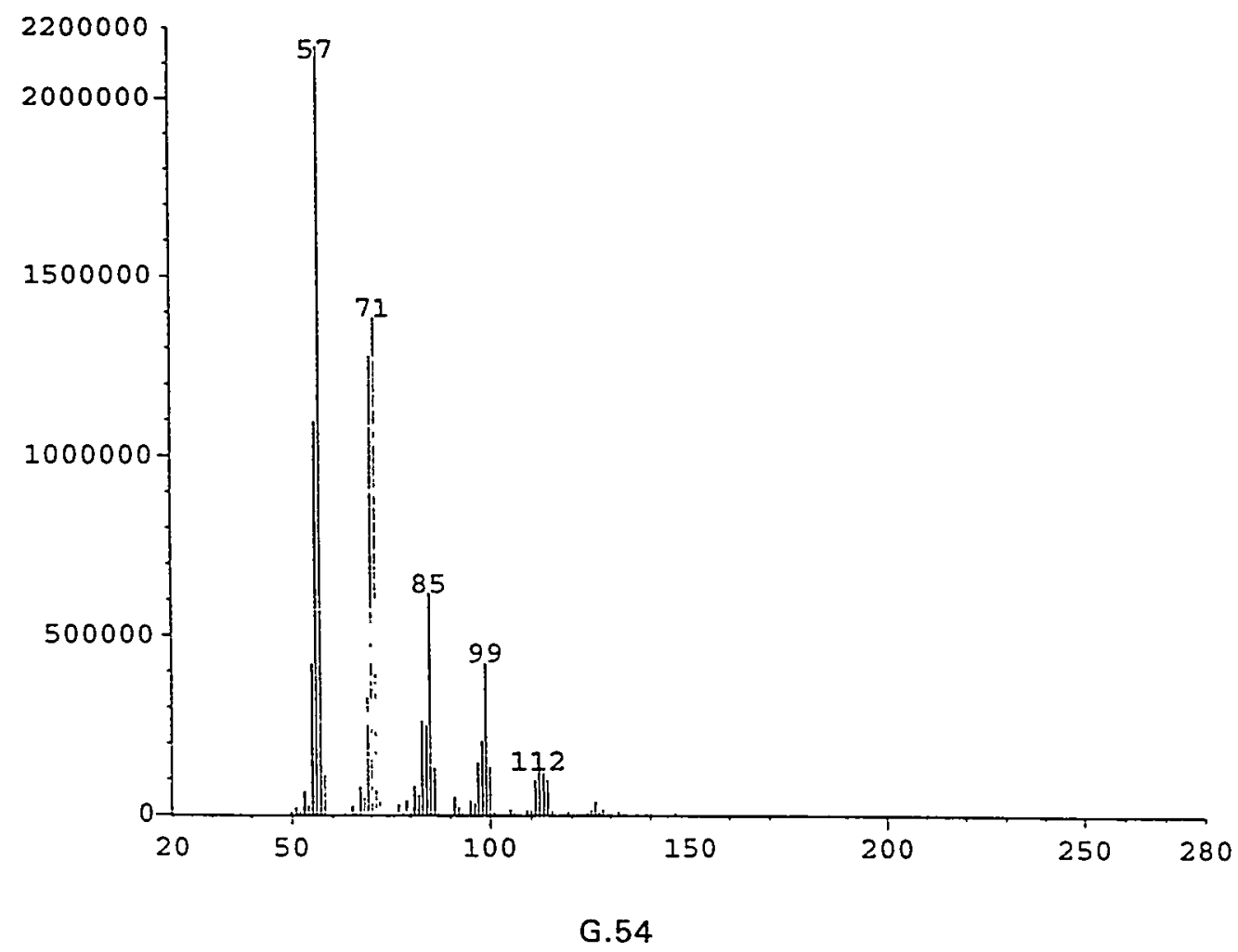


Page: 1

plotData

$1884 \cdot 1$

0072: Scan Avg 1-28 (0.00-0.10 min)

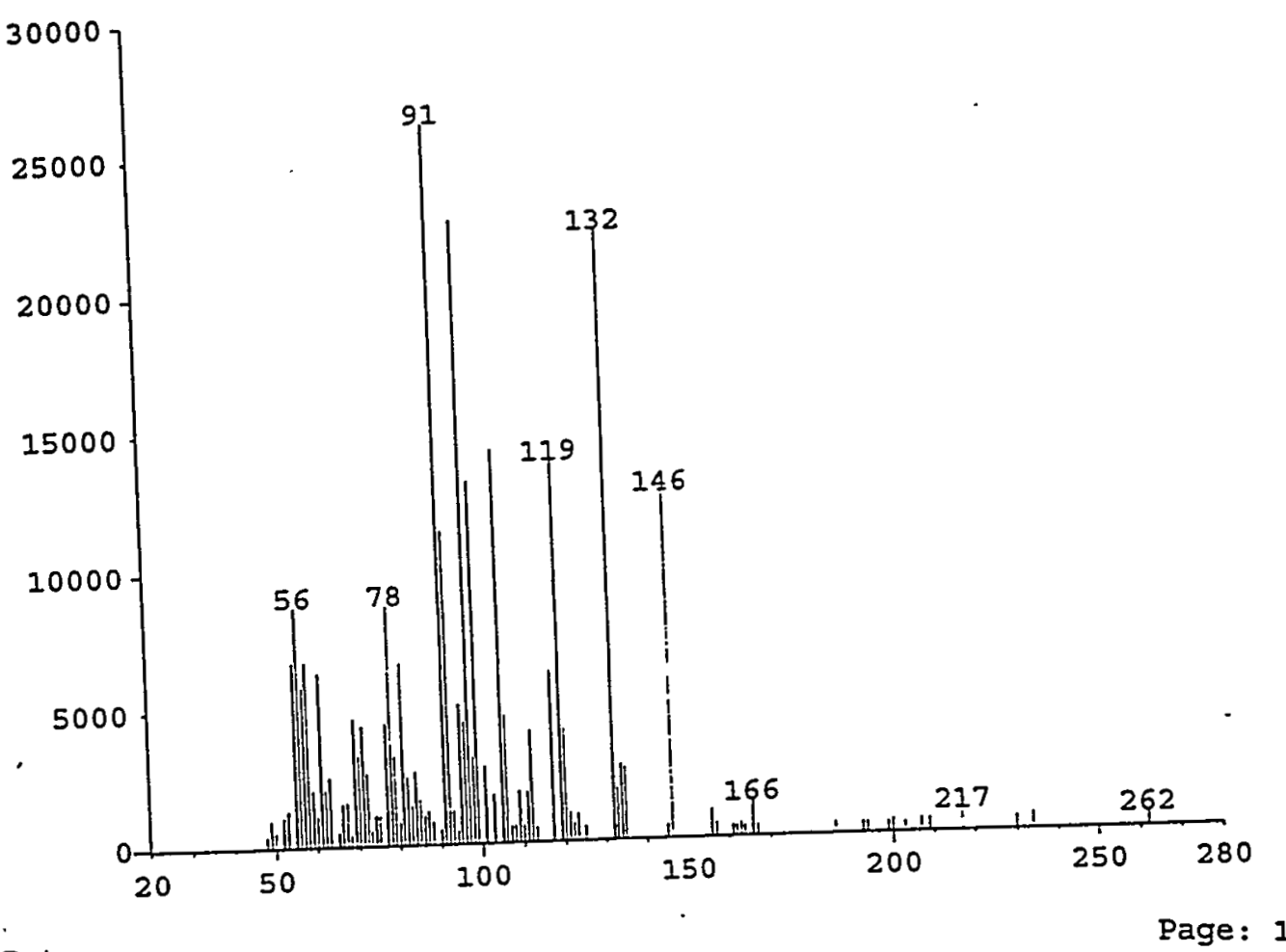

plotData

$1894 \cdot 1$

$0073:$ Scan Avg 1-28 (0.00-0.10 min)

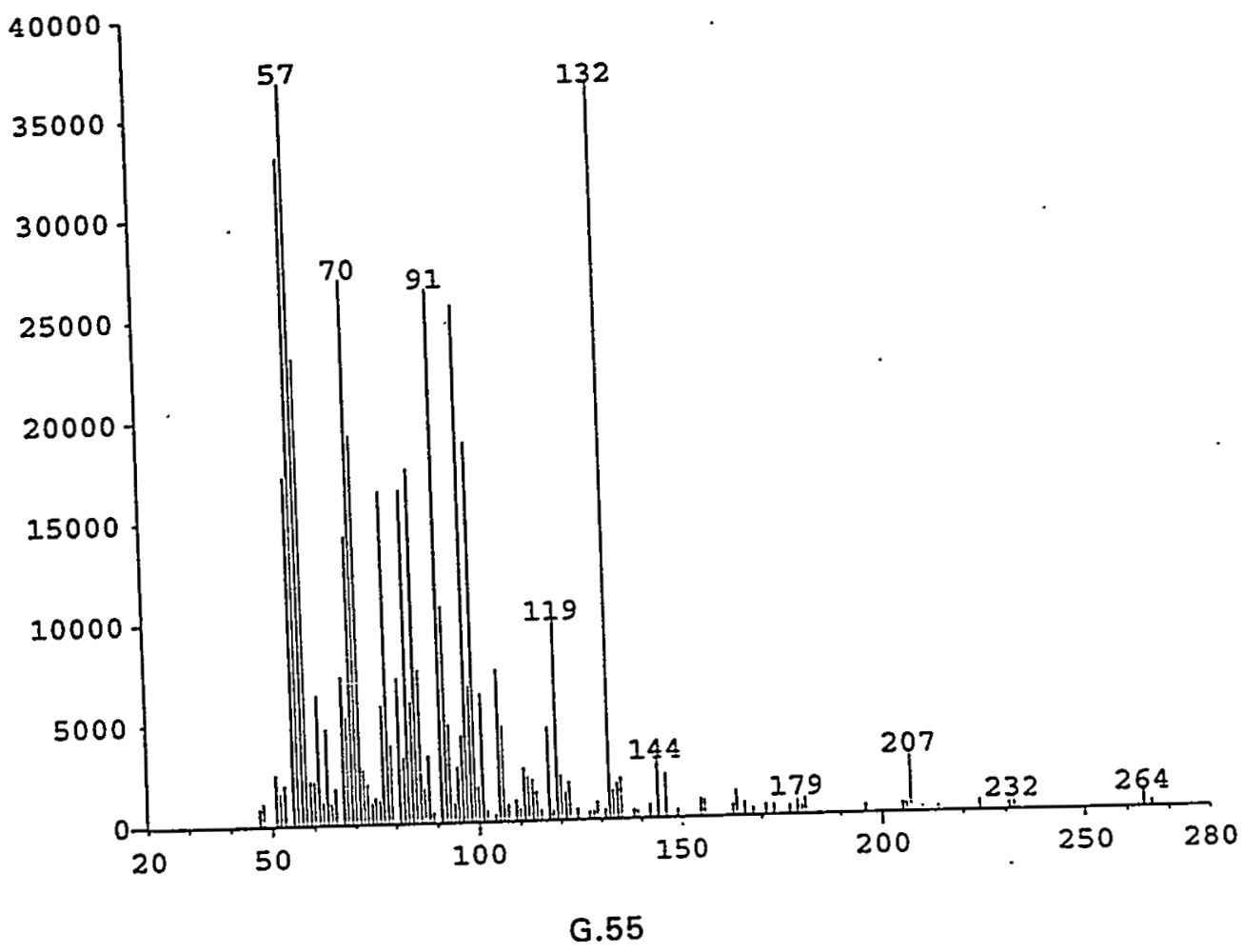




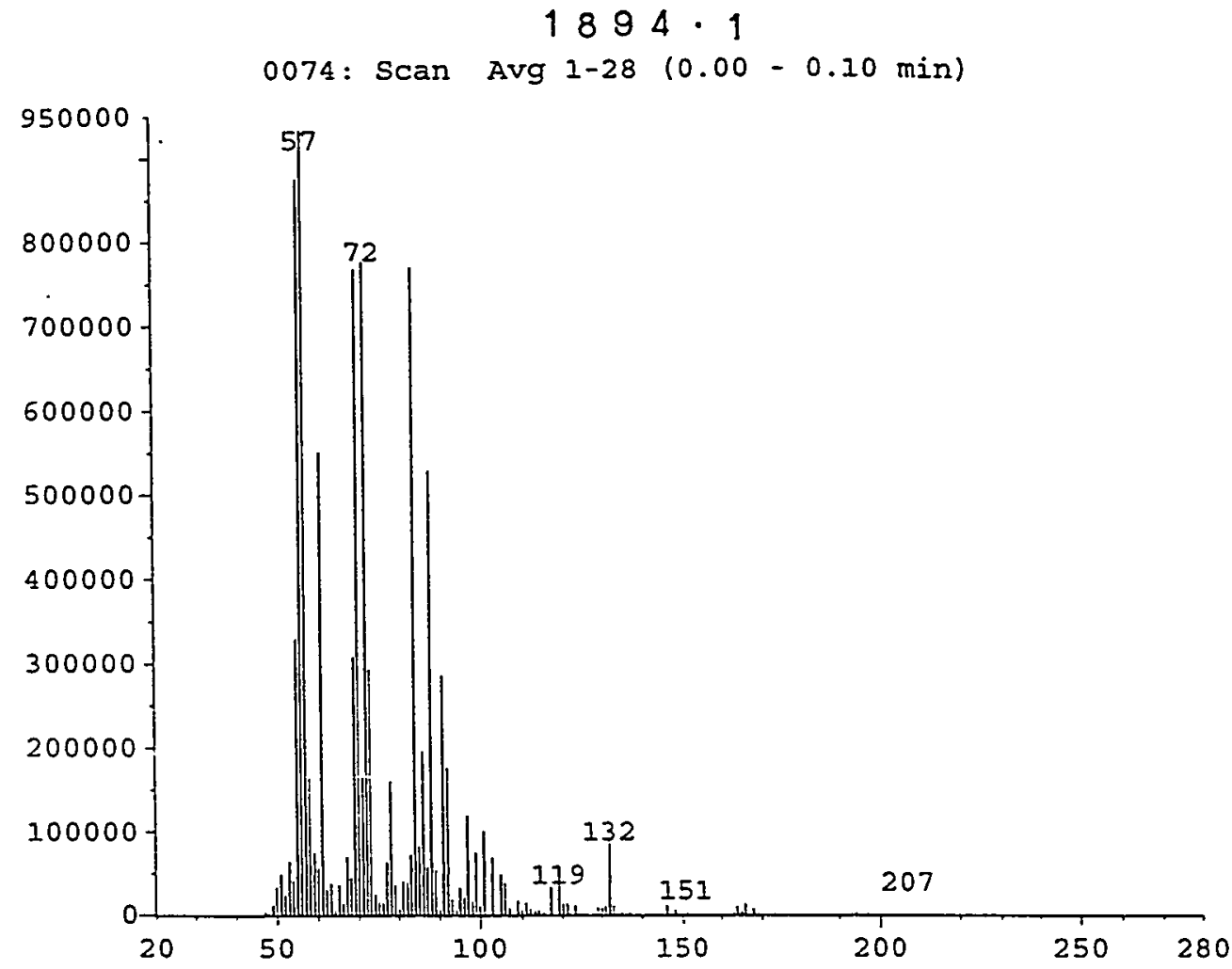

PlotData

\section{$1894 \cdot 1$}

Page: 1

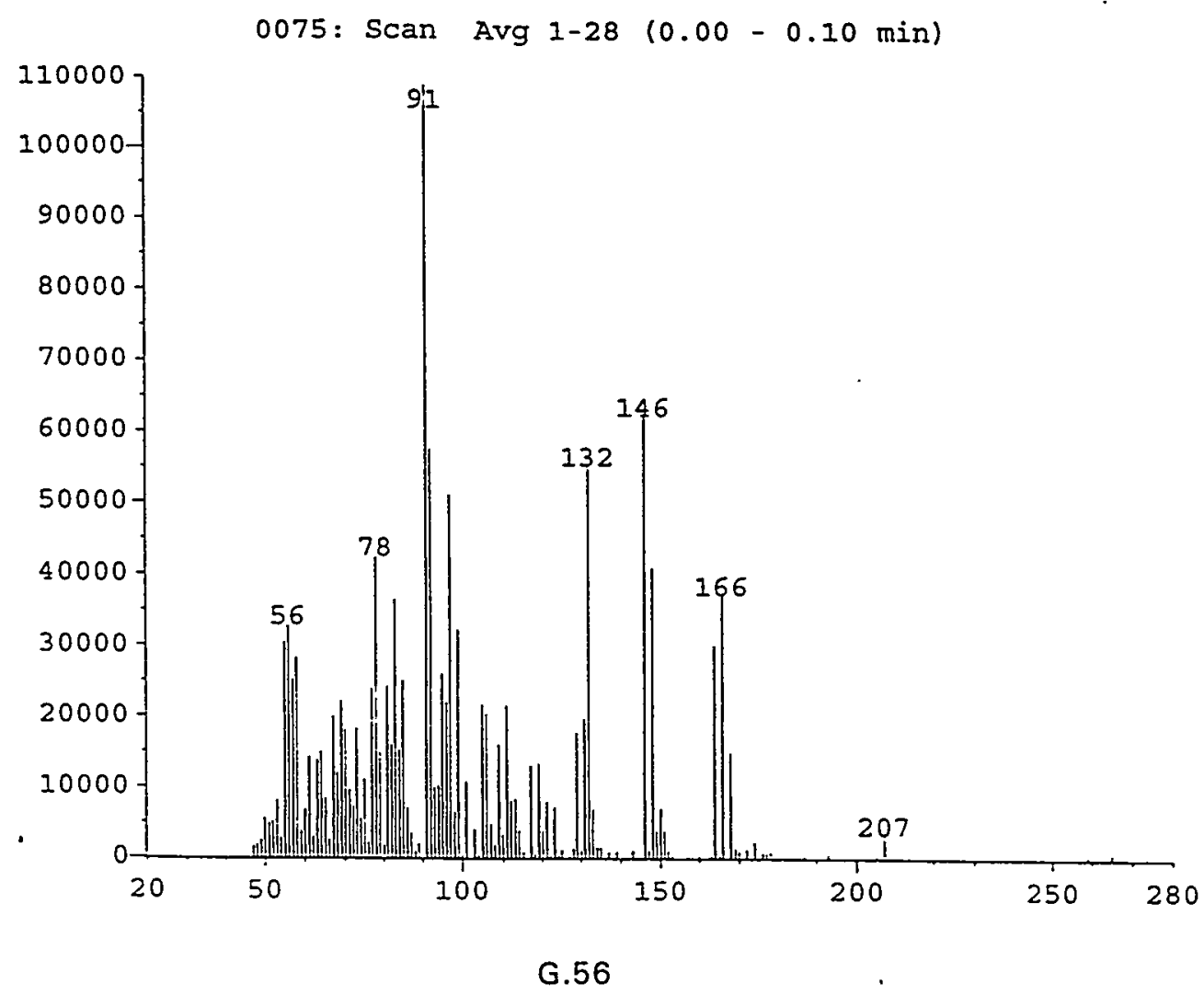


$=\quad 1894 \cdot 1$

0076: Scan Avg 1-28 (0.00-0.10 min)

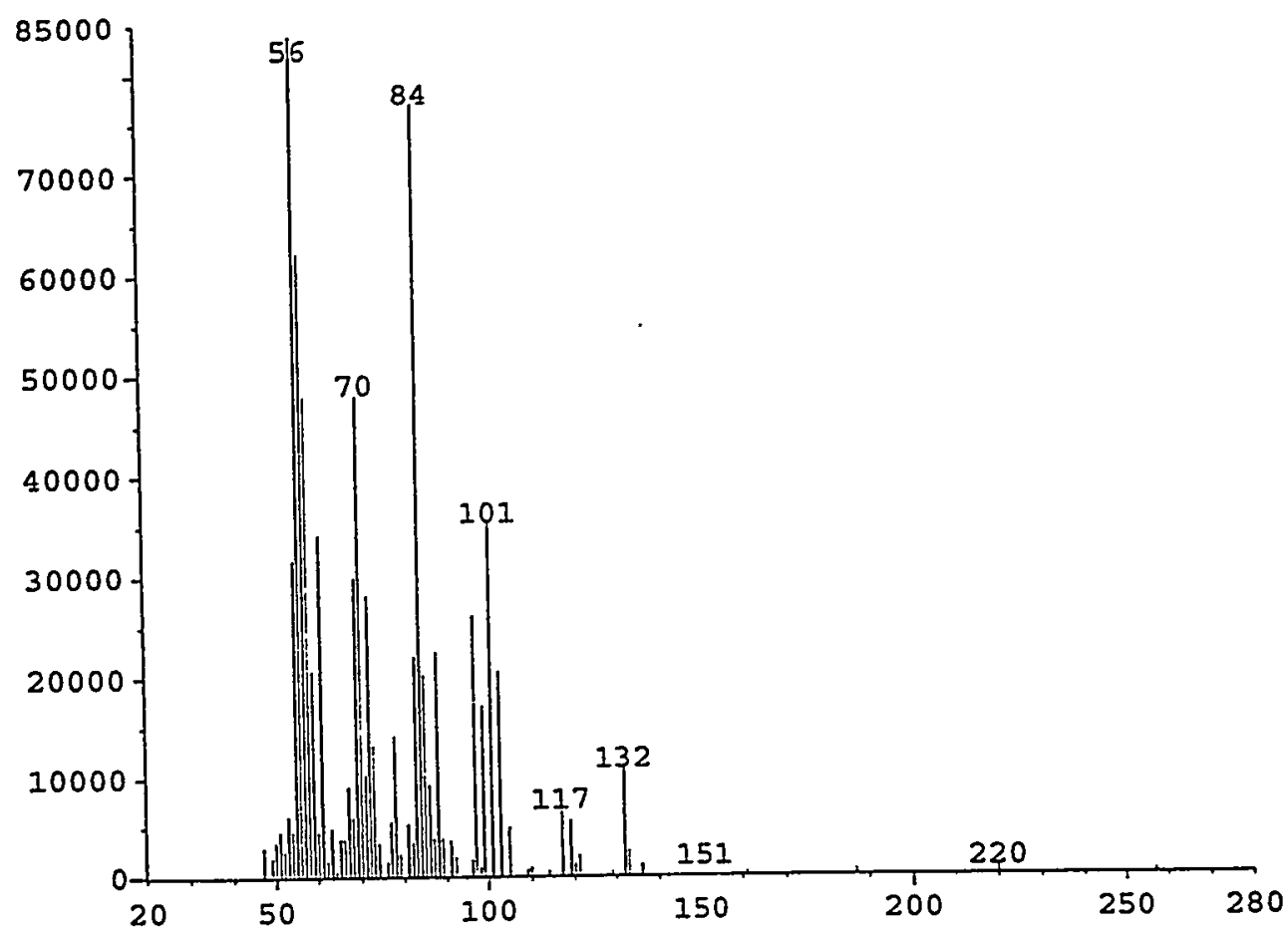

PlotData

Page: 1

$1894 \cdot 1$

0077: Scan Avg 1-28 (0.00 - $0.10 \mathrm{~min})$

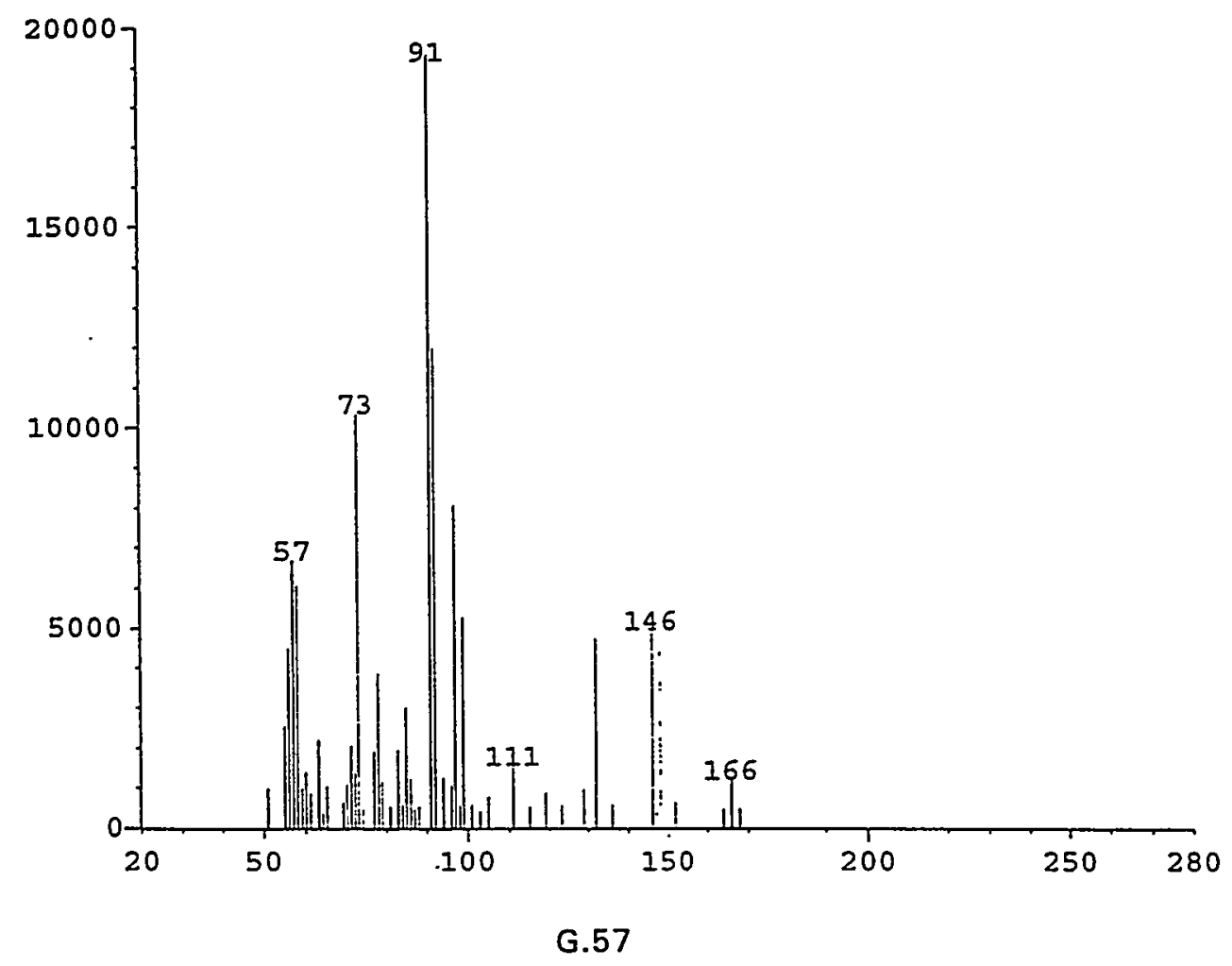




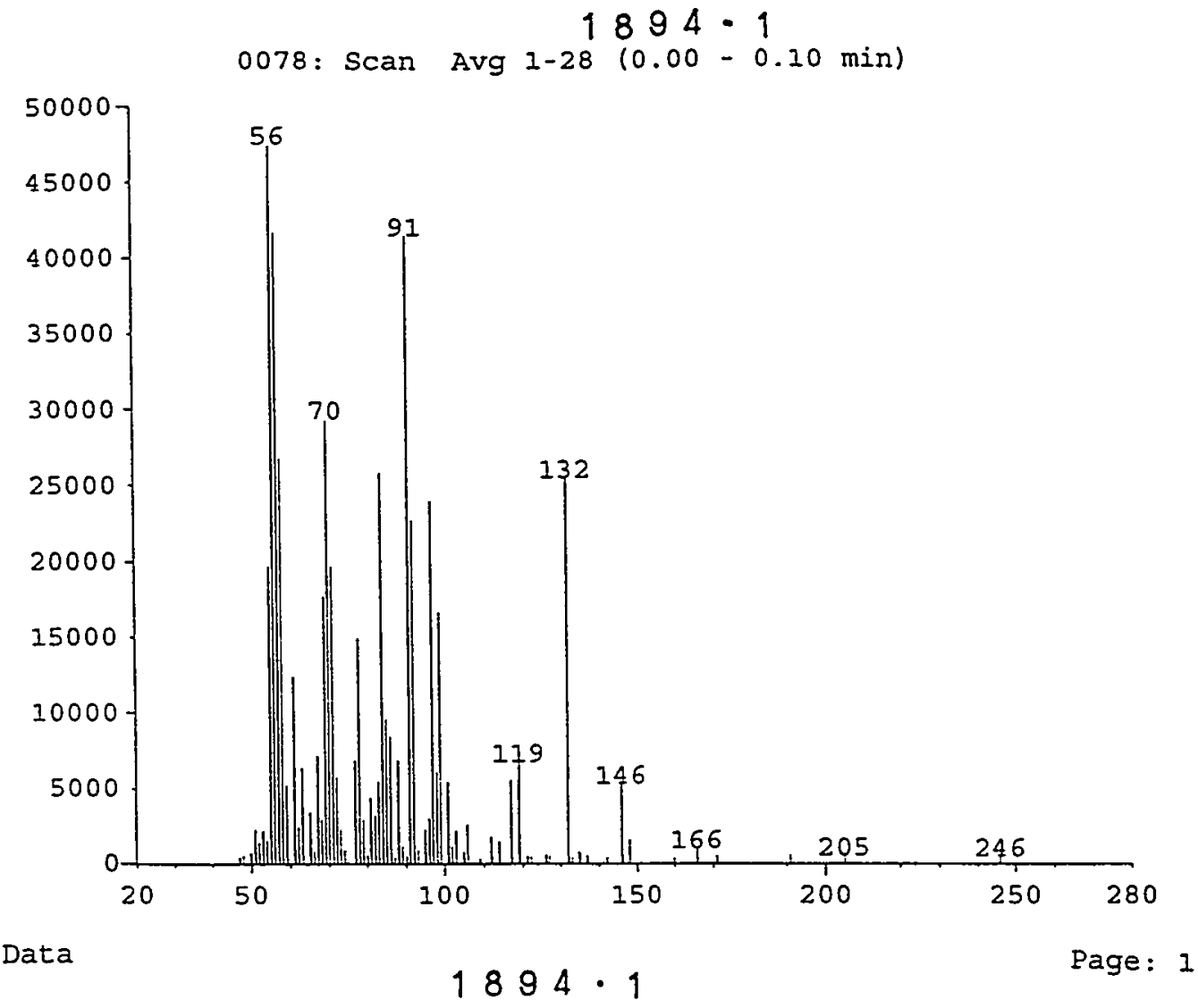

PlotData

$1894 \cdot 1$

0079: Scan Avg 1-28 (0.00-0:10 min)

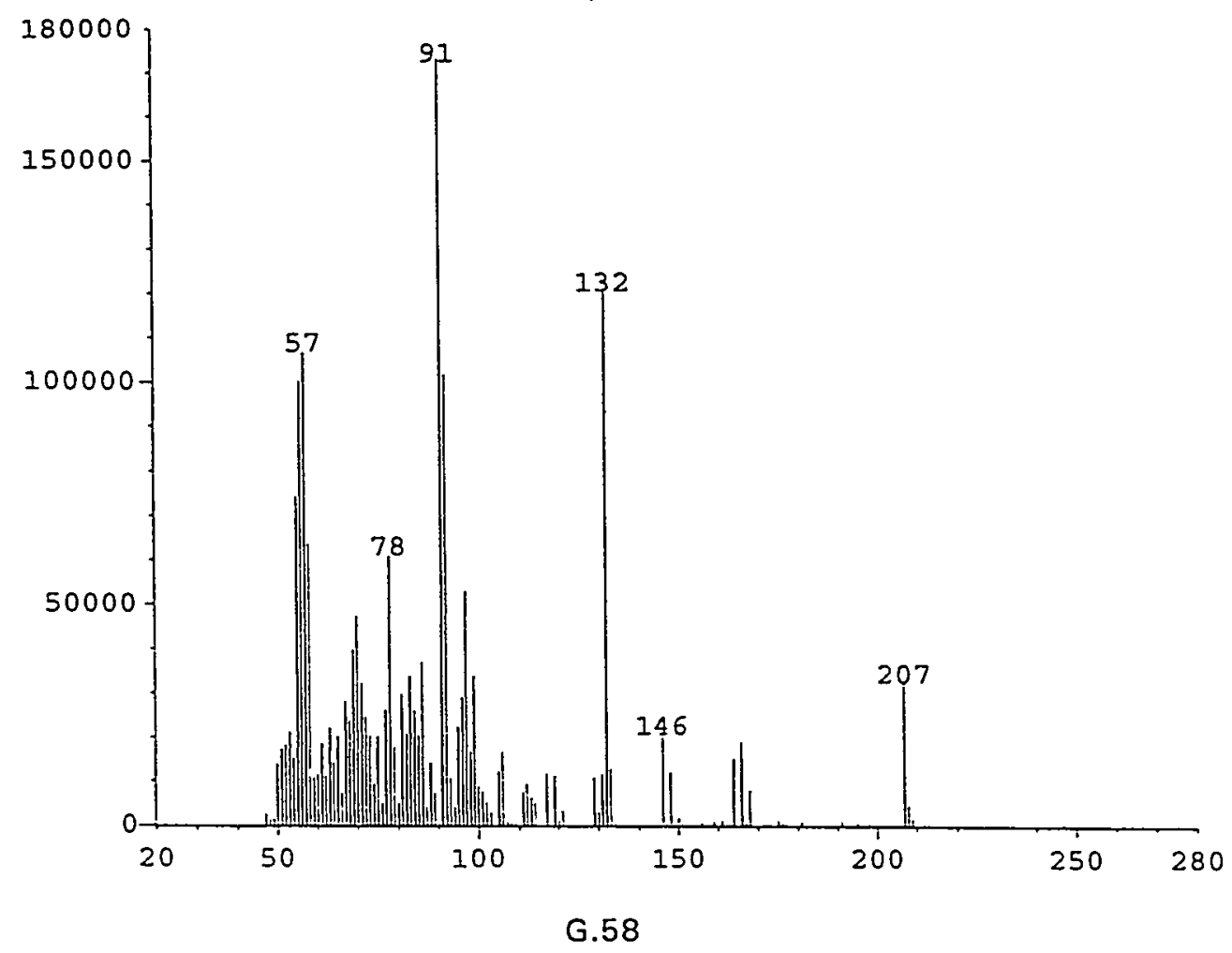


PlotData

Page: 1

$$
\begin{aligned}
& 1894 \cdot 1 \\
& 0080: \operatorname{Scan} \operatorname{Avg} 1-28(0.00-0.10 \mathrm{~min})
\end{aligned}
$$

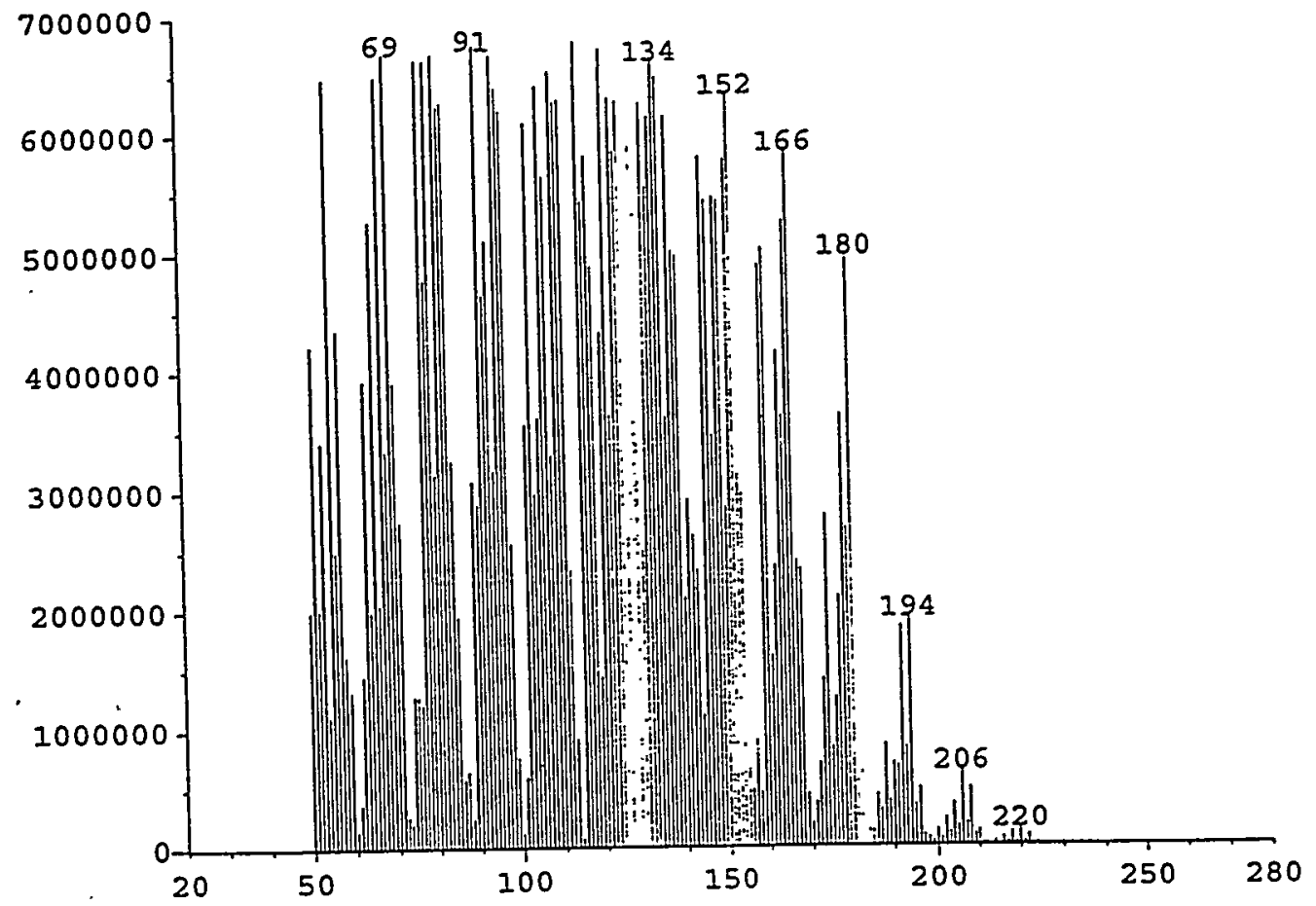

PlotData

$1894 \cdot 1$

Page: 1

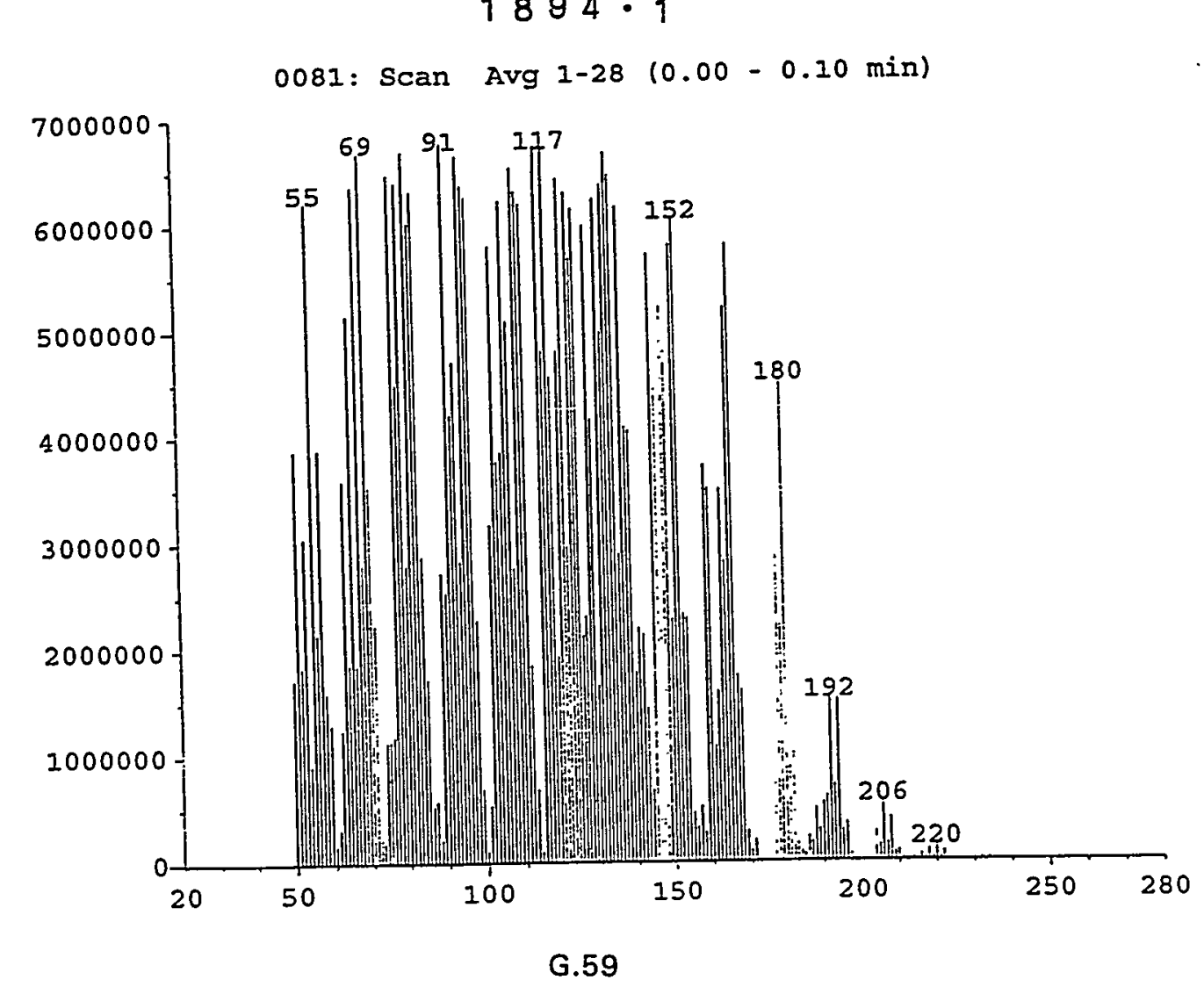




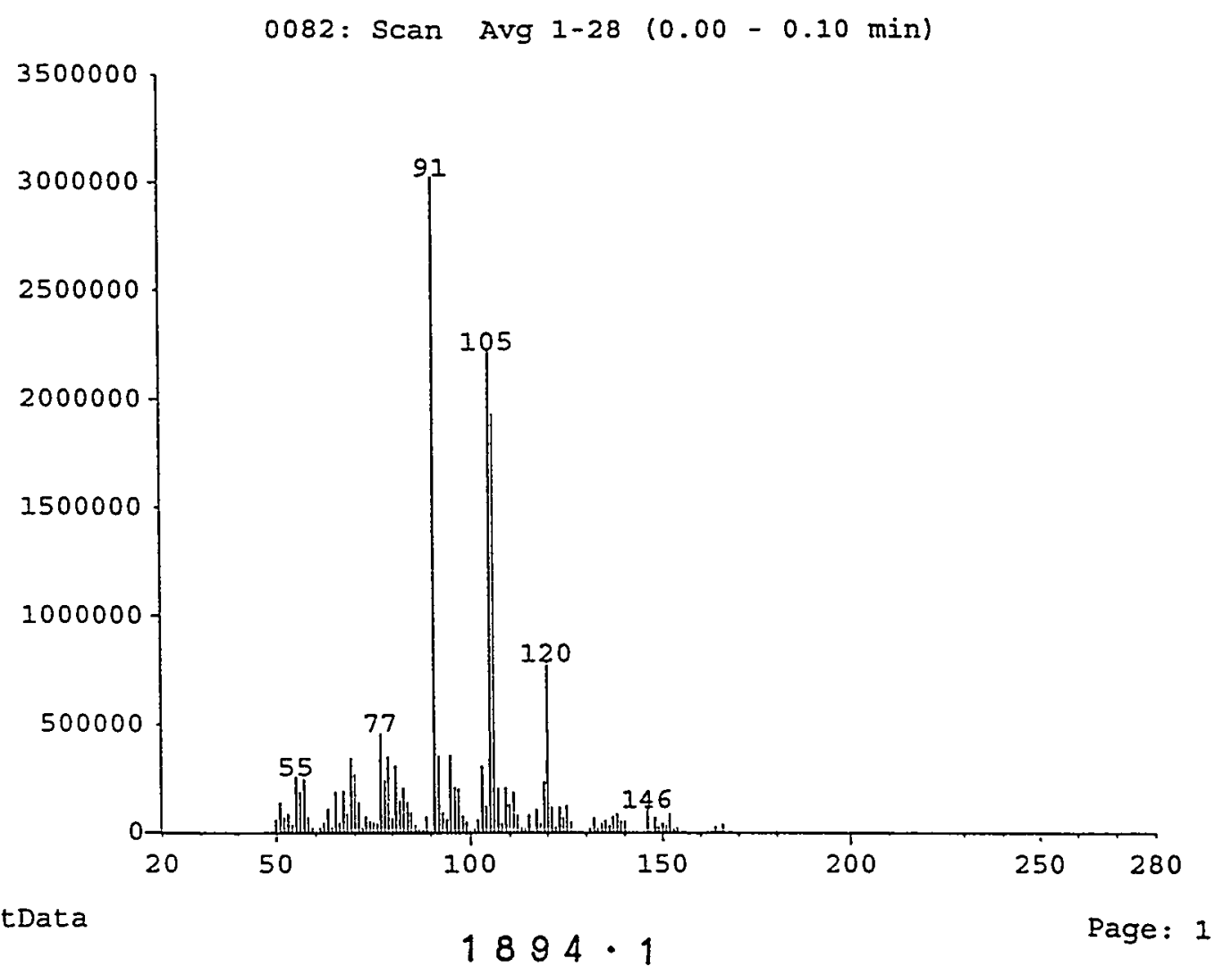

PlotData

$1894 \cdot 1$

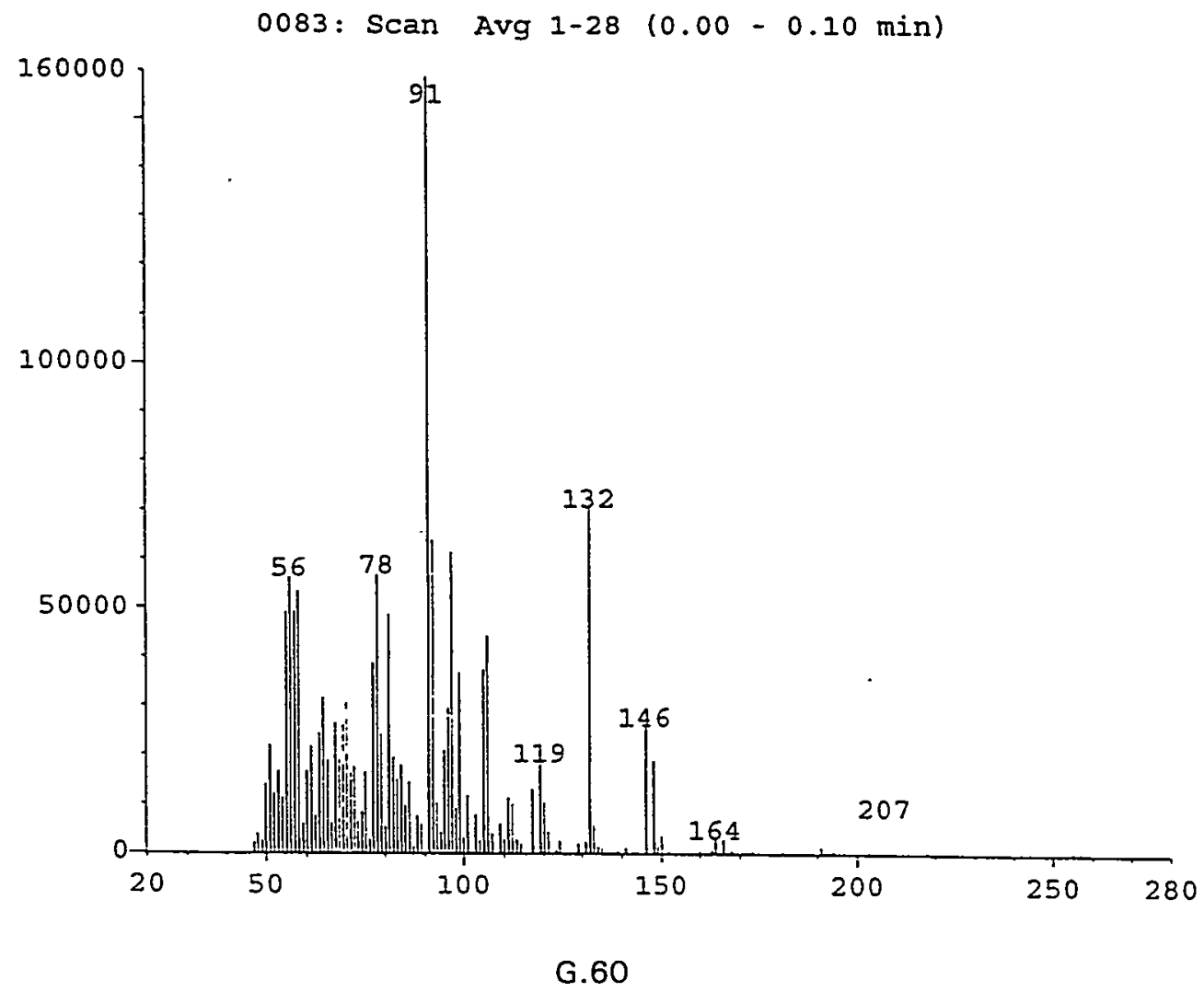




$$
\begin{aligned}
& 1894 \cdot 1 \\
& 0084: \operatorname{Scan} \operatorname{Avg} 1-28(0.00-0.10 \mathrm{~min})
\end{aligned}
$$

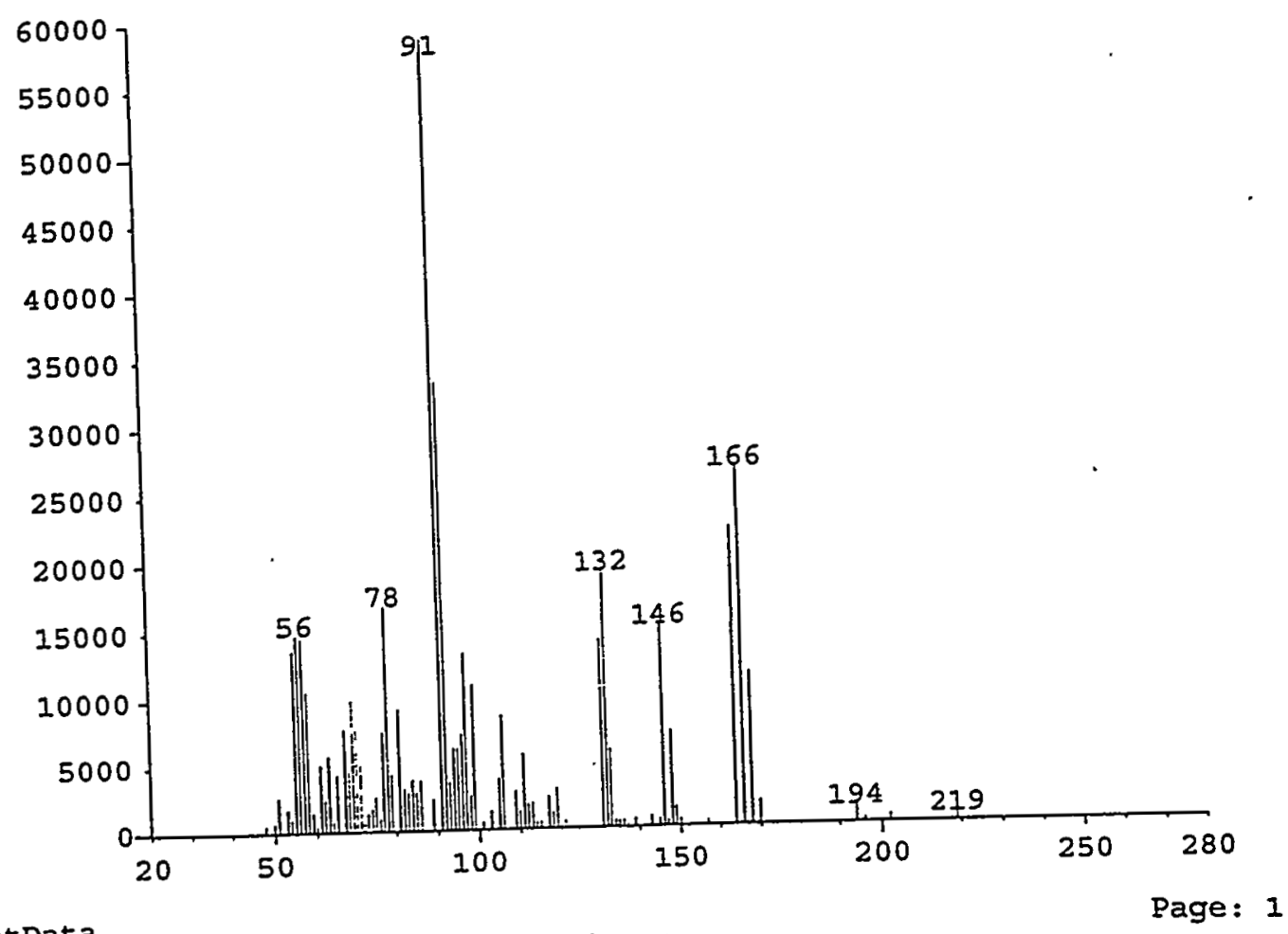

PlotData

$1894 \cdot 1$

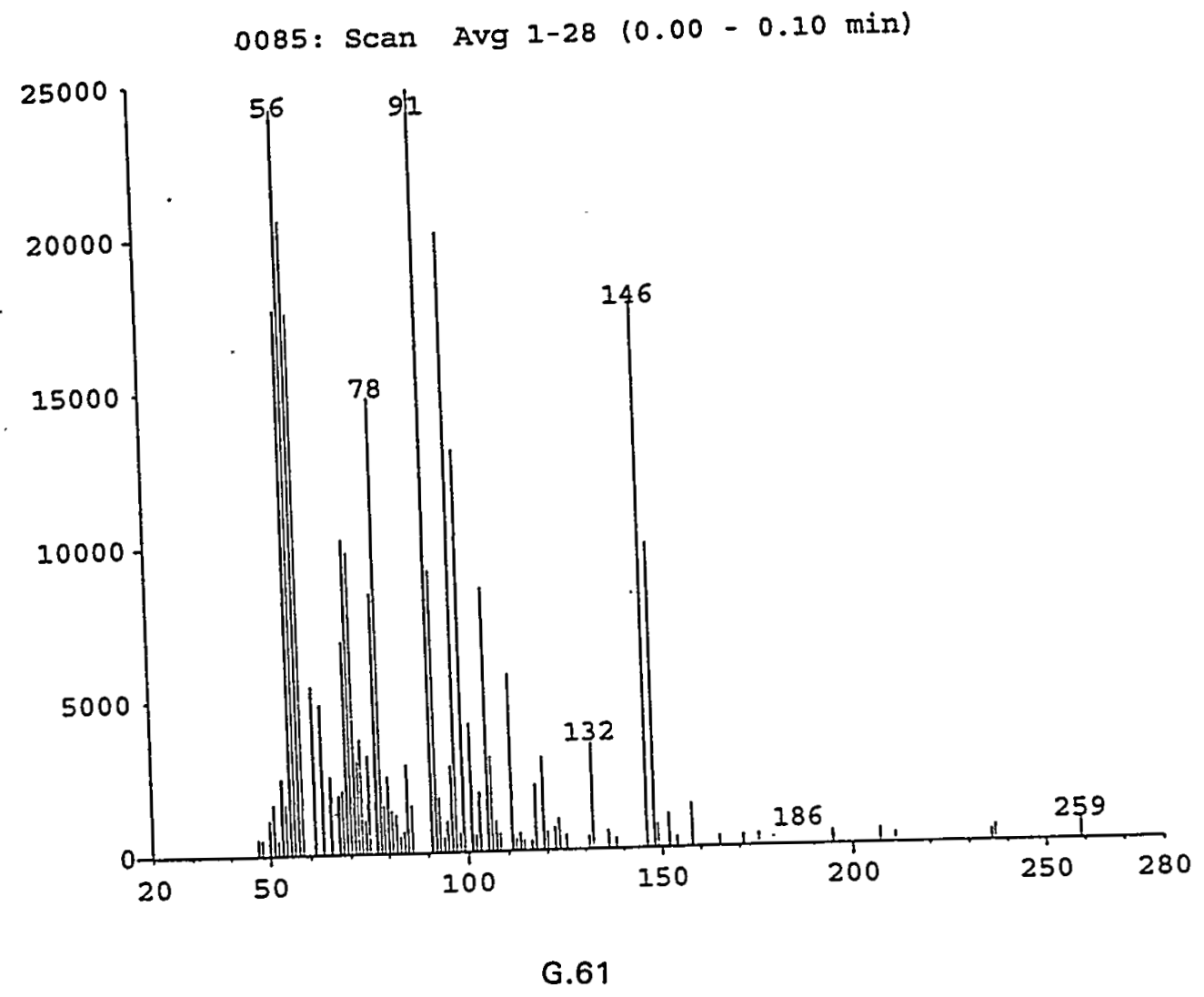


$1884 \cdot 1$

1001

0086 : Scan Avg 1-28 (0.00-0.10 min)

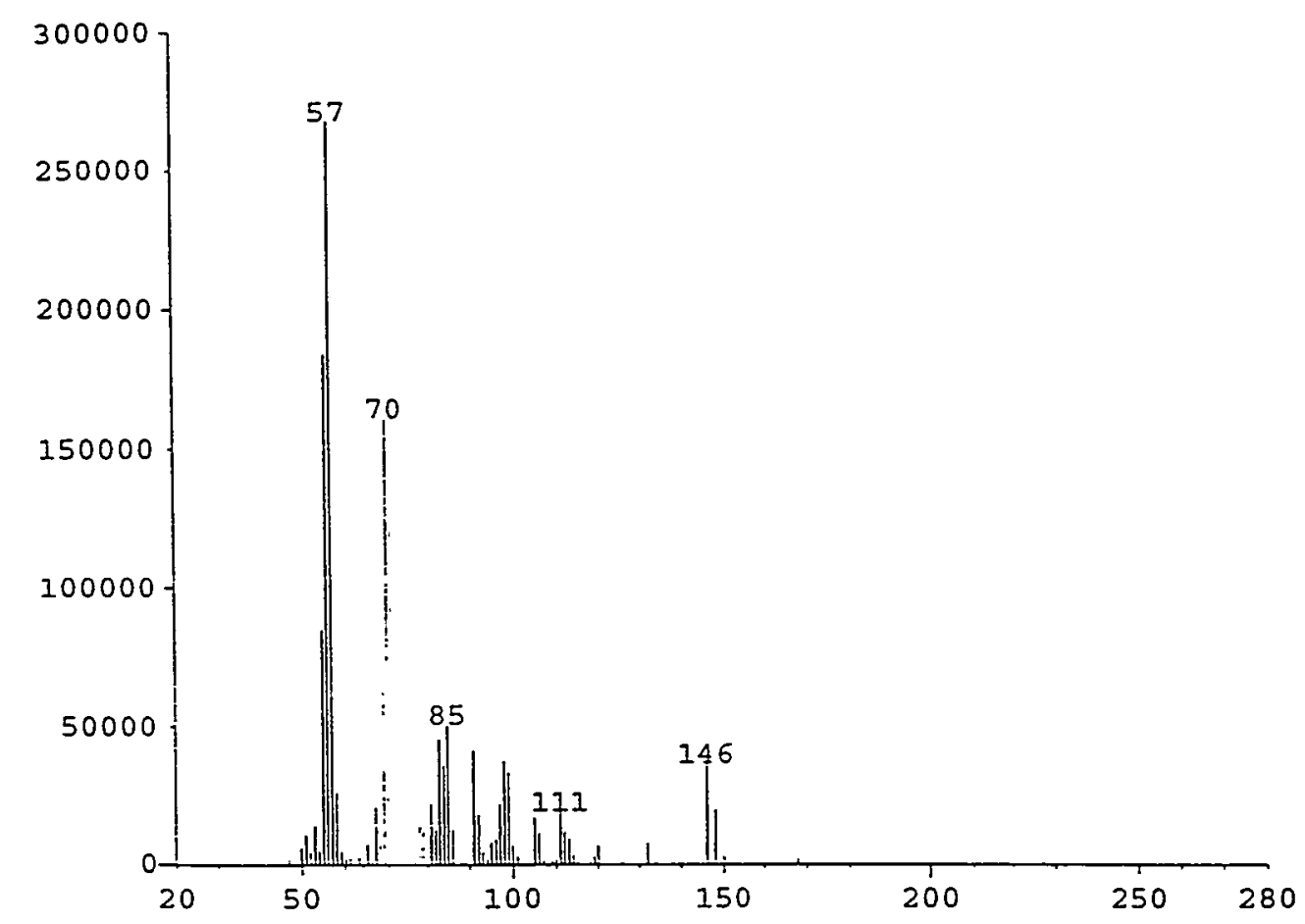

PlotData

$1894 \cdot 1$

Page: 1

0087: Scan Avg 1-28 (0.00-0.10 min)

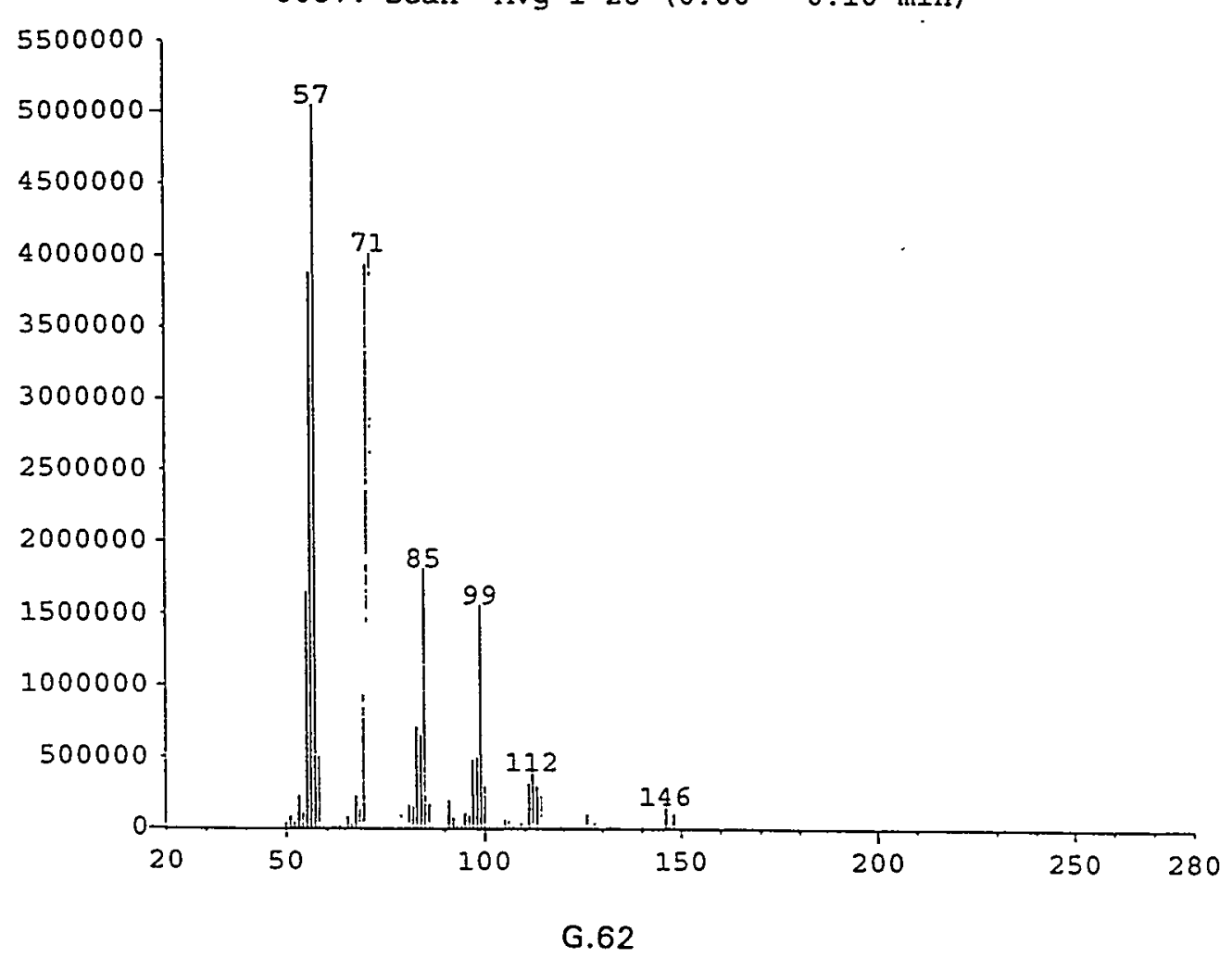



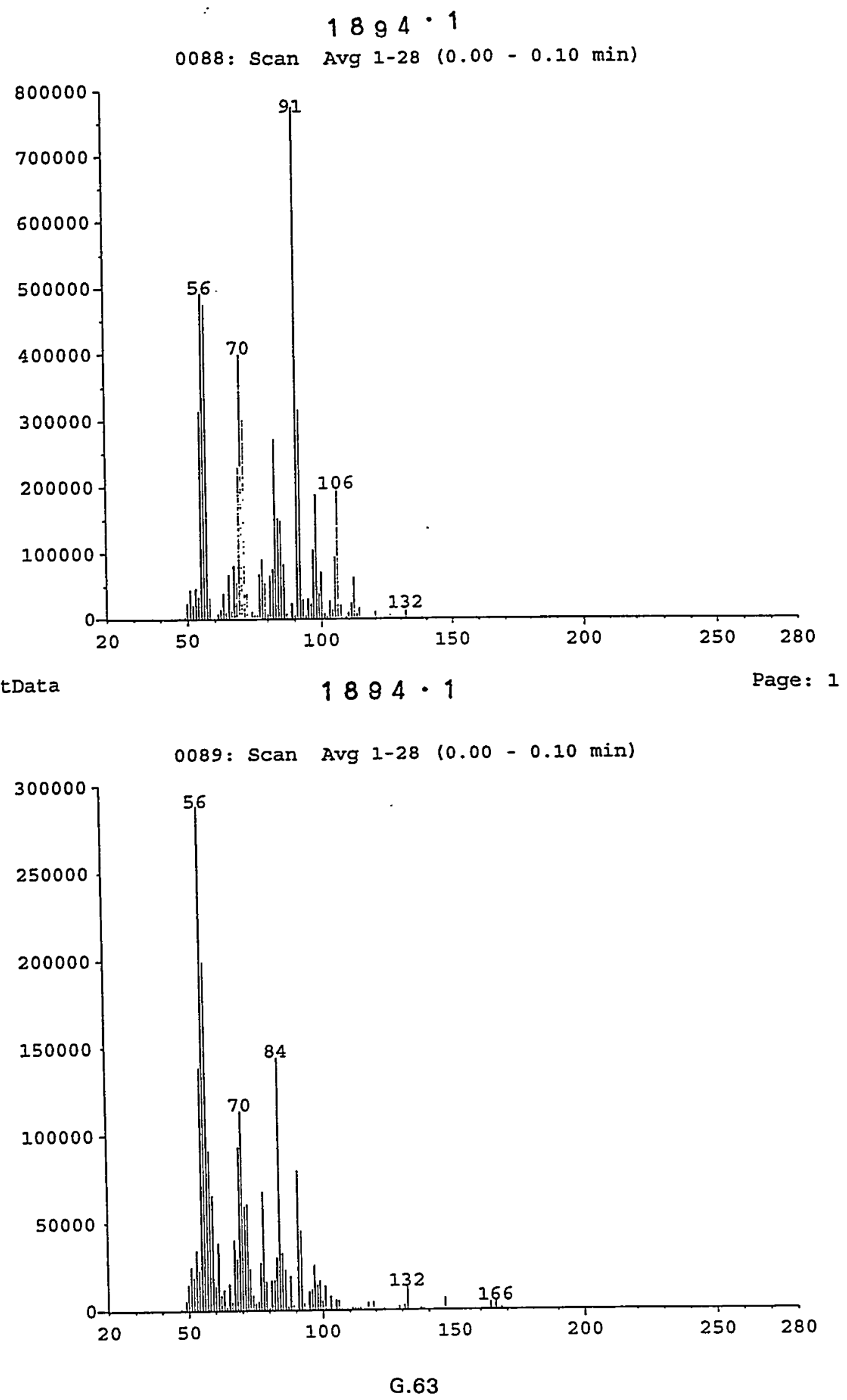
PlotData

$1894 \cdot 1$

Page: 1

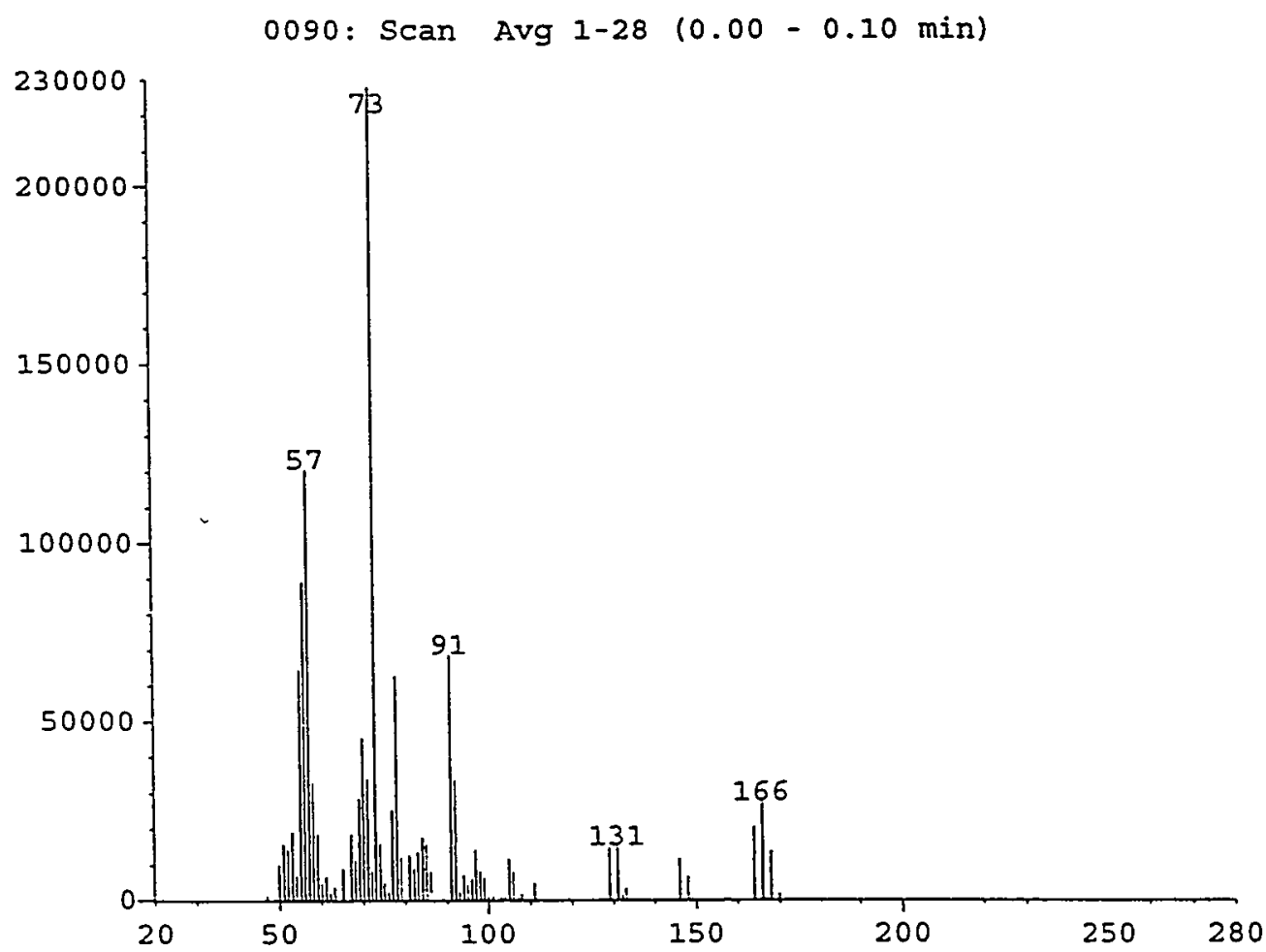

PlotData

$1894 \cdot 1$

Page: 1

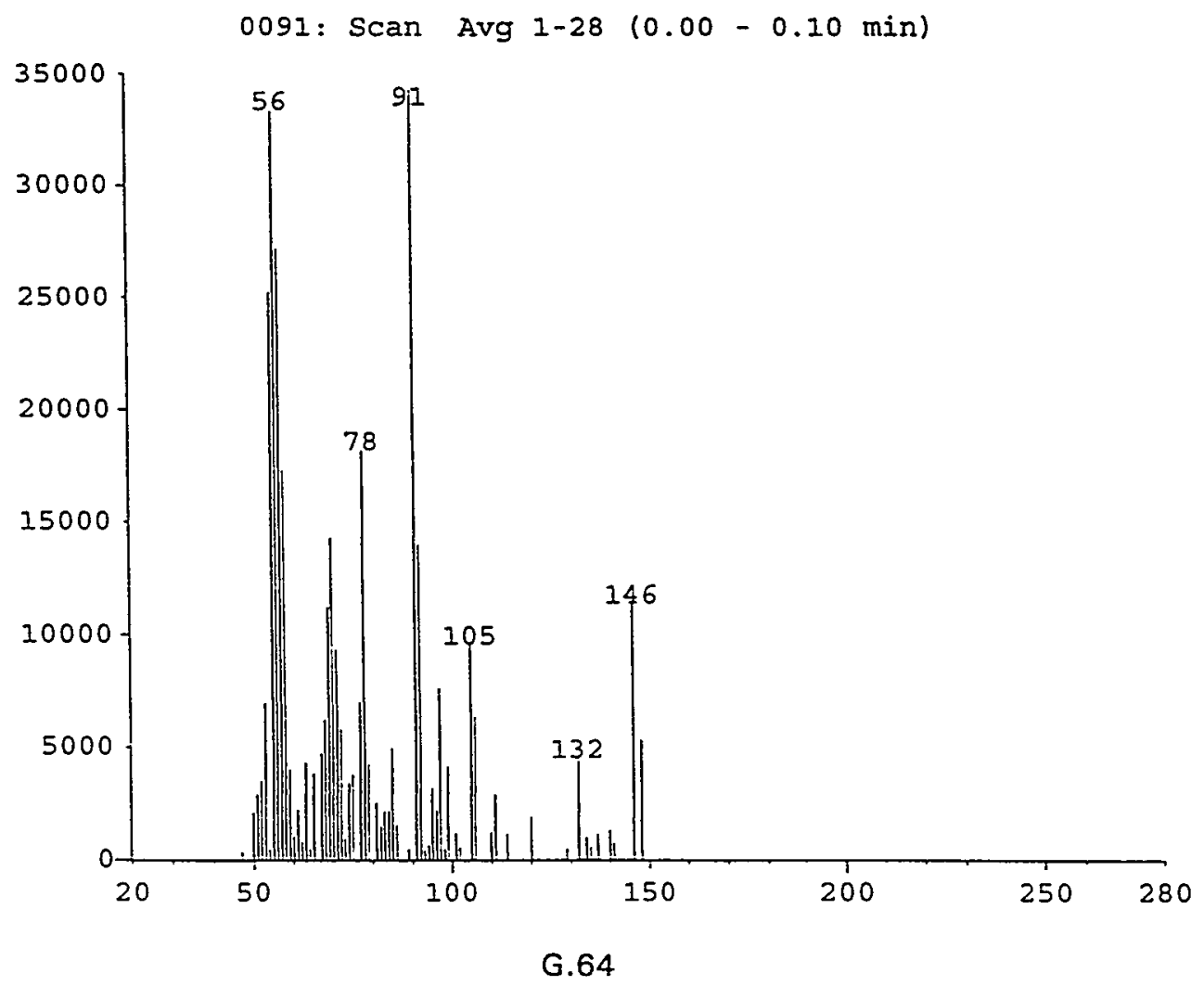




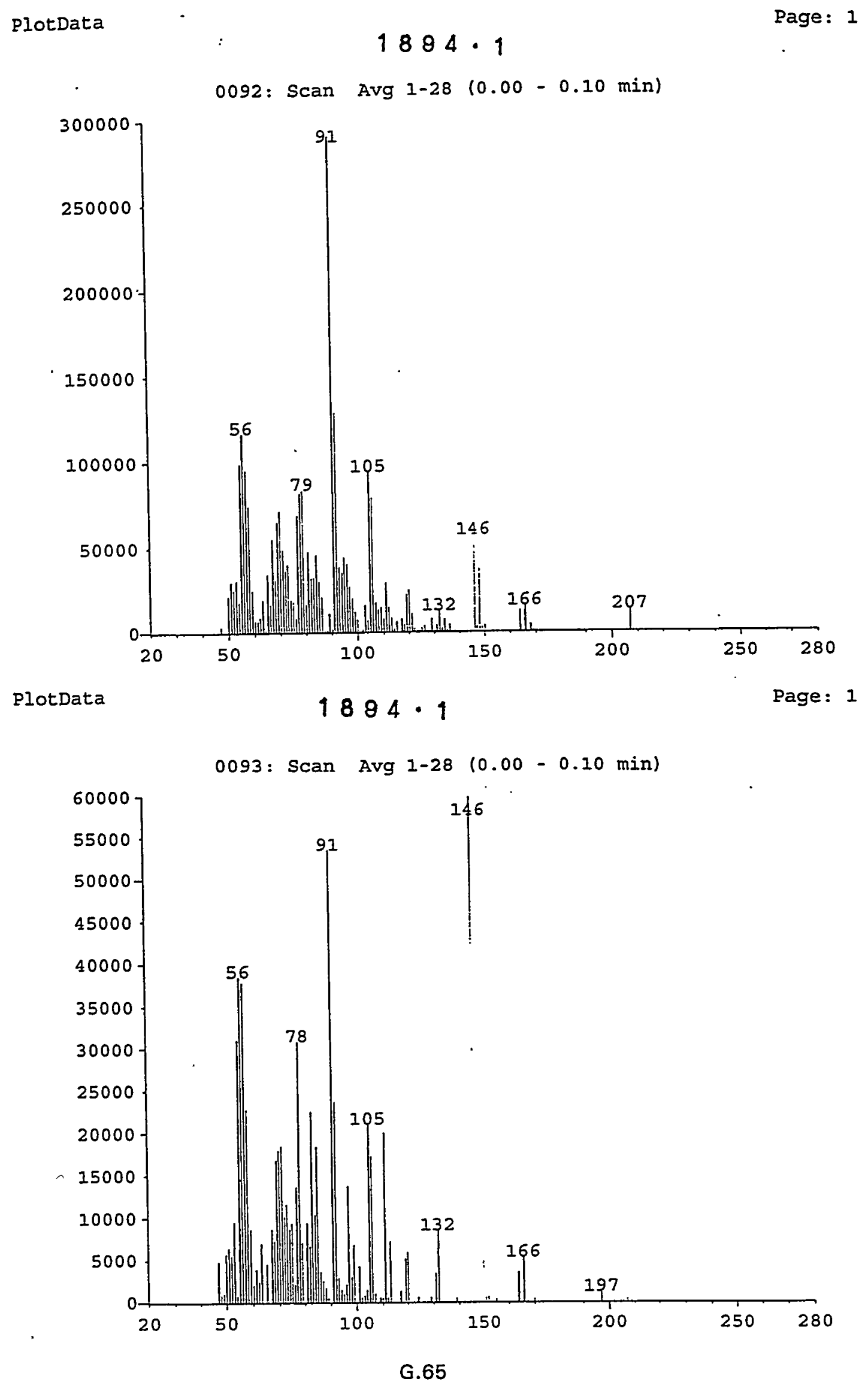


$1894 \cdot 1$

0094: Scan Avg 1-28 (0.00-0.10 min)

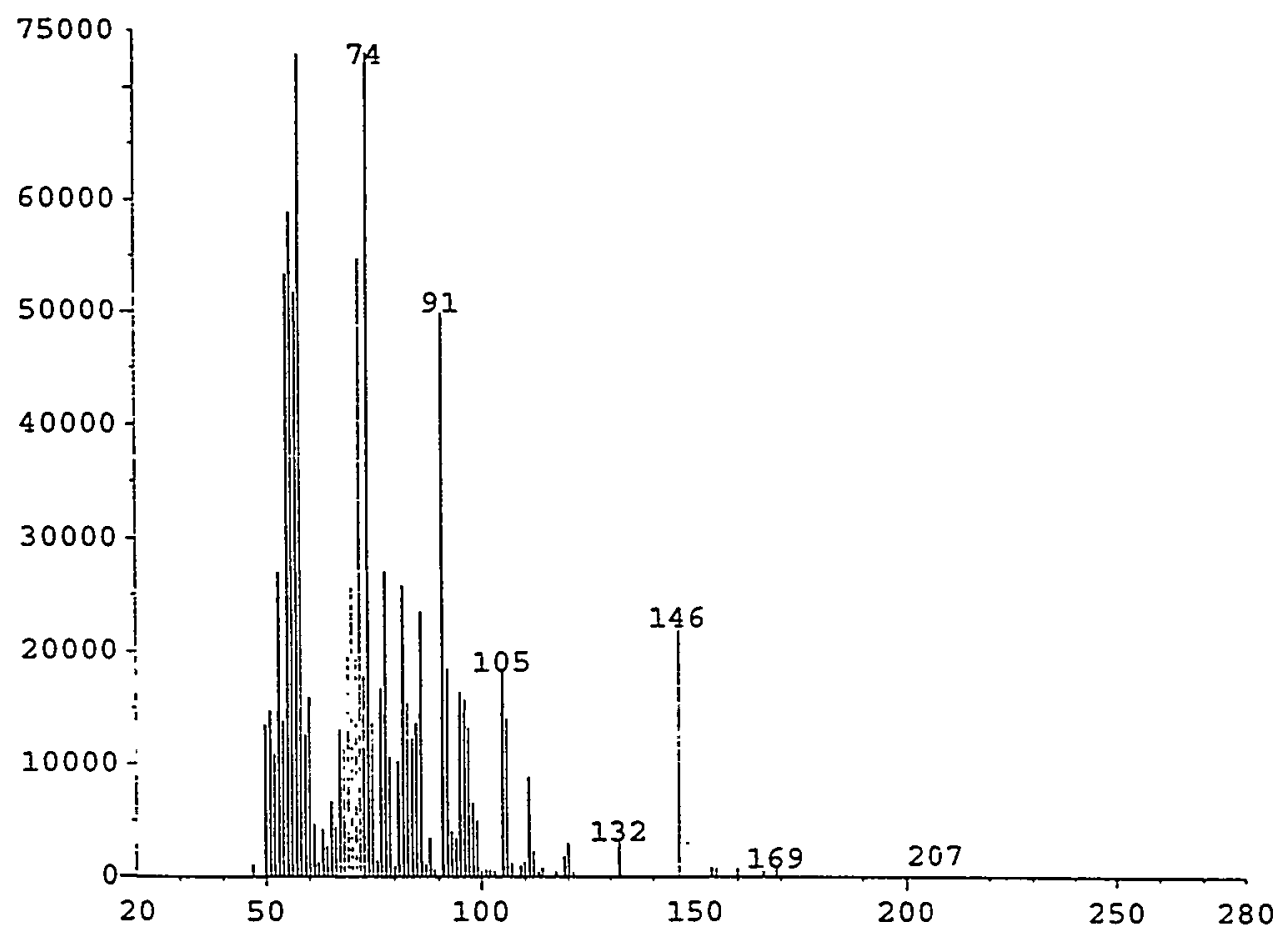

PlotData

$1894 \cdot 1$

Page: 1

0095: Scan Avg 1-28 (0.00-0.10 min)

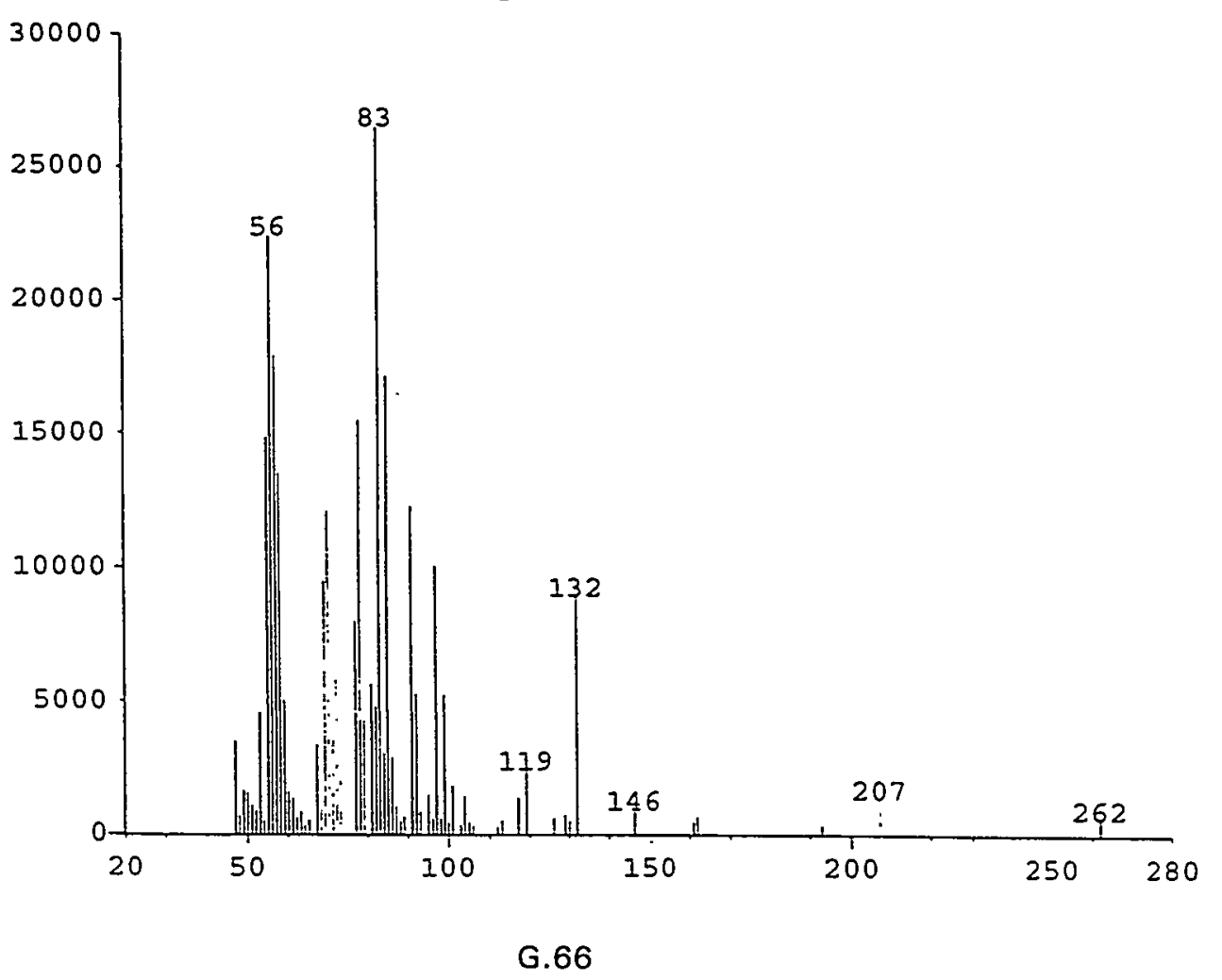


PlotData

$1894 \cdot 1$

Page: 1

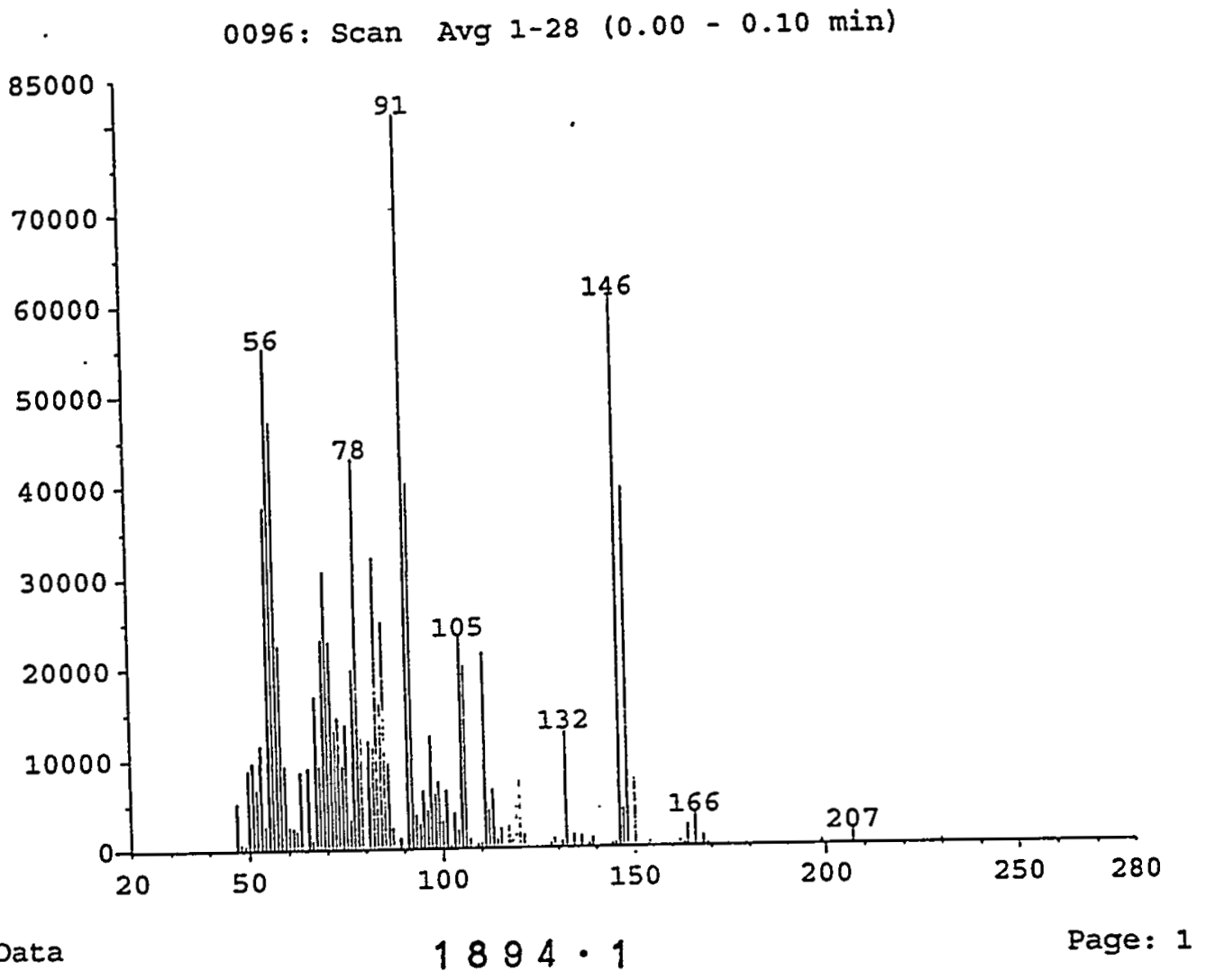

PlotData

$1894 \cdot 1$

$0097:$ Scan Avg $1-28(0.00-0.10 \mathrm{~min})$

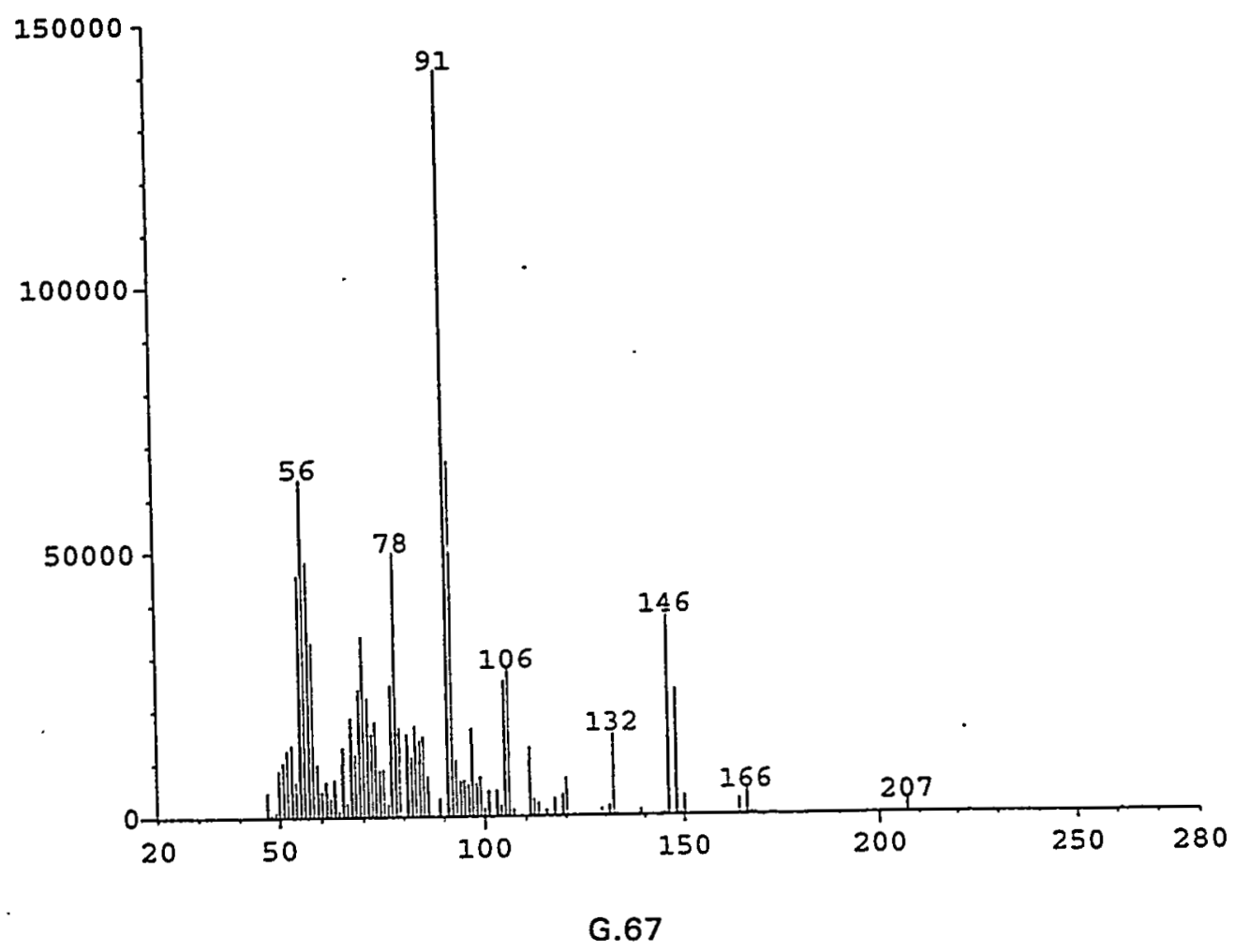




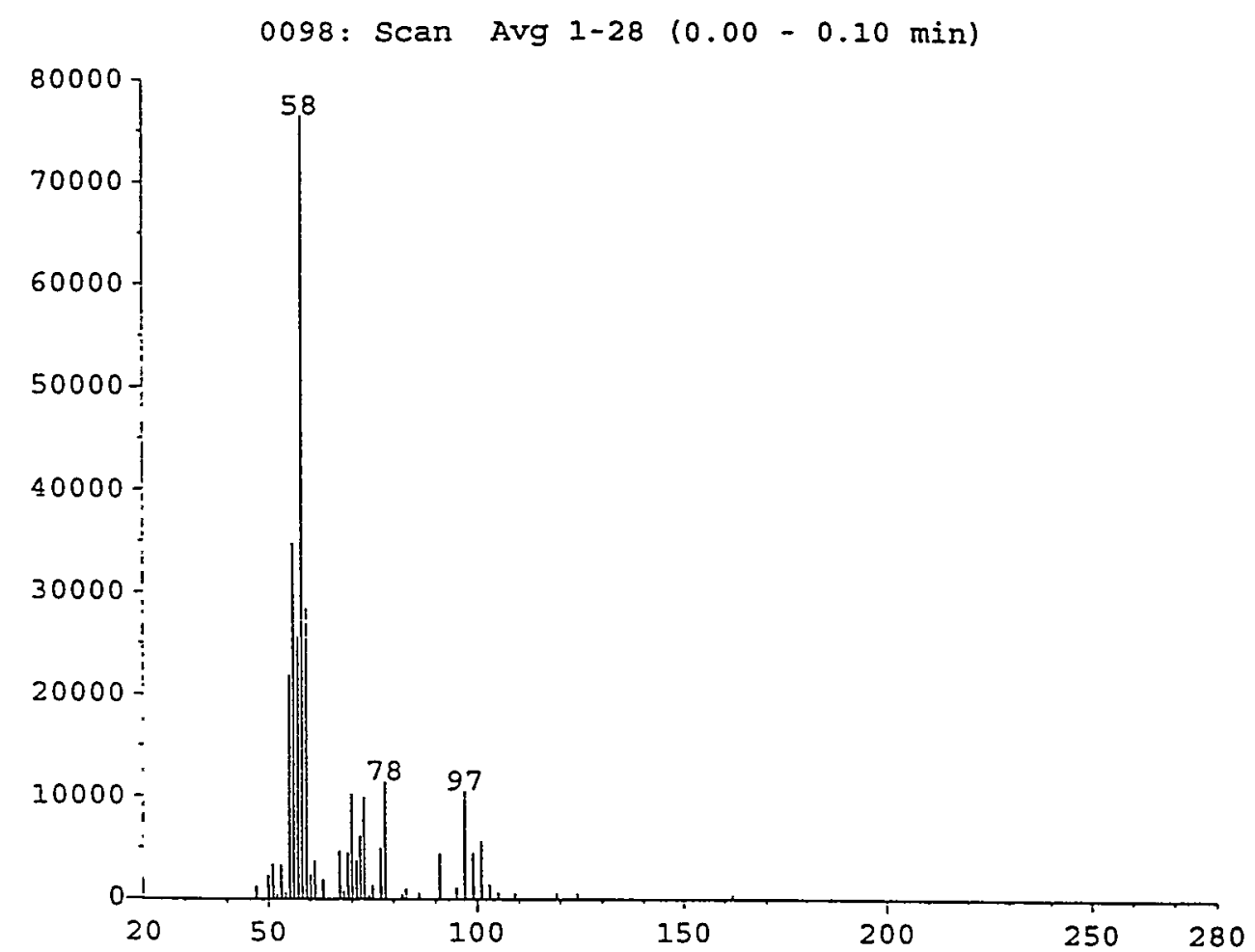

plotData

$$
1884 \cdot 1
$$

Page: 1

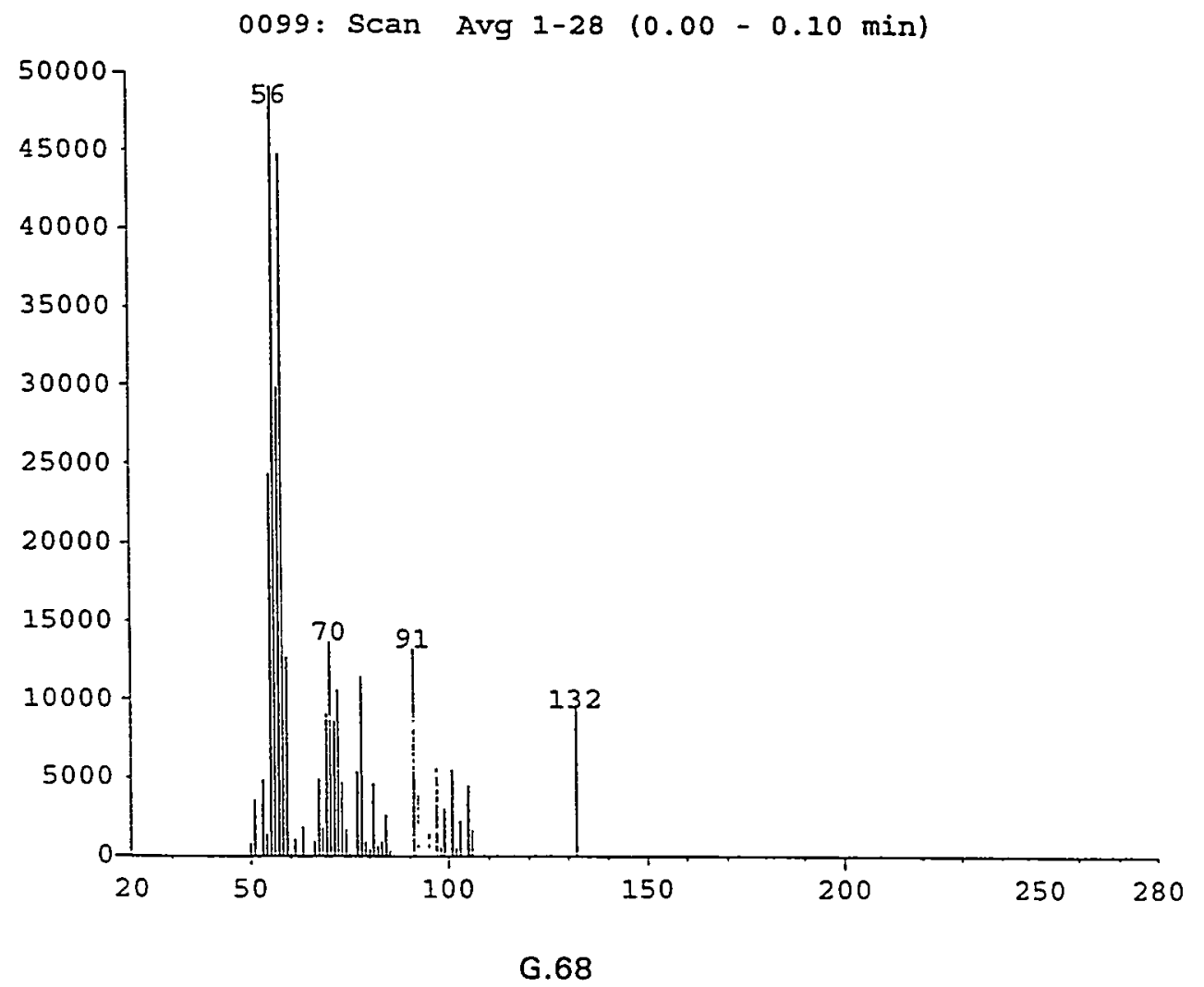


Plotbata

$1894 \cdot 1$

Page: 1

:

0100: Scan Avg 1-28 (0.00-0.10 min)

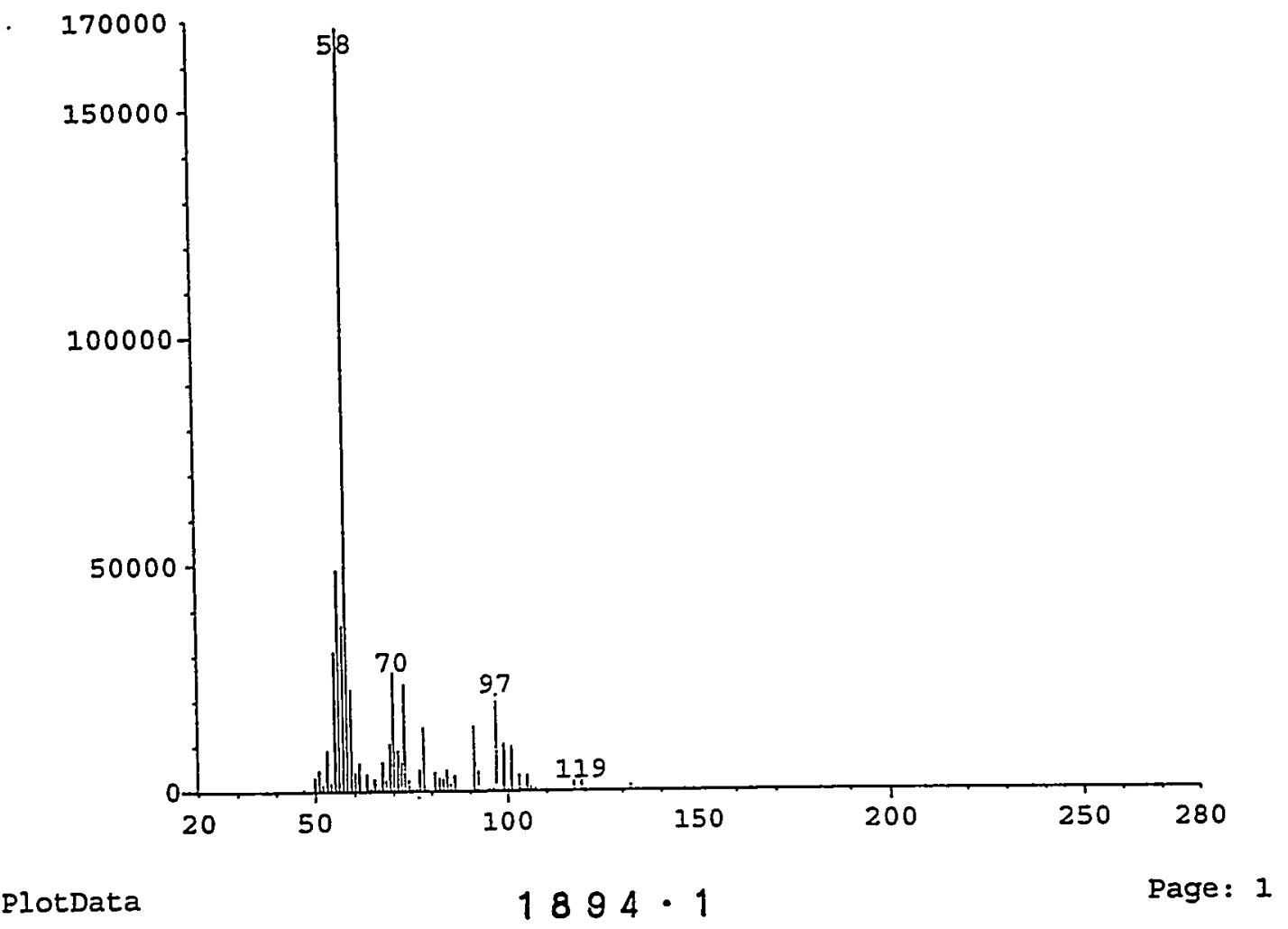

PlotData

$1894 \cdot 1$

0101: Scan Avg 1-28 (0.00-0.10 min)

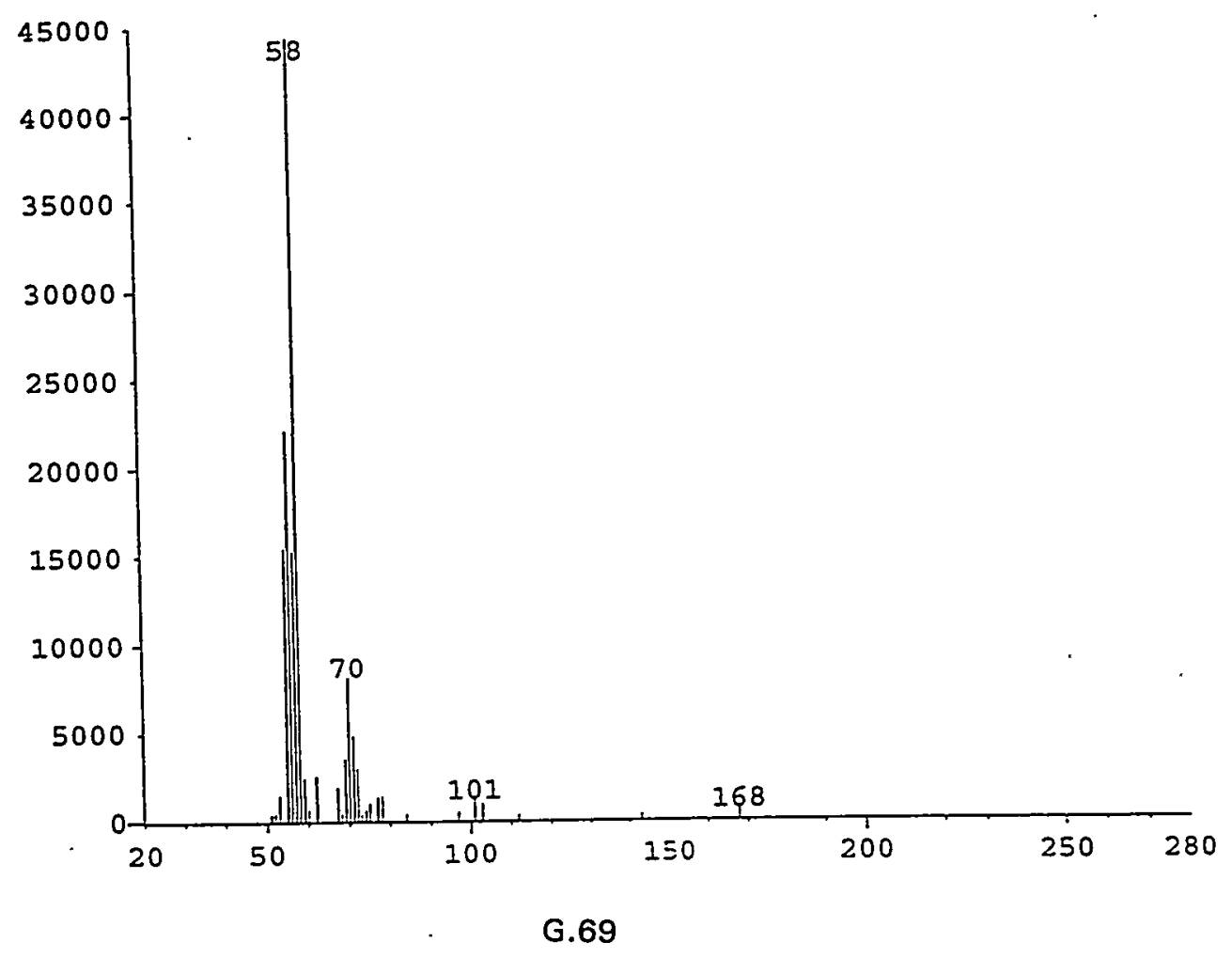


PlotData

$1894 \cdot 1$

Page: 1

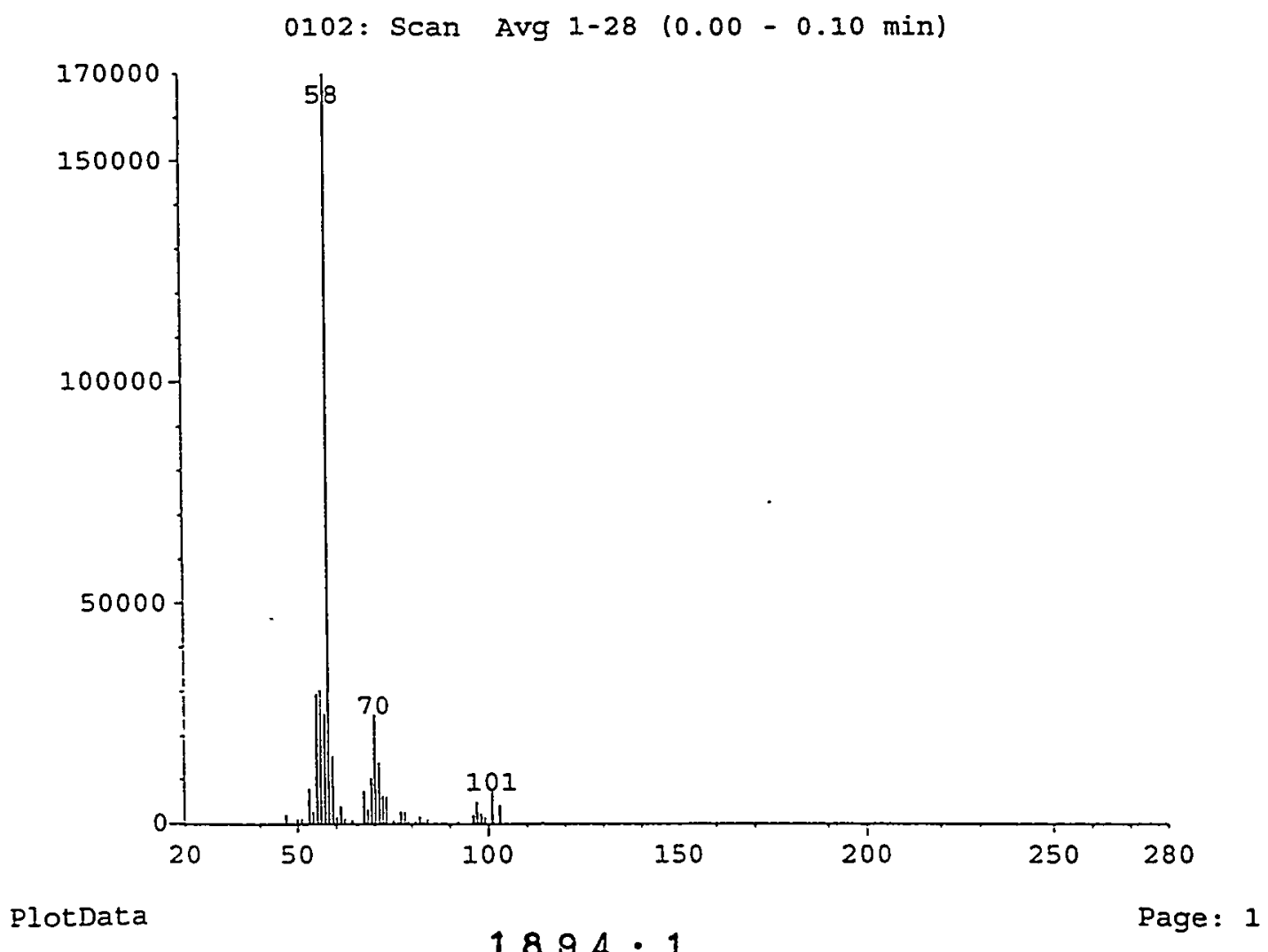

$1894 \cdot 1$

$0103:$ Scan Avg 1-28 (0.00-0.10 min)

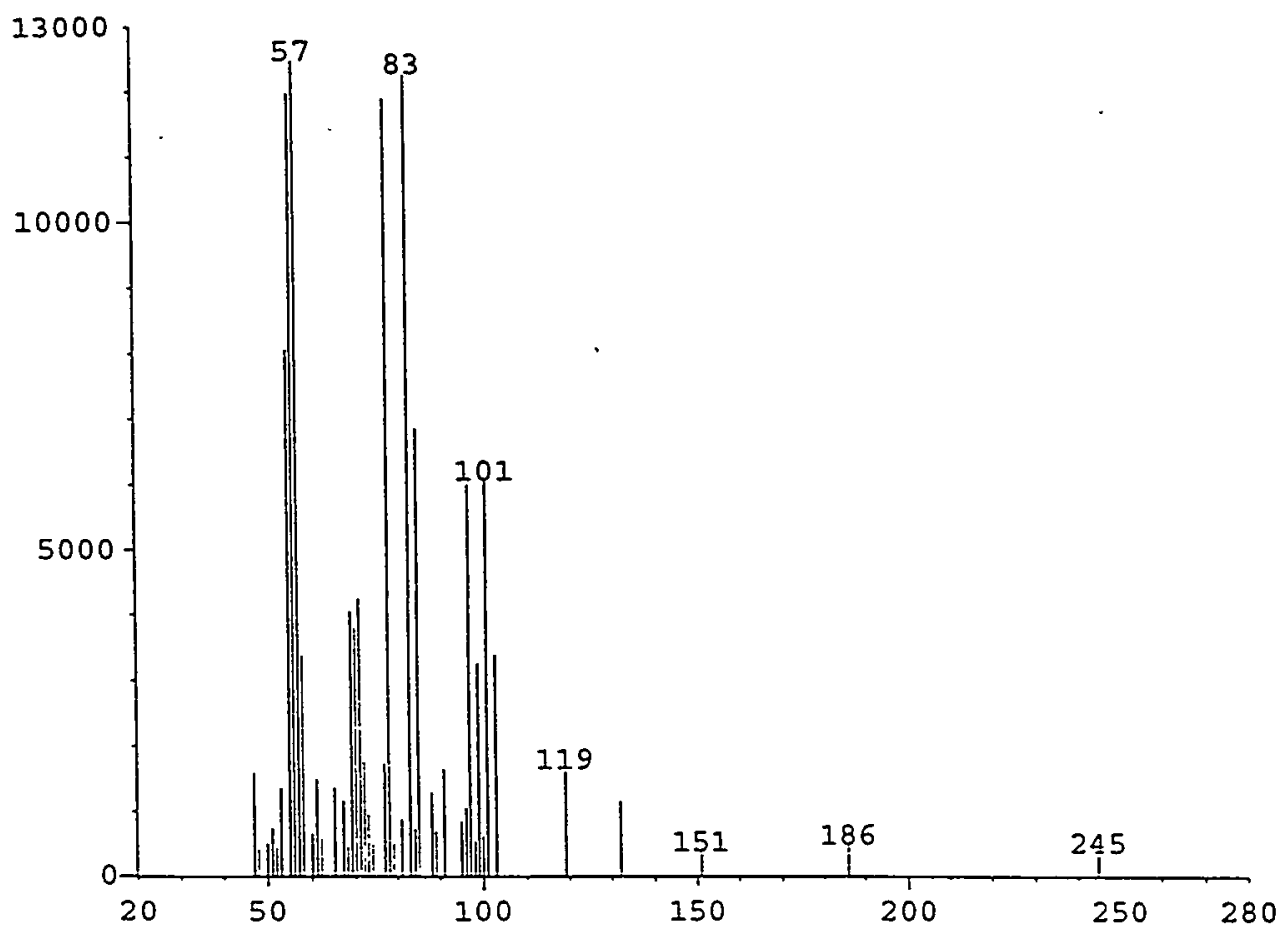

G.70 


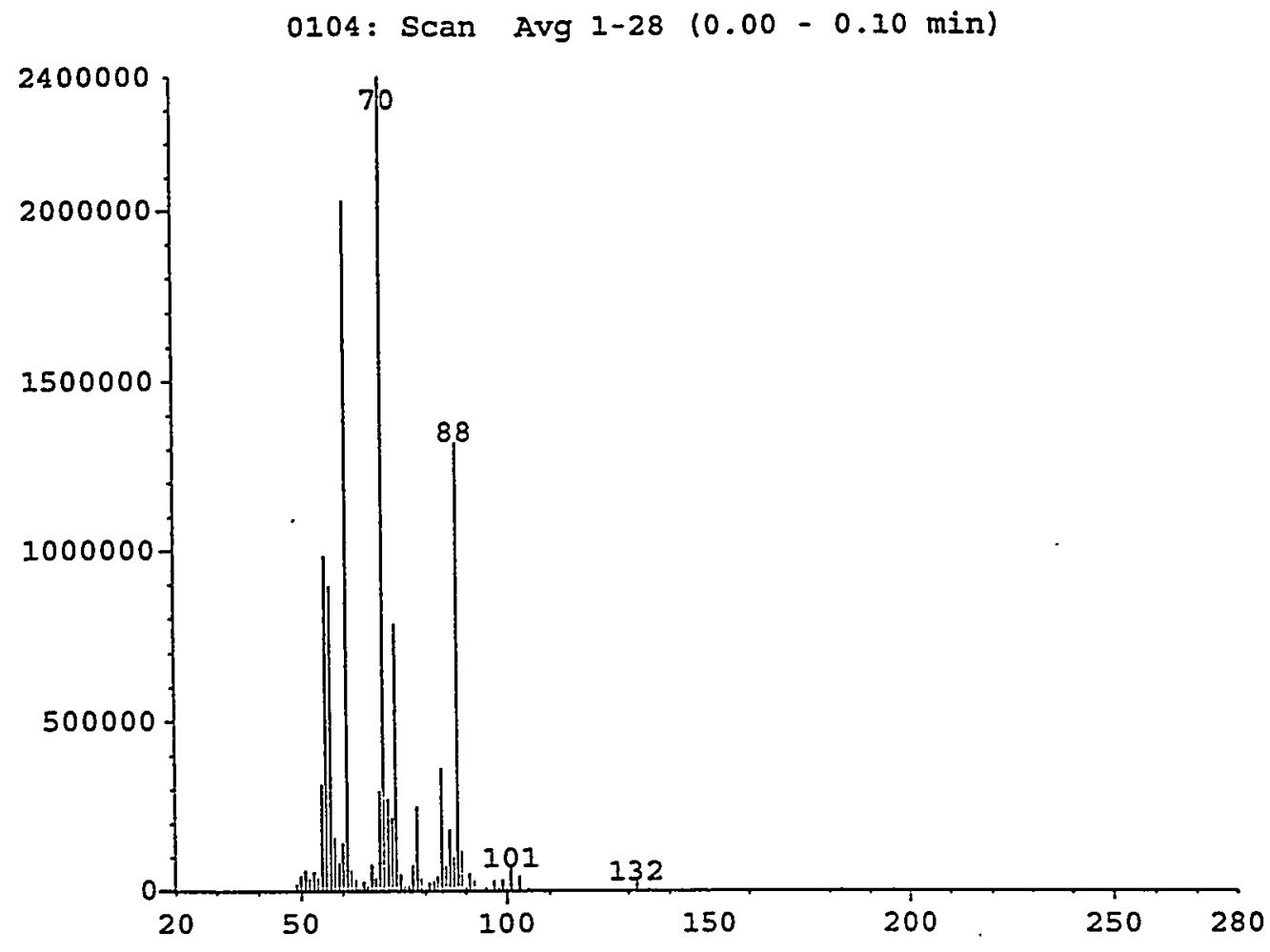

PlotData

$1894 \cdot 1$

Page: 1

$0105:$ Scan Avg 1-28 (0.00-0.10 min)

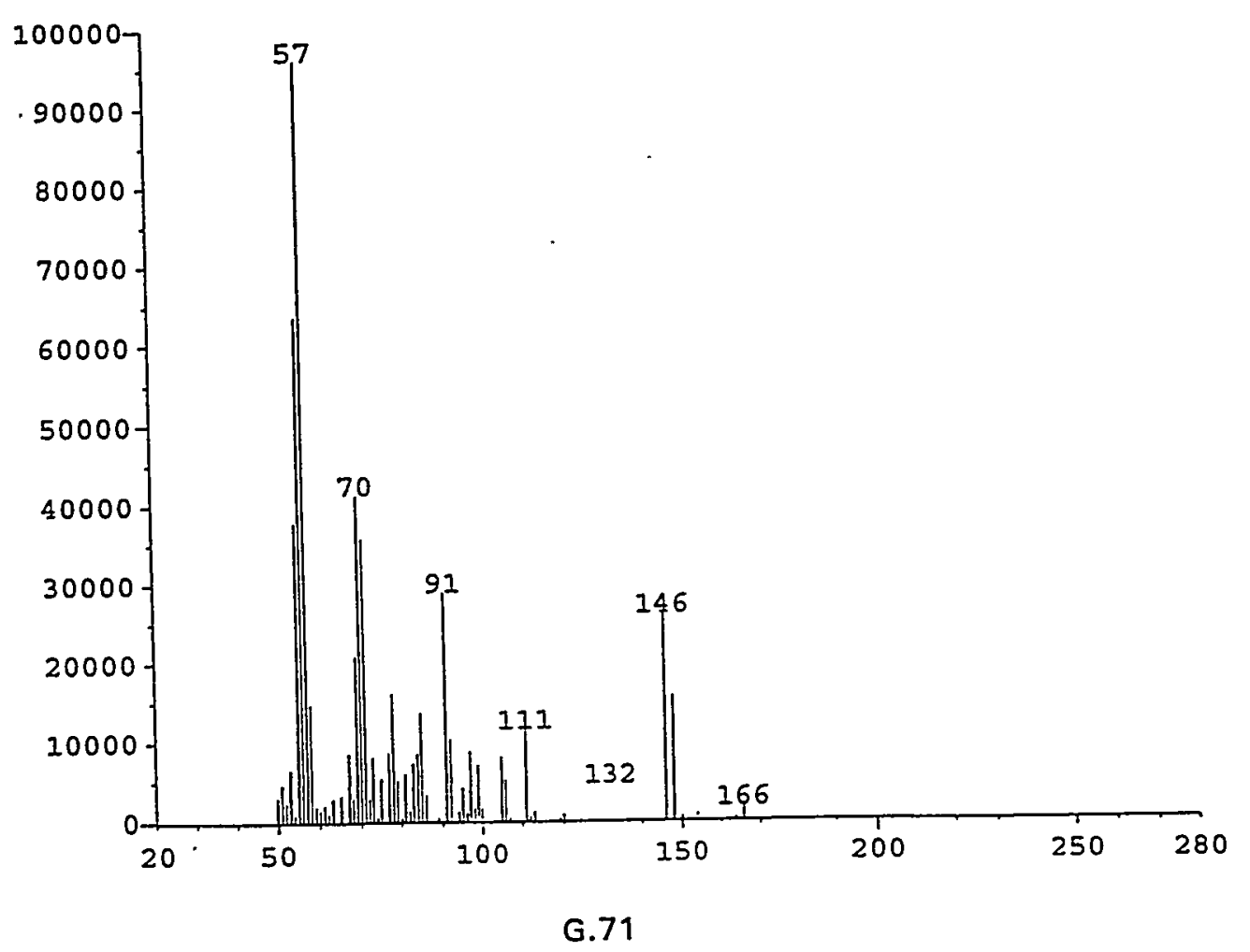


PlotData

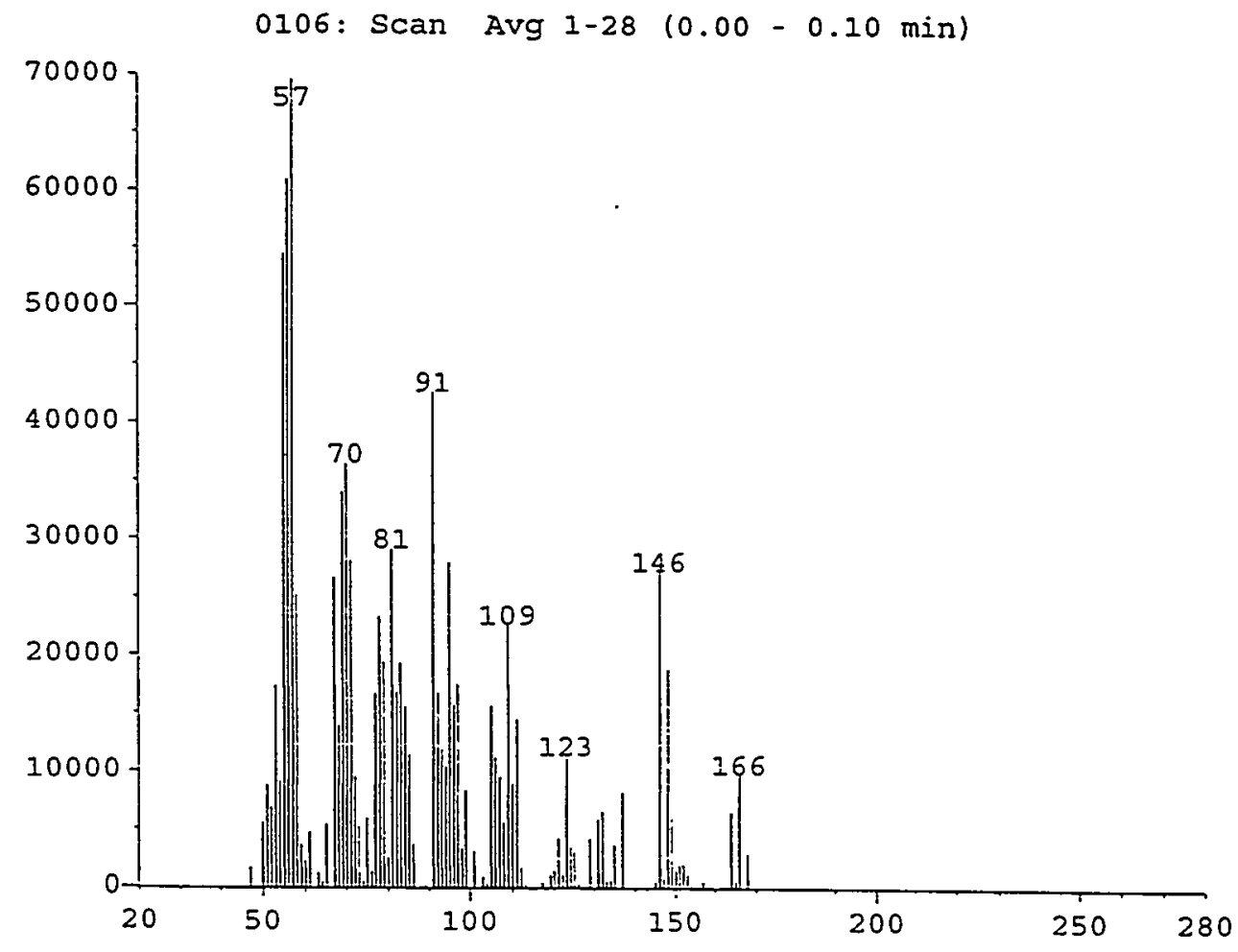

PlotData

$1894 \cdot 1$

Page: 1

0107: Scan Avg 1-28 (0.00-0.10 min)

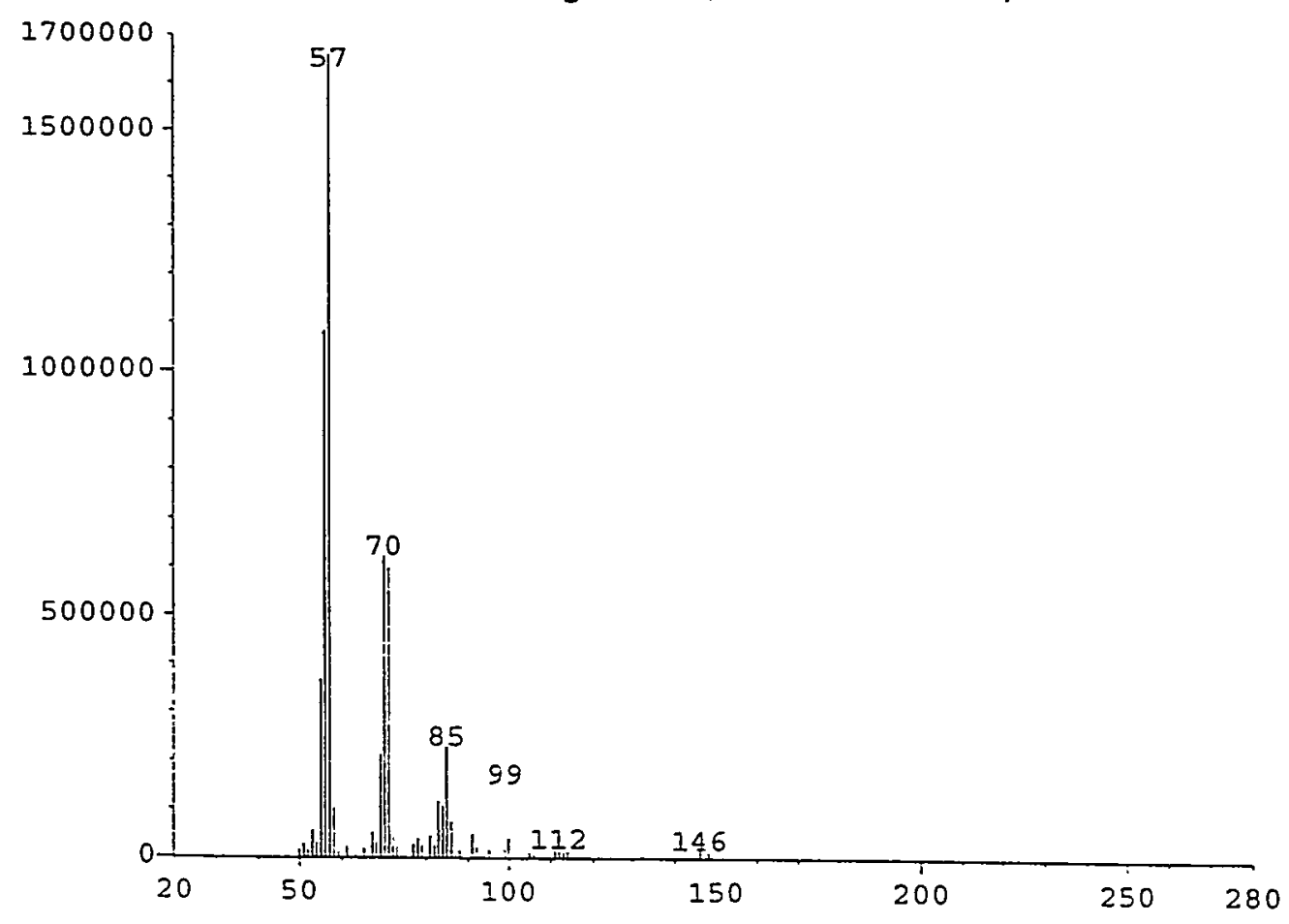

G.72 
PlotData

$\therefore \quad 1894 \cdot 1$

0108: Scan Avg 1-28 (0.00 - $0.10 \mathrm{~min})$

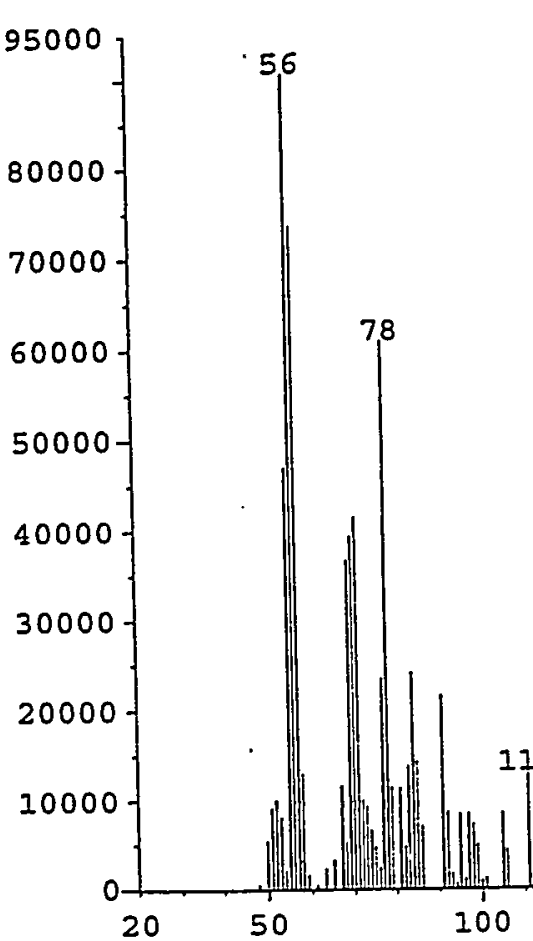

PlotData

$1884 \cdot 1$

0109: Scan Avg 1-28 (0.00-0.10 min)

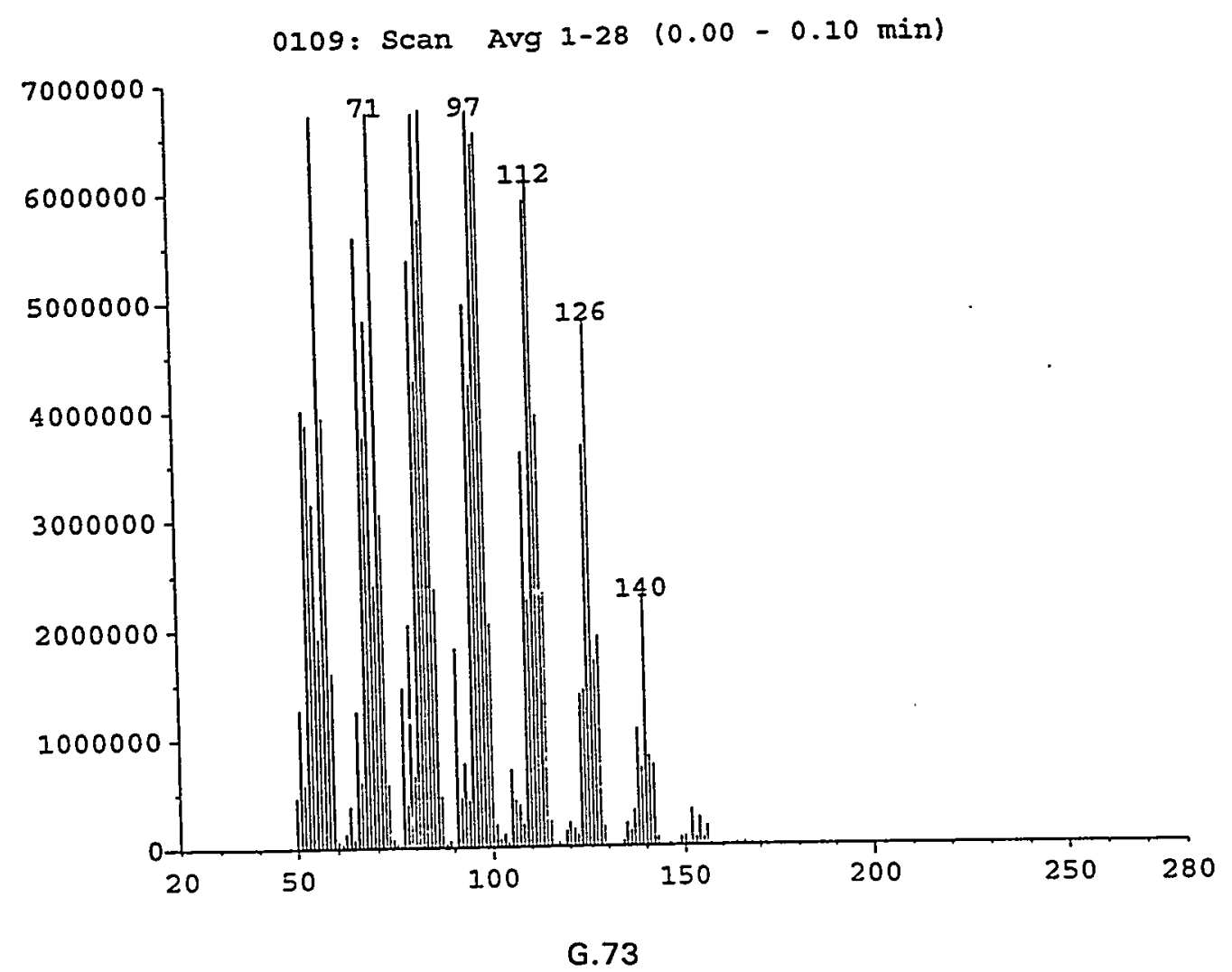

G.73 


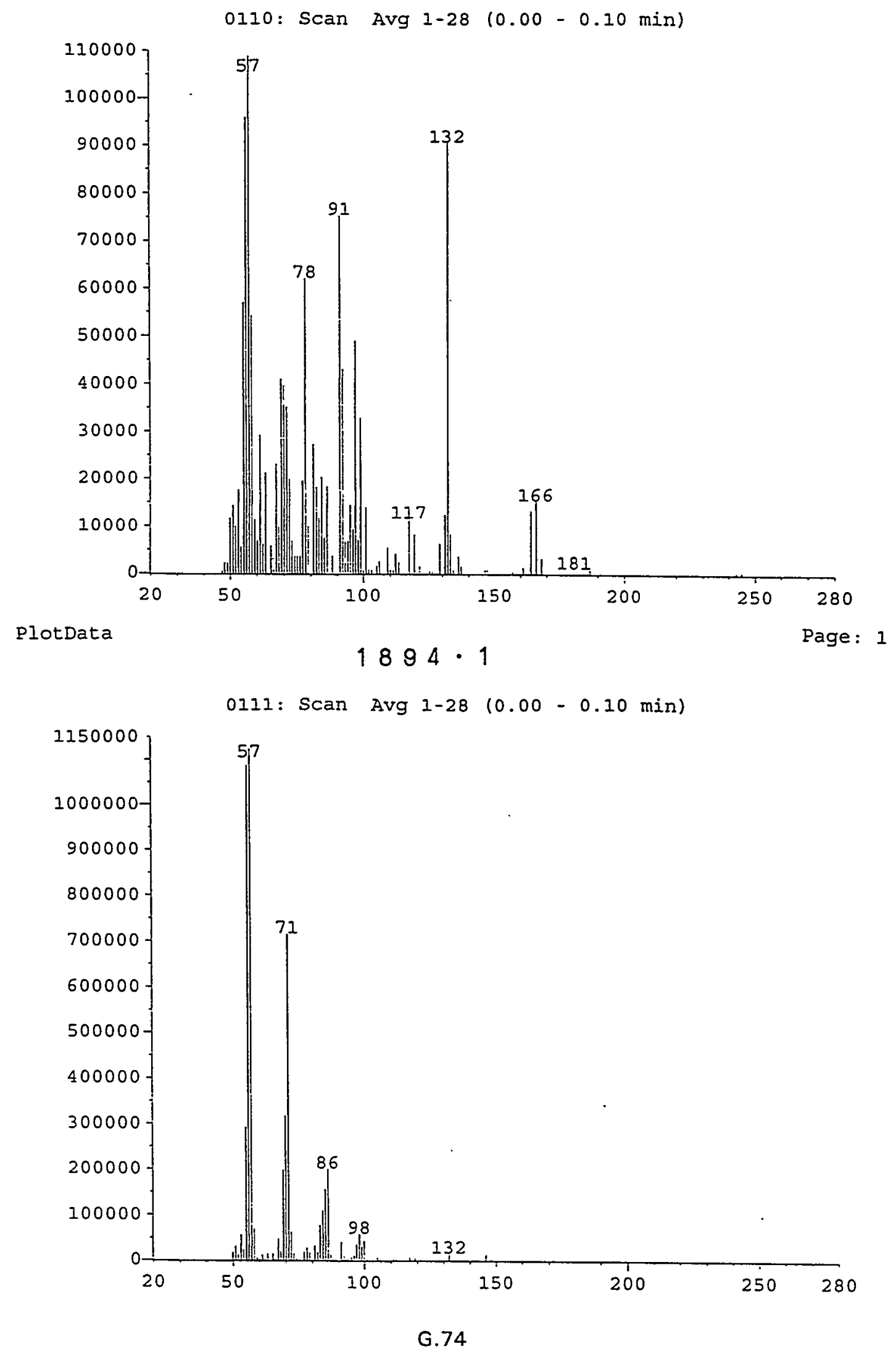




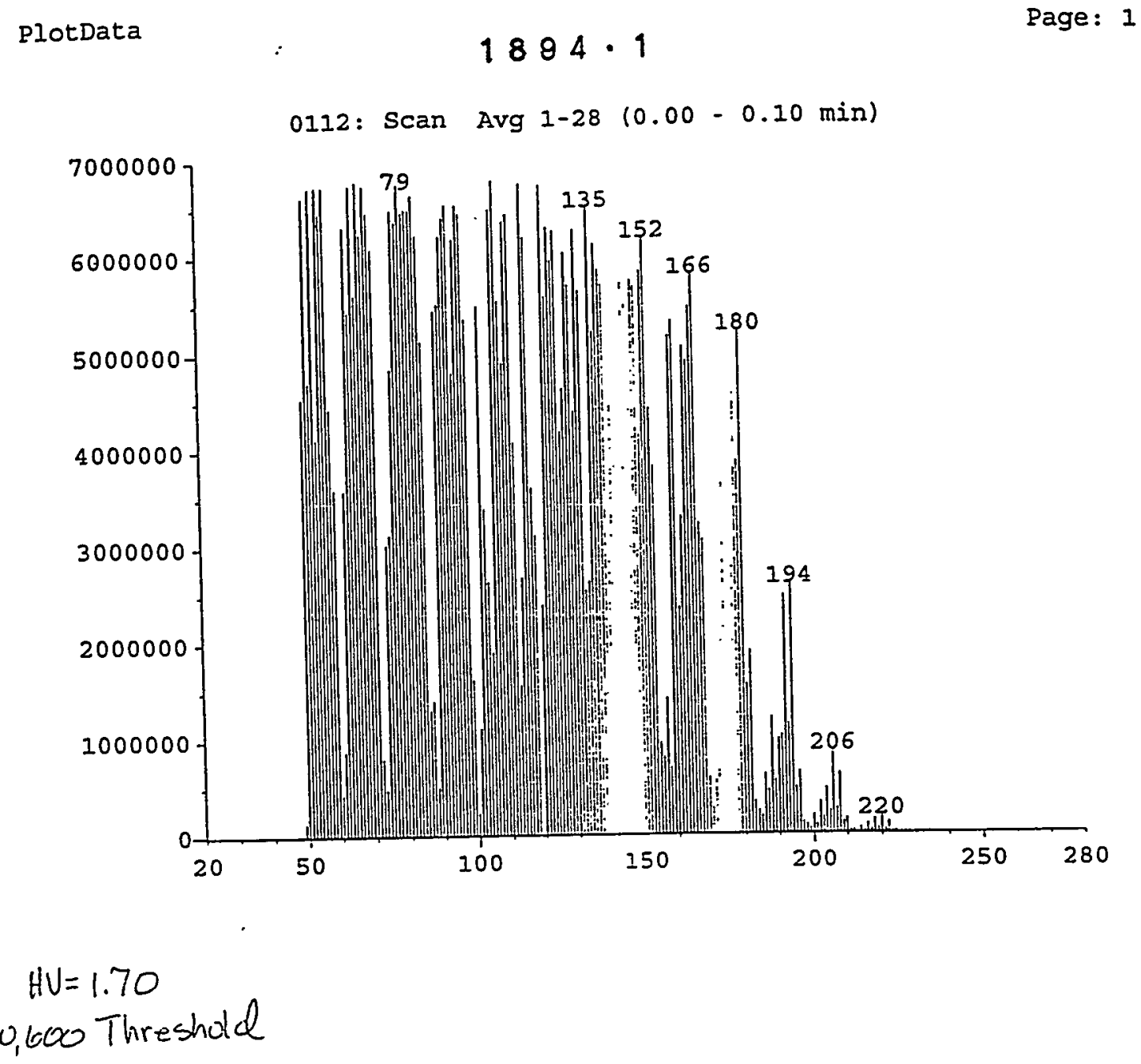

G.75 
APPENDIX D

TABLE OF DATA

G.76 


\section{Table of TD-GC/MS Data \\ for the Petrex Soil Gas Survey \\ Conducted at Eielson Air Force Base \\ In Alaska \\ for Battelle Pacific Northwest Laboratories \\ NERI Project Number 1894 \\ July 19, 1993}

Sample Number 39

2-Methyl-1-Propene

2-Methyl Pentane

5-Methyl-2-Hexanone

3-Methyl Pentane

2-Methyl-1-Pentene

Hexane

2,2-Dimethyl Pentane

2,4-Dimethyl Pentane

Methyl Cyclopentane

3,3-Dimethyl Pentane

2-Methyl Hexane

2,3-Dimethyl Pentane

3-Methyl Hexane

1,1-Dimethyl Cyclopentane

Isooctane

1,2-Dimethyl Cyclopentane

Heptane

2-Methyl-2-Hexene

2,3-Dimethyl-1-Pentene

2,2-Dimethyl Hexane

2,5-Dimethyl Hexane

2,2,3-Trimethyl Pentane

3,3-Dimethyl Hexane

2,3,4-Trimethyl Pentane

2,3,3-Trimethyl Pentane

3-Methyl Heptane

Trimethyl Hexane

1,2-Dimethyl Cyclohexane

2,4-Dimethyl Heptane

2,5-Dimethyl Heptane
Area Counts

97,000

654,111

122,719

393,141

15,247

236,186

275,610

$1,431,912$

357,482

498,882

$2,328,378$

$3,518,324$

$3,244,544$

160,504

$6,538,596$

365,606

331,500

107,543

21,323

502,965

$2,188,065$

575,742

$1,678,898$

$5,755,228$

$8,086,799$

$5,849,001$

$1,791,363$

$1,426,463$

$1,090,322$

$1,561,789$ 
Sample Number 39 (continued)

3,5-Dimethyl Heptane

Ethyl Cyclohexane

3-Ethyl-2-Methyl Hexane

3,4-Dimethyl Heptane

1,3,5-Trimethyl Cyclohexane

2,2,4-Trimethyl Decane

2,2,8-Trimethyl Decane

Xylenes

2,5,5-Trimethyl Heptane

3-Methyl Nonane

2,5-Dimethyl Octane

3-Ethyl-2-Methyl Heptane

4-Ethyl Octane

2,2,6-Trimethyl Octane

2,2,9-Trimethyl Decane

1-Ethyl Methyl Benzene

1,2,4-Trimethyl Benzene

1,3,5-Trimethyl Benzene

1-Methyl Ethyl Benzene

1-Ethenyl-2-Methyl Benzene

3-Methyl-5-Propyl Nonane

1,2,3-Trimethyl Benzene

1-Methyl-4,1-Methylethyl Benzene

1-Methyl Propyl Benzene

Decahydro Naphthalene

Diethyl Benzene

2-Ethyl-1,3-Dimethyl Benzene

1,2,3,5-Tetramethyl Benzene

Toluene

3,4-Dimethyl Benzaldehyde

Naphthalene
Area Counts

503,563

112,298

$1,276,793$

$3,289,732$

312,267

449,765

$1,693,954$

$1,548,130$

$2,304,600$

321,736

833,699

$2,380,261$

999,200

$6,345,654$

$2,393,170$

$4,307,699$

$3,594,402$

$3,236,346$

$1,364,513$

945,294

$4,831,453$

$2,016,764$

261,392

$3,860,990$

234,202

414,780

$2,134,746$

$3,478,675$

$1,010,967$

208,570

101,730
Sample Number 48

Benzene

2,3,4-Trimethyl Pentane

Trimethyl Benzene

1-Methylethyl Benzene
Area Counts

16,951

12,730

14,936

12,555 
Sample Number 49

2-Methyl Propene

Pentane

2-Methyl Pentane

3-Methyl Pentane

Propyl Cyclopropane

Hexane

2-Hexene

3-Methyl-2-Pentene

2,2-Dimethyl Pentane

2,4-Dimethyl Pentane

Methyl Cyclopentane

3,3-Dimethyl Pentane

2-Methyl Hexane

2,3-Dimethyl Pentane

3-Methyl Hexane

1,1-Dimethyl Cyclopentane

Benzene

2,2,4-Trimethyl Pentane

1,2-Dimethyl Cyclopentane

Heptane

2-Methyl-2-Hexene

3-Methyl-2-Hexene

2,2-Dimethyl Hexane

2,5-Dimethyl Hexane

2,2,3-Trimethyl Pentane

3,3-Dimethyl Hexane

2,3,4-Trimethyl Pentane

4-Methyl Heptane

3-Methyl Heptane

2,2,5-Trimethyl Hexane

1,3-Dimethyl Cyclohexane

Toluene

Octane

1,2-Dimethyl Cyclohexane

2,4-Dimethyl Heptane

2,5-Dimethyl Heptane

Ethyl Cyclohexane

2,3-Dimethyl Heptane
Area Counts

69,985

178,873

$1,411,089$

793,186

27,171

818,448

22,110

18,632

206,842

815,286

745,546

271,252

$1,807,283$

$2,379,429$

$2,176,378$

110,709

796,515

$2,589,244$

284,361

$1,000,687$

106,850

27,271

265,874

$1,091,892$

187,404

754,704

$2,409,398$

$1,021,342$

$3,393,912$

669,702

875,724

$1,439,417$

658,982

496,015

588,573

$1,185,910$

333,211

696,870 
Sample Number 49 (continued)

4-Methyl Octane

1,3,5-Trimethyl Cyclohexane

3-Methyl Octane

2,2,6-Trimethyl Decane

2,2,3,4,6,6-Hexamethyl Heptane

Xylenes

4-Ethyl Octane

3-Ethyl-2-Methyl Heptane

2,5-Dimethyl Octane

Ethyl Benzene

1-Ethyl Methyl Benzene

1,2,3-Trimethyl Benzene

1,2,4-Trimethyl Benzene

1-Methyl Ethyl Benzene

2,2,4,6,6-Pentamethyl Heptane

2,3-Dihydro-1H-Indene

3-Methyl-5-Propyl Nonane

1-Methyl-4,1-Methylethyl Benzene

1-Ethyl-4-Methyl Benzene

1-Methyl Propyl Benzene

Decahydro Naphthalene

1,2-Diethyl Benzene

1-Methyl-4-Propyl Benzene

2,3-Dihydro-2-Methyl-1H-Indene

4,1-Propenyl Toluene

1,1,1-Dimethylethyl-4-Methyl Benzene

1,4-Dimethyl-2,1-Methyl Ethyl Benzene

Ethyl-1,2,4-Trimethyl Benzene

1-Ethy!-4,1-Methylethyl Benzene

Dimethyl Benzaldehyde

Naphthalene

1,3-Dimethyl-5,1-Methylethyl Benzene

2,3-Dihydro-4,7-Dimethyl-1 H-Indene

2,4,5-Trimethyl Benzaldehyde

Methyl Naphthalene

2,4,6-Trimethyl Benzaldehyde
Area Counts

$2,506,351$

160,709

$1,481,831$

258,806

87,829

$3,747,367$

135,467

721,167

916,139

$4,951,144$

$5,369,452$

$2,935,889$

$2,417,520$

$4,892,519$

259,088

715,545

$1,030,752$

$1,972,856$

$5,138,464$

$11,666,696$

134,319

852,310

$4,001,341$

84,136

$1,663,014$

263,643

$1,428,365$

962,439

898,243

434,679

$2,017,782$

266,335

176,601

58,414

204,954

64,358 
Sample Number 55

Area Counts

2-Methyl-1-Propene

200,557

Pentane

649,126

2-Methyl Pentane

$5,160,952$

3-Methyl Pentane

$3,300,981$

2-Methyl-1-Pentene

126,466

Hexane

774,134

31,468

3-Methyl-2-Pentene

2,2-Dimethyl Pentane

$1,351,581$

2,4-Dimethyl Pentane

$5,050,740$

3,3-Dimethyl Pentane

$2,177,676$

2-Methyl Hexane

2,3-Dimethyl Pentane

$1,942,584$

$7,875,950$

3-Methyl Hexane

$5,358,436$

2,2,4-Trimethyl Pentane

$12,377,982$

1,2-Dimethyl Cyclopentane

$2,751,826$

99,130

2-Methyl-2-Hexene

155,106

3-Methyl-2-Hexene

1,1,2,3-Tetramethyl Cyclopropane

160,166

2,2,3-Trimethyl Pentane

2,3,3-Trimethyl Pentane

$1,340,715$

$4,472,863$

2,3,4-Trimethyl Pentane

$6,589,891$

3-Ethyl Hexane

$3,593,972$

2,2,5-Trimethyl Hexane

1-Ethyl-2-Methyl Cyclopentane

$2,337,736$

$1,903,583$

1,2-Dimethyl Cyclohexane

$2,607,888$

$2,722,131$

2,3,5-Trimethyl Hexane

$1,166,167$

$2,120,497$

3,5-Dimethyl Heptane

$6,391,239$

5-Methyl Decane

$1,826,420$

370,343

506,182

3-Ethyl Heptane

4-Ethyl-2,2,6,6-Tetramethyl Heptane

$2,651,696$

2,2,4-Trimethyl Decane

1,2,4-Trimethyl Cyclohexane

$1,042,100$

554,925

Xylenes

$3,699,221$

3,3,5-Trimethyl Heptane

$1,490,687$

6-Methyl Dodecane

841,444

2,3,5-Trimethyl Heptane 
Sample Number 55 (continued)

1-Ethyl Methyl Cyclohexane

3-Ethyl-2-Methyl Heptane

4-Ethyl Octane

2-Methyl Decane

1-Ethyl-2-Methyl Benzene

Decahydro Naphthalene

Methyl Cyclopentane

2,4-Dimethyl-1-Pentene

Sample Number 57

2-Methyl Propene

Pentane

2-Methyl Pentane

3-Methyl Pentane

Hexane

2,2-Dimethyl Pentane

2,4-Dimethyl Pentane

Methyl Cyclopentane

3,3-Dimethyl Pentane

2-Methyl Hexane

2,3-Dimethyl Pentane

3-Methyl Hexane

1,1-Dimethyl Cyclopentane

Benzene

Isooctane

1,2-Dimethyl Cyclopentane

Heptane

2,2,4,4-Tetramethyl Pentane

Methyl Cyclohexane

Ethyl Cyclopentane

2,3,4-Trimethyl Pentane

2,3,3-Trimethyl Pentane

Trimethyl Hexane

Toluene

2,4-Dimethyl Heptane

2,5-Dimethyl Heptane

2,2,7-Trimethyl Decane

Xylenes

\section{Area Counts}

$1,378,317$

$3,281,151$

743,938

$3,010,576$

215,901

182,584

$1,319,600$

61,546

Area Counts

34,322

83,702

58,631

40,111

186,956

16,526

50,673

75,546

40,414

121,539

264,525

219,149

14,852

97,147

263,466

79,384

65,088

21,973

428,576

74,280

196,425

315,326

57,845

60,484

16,433

17,350

17,598

23,340 
Sample Number 57 (continued)

Area Counts

Trimethyl Benzene

217,490

1-Ethyl-2-Methyl Benzene

123,637

1-Ethyl-2,2,6-Trimethyl Cyclohexane

34,485

1-Ethyl-Dimethyl Benzene

42,750

Decahydro-2-Methyl Naphthalene

77,971

Naphthalene

36,886

Methyl Naphthalene

68,823

1,1-Biphenyl

13,720

Dimethyl Naphthalene

56,086

Sample Number 65

Area Counts

Benzene

18,494

Toluene

28,067

Sample Number 80

Area Counts

3,3-Dimethyl Pentane

46,392

2,3-Dimethyl Pentane

154,758

3-Methyl Hexane

270,407

3-Ethyl Pentane

112,811

1,2-Dimethyl Cyclopentane

28,843

2,2-Dimethyl Hexane

108,632

2,5-Dimethyl Hexane

193,270

2,4-Dimethyl Hexane

427,771

3,3-Dimethyl Hexane

254,280

2,3-Dimethyl Hexane

462,610

3-Ethyl Pentane

514,584

Toluene

21,530

82,498

1-Ethyl-2-Methyl Cyclopentane

156,545

2,4-Dimethyl Heptane

171,303

2-Methyl Octane

306,384

2,5-Dimethyl Heptane

56,505

3,5-Dimethyl Heptane

88,461

3,3-Dimethyl Heptane

40,405

Ethyl Cyclohexane 
Sample Number 80 (continued)

Area Counts

2,3-Dimethyl Heptane

155,634

1,3,5-Trimethyl Cyclohexane

33,145

4-Methyl Octane

602,621

1,2,3-Trimethyl Cyclohexane

59,696

Xylenes

Ethyl Benzene

515,914

Diethyl Cyclohexane

$3,683,845$

128,046

425,947

1,1,2,3-Tetramethyl Cyclohexane

$1,625,850$

1-Ethyl Methyl Benzene

Trimethyl Benzene

$3,639,979$

1-Methyl Ethyl Benzene

1-Ethenyl-2-Methyl Benzene

1-Methyl Propyl Benzene

$4,676,958$

490,156

1-Ethyl Dimethyl Benzene

$1,263,116$

$1,978,114$

1-Methyl-4,1-Methylethyl Benzene

$1,393,998$

1,2,3,4-Tetramethyl Benzene

$2,983,669$

Decahydro-2-Methyl Naphthalene

$1,381,462$

267,790

Diethyl Methyl Benzene

2-Butyl-1,1,3-Trimethyl Cyclohexane

$1,140,937$

Naphthalene

$1,618,889$

Methyl Naphthalene

537,312

Sample Number 81

Area Counts

67,894

13,329

15,948

29,427

68,293

101,396

45,061

51,696

86,444

202,561

115,052

250,318

52,846

Dimethyl Cyclohexane 
Sample Number 81 (continued)

Toluene

1-Ethyl-2-Methyl Cyclopentane

2,4-Dimethyl Heptane

2,6-Dimethyl Heptane

2,5-Dimethyl Heptane

3,3-Dimethyl Heptane

2,3-Dimethyl Heptane

4-Methyl Octane

1,2,4-Trimethyl Cyclohexane

Xylenes

Ethyl Benzene

1-Ethyl-2-Methyl Benzene

Trimethyl Benzene

1-Methyl Ethyl Benzene

1-Propenyl Benzene

1-Ethyl-4,1-Methylethyl Benzene

1,1-Dimethyl-2-Propyl Cyclohexane

1-Methyl Propyl Benzene

1-Ethyl-2,3-Dimethyl Benzene

1-Methyl-4,1-Methyl Ethenyl Cyclohexane

1-Ethyl-4,1-Dimethyl Benzene

1-Methyl-1-Methylethyl Benzene

Decahydro-2-Methyl Naphthalene
Area Counts

40,680

31,187

101,834

124,074

209,193

68,585

152,496

537,007

30,561

$2,775,640$

$3,200,518$

$4,957,179$

$4,692,203$

$4,238,376$

138,015

543,473

361,278

$1,432,647$

$2,158,410$

881,355

$2,179,550$

$1,430,985$

$1,195,295$

Area Counts

13,513

11,409

Sample Number 93

Toluene

Methyl Naphthalene 


\section{Distribution}

No. of

Copies

OFFSITE

$12 \mathrm{DOE} / \mathrm{Office}$ of Scientific and Technical Information

Eielson AFB

343 Sptg.-DEVR

2558 Central Ave., Suite 1

Eielson AFB, Alaska 99702

Att: T. Merrymon

M. Raabe

K. Trahanovsky (5)

Administrative Record (4)

- 24 Pacific Northwest Laboratory

R. W. Bryce

K6-96

E. A. Clayton

J. C. Evans (2)

J. S. Fruchter
No. of

Copies

ONSITE

D. W. Glover

K6-96

D. C. Lanigan

T. L. Liikala (5)

K6-84

K6-84

P. E. Long

M. T. Murphy

K6-84

K6-84

K. B. Olsen

K6-96

R. M. Smith

K6-96

C. Veverka

K6-96

Publishing Coordination

Technical Report Files (5)

\section{Routing}

R. M. Ecker

SEQUIM

M. J. Graham

K6-78

P. M. Irving

K6-98

C. S. Sloane

K6-04

P. C. Hays (last)

K9-41 